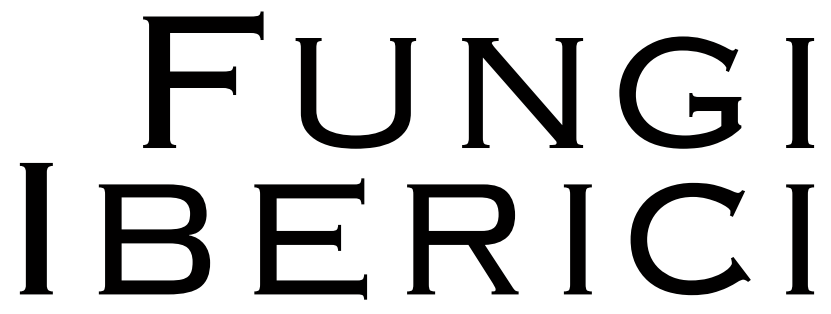

REVISTA DE LA SOCIEDAD IBÉRICA DE MICOLOGÍA REVISTA DA SOCIEDAdE IBERICA DE MICOLOGIA

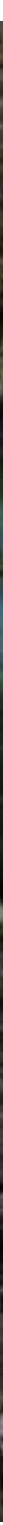




\section{COMITÉ CIENTÍFICO / COMITÊ CIENTÍFICO}

Ibai Olariaga Ibarguren (coordinador),

Universidad Rey Juan Carlos

Luis Alberto Parra Sánchez,

Asociación Micológica Arandina

Juan Carlos Zamora Señoret,

Universidad de Upsala

\section{COMITÉ EDITORIAL / COMITÊ EDITORIAL}

Fernando Esteve Raventós,

Universidad de Alcalá

Isaac Garrido Benavent,

Real Jardín Botánico (CSIC)

Carlos Lado Rodríguez,

Real Jardín Botánico (CSIC)

Gabriel Moreno Horcajada,

Universidad de Alcalá

Fermín Pancorbo Maza,

Sociedad Micológica de Madrid

Luis A. Parra Sánchez,

Asociación Micológica Arandina

Ita Paz Conde,

Agrupació Micològica Berguedana
Pablo Pérez Daniëls,

Universidad de Córdoba

Sergio Pérez Gorjón,

Universidad de Salamanca

Luis Quijada Fumero,

Dept. Organismic and Evolutionary Biology,

Harvard Herbarium

Borja Rodríguez De Francisco,

Instituto Pasteur

Chemi Traba Velay,

Federación Galega de Micoloxía

Juan Manuel Velasco Santos,

Sociedad Micológica Salmantina Lazarillo

João Luís Baptista-Ferreira,

Faculdade de Ciências da Universidade de Lisboa

\section{COMITÉ REDACTOR / COMITÊ DE REDAÇÃO}

Julián Alonso Díaz,

Universidade de Santiago de Compostela.

Sociedades Micolóxica Lucus

Fermín Pancorbo Maza,

Sociedad Micológica de Madrid

Francisco José Rodríguez Campo,

Sociedad Micológica de Madrid

Juan Manuel Velasco Santos,

Sociedad Micológica Salmantina Lazarillo

João Luís Baptista-Ferreira,

Faculdade de Ciências da Universidade de Lisboa 


\section{Índice}

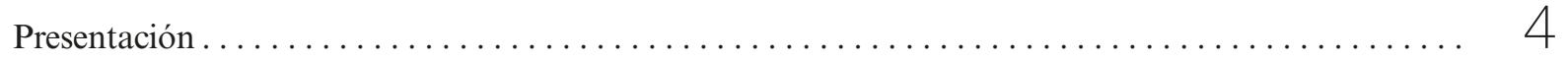

Apresentação $\ldots \ldots \ldots \ldots \ldots \ldots \ldots \ldots \ldots \ldots \ldots \ldots \ldots \ldots \ldots \ldots \ldots \ldots \ldots \ldots \ldots \ldots \ldots \ldots \ldots$

II Encuentro de la Sociedad Ibérica de Micología

(Cerler, 26-30 de septiembre de 2018): hallazgo de 103 especies nuevas

para Aragón, 15 para la Península Ibérica y 11 especies nuevas para la ciencia

por OLARIAGA I., BALLESTER L., FERNANDES U., LÓPEZ-AMIANO J.I., MAGAÑA V., MARTÍNEZ-GIL R.

MARTÍN J., PANCORBO F., PARRA L.A., PÉREZ-DANIËLS P., PÉREZ-DEL-AMO C., RODRÍGUEZ-ANDRADE E., RODRÍGUEZ-ARRIBAS C., SÁNCHEZ-DUEÑAS G., TERES J.L., TORRES D. \& TRABA J.M.

Instrucciones para autores / Instruções para autores 


\section{Presentación}

$\mathrm{L}$

a Península Ibérica es uno de los territorios en el que existen más micólogos en Europa, aunque sorprendentemente, no existía ninguna asociación que los representara. Con la excepción de la Sociedad

Española de Micología y la Asociación Portuguesa de Micología Médica, que agrupa micólogos dedicados a la rama médica, España y Portugal son prácticamente los dos únicos países europeos sin sociedades micológicas estatales. La falta de organización y coordinación entre micólogos ibéricos se reflejaba, entre otras cosas, en la alta dispersión de la información, en la escasa colaboración entre micólogos aficionados y profesionales y la falta de una voz colectiva para la interlocución con entidades oficiales.

En este escenario, durante 2015 surge la idea de crear la Sociedad Ibérica de Micología. Se organizaron tres reuniones moderadas por Ibai Olariaga, Luis Rubio Casas y Juan Carlos Zamora, en la que se expusieron los problemas anteriormente indicados. El objetivo de estas reuniones fue valorar la posibilidad de la creación de una sociedad micológica que agrupara nuestro colectivo. La primera reunión tuvo lugar en Donostia-San Sebastián (10 de octubre de 2015), la segunda en Jaca (11 de octubre de 2015) y la tercera, en Fornos de Algodres (11 de noviembre de 2015), aprovechando la celebración de otros eventos micológicos.

Esta iniciativa tuvo una acogida muy positiva entre los asistentes a las tres reuniones, lo que nos motivó aún más a seguir trabajando en este proyecto, creando como primer paso un foro de debate abierto a toda la gente interesada en la incipiente sociedad, en el que tomar las decisiones pertinentes para su constitución. De esta manera, la Sociedad Ibérica de Micología/Sociedade Ibérica de Micologia (SIM) quedó registrada como asociación en marzo de 2018, y celebró su primera reunión en Riaza, entre el 11 y 13 de mayo de 2018. El objetivo de esta primera reunión fue establecer algunas pautas de funcionamiento y analizar las estrategias a seguir para dar a conocer nuestra recién creada asociación a la sociedad. Durante esta reunión, surge, entre otras, la idea de dotar a la SIM de una revista electrónica que permita publicar artículos centrados en su ámbito de estudio (Península Ibérica, las ciudades autónomas de Ceuta y Melilla, las islas de la Macaronesia, las Islas Baleares, así como otras pequeñas islas mediterráneas y atlánticas pertenecientes a España y Portugal) y contribuir así al conocimiento de la diversidad fúngica de este extenso territorio.

Este encuentro y los otros tres que le siguieron en Cerler (septiembre de 2018), Miraflores de la Sierra (mayo de 2019) y en Aguiar da Beira (noviembre de 2019) dieron a conocer la SIM en sus primeros pasos y fueron el caldo de cultivo para aglutinar las ideas que dinamizarían su funcionamiento. Fruto de las iniciativas presentadas en estos encuentros, y el apoyo de sus socios, la SIM cuenta ahora con una página web (https:// micologiaiberica.org/), un grupo de google (https://groups.google.com/g/micoliber), un página de Facebook (https://www.facebook.com/Sociedad-Ib\%C3\%A9rica-de-Micolog\%C3\%ADa-391066081370272/), un foro (https://sim.mforos.com/) para discusiones taxonómicas, además de una base de datos de citas ibéricas cada vez más completa que se incorpora a GBIF (www.gbif.org) periódicamente y que cuenta ya con unos 10000 registros. Además, este año se han programado 5 conferencias telemáticas, y el número de socios asciende actualmente a 165 .

Ahora, tengo la satisfacción de informaros con esta presentación que otra iniciativa de la SIM se pone en marcha con la publicación de este primer número de Fungi Iberici, la revista de la SIM.

Ibai Olariaga Ibarguren

Presidente de la SIM 


\section{Apresentação}

Península Ibérica é um dos territórios da Europa em que existem mais micólogos, embora, surpreen1 dentemente, não tenha havido até aqui nenhuma associação que os representasse. Com exceção da 1 Sociedad Española de Micología e da Associação Portuguesa de Micologia Médica, que agrupam micólogos dedicados ao ramo médico, Espanha e Portugal são praticamente os dois únicos países europeus sem outro tipo de sociedades micológicas de âmbito nacional. A falta de organização e de coordenação entre os micólogos ibéricos reflectia-se, entre outras coisas, na elevada dispersão da informação, na escassa colaboração entre micólogos amadores e profissionais e na falta de uma voz colectiva para o diálogo com as entidades oficiais.

Foi neste cenário que, em 2015, surgiu a ideia de criar a Sociedade Ibérica de Micologia. Foram organizados três encontros, moderados por Ibai Olariaga, Luis Rubio Casas e Juan Carlos Zamora, em que foram apresentados os referidos problemas. $\mathrm{O}$ objectivo desses encontros era avaliar a possibilidade de criar uma sociedade micológica que reunisse o nosso grupo. O primeiro encontro teve lugar em Donostia-San Sebastián (10 de Outubro de 2015), o segundo em Jaca (11 de Outubro de 2015) e o terceiro, em Fornos de Algodres (11 de Novembro de 2015), aproveitando a realização de eventos micológicos locais.

Esta iniciativa teve uma recepção muito positiva entre os presentes nos três encontros, o que nos motivou ainda mais a continuar a trabalhar neste projeto, criando, como primeiro passo, um fórum de discussão aberto a todos os interessados na sociedade nascente, em que se pudessem tomar as decisões pertinentes para a sua constituição. Desta forma, a Sociedade Ibérica de Micología / Sociedade Ibérica de Micologia (SIM) foi registada como associação em Março de 2018, tendo-se realizado a sua primeira reunião em Riaza, de 11 a 13 de Maio de 2018. O objectivo desta primeira reunião era estabelecer algumas diretrizes de atuação e analisar as estratégias a seguir para dar a conhecer à sociedade a nossa recém-criada associação. Neste encontro surgiu, entre outras coisas, a ideia de dotar a SIM de uma revista electrónica que permitisse a publicação de artigos centrados na sua área de estudo (Península Ibérica, as cidades autónomas de Ceuta e Melilha, as ilhas da Macaronésia, as Ilhas Baleares, bem como outras pequenas ilhas mediterrânicas e atlânticas pertencentes a Espanha ou Portugal) e assim contribuir para o conhecimento da diversidade micológica deste extenso território.

Este encontro e os outros três que se seguiram em Cerler (Setembro de 2018), Miraflores de la Sierra (Maio de 2019) e Aguiar da Beira (Novembro de 2019) deram a conhecer a SIM nos seus primeiros passos e foram o "meio de cultura" para reunir e fazer crescer as ideias que dinamizariam o seu funcionamento. Como resultado das iniciativas apresentadas nesses encontros, e do apoio dos seus associados, a SIM passou a contar com um site (https://micologiaiberica.org/pt-pt/), um grupo Google (https://groups.google.com/g/ micoliber), uma página no Facebook (https://www.facebook.com/Sociedad-Ib\%C3\%A9rica-de-Micolog\%C3\%ADa-391066081370272/), um fórum (https://sim.mforos.com/) para discussões sobre taxonomia, bem como uma base de dados cada vez mais completa de registos ibéricos que são periodicamente incorporados no GBIF (www.gbif.org) e que conta já com cerca de 10000 entradas. Além disso, este ano foram agendadas 5 conferências telemáticas, sendo atualmente 165 o número de associados.

Com esta apresentação, tenho o prazer de informar que está a ser lançada mais uma iniciativa da SIM com a publicação deste primeiro número da Fungi Iberici, a revista da SIM.

Ibai Olariaga Ibarguren Presidente da SIM 


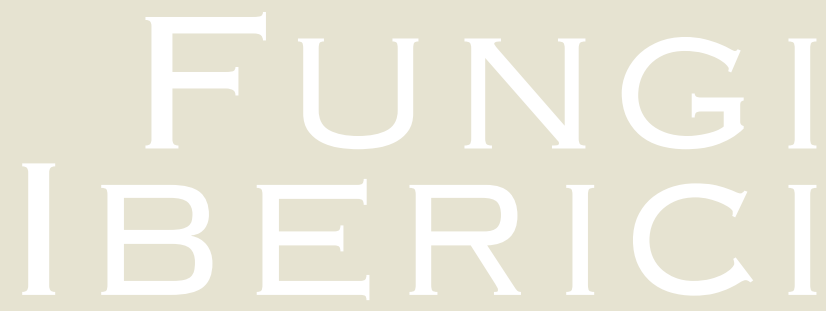

REVISTA DE LA SOCIEDAD IBÉRICA DE MICOLOGÍA REVISTA DA SOCIEDADE IBERICA DE MICOLOGIA 


\title{
II Encuentro de la Sociedad Ibérica de Micología (Cerler, 26-30 de septiembre de 2018): hallazgo de 103 especies nuevas para Aragón, 15 para la Península Ibérica y 11 especies nuevas para la ciencia
}

\author{
OLARIAGA I. ${ }^{1,2}$, BALLESTER L. ${ }^{3}$, FERNANDES U. ${ }^{2}$, LÓPEZ-AMIANO J... ${ }^{2}$, MAGAÑA V. ${ }^{4}$, MARTÍNEZ-GIL R. ${ }^{5}$, MAR- \\ TÍN J. ${ }^{2}$, PANCORBO F. ${ }^{6}$, PARRA L.A. ${ }^{7}$, PÉREZ-DANIËLS P. ${ }^{8}$, PÉREZ-DEL-AMO C. ${ }^{5}$, RODRÍGUEZ-ANDRADE E. ${ }^{4}$, \\ RODRÍGUEZ-ARRIBAS C. ${ }^{1}$, SÁNCHEZ-DUEÑAS G. ${ }^{6}$, TERES J.L. ${ }^{2}$, TORRES D. ${ }^{4}$ \& TRABA J.M. ${ }^{9}$ \\ ${ }^{1}$ Universidad Rey Juan Carlos, Dep. Biología y Geología, Física y Química Inorgánica. C/ Tulipán s/n, 28933 Móstoles, Madrid. \\ E-mail: ibai.olariaga@urjc.es \\ ${ }^{2}$ Aranzadi Zientzia Elkartea-Sociedad de Ciencias Aranzadi. Sección de Micología. C/ Zorroagagaina 11, 20014 Donostia-San \\ Sebastián, Gipuzkoa \\ ${ }^{3}$ C/ Octavio de Toledo 25, 2 izq., 50007 Zaragoza. E-mail: luisballester.zar@gmail.com \\ ${ }^{4}$ Universitat Rovira i Virgili, Facultad de Medicina y Ciencias de la Salud. Unidad de Microbiología. C/ Sant Llorenç 21, 43201 \\ Reus, Tarragona \\ ${ }^{5}$ Grupo Cultural Micológico "Verpa”, centro Cívico de Yagüe. C/ Pamplona 2, planta 2 (local 4), 26006 Logroño. E-mail: laruy- \\ natotal@gmail.com,cmperez@coaatrioja.org \\ ${ }^{6}$ Sociedad Micológica de Madrid, Real Jardín Botánico. C/ Claudio Moyano 1, 28014 Madrid. E-mail: fermin@socmicolmadrid. \\ org, gonzalo.s.du@gmail.com \\ ${ }^{7}$ Avda. Miranda do Douro 7, 5 G. 09400 Aranda de Duero, Burgos. E-mail: agaricus@telefonica.net \\ ${ }^{8}$ Universidad de Córdoba, Dep. Botánica, Ecología y Fisiología Vegetal, Campus de Rabanales. Ed. Celestino Mutis, $3^{\mathrm{a}}$ pta., \\ 14071 Córdoba. E-mail: ppdaniels@hotmail.com \\ ${ }_{9}^{9}$ Plaza de España, nº-1, 5 A. 15001 A Coruña. E-mail: chemitraba@gmail.com
}

\section{Resumen}

Se presentan los resultados científicos derivados de la celebración del $2^{\circ}$ Encuentro de la Sociedad Ibérica de Micología celebrado en Cerler (Huesca, España). Tras la prospección de 8 localidades se generaron 949 registros georreferenciados de hongos que pertenecen al menos a 545 especies. Un total de 103 especies se citan por primera vez en Aragón, mientras que dos, Agaricus moelleroides e Hygrophorus hedrychii representan primeras citas para España y 15 taxones constituyen nuevas citas para la Península Ibérica. Además, durante el encuentro se recolectó material de 11 nuevas especies para la ciencia, en diferentes etapas de estudio, presentándose aquí dos de estas especies, Entoloma "stenocystis" y Mycetinis "gramineus" de las que ha de ser recolectado más material para su descripción formal. El volumen y relevancia de los resultados obtenidos tras muestreos durante tan sólo tres días de campo, respaldan la idoneidad de este tipo de eventos para contribuir al conocimiento micológico de diferentes áreas de nuestro territorio.

Palabras clave: Península Ibérica, diversidad fúngica, Pirineos.

\section{Resumo}

São apresentados os resultados científicos decorrentes da realização do $2^{\circ}$ Encontro da Sociedade Ibérica de Micologia, que decorreu em Cerler (Huesca, Espanha). Após prospecção em 8 localidades foram gerados 949 registos georreferenciados de fungos pertencentes a pelo menos 545 espécies. Um total de 103 espécies são citadas pela primeira vez em Aragão, enquanto duas, Agaricus moelleroides e Hygrophorus hedrychii, representam as primeiras citações para Espanha e 15 taxa constituem citações novas para a Península Ibérica. Durante a reunião foi ainda coletado material que provavelmente resultará em 11 novos taxones para a ciência, mas que estão em diferentes fases de investigação. Dois deles, Entoloma "stenocystis" e Mycetinis "gramineus" são provisoriamente aqui propostos como novos, embora seja necessário encontrar mais material para uma descrição formal. O volume e a relevância destes resultados, obtidos numa amostragem realizada durante apenas três dias no campo, comprovam a adequação deste tipo de eventos para o conhecimento do micobiota em diferentes áreas do território.

Palabras clave: Península Ibérica, diversidade de fungos, Pirinéus. 


\section{Summary}

The scientific outcome of the $2^{\text {nd }}$ Meeting of the Iberian Mycological Society, held in Cerler (Huesca, Spain), is presented here. After conducting fieldwork in 8 localities 949 georeferenced records of fungi belonging to at least 545 species were generated. One hundred and four species are reported for the first time for Aragon, whereas two, Agaricus moelleroides and Hygrophorus hedrychii are reported for the first time in Spain, and 15 taxa represent novelties for the Iberian Peninsula. Furthermore, during the meeting material belonging to 11 new to science species was collected, which are at different stages of investigation. Two of these, Entoloma "stenocystis" and Mycetinis "gramineus" are proposed provisionally here as new, albeit further material of them needs to be found for a formal description. The amount and interest of the results presented here, obtained after conducting fieldwork during only three days substantiates the idea that this kind of events contribute significantly to the knowledge of the mycological flora of different areas of our territory.

Keywords: Iberian Peninsula, fungal diversity, Pyrenees.

\section{Introducción}

Entre el 26 y 30 de septiembre de 2018 se celebró en Cerler (Huesca) el $2^{\circ}$ Encuentro de la Sociedad Ibérica de Micología (SIM), tras su reciente creación. Tras realizar una primera reunión en primavera para definir las actividades de la sociedad, el objetivo principal de este segundo encuentro fue prospectar y contribuir al conocimiento micológico de esta diversa zona del Pirineo aragonés. En el territorio abarcado por la SIM (Península Ibérica, Ceuta, Melilla, islas de la Macaronesia, Islas Baleares e islas mediterráneas y atlánticas pertenecientes a España y Portugal), apenas se han realizado hasta la fecha reuniones micológicas con la asistencia de micólogos especialistas y cuyo objetivo fuera divulgar los hallazgos a través de publicaciones conjuntas a corto plazo. Sin embargo, este tipo de encuentros se realizan con asiduidad en diversos países europeos y contribuyen notablemente al incremento del conocimiento micológico de sus respectivos territorios. El $2^{\circ}$ Encuentro de la SIM consistió en trabajo de campo por las mañanas e identificación de material en el laboratorio por las tardes, contando con unos 40 participantes. Durante el encuentro se visitaron ecosistemas variados, como bosques mixtos, hayedos, abetales, praderas subalpinas con Pinus uncinata o praderas alpinas con Salix enanos y Dryas octopetala.

En este trabajo pretendemos divulgar los resultados científicos del encuentro. Con la ayuda de las propicias condiciones meteorológicas de manera previa al encuentro y gracias al trabajo de los asistentes, se realizaron numerosos hallazgos de especies con pocas citas en el territorio, nuevas para el territorio, o incluso nuevas para la ciencia. Dado que el volumen de recolecciones y especies es muy elevado, y que algunas muestras requieren aún estudios en más profundidad, en el presente trabajo presentamos un listado provisional de las especies halladas, y describimos con más detalle algunos de los hallazgos más relevantes que hemos podido confirmar hasta la fecha.

\section{Material y métodos}

\section{Localidades}

Todas las localidades prospectadas se encuentran en el valle del río Ésera, en la comarca de La Ribagorza (Huesca, Fig. 1). Los asistentes fueron divididos en 2 o 3 grupos cada día para prospectar el mayor número de localidades. Se enumeran abajo las localidades visitadas (Fig. 1), junto con una breve descripción de los hábitats de cada localidad:

1. La Selva de Cerler (Benasque, 27-IX) (Fig. 2A): bosque mixto dominado por Pinus sylvestris, Populus tremula, Fraxinus excelsior, Buxus sempervirens. Altura: 1500-1600 m. Coordenadas: 42.5853342 0.5324821 .

2. Collada de Basibé (Montanuy, 27-IX) (Fig. 2B): praderas alpinas sobre litología caliza, con Dryas octopetala, Salix herbacea y Salix reticulata. Altura: entre 2250-2350 m. Coordenadas: 42.58533420 .5324821$.

3.- Trigars, Barbaruéns (Seira, 28-IX): bosque mixto sobre litología caliza, dominado por Abies alba y Fagus sylvatica; bosque de Pinus sylvestris. Altura: 1450-1550 m. Coordenadas: 42.52446090 .3803049$.

4. Puerto de la Glera (Benasque, 28-IX) (Fig. 2C-D): praderas alpinas sobre litología silícea, con Salix herbacea. Altura: 2370 m. Coordenadas: 42.70076 0.60342 .

5. La Besurta (Benasque, 29-IX) (Fig. 2E): praderas subalpinas con bosque abierto de Pinus uncinata, sobre litología silícea y caliza. Altura 1900 m. Coordenadas: 42.6787530 .649818$.

6. Plan de Senarta (Benasque, 29-IX) (Fig. 2F): bosque maduro de Abies alba en pendiente, sobre litología calcárea. Altura: 1450-1500 m. Coordenadas: 42.640864 0.567172.

7. Plan de Turpí, Senda Botánica (Benasque, 29-IX): bosque mixto con Abies alba, Pinus uncinata, Fagus sylvatica, Corylus avellana. Altura: 1500-1600 m. Coordenadas: 42.6685910 .584534$. 


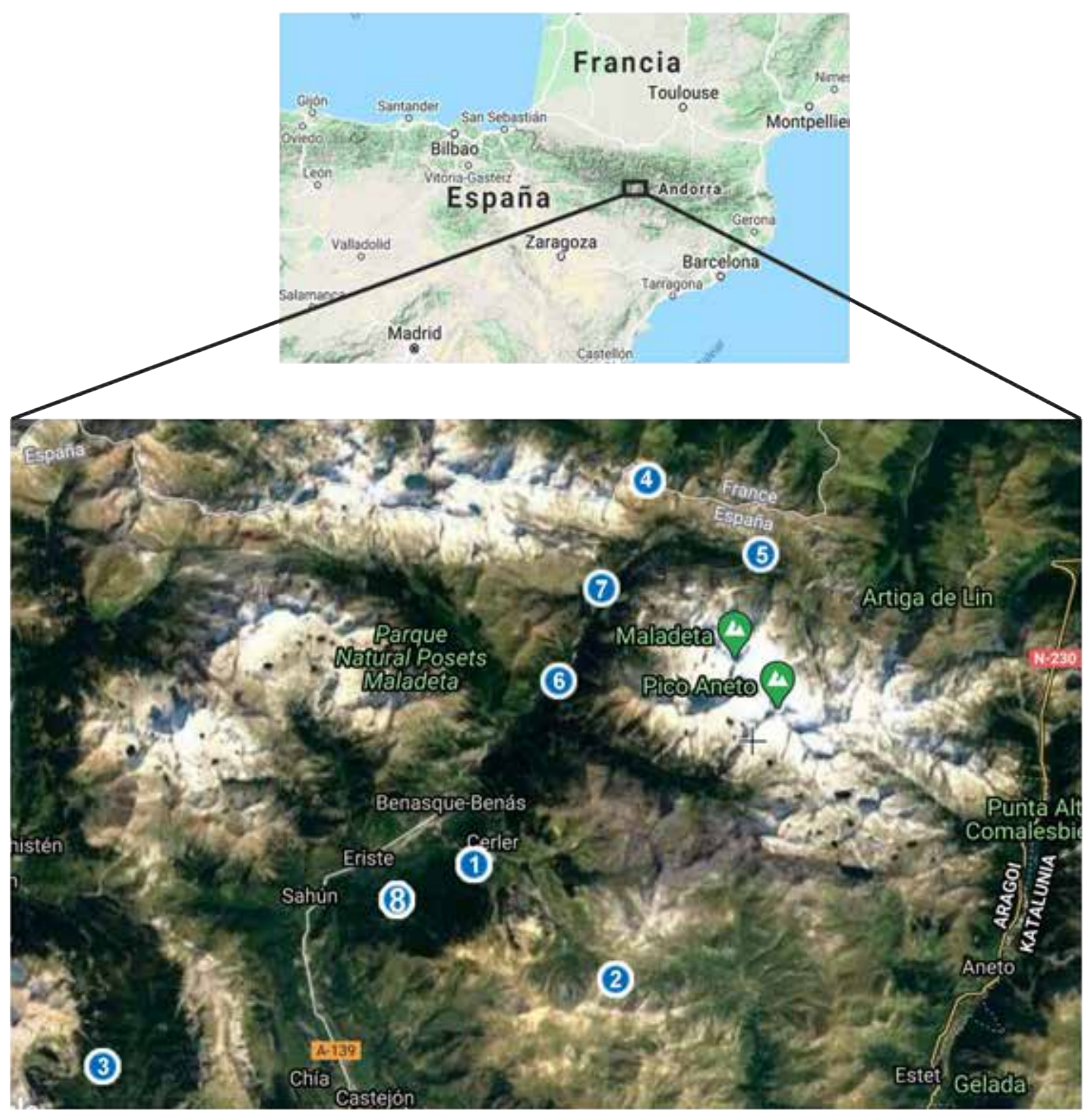

Fig. 1. Localización geográfica de las localidades prospectadas durante el II Encuentro de la Sociedad Ibérica de Micología. Los números indican cada una de las localidades. 1: Selva de Cerler; 2: Collada de Basibé; 3: Trigars, Barbaruéns; 4: Puerto de la Glera; 5: La Besurta; 6: Plan de Senarta; 7: Plan de Turpí, Senda Botánica; 8: Selva de Conques.

8. Selva de Conques (Eriste, 30-IX): bosque de Quercus pubescens, Corylus avellana y Buxus sempervirens, sobre litología caliza. Altura: 1200-1300 m. Coordenadas: 42.58533420 .5324821$.

\section{Estudio morfológico y material}

Las descripciones fueron realizadas basándose en material fresco y completadas a partir de material desecado. Los caracteres microscópicos, salvo cuando se señala lo contrario, fueron observados utilizando material rehidratado en hidróxido potásico $(\mathrm{KOH})$ 5\% o Rojo Congo en SDS al 1\%. Las reacciones amiloides, dextrinoides o hemiamiloides fueron obser- vadas mediante el reactivo de Melzer (MLZ) o una solución de Lugol (IKI) para Basidiomycota o Ascomycota, respectivamente. Las esporas fueron medidas en vista lateral y excluyendo la ornamentación. Las medidas de los basidios excluyen los esterigmas. En las descripciones de Hebeloma geminatum, $H$. ingratum, Hygrophorus hedrychiii y Tricholoma frondosae, los rangos y estadísticas esporales han sido calculados tomando el 95\% de probabilidad según una distribución normal gaussiana.

Las muestras se encuentran depositadas en los herbarios institucionales AH y ARAN y en los herbarios privados de L. Ballester (LB), P.P. Daniëls (Daniëls), R. Martínez Gil (RM), L.A. Parra (LAPAG), C. Pérez del Amo (CMP), G. Sánchez Dueñas 

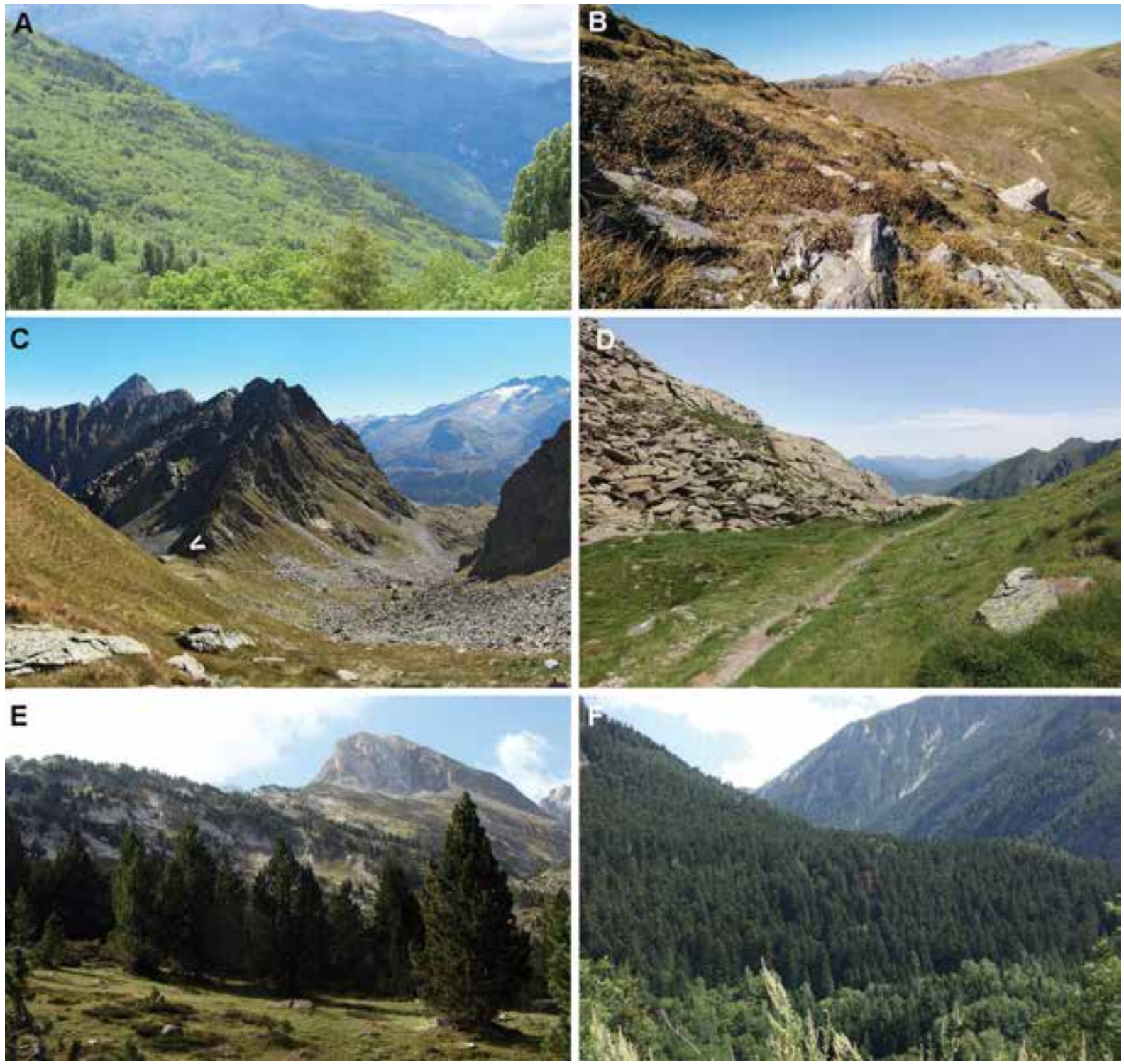

Fig. 2. Algunas de las localidades visitadas durante el II Encuentro de la Sociedad Ibérica de Micología. A: Bosque mixto llamado la selva de Cerler. B: ladera calcárea a unos $2100 \mathrm{~m}$ de altitud, con céspedes de Dryas octopetala, en la Collada de Basibé (Montanuy). C: Cercanías del Puerto de la Glera (Benasque), lugar de recolección de 4 taxones nuevos para la Península Ibérica y dos posibles especies nuevas para la ciencia. La flecha blanca marca el punto exacto. D: Vista más cercana del Puerto de la Glera. E: bosque de Pinus uncinata en las inmediaciones de La Besurta (Benasque). F: abetal de Plan de Senarta (Benasque). Fotografías: A J. Garrido; B F. Pancorbo; C J. Hernanz; D I. Olariaga; E J. Teres; F I. Olariaga.

(GSD) y J.M. Traba (CHT). Asimismo, se ha revisado material adicional de herbarios institucionales, bien a través de préstamos $(\mathrm{K})$ o visitas a herbarios (PC, UPS). Los acrónimos de los herbarios siguen a Index Herbariorum (THIERS 2020).

\section{Abreviaturas y símbolos}

IKI: solución de Lugol

$\mathrm{KOH}$ : hidróxido potásico

$\mathrm{L}_{\mathrm{m}}: \quad$ longitud media
L: número de láminas que llegan desde el margen del píleo al estípite

1: número de láminas que no llegan al estípite

MLZ: reactivo de Melzer

$\mathrm{n}$ : número de esporas o estructuras medidas para el cálculo de estadísticos

Q: longitud / anchura

$\mathrm{Q}_{\mathrm{m}}: \mathrm{L}_{\mathrm{m}} / \mathrm{W}_{\mathrm{m}}$

SDS: dodecilsulfato sódico

$\mathrm{W}_{\mathrm{m}}$ : anchura media

*: $\quad$ estructuras vivas en Ascomycota

$\dagger$ estructuras muertas en Ascomycota

ø: nulo 


\section{Estudio molecular}

El objetivo de los estudios moleculares realizados es respaldar el material citado mediante una interpretación molecular. Las extracciones de ADN se realizaron a partir de material seco o depositado en un tampón de extracción de ADN, utilizando el DNeasy Plant Minikit (QIAGEN GmbH, Hilden, Alemania). Las regiones amplificadas fueron principalmente el ITS y el LSU del rDNA (dominios D1-D3). La región ITS fue amplificada mediante los cebadores ITS1, ITS5 e ITS4 (WHITE \& al. 1990), mientras que los cebadores LR0R y LR 5 fueron empleados para la región LSU (CUBETA \& al. 1991; VILGALYS \& HESTER 1990). Para amplificar la región 12S (SSU mitocondrial), se emplearon los primers mtSSU1 y mtSSU3R (ZOLLER \& al. 1999). Las condiciones PCR fueron las siguientes: 5 min a $94{ }^{\circ} \mathrm{C} ; 35-40$ ciclos de $30 \mathrm{~s}$ a $94^{\circ} \mathrm{C}, 30 \mathrm{~s}$ a $55^{\circ} \mathrm{C}, 1 \mathrm{~min}$ a $72{ }^{\circ} \mathrm{C} ; 7$ min a 72 ${ }^{\circ} \mathrm{C}$. Los fragmentos se visualizaron mediante electroforesis en geles de agarosa al 1\%, teñido con MIDO$\mathrm{RI}^{\mathrm{Green}}$ Xtra (Nippon Genetics) y se visualizaron con un transiluminador de luz azul. Las muestras amplificadas se purificaron mediante ExoSAP-IT® (USB, Cleveland, OH, USA). Para verificar preliminarmente la identidad de las secuencias se realizaron búsquedas BLAST (ALTSCHUL \& al. 1990).

En este trabajo se han generado un total de 17 secuencias de la región ITS y 12 secuencias de la LSU (Tabla Suplementaria 1). Las matrices de secuencias se recopilaron mediante la descarga de los registros más próximos en búsquedas BLAST y la selección de una o varias secuencias como grupo externo de acuerdo con estudios filogenéticos basados en más marcadores. Las secuencias fueron alineadas en Aliview (LARSSON 2014) y depuradas manualmente. Los alineamientos fueron analizados mediante métodos de máxima verosimilitud (ML) y Bayesianos (MB), en el CIPRES Science Gateway (MILLER \& al. 2010). Los análisis ML fueron realizados utilizando la herramienta "RAxML HPC2 on XSEDE" (STAMATAKIS 2014), utilizando el modelo GTR-GAMMA y comenzando con un árbol aleatorio. Para determinar el apoyo de los nodos, se realizaron 1000 réplicas bootstrap rápidas y no parámetricas. El análisis $\mathrm{MB}$ se realizó en $\mathrm{MrBa}-$ yes 3.2.7 (RONQUIST \& al. 2012). Los modelos de sustitución se muestrearon dentro del espacio GTR (RONQUIST \& al. 2012), utilizando dos análisis de cuatro cadenas MCMC durante 5 millones de generaciones, comenzando por un árbol aleatorio y muestreando un árbol cada 1000 generaciones. Se asumió que las cadenas convergieron adecuadamente cuando los valores de desviación estándar de las frecuencias de los grupos cayeron por debajo de 0,01 . Se seleccionó un burn-in de 2501 árboles que fueron descartados de cada análisis. El apoyo de las ramas (valores de probabilidad posterior, BPP) se calculó mediante el árbol consenso " $50 \%$ majority rule" de los 5002 árboles restantes. Los nodos con valor ML bootstrap $>70 \%$ o BPP $>95 \%$ fueron considerados filogenéticamente apoyados.

\section{Búsqueda de citas previas en el territorio}

En la actualidad resulta extremadamente complicado buscar citas previas de hongos en la Península Ibérica, debido sobre todo a la alta dispersión de la información, existencia de numerosas fuentes de datos y escasez de trabajos recopilatorios. Sin embargo, recopilar información previa de las especies halladas en el presente trabajo es imprescindible para poner en contexto la importancia de los hallazgos y medir la relevancia del presente estudio.

Para determinar la presencia de registros previos de las especies en la Península Ibérica se consultó inicialmente GBIF, y posteriormente el Banc de Dades de Biodiversitat de Catalunya (LLISTOSELLA 2020), el Catálogo de macromicetos de Asturias (RUBIO \& al. 2006), el IMBA (JUNTA DE ANDALUCÍA 2004), y otras fuentes si no se halló ningún registro en GBIF. Ante la imposibilidad de revisar toda la literatura existente, resulta remotamente plausible que exista alguna cita previa de especies de las que no hemos hallado registros previos, problema que padece la comunidad científica dedicada a la micología en el territorio y que requiere urgente solución.

Para comprobar la existencia de registros previos en la comunidad autónoma de Aragón, se consultó inicialmente el Atlas de hongos de Aragón (GOBIERNO DE ARAGÓN 2020), que parece no haber sido actualizado desde 2013. Por tanto, para aquellos taxones no recogidos en tal fuente, se consultaron además los artículos más relevantes publicados acerca de hongos en Aragón (CAMPOS \& al. 2014; RIBES \& al. 2016; PANCORBO \& al. 2017) en los últimos años. Para hongos liquenizados y liquenícolas, se consultó ETAYO (2010).

\section{Resultados}

Se generaron 949 registros de 545 especies y se herborizaron al menos 240 especímenes. El listado total de especies se puede consultar en la Tabla Suplementaria 2, así como en el juego de datos publicado en GBIF (SOCIEDAD(E) IBÉRICA DE MICOLOGÍA 2019). Una pequeña parte del material requiere aún de estudios más detallados y ello incrementará en un futuro el volumen de los hallazgos presentados aquí. Según nuestra búsqueda bibliográfica, 103 
de estas especies son citadas por primera vez para Aragón, habiéndose depositado especímenes de 74 de estas especies en diferentes herbarios. Desafortunadamente, 29 especies que constituyen nuevas citas para Aragón no fueron herborizadas, debido al hecho de que no existe ninguna herramienta que permita realizar consultas de citas previas con agilidad y no se pudo determinar que representaban citas nuevas durante el encuentro. Para tales casos, el determinador del material de cada especie se recoge en la Tabla Suplementaria 2. Todos los registros que constituyen especies nuevas para Aragón pero que no están respaldados por un espécimen de herbario poseen coordenadas de gran precisión en GBIF, lo cual resulta de ayuda para confirmar en el futuro la presencia de estas especies en Aragón.

Dos especies más, Agaricus moelleroides e Hygrophorus hedrychii constituyen nuevas citas para España, mientras que un total de 15 taxones son citados por primera vez para la Península Ibérica según nuestra búsqueda: Agaricus porphyrocephalus subsp. alpinus, Clavaria tenuipes, Clavulina incarnata, Exarmidium hemisphaericum, Exophiala salmonis, Grahamiella dryadis, Hebeloma geminatum, $H$. ingratum, Isothea rhytismoides, Penicillium bissetti, P. miczynskii, Pseudotryblidium neesii, Pulvinula niveoalba, Ramariopsis subarctica y Russula subrubens. Así mismo, el estudio del material recolectado en el encuentro ha deparado, hasta la fecha, el hallazgo de 11 especies nuevas para la ciencia, en diferentes etapas de estudio. Dos de estas especies han sido ya publicadas como nuevas para la ciencia, concretamente Emmonsiellopsis tuberculata (CROUS \& al. 2019) y Helvella terricola (SKREDE $\&$ al. 2020). Dos especies más de la que se ha recolectado poco material son publicadas aquí provisionalmente, a la espera de recolectar más material que permita su descripción formal: Entoloma "stenocystis" y Mycetinis "gramineus". Las 5 especies restantes, Erioscyphella sp., Inocybe sp. (F. Esteve-Raventós \& F. Pancorbo), Lamprospora sp. (R. Martínez-Gil), Leptographium sp. (Unidad de Micología de la Universitat Rovira i Virgili) y Typhula sp. (I. Olariaga), serán publicadas en el futuro cuando se culminen los estudios taxonómicos pertinentes para ello.

Cabe destacar que además de las novedades mencionadas anteriormente, un buen número de citas representan especies muy poco citadas en la Península Ibérica, en su mayoría segundas o terceras citas ibéricas, entre otras: Caloplaca stillicidiorum, Clavaria greletii, Cortinarius aleuriolens, Flagelloscypha kavinae, Helvella sulcata, Mallocybe fulvipes, Paraxerula caussei, Russula azurea, R. flavispora y Tricholoma frondosae. Algunas de estas especies, dada la magnitud de los resultados derivados del encuentro, no han podido recibir la atención requerida en este artículo.

A continuación se describen, ilustran y comentan algunas de las especies mencionadas anterioremente.

\section{Phylum Ascomycota}

Exarmidium hemisphaericum (Fr.) Aptroot, Nova

Hedwigia 66(1-2): 138. 1998.

= Stictis hemisphaerica Fr., Syst. Mycol. 2(1): 196.

1822, nom. sanct.

=Xylographa hemisphaerica (Fr.) Fuckel, Jahrb. Nassauischen Vereins Naturk. 29-30: 27. 1876.

=Odontotrema hemisphaericum (Fr.) Rehm, Pilze Deutsch., Hyster. Discomyc.: 205. 1896.

$\equiv$ Xylopezia hemisphaerica (Fr.) Sherw., Sherwood-Pike \& Boise, Brittonia 38(1): 41. 1986.

Fig. 3

Ascomas apotecioides, gregarios o dispersos, inicialmente inmersos, posteriormente erumpentes, de perfil redondeado a oblongo, de 0,2-0,4 × 0,15$0,3 \mathrm{~mm}$, con un disco en modo de poro, circular, no dentado, de color naranja pálido. Exterior de color negro brillante carbonizado.

Ascosporas de obclaviformes a estrechamente fusiformes, con 3(4) septos, constreñidas en los septos, con pequeñas gútulas dispersas en el interior y de pared delgada*, con gútulas poco evidentes y con el protoplasma contraído (confiriendo aspecto de tener pared gruesa $)^{\dagger}$, de $18-22 \times 4,5-6,5 \mu \mathrm{m}$ $\left(\mathrm{L}_{\mathrm{m}}=19,4, \mathrm{~W}_{\mathrm{m}}=5,4, \mathrm{Q}_{\mathrm{m}}=3,6, \mathrm{n}=6\right)^{*}, 15-21 \times 4-5 \mu \mathrm{m}$ $\left(\mathrm{L}_{\mathrm{m}}=18,5, \mathrm{~W}_{\mathrm{m}}=4,5, \mathrm{Q}_{\mathrm{m}}=3,6, \mathrm{n}=6\right)^{\dagger}$. Ascas cilíndricas a estrechamente claviformes, no operculadas, de pared gruesa en la juventud, posteriormente de pared delgada, sin aparato apical, 8 ascosporas dispuestas de maneras más o menos biseriada, de $71 \times 10 \mu \mathrm{m} *$, 59-71 $\times 10-12 \mu \mathrm{m}^{\dagger}$, pleurorrincas, IKI $\varnothing, \mathrm{KOH}+$ IKI $\varnothing$. Tipo de dehiscencia no observado, pero en $\mathrm{KOH}$ la exotúnica se desprende de la endotúnica ${ }^{\dagger}$. Paráfisis cilíndricas, ramificadas, con algunas protuberancias, de 1,6-2,4 $\mu \mathrm{m}$ de grosor en el ápice, sin gútulas o pigmento*. Excípulo ectal de hasta $50 \mu \mathrm{m}$ de grosor, compuesto de textura angularis-prismática en modo compacto, con hifas ovoides a cilíndricas, de pared delgada, de color pardo claro (sepia), gelatinizadas, de 3-4,5 $\mu \mathrm{m}$ de grosor, de color pardo rojizo en KOH. Subhimenio dispuesto directamente sobre el substrato. Algas verdes unicelulares observadas de manera abundante alrededor de los ascomas, sin formar un verdadero talo liquenizado.

Material estudiado. ESPAÑA. Huesca: Benasque, alrededores del parking de la Besurta, 42.67898452 0.65034732 ( $\pm 10 \mathrm{~m}), 1859 \mathrm{~m}$, ramita muerta y decorticada de Pinus uncinata, aún unida al árbol, 29IX-2018, leg. et det. I. Olariaga, ARAN-Fungi 13806 (ITS Genbank MW248485; LSU MW248509).

Comentarios: Exarmidium hemisphaericum es una especie caracterizada por sus apotecios de globosos a oblongos, inmersos en el substrato, cuyo exterior es de color negro y cuyo himenio es visible únicamente a través de un pequeño poro que solo se abre 

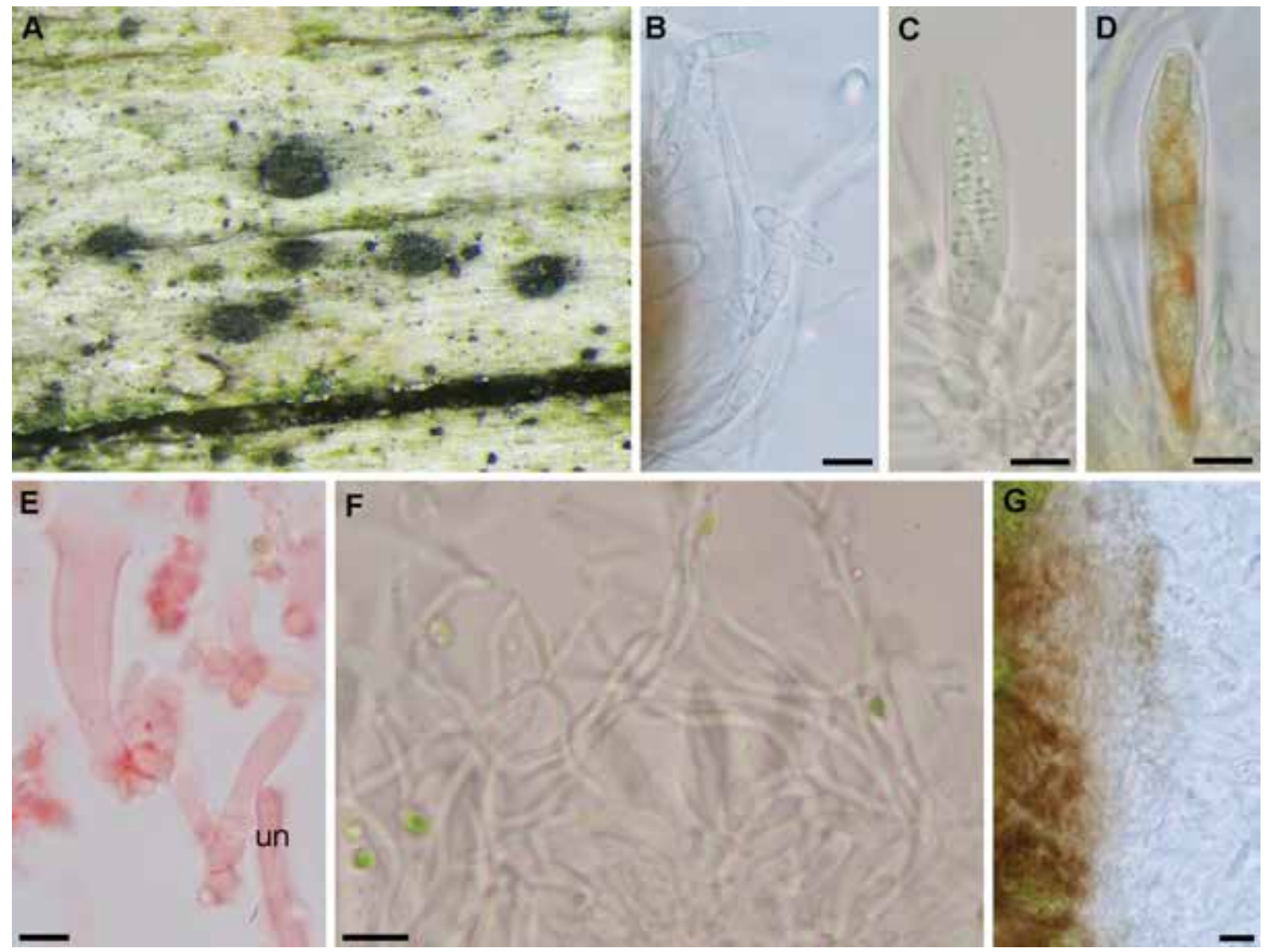

Fig. 3. Exarmidium hemisphaericum (ARAN-Fungi 13806). A: Ascomas sobre madera descortezada de Pinus uncinata. B: Ascosporas en agua. C: Asca en agua. D: Asca en IKI. E: Ascas en Rojo Congo-SDS, mostrando dehiscencia fisitunicada y un uncínulo basal (un). F: Hamatecio en KOH, mostrando paráfisis simples. G: Sección del margen del apotecio en agua. Barras de escala 10 $\mu \mathrm{m}$. Fotografías I. Olariaga.

en la madurez. Microscópicamente, las esporas que poseen habitualmente 3 septos, las ascas de reacción negativa con IKI y el excípulo ectal no gelatinizado, con hifas de ovoides a cilíndricas, son caracteres diagnósticos (SHERWOOD-PIKE \& BOISE 1986). Nuestro material coincide perfectamente con la descripción de SHERWOOD-PIKE \& BOISE (1986), salvo en que las esporas son de pared delgada en nuestro material. Exarmidium hemisphaericum parece ser una especie muy común en Norteamérica (SHERWOOD-PIKE 1987), pero no así en Europa, donde las citas son escasas y no existen hallazgos recientes y bien documentados. SHERWOOD-PIKE \& BOISE (1986) estudiaron material de Finlandia y del Reino Unido y hemos podido hallar citas de Suecia (ERIKSSON 2014) y Alpes (REHM 1896). Por tanto, según nuestra búsqueda, nuestro material corresponde a la primera cita en los Pirineos y en la Península Ibérica. Exarmidium hemisphaericum parece ser una especie típica de madera decorticada de coníferas y aparece en localidades alpinas.

Exarmidium hemisphaericum es, además, el tipo del género Xylopezia Höhnel, aún reconocido por algunos autores y cuya posición sistemática ha sido dudosa (SHERWOOD-PIKE \& BOISE 1986; WIJAYAWARDENE \& al. 2017). SHERWOOD-PIKE \& BOISE (1986) excluyeron Xylopezia de Odontotremataceae (Ostropomycetidae) por sus paráfisis ramificadas y ascas de pared gruesa y de aspecto bitunicado, pero no propusieron una clasificación a nivel de familia. Tampoco lo hicieron ERIKSSON \& HAWKSWORTH (1983), quienes emplazaron Xylopezia en Dothideomycetes, Incertae Sedis. APTROOT (1998) sinonimizó Xylopezia con Exarmidium P. Karst, y combinó $X$. hemisphaerica en el último género. Curiosamente, los ascomas de algunas especies clasificadas en Exarmidium han sido tratados como apotecioides (SHERWOOD-PIKE \& BOISE 1986), mientras que en otras fueron considerados peritecioides (BARR \& BOISE 1985). De manera similar, la posición filogenética de Exarmidium es dudosa. BARR \& BOISE (1985) propusieron incluirla en Hyponectriaceae (Sordariomycetes), no existiendo ninguna secuencia de Exarmidium (WIJAYAWARDENE \& al. 2017). En este trabajo se aporta por primera vez una secuencia del género Exarmidium 


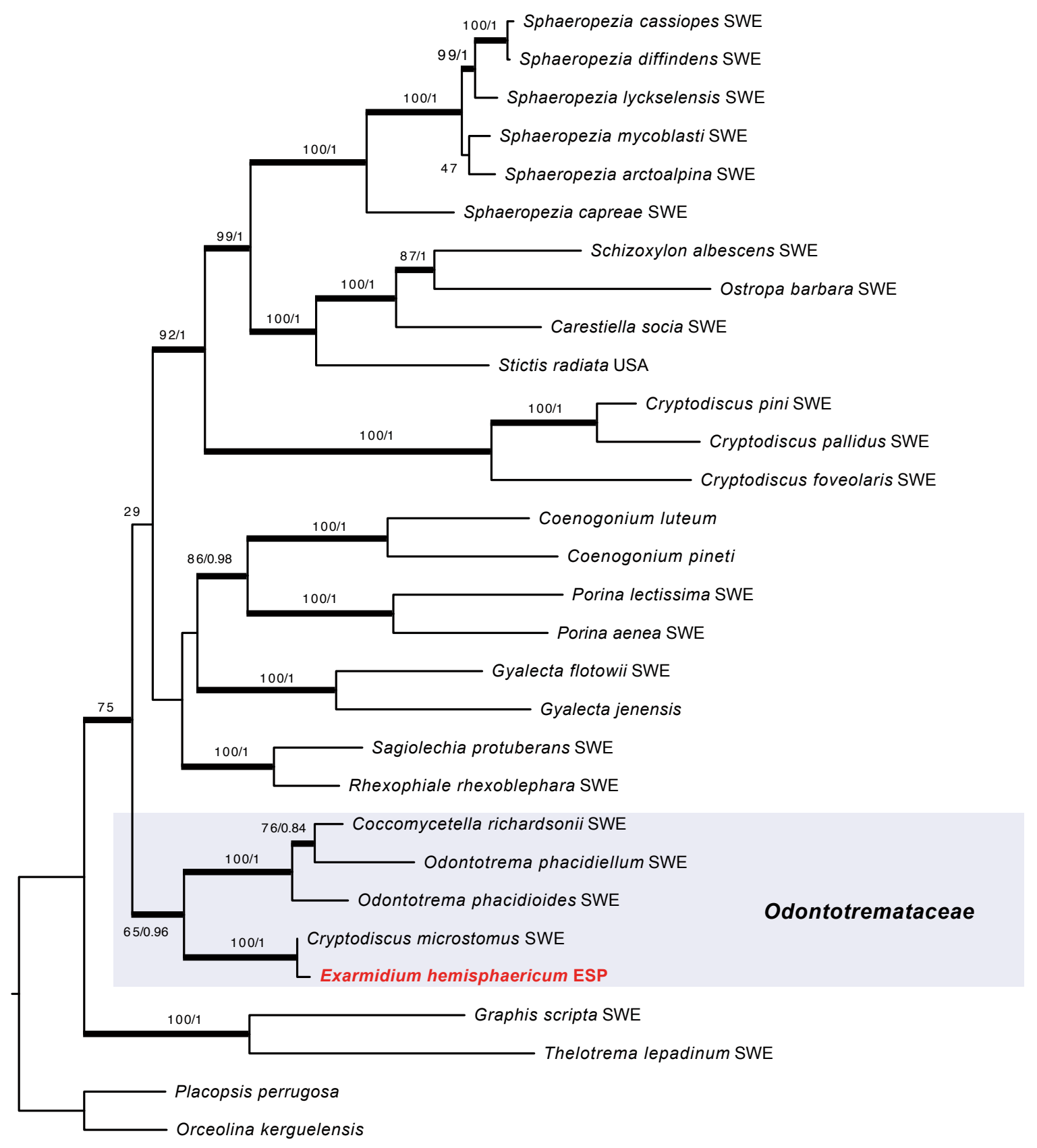

0.06

Fig. 4. Árbol más probable inferido mediante el análisis de máxima verosimilitud (ML) de las regiones 28S rDNA-12S mtDNA-RPB2 (excluyendo el $3^{\circ}$ codon) en Ostropomycetidae. Se muestran los valores bootstrap-ML / probabilidad posterior del análisis bayesiano alrededor de las ramas. Las ramas gruesas indican los nodos con apoyo filogenético al menos en un análisis (valores bootstrap $\geq 70 \%$ o probabilidad posterior $\geq 0.95$ ). Se emplearon secuencias de Placopsis perrugosa y Orceolina kerguelensis para enraizar el árbol. El país de origen de cada colección se abrevia mediante códigos ISO, marcándose en negrita y color rojo el espécimen estudiado en este artículo.

y nuestros análisis (Fig. 4) demuestran además que Exarmidium pertenece a Ostropomycetidae. Si bien nuestro análisis no resuelve con apoyo la relación de E. hemisphaericum con el resto de Ostropomycetidae, E. hemisphaericum forma un clado con especies de Odontotrema y Coccomycetella richardsonii, apoyado en el análisis bayesiano $(\mathrm{ML}=65 \%, \mathrm{BPP}=0.96)$, por lo que, provisionalmente, proponemos que Exarmidium debe de ser clasificado en Odontotremataceae. De acuerdo con SHERWOOD-PIKE (1987), Exarmidium difiere de Odontotrema (como Xylopezia) por la ausencia de perifisoides, paráfisis ramificados 

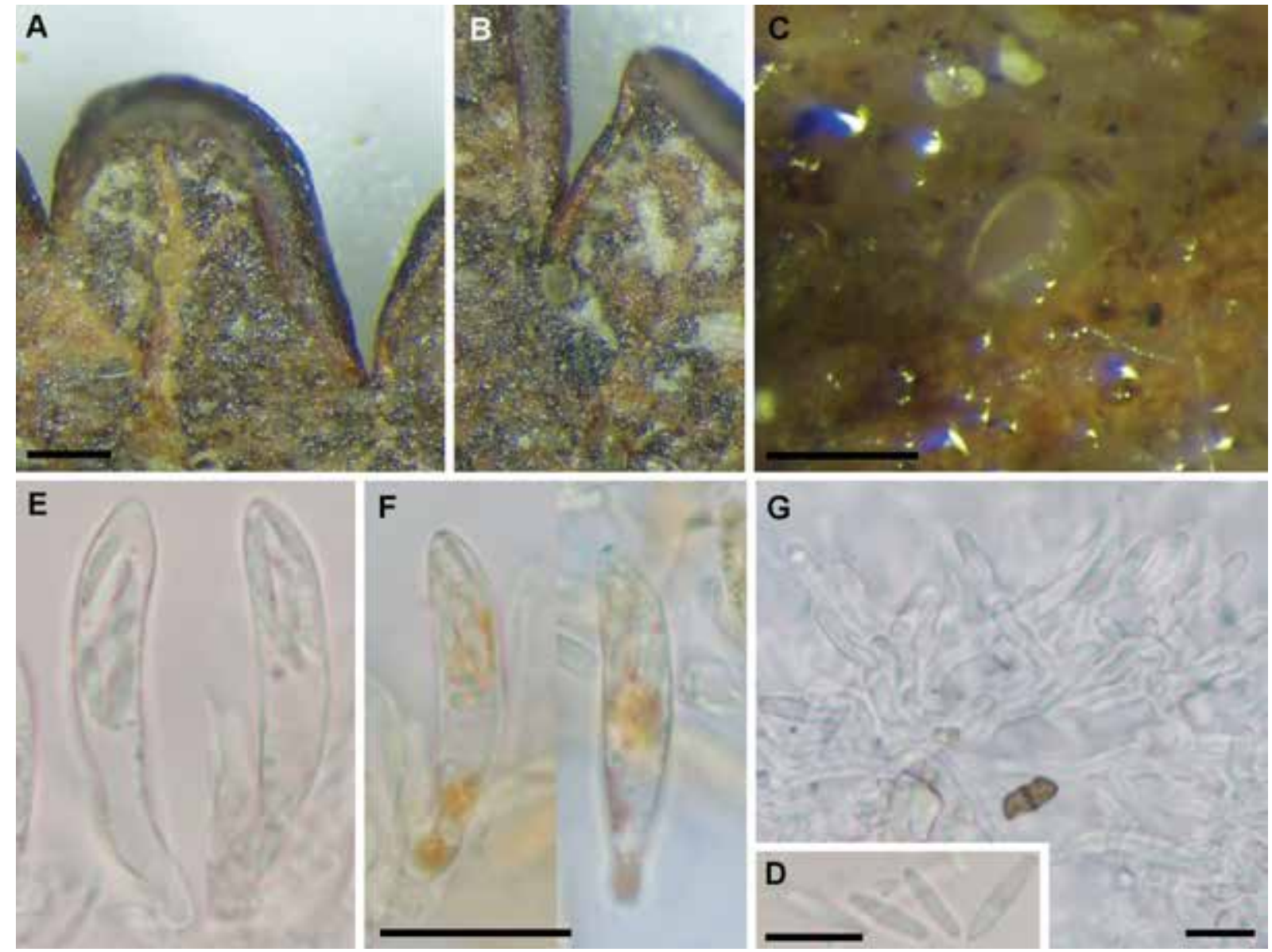

Fig. 5. Grahamiella dryadis (ARAN-Fungi 11295). A-B: Ascomas en el envés de hojas de Dryas octopetala. C: Detalle de apotecio. D: Ascosporas en agua. E: Ascas en agua. E: Ascas en IKI mostrando poro apical amiloide. F: Pelos marginales en agua. Barras de escala: A-B 0,5 mm, C 1 mm, D-F $10 \mu \mathrm{m}$. Fotografías I. Olariaga.

y ausencia de reacción alguna del himenio en IKI, si bien APTROOT (1998) cita que las ascas de algunas especies azulean de manera no constante en IKI. Nuestros análisis también sugieren que Cryptodiscus microstomus (Berk.) Sacc., especie excluida de Cryptodiscus por BALOCH \& al. (2009), podría pertenecer a Exarmidium, siempre y cuando el material aportado por estos autores estuviera identificado correctamente.

Grahamiella dryadis (Nannf. ex L. Holm) Spooner, Trans. Brit. Mycol. Soc. 76(2): 281. 1981.

$\equiv$ Allophylaria dryadis Nannf. ex L. Holm, Bot. Not. 132(1): 80. 1979.

Fig. 5

Apotecios gregarios, de 0,19-0,23 mm de diámetro, sésiles, creciendo sobre el envés de las hojas, ligeramente urceolados o cóncavos, de color pardo oliváceo pálido. Exterior del mismo color, liso, que excede el disco por la presencia de pelos fasciculados en el margen.

Ascosporas subcilíndricas, uniseptadas en la madurez, hialinas, biseriadas, de 11,9-14,8 × 2,6-3,3 $\mu \mathrm{m} *$. Ascas cilíndrico-claviformes, aporrincas, poro apical azul en IKI, de 53-63 × 9-10,5 $\mu \mathrm{m}^{*}$. Paráfisis de 1-2,5 $\mu \mathrm{m}$ de grosor, cilíndricas, rectas, septadas, hialinas, con pequeñas gútulas poco refringentes*, de color anaranjado en MLZ ${ }^{\dagger}$. Pelos marginales cilíndricos, obtusos, sinuosos, de pared gruesa $(0,7-1 \mu \mathrm{m})$, hialinos, de hasta $29 \times 3,8-5,2 \mu \mathrm{m}$, IKI $\varnothing$.

Material estudiado: ESPAÑA. Huesca: Montanuy, Collada de Basibé, $42.5533100 .591891( \pm 20$ $\mathrm{m}), 2370 \mathrm{~m}$, sobre tomento en el envés de hojas muertas de Dryas octopetala, 27-IX-2018, leg. et det. I. Olariaga, ARAN-Fungi 11295.

Comentarios: Especie inconfundible debido a su ecología exclusiva sobre el tomento del envés de hojas muertas de Dryas octopetala, sus apotecios minúsculos con esporas uniseptadas, pelos marginales cortos y de pared gruesa (SPOONER 1981). Según este último, el margen puede también presentar en ocasiones escamas triangulares compuestas de pelos fasciculados. Originalmente descrita de Suecia e Islandia (HOLM 1979), también ha sido citada del 
Reino Unido (SPOONER 1981). Nuestra cita parece corresponder a la primera realizada tanto en los Pirineos como en la Península Ibérica y extiende su área de distribución considerablemente hacia el sur. Probablemente se trate de una especie común allá donde crece Dryas octopetala, ya que los ascomas fueron detectados bajo la lupa binocular tras recolectar al azar hojas muertas de D. octopetala.

Helvella sulcata Afzel., Kongl. Vetensk. Acad. Nya Handl. 4: 305. 1783.

Fig. 6

Ascomas estipitados de hasta $70 \mathrm{~mm}$ de altura y $40 \mathrm{~mm}$ de anchura. Mitra de hasta $40 \times 3 \mathrm{~mm}$ de grosor, en forma de silla de montar extremadamente irregular, adnata, con el margen unido al estípite en 3-4 puntos. Estípite de hasta $50 \times 12 \mathrm{~mm}$, desnudo, hueco, con costillas prominentes y profundas, algunas con doble filo y parcialmente anastomosadas, con 'agujeros' profundos (lagunas), con el mismo color que el himenio, pero de tonos más claros; himenio de color gris-parduzco con tonos muy heterogéneos, siempre con reflejos grisáceos, arrugado o incluso abollado; excípulo de color gris claro, sin costillas pero arrugado o abollado. Contexto delgado, blanquecino. Olor no característico y sabor suave.

Ascosporas anchamente elipsoidales de 17,1$20,5 \times 11,1-14,5 \mu \mathrm{m}, \mathrm{Q}=1,4-1,6\left(\mathrm{~L}_{\mathrm{m}}=18, \mathrm{~W}_{\mathrm{m}}=12\right.$, $\left.\mathrm{Q}_{\mathrm{m}}=1,5 ; \mathrm{n}=10\right)$, lisas, hialinas, con una gran gota lipídica central. Ascas cilíndricas atenuadas hacia la base, de 290-320 × 13-16 $\mu \mathrm{m}$, no amiloides, pleurorrincas, operculadas, con 8 esporas uniseriadas. $\mathrm{Pa}$ ráfisis cilíndricas, de 3-4 $\mu \mathrm{m}$ de grosor, ensanchadas gradualmente hasta un ápice clavado irregular de 5-6,5 $\mu \mathrm{m}$ de diámetro, septadas, de color beige en su tercio inferior, oscureciéndose hasta color pardo en el superior. Excípulo medular de textura intricata, formado por hifas hialinas de 4-6 $\mu \mathrm{m}$ de ancho. Excípulo ectal de textura angularis a prismatica, formado por células de $8-15 \mu \mathrm{m}$, hialinas, donde emergen las más externas en forma de maza, de 10-30 × 5-15 $\mu \mathrm{m}$, que se vuelven perpendiculares a la superficie del receptáculo.

Material estudiado: ESPAÑA. Huesca: Seira, Barbaruéns, bordas de Trigars, 42.5160 .376 ( \pm 10 m), 1412 m, en suelo básico, con Abies alba y Fagus sylvatica, 28-IX-2018, leg. F. Pancorbo \& L. Ballester, det. L. Ballester, I. Skrede \& T. Schumacher, LB18092802; proximidades del barranco de Trigars, 42,521 0,387 ( $\pm 10 \mathrm{~m}), 1503 \mathrm{~m}$, en suelo básico con Abies alba y Fagus sylvatica, 28-IX-2018, leg. R. Martínez-Gil \& L. Ballester, det. L. Ballester, I. Skrede \& T. Schumacher, LB18092809.

Comentarios: Helvella sulcata pertenece al complejo de especies entorno a $H$. lacunosa Afzel. nom sanct. (clado C en SKREDE \& al. 2017), compuesto por especies cuyos apotecios poseen estípite surcado, mitra en general en forma de silla de montar y de color pardo oscuro a negro. Dentro de este complejo, H. sulcata se caracteriza por su mitra irregular, en forma de silla de montar, de color gris oscuro a negro, y el estípite concolor, si bien los caracteres moleculares representan el carácter diagnóstico más importante (SKREDE \& al. 2017, 2020).

El material hallado durante el encuentro correspondiente a la segunda cita de $H$. sulcata en la Península Ibérica, hallazgo que ha sido ya divulgado en SKREDE \& al. (2020), donde se aporta confirmación molecular. La primera cita ibérica de La Rioja (RM-2238) se recoge en SKREDE \& al. (2017). Es muy probable que $H$. sulcata posea una distribución mucho más amplia en el territorio, dado que su hábitat no parece específico.

Helvella terricola Skrede \& T. Schumach., Fungal Syst. Evol. 6: 91. 2020.

Fig. 7

Ascomas estipitados de hasta $70 \mathrm{~mm}$ de altura y $40 \mathrm{~mm}$ de anchura. Mitra en forma de silla de montar con 2 lóbulos bastante regulares. Estípite de hasta $50 \times 10 \mathrm{~mm}$, ligeramente adelgazado en la parte superior, sólido, con 4-6 costillas longitudinales, a veces con el filo hendido, de color gris oscuro; el margen de la mitra es incurvado, a veces pegado al estípite pero nunca soldado; himenio de color casi negro, rugoso; excípulo de color gris oscuro, subtomentoso. Olor no característico, sabor suave.

Ascosporas elipsoidales de 15,0-19,5 × 10,8-12,6 $\mu \mathrm{m} \mathrm{Q}=1,3-1,7\left(\mathrm{~L}_{\mathrm{m}}=17,8, \mathrm{~W}_{\mathrm{m}}=11,5, \mathrm{Q}_{\mathrm{m}}=1,55 ; \mathrm{n}=10\right)$. lisas, hialinas. Ascas cilíndricas de 260-320 × 12-15 $\mu \mathrm{m}$, no amiloides, pleurorrincas, operculadas, con 8 esporas uniseriadas. Paráfisis cilíndricas, de 2-3 $\mu \mathrm{m}$ de ancho, ensanchadas gradualmente hasta un ápice clavado irregular de 5-10 $\mu \mathrm{m}$ de diámetro, septadas, con pigmento parietal de color marrón claro. Excípulo medular de textura intricata, formado por hifas hialinas de 4-8 $\mu \mathrm{m}$ de ancho. Excípulo ectal de textura globulosa-angularis, formado por células de 20 a $40 \mu \mathrm{m}$ de diámetro, hialinas con pigmento parietal de color marrón claro similar al de las paráfisis, las externas más alargadas y de textura prismática que dan lugar a una empalizada de células en forma de maza densamente compactas que se vuelven perpendiculares a la superficie del receptáculo.

Material estudiado: ESPAÑA. Huesca: Benasque, Cerler, Selva de Conques, 42.585207410 .53290399 $( \pm 10 \mathrm{~m}), 1400 \mathrm{~m}$, en el cauce de un barranco, entre el limo, con Betula pendula, Corylus avellana, Populus tremula y Fraxinus excelsior, 28-IX-2018, leg. F. Cervera \& L. Ballester, LB18092810. 

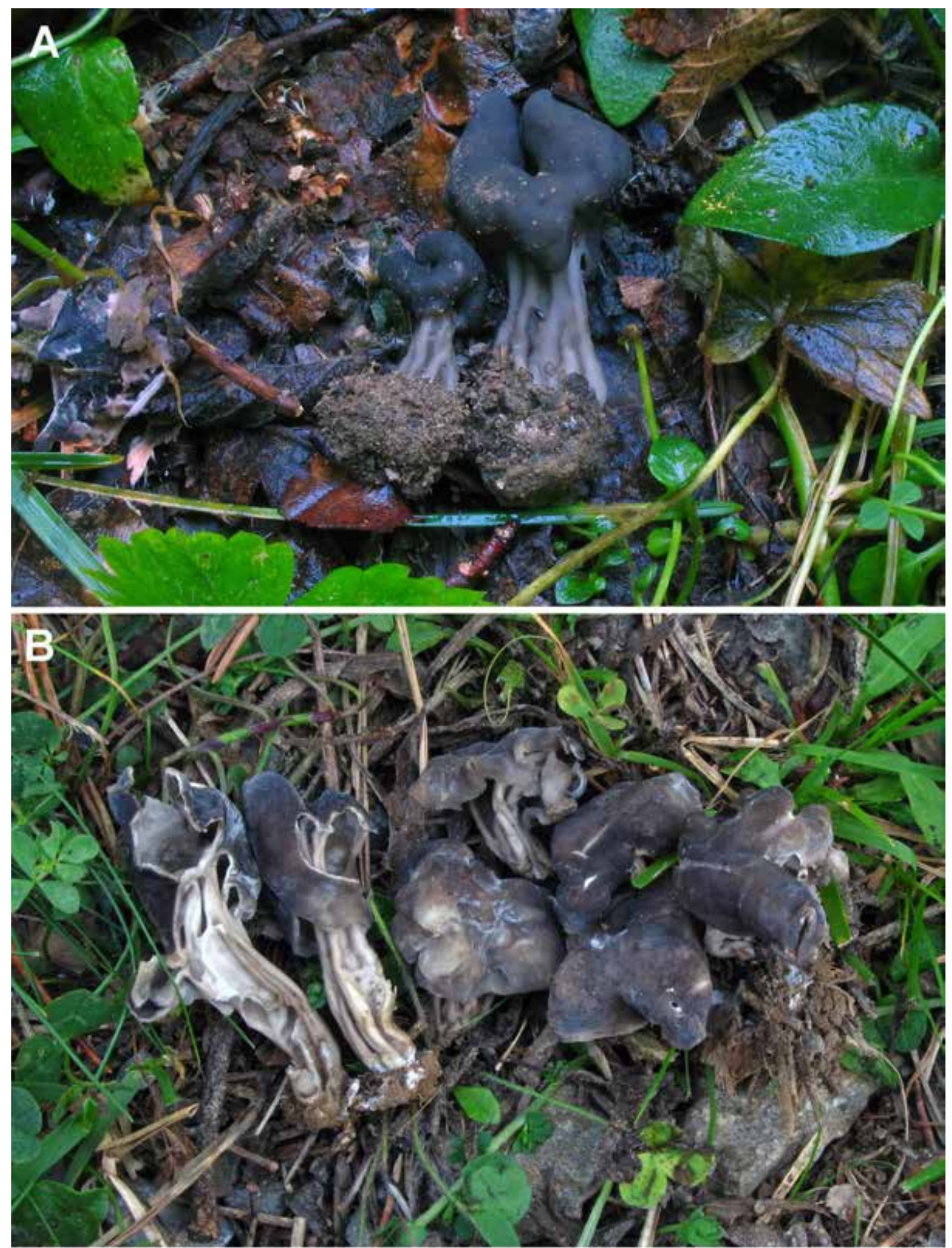

Fig. 6. Helvella sulcata. Ascomas in situ. A: LB18092802. B: LB18092809. Fotografías: L. Ballester. 


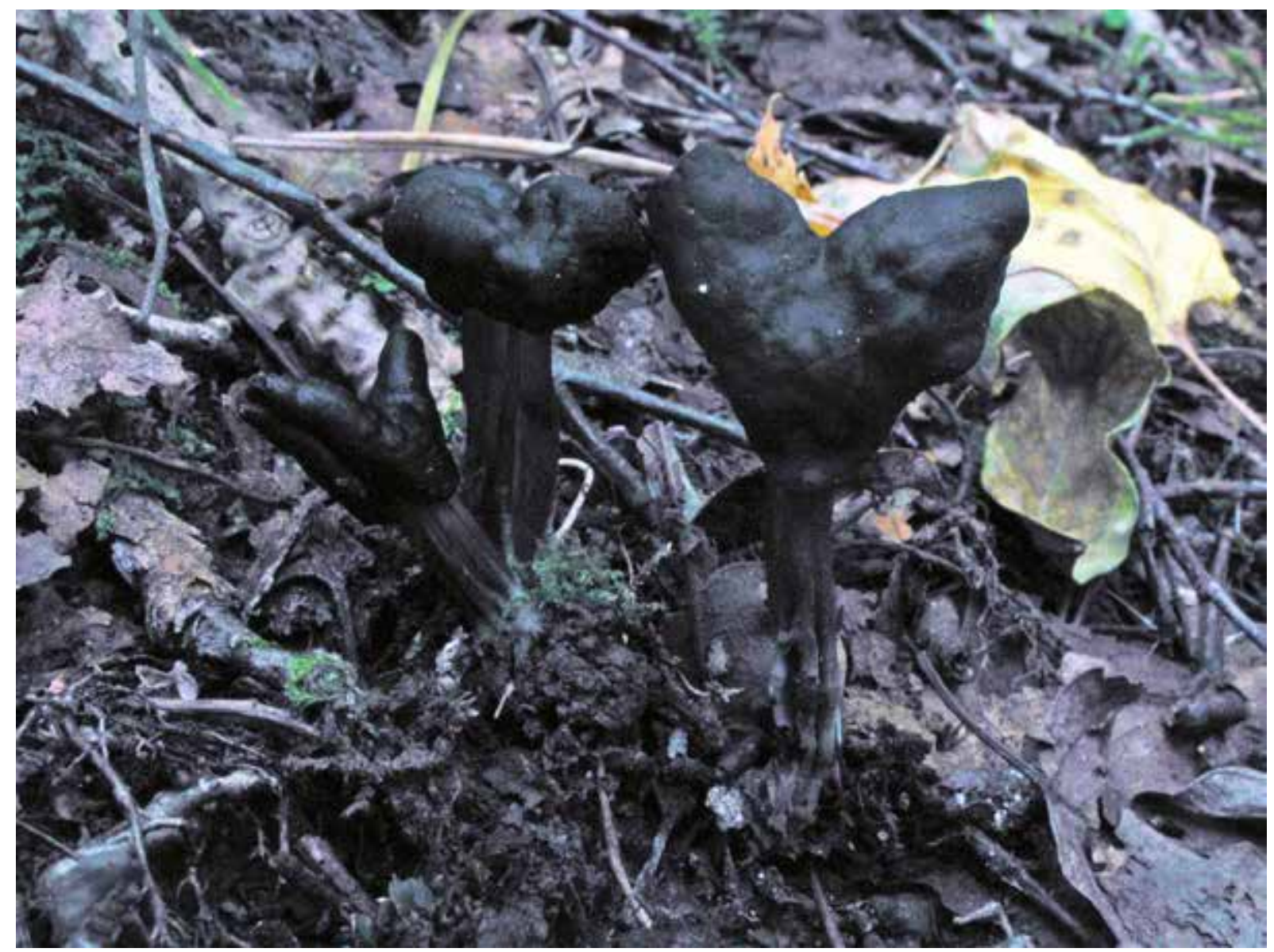

Fig. 7. Helvella terricola (LB18092810). Ascomas in situ. Fotografía: L. Ballester.

Comentarios: Helvella terricola es otra especie del complejo $H$. lacunosa que pertenece al linaje $H$. philonotis-palustris. Las especies de este linaje poseen una mitra sin lóbulos o con 2-3 lóbulos y tamaño medio (SKREDE \& al. 2017). Helvella terricola ha sido descrita recientemente como especie nueva basándose en una única recolección realizada durante el encuentro de Cerler (SKREDE \& al. 2020). Helvella terricola es una especie muy próxima a $H$. palustris Peck, de la que aparentemente no puede distinguirse morfológicamente y difiere en 3 sustituciones en el gen HSP y otras 3 en el RPB2. SKREDE \& al. (2020), proponen también que las dos especies difieren sustancialmente en ecología; $H$. palustris crece en pantanos y riachuelos minerotróficos, mientras que $H$. terricola crece en suelo desnudo y húmedo. Sin embargo, pensamos que una única colección no es suficiente para conocer la amplitud ecológica de $H$. terricola, y que esta conclusión debe de ser evaluada mediante la recolección de más especímenes. Helvella philonotis Dissing, especie propia de zonas húmedas del piso subalpino como H. palustris, se diferencia por la mitra acopada inicialmente, y por el margen libre y revoluto (SKREDE \& al. 2017).
Isothea rhytismoides Fr., Summa Veg. Scand.: 421. 1849. [nom. nov. para Sphaeria rhytismoides C. Bab. ex Berk.].

= Sphaeria rhytismoides C. Bab. ex Berk., Ann. Mag. Nat. Hist., Ser. 1, 6: 361. 1841. nom. illeg. (Art. 53.1), homónimo posterior de Sphaeria rhytismoides Corda, Icon. Fung. 4: 42. 1840. [“1838"].

- Sphaeria rhytismoides C. Bab., Proc. Linn. Soc. 1: 32. 1839. [nom. inval. publ. nom. nudum, Art. 38.1(a)].

Fig. 8

Estromas creciendo en hojas vivas de Dryas octopetala, de hasta $3 \mathrm{~mm}$ de diámetro, de color negro, generalmente visibles solamente en al haz de la hoja, brillantes, con pequeñas protuberancias que coinciden con los pseudotecios. Pseudotecios inmersos, subcuticulares, bien visibles, con ostiolo inconspicuo, de alrededor de $0,2 \mathrm{~mm}$ de diámetro.

Ascosporas ovoides, a menudo más anchas en uno de los polos, aseptadas, hialinas, con contenido plurigutulado y refringente, dejando visible un núcleo voluminoso, de 12,5-16,3 × 5,7-7,3 $\mu \mathrm{m}$. Ascas claviformes, de pared delgada, con aparato apical inconspicuo, IKI $\varnothing$, con un largo pedicelo en la base, con 8 ascosporas, de hasta $90 \times 20 \mu \mathrm{m}$. 

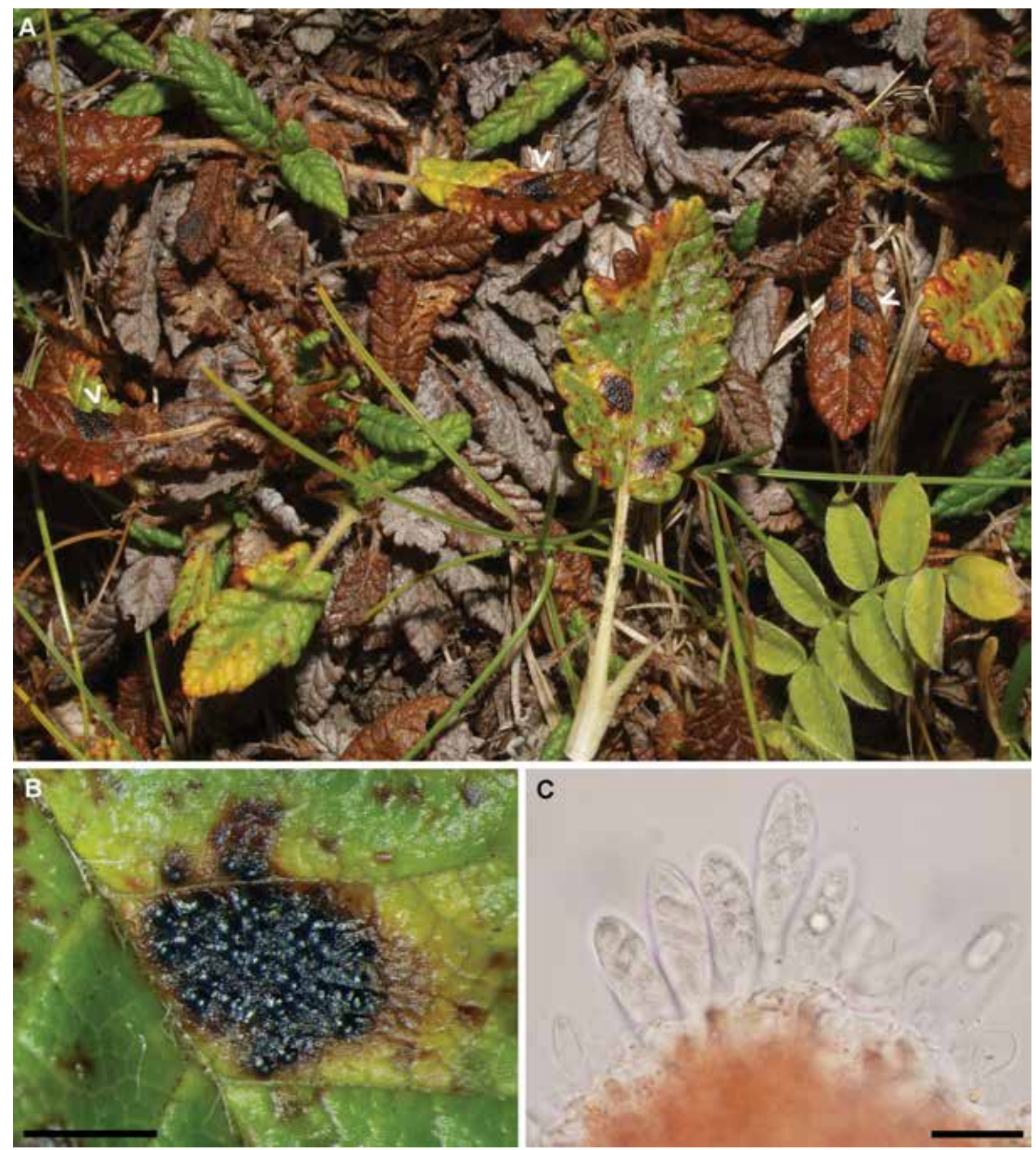

Fig. 8. Isothea rhytismoides (ARAN-Fungi 11295). A: Estromas negros sobre el haz de las hojas de Dryas octopetala. Las flechas blancas señalan algunos de los estromas. B: Detalle de estroma. C: Ascas mostrando ascosporas. Barras de escala $10 \mu \mathrm{m}$. Fotografías: I. Olariaga.

Material estudiado: ESPAÑA. Huesca: Montanuy, Collada de Basibé, 42.553226780 .59197995 ( \pm $10 \mathrm{~m}), 2370 \mathrm{~m}$, sobre tomento en el envés de hojas muertas de Dryas octopetala, 27-IX-2018, leg. et det. I. Olariaga, ARAN-Fungi 11295.

Comentarios: Especies parásita que resulta inconfundible por sus estromas negruzcos que recuerdan a los de Rhytisma Fr. y que aparecen sobre hojas vivas de Dryas octopetala. Según HOLM (1979) I. rhytismoides es una de las especies de Ascomycota más comunes sobre $D$. octopetala, y existen citas alpinas en varios países, Dinamarca (Groenlandia), Noruega, Irlanda, Islandia, e incluso Norteamérica (BRITISH MYCOLOGICAL SOCIETY 2020; RAMÍREZ $\&$ al. 2020). Según nuestra búsqueda bibliográfica, nuestra cita corresponde a la primera de los Pirineos y de la Península Ibérica. 
Comentario nomenclatural: La autoría de $S$. rhytismoides es errónea en las bases de datos Index Fungorum y MycoBank. Ambas bases de datos mencionan como autor "Bab." que es la abreviatura estándar de Charles Cardale Babington, tío del autor correcto Churchill Babington (C. Bab.) quien fue el recolector del material original de esta especie y a quien Berkeley le dedicó la especie. Además Index Fungorum usa la notación "in Berk." lo que no es posible ya que fue publicado en un revista, por lo que no se debe citar el autor de un artículo de la misma (Art. 46.2, Ej. 13). En ninguna parte Berkeley menciona que la descripción le fuese suministrada por Churchill Babington y por tanto la autoría correcta es “C. Bab. ex Berk.". CANNON (1996: 1409-1410) cita la autoría correctamente pero indica que no encontró la referencia suministrada por Berkeley "Abstr. Linn. Trans. p. 32", lo cual es muy importante para saber si el nombre fue publicado válidamente anteriormente, y si el autor fue Charles Cardale Babington (como indican las bases de datos mencionadas) o por Churchill Babington como indica Cannon. Después de una búsqueda dificultosa por internet con los escasos datos de la referencia dada por Berkeley se encontró que la referencia correcta donde Churchill BABINGTON (1839) menciona tan solo el nombre "Sphaeria rhytismoides" en una lista de hongos, y por tanto publicó inválidamente este nombre.

Marcelleina persoonii (P. Crouan \& H. Crouan) Brumm., Persoonia, Suppl. 1: 233. 1967.

=Ascobolus persoonii $\mathrm{P}$. Crouan \& H. Crouan, $\mathrm{Fl}$. Finistère: 56. 1867.

= Humaria persoonii (P. Crouan \& H. Crouan)

Quél., Compt. Rend. Assoc. Franç. Avancem. Sci. Assoc. Sci. France 14(2): 451. 1886.

= Barlaea persoonii (P. Crouan \& H. Crouan)

Sacc., Syll. Fung. 8: 116. 1889.

=Plicaria persoonii (P. Crouan \& H. Crouan)

Boud., Icon. Mycol. 2(livr.): [3]. 1904.

= Barlaeina persoonii (P. Crouan \& H. Crouan)

Sacc. \& Traverso, Syll. Fung. 19: 140. 1910.

= Pulparia persoonii (P. Crouan \& H. Crouan)

Korf, Pfister \& J.K. Rogers, Phytologia 21(4): 205. 1971.

Figs. 9-10

Apotecios de hasta $10 \mathrm{~mm}$ de diámetro, sésiles, pulvinados, luego discoidales. Himenio liso o ligeramente pruinoso, de color violeta oscuro pasando a tonos más claros o marrones al madurar. Exterior liso, ligeramente más pálido que el resto. Margen delimitado y concolor. Contexto frágil, de color violeta parduzco.

Ascosporas de 10,3-11,5 $\mu \mathrm{m}$ de diámetro incluida la ornamentación, esféricas, hialinas, con una gran gútula en su interior rodeada de otras más peque- ñas; adornadas con crestas sinuosas cianófilas que se unen formando un retículo irregular completo o a veces incompleto y con verrugas aisladas intercaladas. Ascas de 200-250 × 13-16,5 $\mu \mathrm{m}$, cilíndricas, atenuadas hacia la base, operculadas, pleurorrincas, no amiloides, con 8 esporas uniseriadas. Paráfisis ligeramente engrosadas en el ápice hasta de $5 \mu \mathrm{m}$ de grosor, cilíndricas, algunas rectas y otras curvadas en su tercio superior, septadas, hialinas, algunas bifurcadas, con una pigmentación pardo rojizo. Excípulo medular de textura intricata, formado por hifas cilíndricas desordenadas, septadas, hialinas, de 3,5-12 $\mu \mathrm{m}$ de grosor y pared delgada. Excípulo ectal formado por células globosas o poligonales, con pigmento extracelular de color pardo rojizo, de 10-40 $\mu \mathrm{m}$ de diámetro, alargándose hacia el margen, formando elementos (parecidos a pelos) septados (1-4 tabiques), cortos, de 6-10 $\mu \mathrm{m}$ de diámetro, con el tramo apical claviforme y pigmento parietal incrustante de color pardo rojizo.

Material estudiado: ESPAÑA. Huesca: Montanuy, Collada de Basibé, 42.552632 0.591244, ( \pm 200 $\mathrm{m}), 2300 \mathrm{~m}$, sobre el suelo entre pequeños musgos dentro de la estación de esquí, 27-IX-2018, leg. et det. R. Martínez-Gil \& C.M.P. Del Amo, RM-2475 (ITS Genbank MW248486; LSU MW248510).

Comentarios: Para la determinación de esta recolecta nos hemos basado en el trabajo de MORAVEC (1987) en el que presenta una clave con 7 especies de Marcelleina Brumm., Korf \& Rifai, incluyendo 2 especies nuevas y combinando otras 2 , y donde destaca que Marcelleina persoonii tendría ascosporas con retículo casi completo y raramente incompleto. MORAVEC (1987) también indica que no le prestaron el holotipo para estudiarlo, por lo que su concepto de la especie Marcelleina persoonii está basado en el lectotipo que estudió VAN BRUMMELEN (1967) de acuerdo con la descripción original. En un primer momento, al encontrar los apotecios descritos en este trabajo, pensamos que podría ser una especie diferente a las que tenemos estudiadas de La Rioja y descritas en MARTÍNEZ-GIL \& CABALLERO (2016), pues el ambiente alpino donde las localizamos es muy diferente al ambiente mediterráneo de las recolectas riojanas, pero después del estudio microscópico que realizamos, creemos que se trata de la misma especie. El análisis de la región LSU (Fig. 11) sitúa nuestra colección en un clado con 4 secuencias más de $M$. persoonii. Desafortunadamente, no existe ninguna secuencia pública de $M$. rickii para poder discriminar ésta a nivel molecular.

Marcelleina rickii (Rehm) Graddon sería una especie cercana y en ocasiones difícil de diferenciar, que desarrolla ascosporas generalmente con retículo incompleto y crestas aisladas. HÄFFNER (1995) 


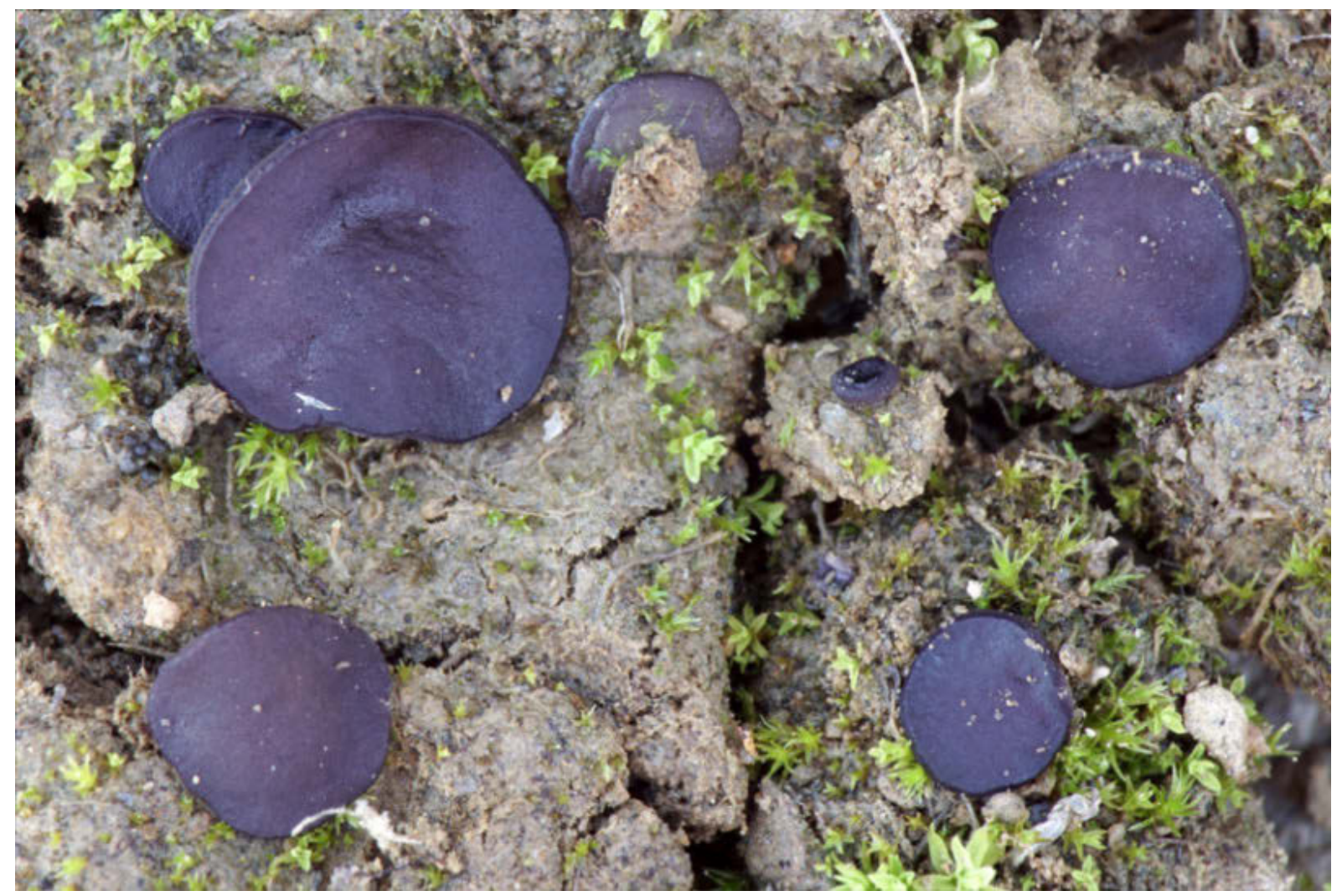

Fig. 9. Marcelleina persoonii (RM-2475). Apotecios in situ. Fotografía: R. Martínez Gil.

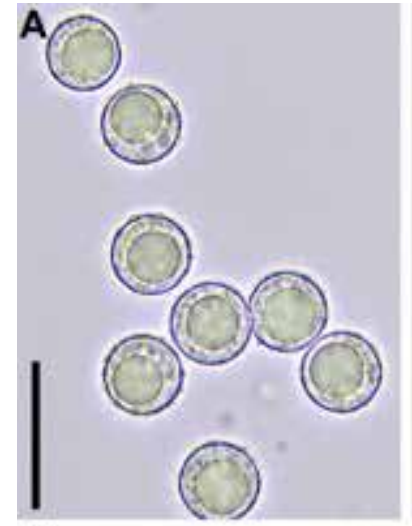

E

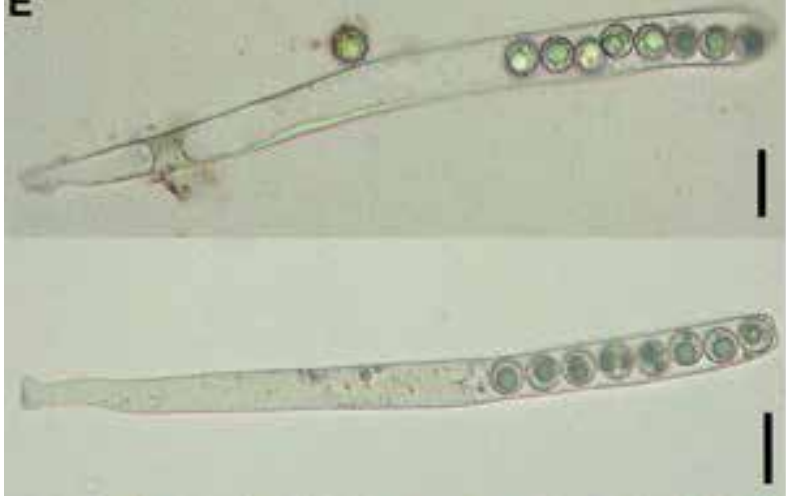

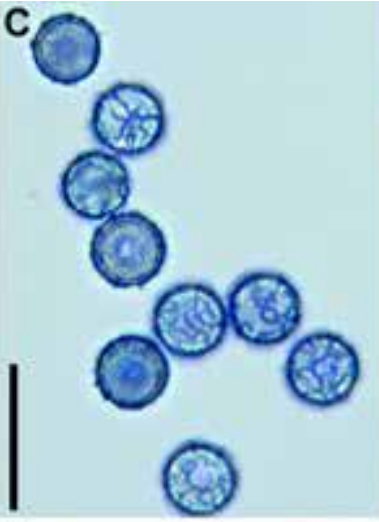

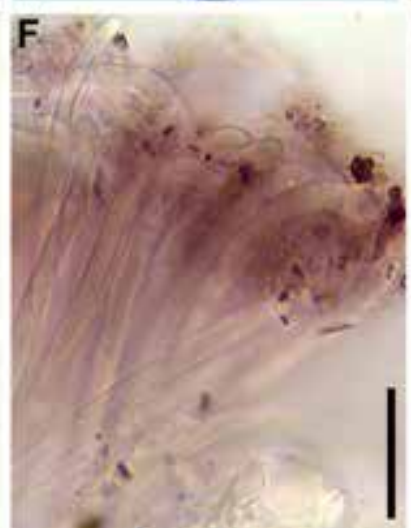

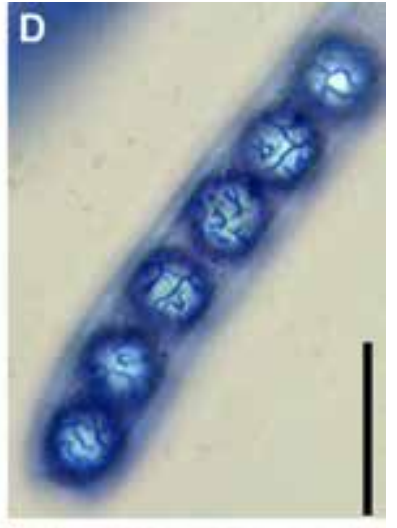

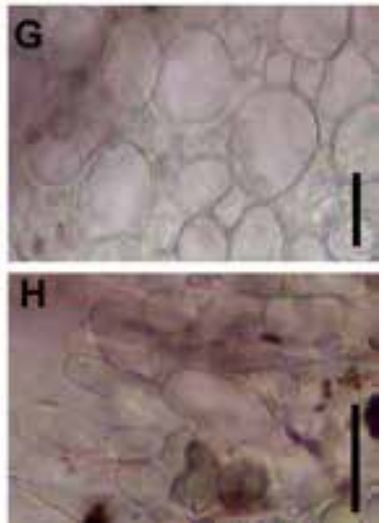

Fig. 10. Marcelleina persoonii (RM-2475). A-B: Ascosporas en agua, C-D: Ascosporas en azul algodón. E: Ascas en agua. F: Paráfisis en agua. G: Excípulo ectal en agua. H: Elementos del margen. Barras de escala $20 \mu \mathrm{m}$. Fotografías: R. Martínez Gil. 

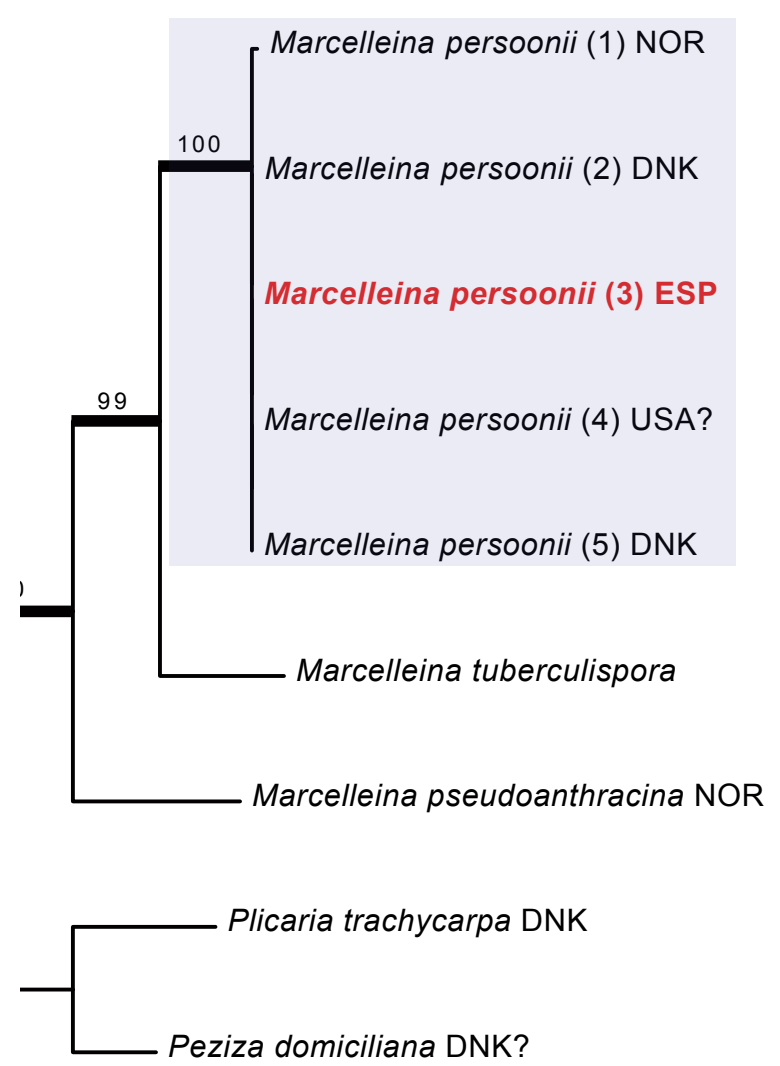

Fig. 11. Árbol más probable inferido mediante el análisis de máxima verosimilitud de la región $28 \mathrm{~S}$ del rDNA nuclear en Marcelleina. Los valores bootstrap se muestran entorno a los nodos. Las ramas gruesas indican los nodos con apoyo filogenético (valores bootstrap $\geq 70 \%$ ). Se emplearon secuencias de Peziza domiciliana y Plicaria trachycarpa para enraizar el árbol. La muestra estudiada en este trabajo se marca en rojo, mientras que el país de origen de cada colección se abrevia mediante códigos ISO.

explica que después de estudiar varias colecciones de $M$. rickii y $M$. persoonii, no encontró diferencias significativas macro ni microscópicas, salvo la pequeña diferencia en la ornamentación esporal comentada anteriormente. MEDARDI (2006) añade que $M$. rickii tendría ascosporas un poco más pequeñas (8-9 $\mu \mathrm{m}$ de diámetro) que M. persoonii $(9-10 \mu \mathrm{m}$ de diámetro). Si nos fijamos en los dibujos de las ascosporas que hacen HÄFFNER (1995) y MORAVEC (1987) en sus trabajos, parece que la altura de las crestas es ligeramente mayor en las de $M$. rickii, dato que también podría tenerse en cuenta para la diferenciación entre ambas especies y que los 2 autores cifran de $0,3-0,6 \mu \mathrm{m}$ de altura para $M$. persoonii y 0,3-0,8(-1,2) $\mu \mathrm{m}$ para $M$. rickii.

Marcelleina persoonii es una especie con pocos registros en la Península Ibérica. Según nuestra búsqueda, se conoce de Alicante (BDBCV-General 650729), Córdoba (DANIËLS \& MORENO-ARROYO 2009), Gerona (MA-Fungi 24999) y Gipuzkoa (ARAN-Fungi 3008175) además de en La
Rioja (MARTÍNEZ-GIL \& CABALLERO 2016). Por tanto, la recolección presentada aquí supondría la primera cita para Aragón.

Pseudaleuria fibrillosa (Massee) J. Moravec, Acta Mus. Morav. Sci. Biol. 88(1/2): 51. 2003 [sub Pseudoaleuria fibrillosa (Currey) J. Moravec].

=Otidea fibrillosa Massee, Brit. Fung.-Fl. 4: 449. 1895 [nom. nov. para Peziza fibrillosa Curr., Trans. Linn. Soc. London 24: 153. 1863., nom. illeg. non Peziza fibrillosa Wallr., Fl. Crypt. Germ. 2: 479. 1833].

=Cheilymenia fibrillosa (Massee) Le Gal, Ann. Sci. Nat., Bot., sér 11, 8: 287. 1947. [sub Cheilymenia fibrillosa (Curr.)].

$\equiv$ Tricharina fibrillosa (Massee) Chin S. Yang \& Korf, Mycotaxon 24: 487. 1985. [sub Tricharina fibrillosa (Currey) Yang \& Korf].

Figs. 12-13

Apotecios de hasta $12 \mathrm{~mm}$ de diámetro, sésiles o subestipitados, primero cupuliformes, luego discoidales. Himenio de color amarillo anaranjado vivo, rodeado por un margen formado por el excedente de pelos del exterior, que es concolor o algo más pálido y cubierto de pelos blanquecinos. Contexto delgado, muy frágil y acuoso.

Ascosporas de 16-19 × 9-10,5 $\mu \mathrm{m}(\mathrm{Q}=1,6-1,8)$, elipsoidales, lisas, hialinas, sin gútulas, con 1 núcleo fácilmente visible. Ascas de 200-250 × 12-15 $\mu \mathrm{m}$, cilíndricas, operculadas, no amiloides, pleurorrincas, con 8 esporas uniseriadas. Paráfisis con el segmento apical claviforme y el ápice bastante engrosado, de 5-12 $\mu \mathrm{m}$ de diámetro en la parte más ancha y 3-4 $\mu \mathrm{m}$ en el resto, filiformes, rectas, septadas, algunas ramificadas, con contenido granuloso interno de color anaranjado. Excípulo ectal de textura angularis formado por células globosas o poligonales, de 20-60 $\mu \mathrm{m}$ de diámetro, hialinas o ligeramente coloreadas de marrón. Pelos de 80-450 × 10-20 $\mu \mathrm{m}$, cilíndricos, con el extremo redondeado, multiseptados, algunos ramificados, hialinos o ligeramente coloreados de marrón, de pared delgada, que se forman en las células más externas del excípulo ectal.

Material estudiado: ESPAÑA. Huesca: Benasque, Senarta, 42.6408640 .567172 ( $\pm 10 \mathrm{~m}), 1370$ $\mathrm{m}$, sobre el suelo entre la hierba alta de un pastizal de montaña entre el río Ésera y un bosque de Abies alba, 29-IX-2018, leg. R. Martínez-Gil \& C.M.P. Del Amo, RM-2479 (ITS Genbank MW248487; LSU MW248511).

Comentarios: Pseudaleuria fibrillosa puede parecerse macroscópicamente a especies de otros géneros de Pezizales, como Aleuria Fuckel, Cheilymenia Boud., Tricharina Eckblad o Paratricharina Van Vooren \& al., pero es relativamente fácil separarla después de un estudio microscópico, fundamental- 


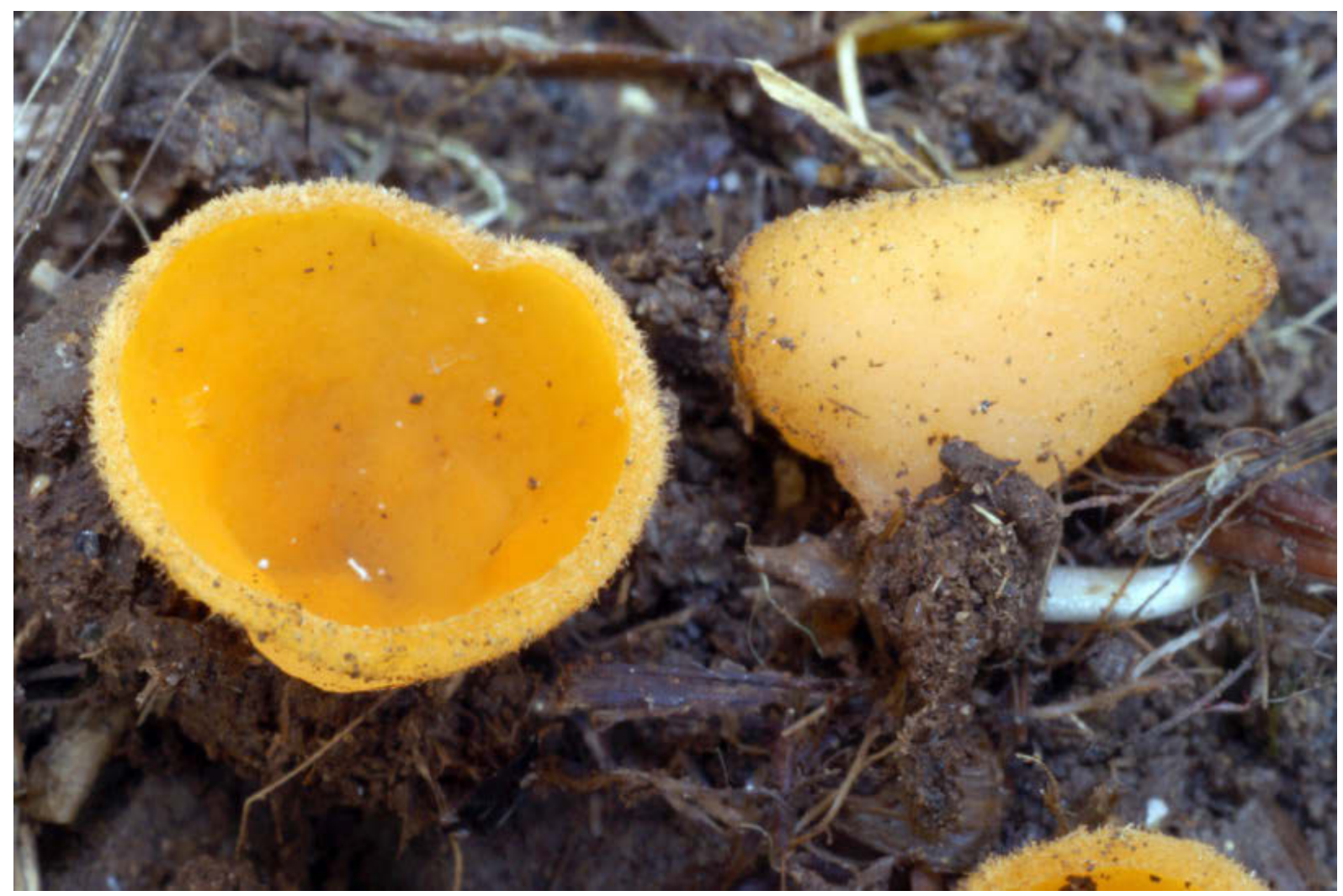

Fig. 12. Pseudaleuria fibrillosa (RM-2479). Apotecios in situ. Fotografía: R. Martínez Gil.

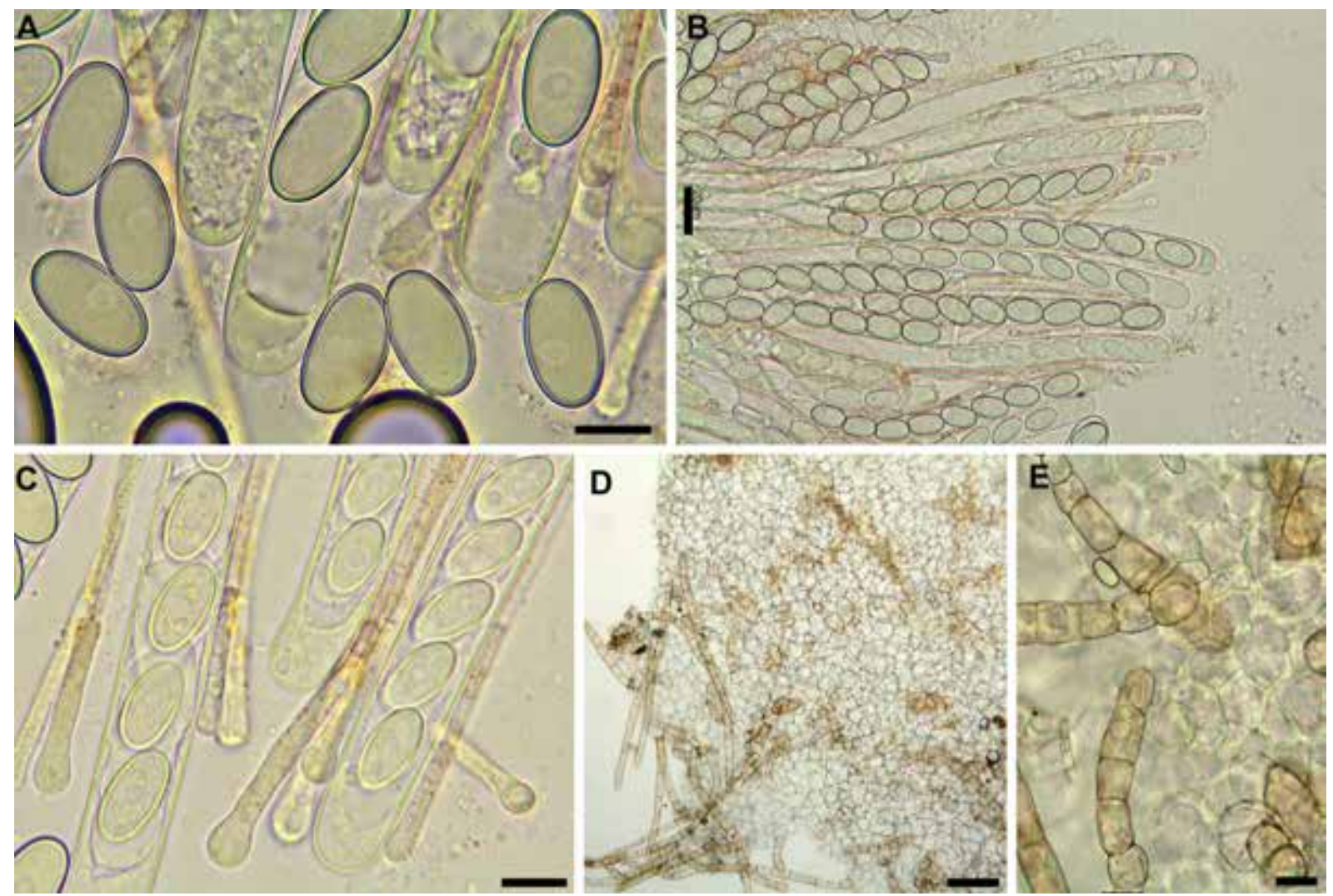

Fig. 13. Pseudaleuria fibrillosa (RM-2479). A: Ascosporas en agua. B-C: Ascas y paráfisis en agua. D-E: Pelos. Barras de escala A-C: $10 \mu \mathrm{m}, \mathrm{D}: 100 \mu \mathrm{m}, \mathrm{E}: 20 \mu \mathrm{m}$. Fotografías: R. Martínez Gil. 


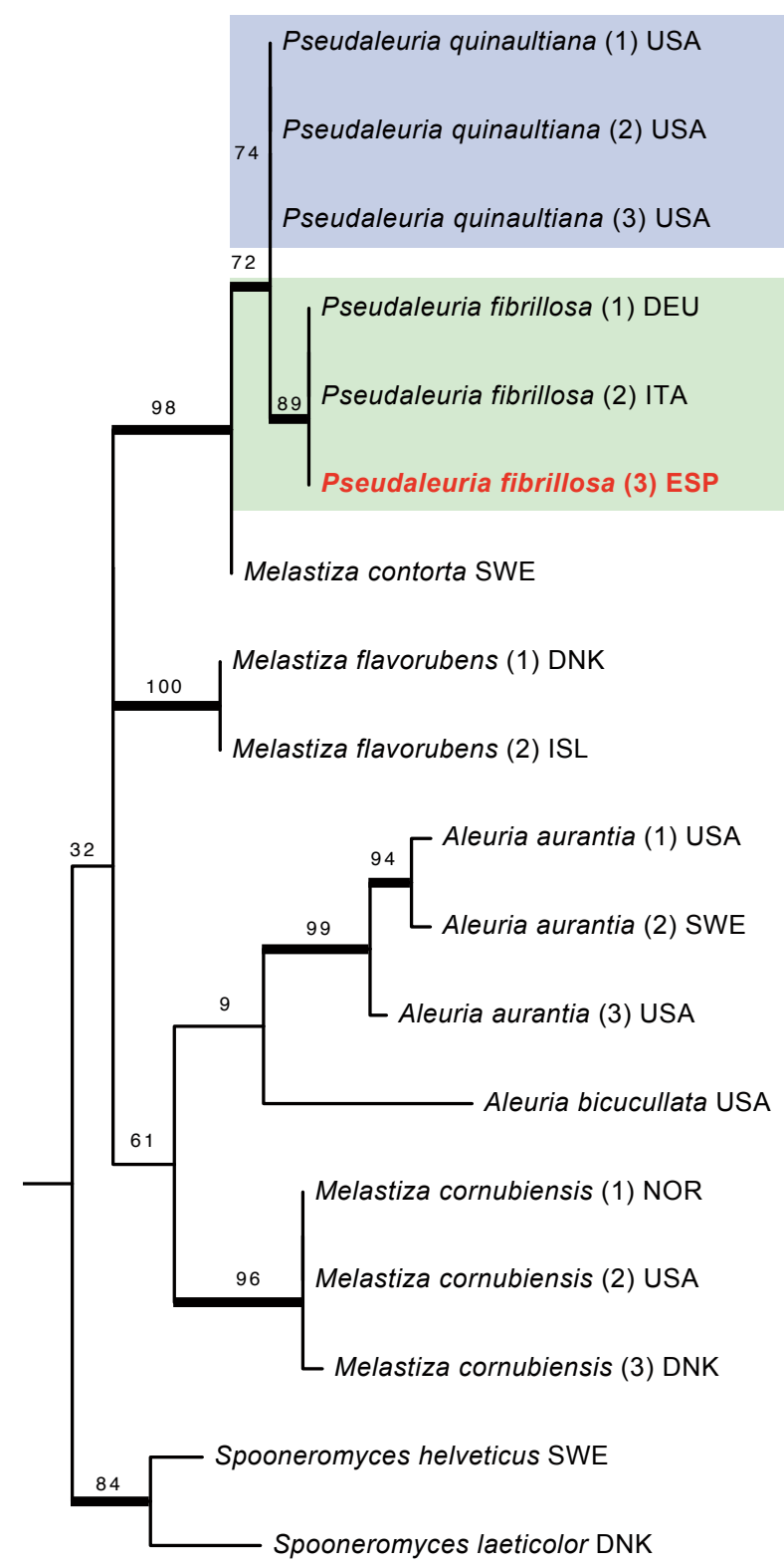

Fig. 14. Árbol más probable inferido mediante el análisis de máxima verosimilitud de la región $28 \mathrm{~S}$ del rDNA nuclear en Pseudaleuria y géneros próximos de Pyronemataceae. Las ramas gruesas indican los nodos con apoyo filogenético (valores bootstrap $\geq 70 \%$ ). Se empleó una secuencia de Byssonectria terrestris para enraizar el árbol. El país de origen de cada colección se abrevia mediante códigos ISO, marcándose las muestra estudiada en este trabajo en negrita y color rojo.

mente por la estructura del excípulo ectal y por poseer pelos con numerosos septos, de pared delgada y ápice redondeado.

LUSK (1982) establece el género Pseudaleuria basándose en la especie tipo Pseudoaleuria quinaultiana Lusk, descrita de Norteamérica, y separándola de $P$. fibrillosa por una supuesta diferencia en la estructura del excípulo ectal, pero MORAVEC (2003) comenta que ambos taxones poseen la misma estructura y combinó ésta última en Pseudaleuria. Nuestro análisis de la región LSU (Fig. 14) separa las muestras americanas identificadas como $P$. quinaultiana de las europeas como P. fibrillosa en dos clados con apoyo filogenético. La comparación de especímenes europeos y americanos, idénticos entre sí, muestra que existen 5 mutaciones y 2 indels ( $1,3 \%$ de divergencia). En cualquier caso, bien interpretando que esta divergencia es suficiente para considerar que $P$. fibrillosa y $P$. quinaultiana son dos especies diferentes, o bien considerando que ambas representan poblaciones de una misma especie que han permanecido reproductivamente aisladas durante largo tiempo, el nombre que debe de ser adoptado para las recolecciones europeas es $P$. fibrillosa, como hacemos aquí.

MORAVEC (2003) estudia el holotipo de Peziza fibrillosa Curr. y obtiene una medida esporal de $(15,0-) 15,5-18,7(-19,3) \times(7,5-) 8-9(-10,5) \mu \mathrm{m}$, muy similar a la que nosotros hemos observado. MARTÍNEZ-GIL \& CABALLERO (2016) describen una recolecta de La Rioja con unas medidas esporales de 16,5-19,8 $\times$ 9,8-11 $\mu \mathrm{m}$, también muy similares a las obtenidas en la recolecta de este trabajo. Sin embargo, DENNIS (1981) describe la especie como Cheilymenia fibrillosa (Currey) Le Gal con esporas de 15-16 × 8-9 $\mu$ m, YANG \& KORF (1985) la describen como Tricharina fibrillosa (Currey) Yang \& Korf con esporas de 13,9-15,8 × 8-9 $\mu$ m y GALÁN \& RAITVIIR (1995) también como T. fibrillosa pero con esporas de 15,4-16,8 × 8-8,8(-9,6) $\mu \mathrm{m}$, ligeramente menores que nuestra recolecta en largura y anchura, pero entendemos que la diferencia puede entrar dentro de la variabilidad de la especie y del método empleado para la obtención de esas esporas. Para las medidas ofrecidas en esta colección hemos tomado los datos de los apotecios frescos y solo las esporas recién expulsadas por las ascas en el momento del análisis microscópico, sin haber realizado un depósito de esporada libre ni una rehidratación posterior.

Pseudaleuria fibrillosa es una especie escasamente citada en la Península Ibérica, pero que sin embargo, parece estar ampliamente distribuida. Además de la cita de La Rioja (MARTÍNEZ-GIL \& CABA- 

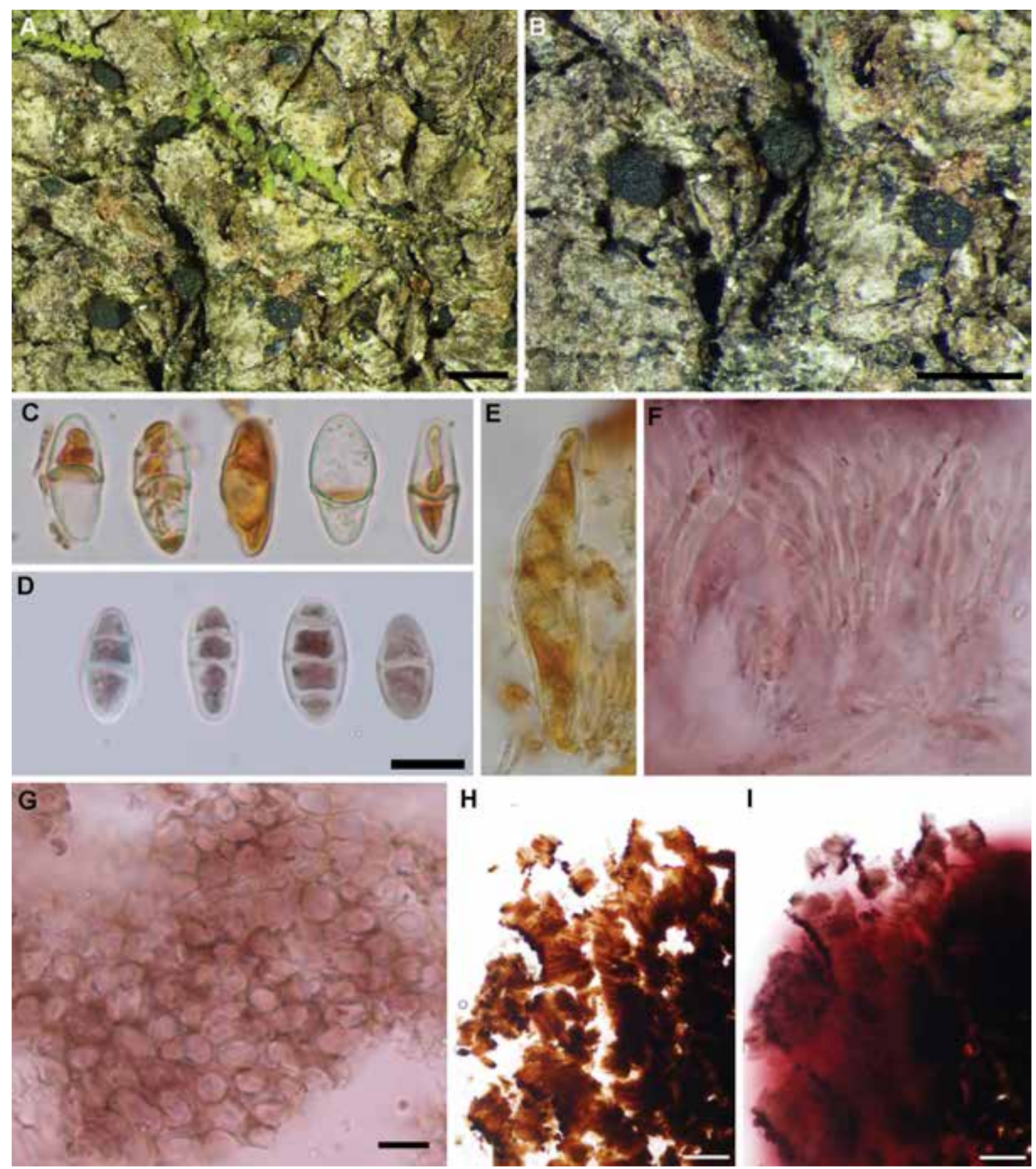

Fig. 15. Pseudotryblidium neesii (ARAN-Fungi 14207). A: Apotecios. B: Apotecios en ásm detalle. C: Ascosporas en agua. D: Ascosporas en KOH. E: Asca en agua. F: Paráfisis en KOH. G: Vista superficial de las células del excípulo ectal en KOH. H: Preparación gruesa del apotecio. I: Misma preparación mostrada en la fig. 15I, mostrando reacción ionomidótica en $\mathrm{KOH}$. Barras de escala $10 \mu \mathrm{m}$. Fotografías: I. Olariaga.

LLERO 2016), existen registros de Álava (VIT-Mycotheca 6319), Asturias (RUBIO \& al. 2006, como Tricharina fibrillosa), Cádiz (GALÁN \& RAITVIIR 1995, como Tricharina fibrillosa), Gipuzkoa (3 especímenes en ARAN-Fungi), Navarra (5 especímenes en ARAN-Fungi, MA-Fungi 65020), Huelva (MA-Fungi 40392), Salamanca (MARCOS-MARTÍNEZ 2017) y Sevilla (MERINO 2014).
Pseudotryblidium neesii (Arnold) Rehm, Pilze Deutsch., Hyster. Discomyc.: 370. 1896.

=Dactylospora neesii Arnold, Flora 57: 108. 1874.

Fig. 15

Ascomas apotecioides, creciendo en modo gregario, de 0,3-0,7 mm de diámetro, de pardo rojizo muy oscuro a negro, ligeramente estipitados, con el margen regular a ligeramente ondulado, a veces estriado en la juventud, de consistencia coriácea. 
Ascosporas de elipsoidales a ovoides, de hialinas a amarillo pálidas, cuando están sobremaduras con contenido pardo amarillento que reacciona a rojo vinoso vivo en $\mathrm{KOH}$, lisas, de pared gruesa, con (0-)1-2 septos, de 18-23 × 7,5-9 $\mu \mathrm{m}$. Epitecio cubierto por cristales amorfos de color pardo amarillento muy oscuro, opaco, que reacciona a rojo vinoso vivo en KOH. Ascas de cilíndricas a estrechamente claviformes, cortamente pedicelados, de pared gruesa (hasta $1 \mu \mathrm{m})$, con 8 esporas dispuestas de manera biseriada, no amiloides ni hemiamiloides, sin aparato apical, de 78-83 × 17-19 $\mu \mathrm{m}$. Paráfisis filiformes, simples o bifurcadas, de 1,5-2 $\mu \mathrm{m}$ de anchura, con los ápices ligeramente aglutinados, claviformes, de 2,6-5,4 $\mu \mathrm{m}$ de anchura, Excípulo ectal de color pardo a pardo oscuro, de textura globulosa con células de 4-9 $\mu \mathrm{m}$ de diámetro, de pared gruesa, de color pardo en agua, cubiertas de cristales amorfos de color pardo amarillento oscuro, con reacción a rojo vinoso vivo en $\mathrm{KOH}$.

Material estudiado: ESPAÑA. Huesca: Benasque, Senarta, 42.6404280 .568777 ( $\pm 10 \mathrm{~m}), 1400 \mathrm{~m}$, sobre corteza viva de Abies alba, 29-IX-2018, leg. et det. I. Olariaga, ARAN-Fungi 14207.

Comentarios: Pseudotryblidium neesii se caracteriza por sus apotecios negros, su ecología sobre árboles vivos del género Abies, y microscópicamente, por sus esporas triseptadas, de pared gruesa y por su reacción ionomidótica (es decir, que disuelve el pigmento liberándolo en el medio de observación) rojo vinosa en KOH (SUIJA \& al. 2020). Los datos moleculares existentes apuntan que $P$. neesii pertenece a la familia Dermataceae en la clase Leotiomycetes.

A pesar de que $P$. neesii fue descrito originalmente a finales del siglo XIX, no parece haber citas recientes hasta el trabajo de SUIJA \& al. (2020), en el que se cita $P$. neesii de Suiza y USA, además de los materiales conocidos de Polonia y Alemania. Según nuestros datos, nuestro registro constituye el primer hallazgo en el Pirineo y en la Península Ibérica. Muestreos posteriores al encuentro en el Pirineo de Huesca (I. Olariaga) constatan que $P$. neesii es una especie común en abetales en buen estado de conservación, apareciendo frecuentemente sobre abetos longevos, tanto en zonas iluminadas como sombrías.

Pulvinula niveoalba J. Moravec, Česká Mykol. 23(4): 231. 1969.

Fig. 16

Apotecios de hasta 2,5 $\mathrm{mm}$ de diámetro, cortamente estipitados y con la base obcónica, pulvinados. Himenio ligeramente pruinoso, de color blanco crema. Exterior liso, concolor. Margen obtuso, concolor. Contexto frágil, de color blanco.

*Ascosporas esféricas, hialinas, con multitud de gútulas esféricas en su interior, lisas, de 10,2-11 $\mu \mathrm{m}$ de diámetro $\left(\mathrm{L}_{\mathrm{m}}=10,6, \mathrm{Q}_{\mathrm{m}}=1\right)$. Ascas cilíndricas, operculadas, no amiloides, con 8 esporas uniseriadas, de 180-220 × 11-13 $\mu \mathrm{m}$, atenuadas hacia la base, pleurorrincas. Paráfisis cilíndricas, curvadas en su tramo apical, de 1,4-2 $\mu \mathrm{m}$ de grosor en el ápice, septadas, hialinas, simples, sin gútulas o pigmento. Excípulo de textura globulosa, formado por hifas esféricas a ovoides, hialinas, de 6-13 $\mu \mathrm{m}$ de diámetro, con pared delgada.

Material estudiado: ESPAÑA. Huesca: Montanuy, Collada de Basibé, 42.553306890 .59260948 , ( $\pm 10 \mathrm{~m}), 2300 \mathrm{~m}$, entre Dryas octopetala, en un agujero con tierra bastante arcillosa, 27-IX-2018, leg. J. Hernanz, det. R. Martínez-Gil \& I. Olariaga, ARAN-Fungi 13804 (ITS Genbank MW248488; MW248512); idem RM-2476).

Comentarios: Pulvinula niveoalba es una especie caracterizada por sus ascomas de color blanco, sus ascas octospóricas, ascosporas pequeñas y apote-
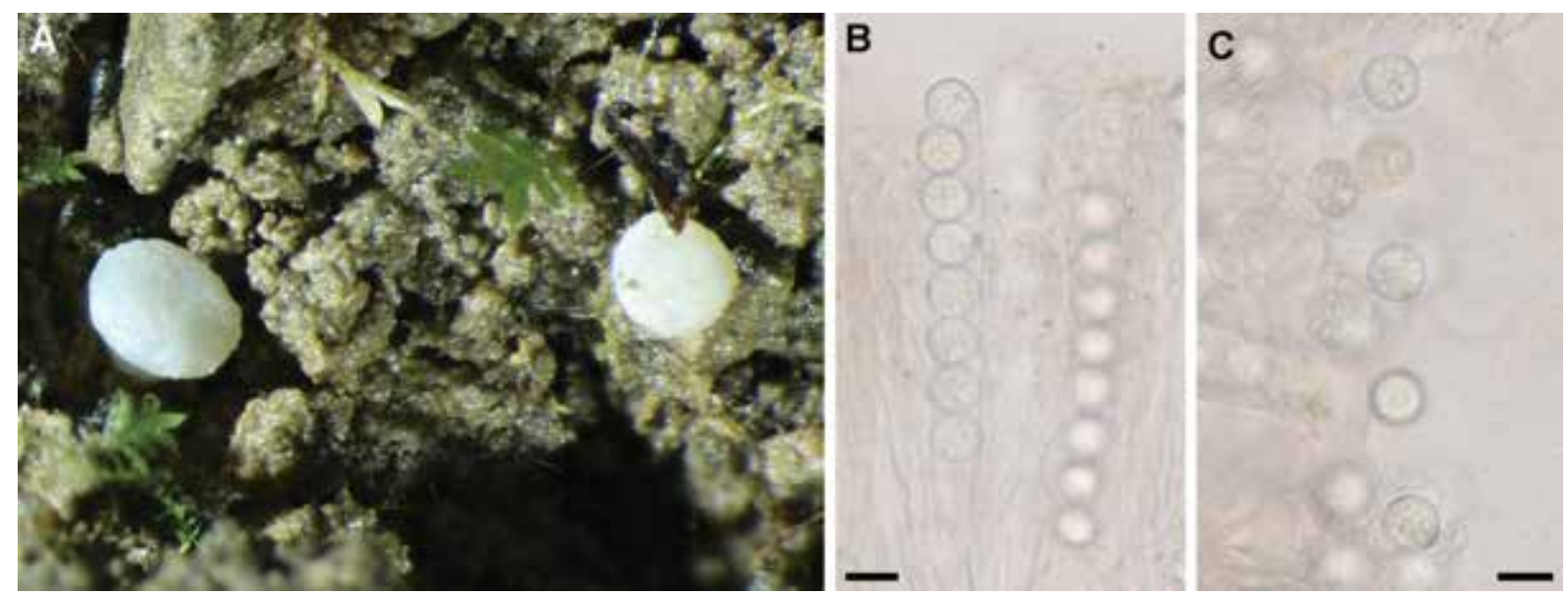

Fig. 16. Pulvinula niveoalba (ARAN-Fungi 13804). A: Apotecios. B: Asca con 8 ascosporas y paráfisis en agua. C: Ascosporas en agua. Barras de escala $10 \mu \mathrm{m}$. Fotografías: I. Olariaga. 


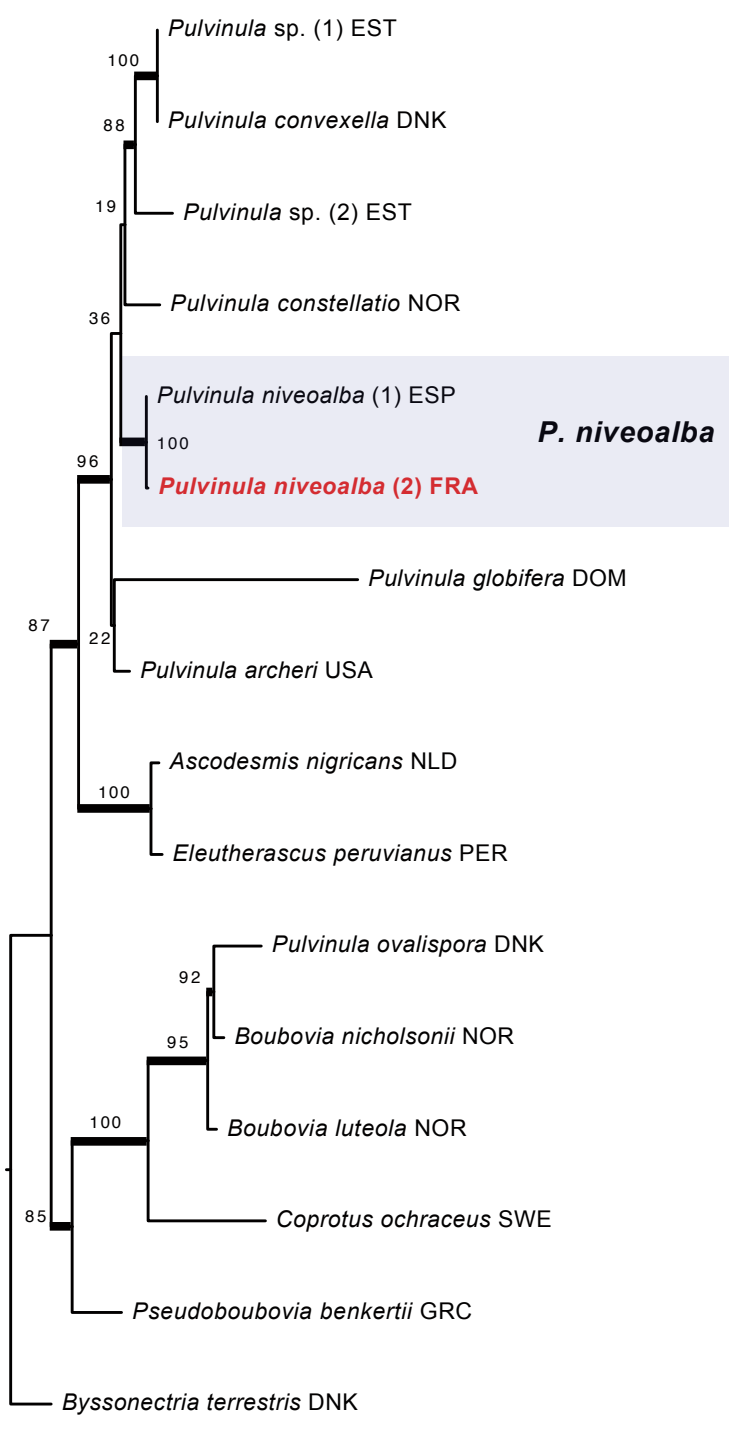

$\overline{0.04}$

Fig. 17. Árbol más probable inferido mediante el análisis de máxima verosimilitud de la región $28 \mathrm{~S}$ del rDNA nuclear en Pulvinula y géneros próximos de Pyronemataceae. Las ramas gruesas indican los nodos con apoyo filogenético (valores bootstrap $\geq 70 \%$ ). Se empleó una secuencia de Byssonectria terrestris para enraizar el árbol. El país de origen de cada colección se abrevia mediante códigos ISO, marcándose la muestras estudiada en este trabajo en rojo y negrita.

cios pequeños (PFISTER 1976). Nuestra recolección encaja perfectamente con el protólogo, si bien las esporas son ligeramente más pequeñas (9,5-12,2 $\mu \mathrm{m}$, MORAVEC 1969). La otra única especie cuyos apotecios son blancos es Pulvinula lacteoalba Moravec, pero sus ascas son constantemente tetraspóricas (MORAVEC 1969). A nivel molecular, nuestros análisis de la región LSU muestran que nuestro espécimen forma un clado bien apoyado con otra muestra identificada como P. niveoalba (Fig. 17). Originalmente descrita de la República Checa (MORAVEC
1969), P. niveoalba parece una especie de distribución septentrional en Europa, donde se conoce de Escandinavia y los Alpes, aunque sus registros no parecen frecuentes. La cita más meridional en Europa es la publicada por RIBES (2010), en el Pirineo francés. Según nuestra búsqueda, no existen registros previos en la Península Ibérica, por lo que el nuestro representa el primero para el territorio.

\section{Phylum Basidiomycota}

Agaricus moelleroides Guinb. \& L.A. Parra, Fungi Europaei 1A: 109. 2013.

Fig. 18

Píleo de 40-120 mm de diámetro, al principio cónico, más tarde casi plano con el margen ligeramente incurvado y con mamelón bajo obtuso en el centro, cubierto de escamas triangulares adpresas dispuestas concéntricamente, de color gris muy oscuro a negruzco, más apretadas hacia el centro que permanece indisociado y algo más separadas hacia el margen sobre un fondo blanquecino. Superficie pileica lisa, mate y seca. Margen delgado, entero, no o ligeramente excediendo a las láminas $(1 \mathrm{~mm})$. Láminas libres, de hasta $6 \mathrm{~mm}$ de alto, apretadas, con laminillas intercaladas, al principio blanquecinas, después rosa grisáceo, más tarde marrones y finalmente de color marrón oscuro casi negro con arista del mismo color que las caras. Estípite de 40-150 × 6-15 mm (de 15-20 mm en la base bulbosa), central, fistuloso, claviforme, bulboso o abruptamente bulboso, liso, glabro, brillante, a veces con superficie ondulada, blanco pero tornándose de color amarillo cromo al frote en la base, provisto de un anillo en su parte alta. Base, a menudo, con un pequeño y frágil rizomorfo. Anillo súpero, membranoso, doble, de hasta $5 \mathrm{~mm}$ de amplitud, delgado en su inserción pero grueso en el margen y amarilleando de forma muy notoria, liso y blanco en su cara superior y con un brazalete con doble margen en la inferior que permanece indiviso o se fragmenta a veces en escamas lineares. Contexto al principio blanco, cambiando a amarillo cromo en la base del estípite, para después de unos 20 minutos pasar a rojo vinoso y más tarde a marrón rojizo. Olor a fenol o yodo, más evidente al corte en la base del estípite. Reacciones macroquímicas no testadas en material fresco. Reacciones de Schäffer negativa $\mathrm{y}$ al $\mathrm{KOH}$ positiva amarilla en material de herbario.

Basidiosporas de 4,84-6,08 × 3,09-3,71(-3,79) $\mu \mathrm{m}$ $\left(\mathrm{L}_{\mathrm{m}}=5,31, \mathrm{~W}_{\mathrm{m}}=3,37, \mathrm{Q}=1,42-1,79, \mathrm{Q}_{\mathrm{m}}=1,58 ; \mathrm{n}=20\right)$, de elipsoides a oblongas, marrones, sin poro, generalmente unigutuladas. Basidios de 15-19 $\times 5-8 \mu \mathrm{m}$, tetraspóricos, raramente bispóricos, claviformes $\mathrm{o}$ ligeramente truncados en el ápice, algunos con pigmento marrón intracelular difuso, con esterigmas de hasta $5 \mu \mathrm{m}$ de largo. Queilocistidios muy abundantes, hialinos o con pigmento marrón difuso, claviformes, piriformes, globosos o esferopedunculados usual- 


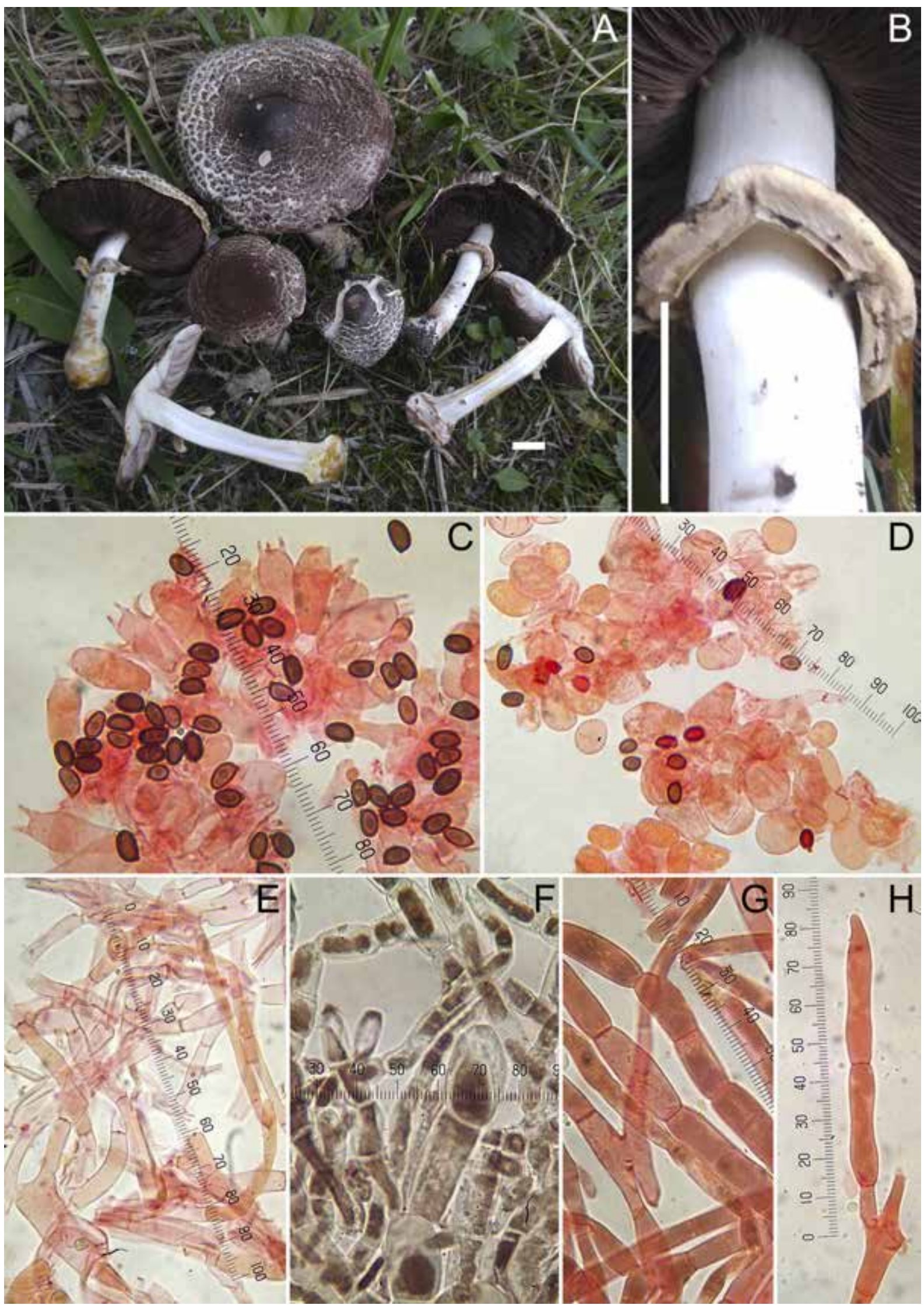

Fig. 18. Agaricus moelleroides (LAPAG 1167). A: Basidiomas. B: Anillo. C: Basidiosporas. D: Queilocistidios. E: Hifas de la supeficie inferior del anillo. F-G: Hifas de la pileipellis. H: Hifa terminal de la pileipellis. Medio de montaje: rojo Congo, excepto F en agua. Barra de escala: $10 \mathrm{~mm}$. Fotografías L. A. Parra. 
mente simples o menos frecuentemente con un septo en el pedúnculo, de 10-22(-25) × 8-14 $\mu \mathrm{m}$. Superficie inferior del anillo compuesta por hifas cilíndricas de 4-10 $\mu \mathrm{m}$ de grosor, no o ligeramente estrechadas en los septos. Pileipellis de tipo cutis, formada por hifas de 4-15 $\mu \mathrm{m}$ de grosor, más estrechadas en los septos cuanto más gruesas, usualmente con pigmento vacuolar o difuso, marrón, interno. Elementos terminales muy abundantes, atenuados hacia el ápice que es redondeado, de 4-8 $\mu$ m de grosor. Fíbulas ausentes en todas las estructuras estudiadas.

Caracteres moleculares: La secuencias ITS de las colecciones aquí descritas son homoalélicas e idénticas a la secuencia del holotipo LAPAG319 (Genbank JN204437). Comparado la secuencia ITS de $A$. moelleri Wasser con $A$. moelleroides, este último se diferencia claramente en 7 posiciones: ggctcCtagga@37, tttcc.gtcag@206, atgttGttcaTtatac@222/227, tttttGcatgg@259,aggggGattgc@601 aatttCttgaa@646 (Tabla 1).

Tabla 1.

Caracteres distintivos entre Agaricus moelleri y $A$. moelleroides de la secuencia ITS.

\begin{tabular}{|l|c|c|c|c|c|c|c|}
\hline ESPECIE/POSICIÓN & 37 & 206 & 222 & 227 & 259 & 601 & 646 \\
\hline moelleri & T & T & A & C & A & - & T \\
\hline moelleroides & C & C & G & T & G & G & C \\
\hline
\end{tabular}

Material estudiado: ESPAÑA. Huesca: Benasque, Cerler, La Selva de Cerler, al borde de un camino en bosque mixto de Pinus sylvestris, y planifolios como bojes, fresnos, avellanos, abedules y álamos temblones, 42.5862250 .53080277 ( \pm 300 m), 1509 m, 28IX-2018, leg. A. Couceiro, det. L.A. Parra, LAPAG 1167 (ITS Genbank MN493149); ibidem, 42.569752 0.509181 ( \pm 300 m), 27-IX-2018, leg. C. Rojo, det. L.A. Parra, LAPAG 1183.

Comentarios: Colecciones gregarias, en pequeños grupos de 6 (LAPAG 1167) o 4 (LAPAG 1183) carpóforos muy próximos. Las colecciones aquí descritas constituyen las primeras citas para España de este taxón, solamente citado con anterioridad en su descripción original (PARRA 2013) en base a tres colecciones, dos de Francia (bajo Abies alba y Fagus sylvatica) recolectadas en Bareilles en el departamento de Hautes Pyrénées (65), a tan solo 40 Km en línea recta de las colecciones de Cerler que aquí se describen, y una de Portugal (bajo Quercus suber) en Monchique. Dado que esta especie no puede ser separada de $A$. moelleri en base a sus caracteres morfológicos es muy posible que un número indeterminado de colecciones identificadas como $A$. moelleri sean en realidad $A$. moelleroides.
Agaricus moelleroides sólo puede ser confundido con $A$. moelleri y con las variedades de $A$. xanthodermus Genev. que tienen el píleo cubierto de escamas oscuras. No obstante, las colecciones de A. moelleroides estudiadas hasta ahora, tienen una anchura esporal con una media de 3,37-3,54 $\mu \mathrm{m}$, por lo que se pueden diferenciar fácilmente de $A$. xanthodermus, con una anchura esporal igual o mayor a $4 \mu \mathrm{m}$ de media.

Agaricus moelleroides y A. moelleri son indistinguibles morfológicamente por lo que solo se pueden distinguir de forma inequívoca por medio de los caracteres moleculares, pero, sorprendentemente, desde un punto de vista filogenético, de acuerdo con sus secuencias ITS, $A$. moelleroides es más cercano a $A$. iodosmus que a $A$. moelleri.

Agaricus porphyrocephalus subsp. alpinus Cappe1li, Bizio, L.A. Parra \& Kerrigan, Micol. Veg. Medit. 33(2): 72. 2019.

Fig. 19

Píleo de 20-50 mm, al principio hemisférico, después plano-convexo, finalmente más o menos aplanado. Superficie pileica seca, mate, al principio lisa, después resquebrajada en grandes escamas poligonales en la parte central, completamente blanca. Margen ligeramente incurvado, excediendo a las láminas. Láminas libres, apretadas, con laminillas intercaladas, al principio rosa pálido, finalmente marrón oscuro casi negro con arista del mismo color. Estípite de 13-26 × 5-14 mm, claviforme o cilíndrico con base atenuada, macizo y blanco. Anillo muy rudimentario, reducido a una sutil banda por encima de la parte media constituido por escasas fibrillas. Por encima del anillo liso o con diminutas escamas furfuráceas dispersas y por debajo liso. Superficie que se torna ocre en la base al roce. Contexto blanco, inmutable o marrón rojizo en la zona de contacto con las láminas y en la parte más externa de la parte superior del estípite, ocrácea en la base del estípite al roce o con la edad. Olor no distintivo. Reacciones macroquímicas no testadas en material fresco. Reacciones de Schäffer y al $\mathrm{KOH}$ negativas en material de herbario.

Basidiosporas de 6,28-7,73 × 4,64-5,67 $\mu \mathrm{m}$ $\left(\mathrm{L}_{\mathrm{m}}=6,84, \mathrm{~W}_{\mathrm{m}}=5,15, \mathrm{Q}=1,23-1,43, \mathrm{Q}_{\mathrm{m}}=1,33 ; \mathrm{n}=20\right)$ de anchamente elipsoides a elipsoides, marrón oscuro, lisas, de pared gruesa, sin poro apical, unigutuladas, bigutuladas o con contenido granular. Se aprecia una fuerte heterosporía con esporas de diferentes formas y tamaños. Basidios de 19-25 × 7-10 $\mu \mathrm{m}$, usualmente tetraspóricos, claviformes o ligeramente truncados en el ápice, con contenido granular y con esterigmas de hasta $3 \mu \mathrm{m}$. Queilocistidios y pleurocistidios no encontrados. Superficie inferior del anillo no estudiada al no apreciarse restos del anillo en el material desecado por ser rudimentario y estar constituido por escasas y sutiles fibrillas. Pileipellis de tipo cutis constituida por hifas cilíndricas de 4-14 

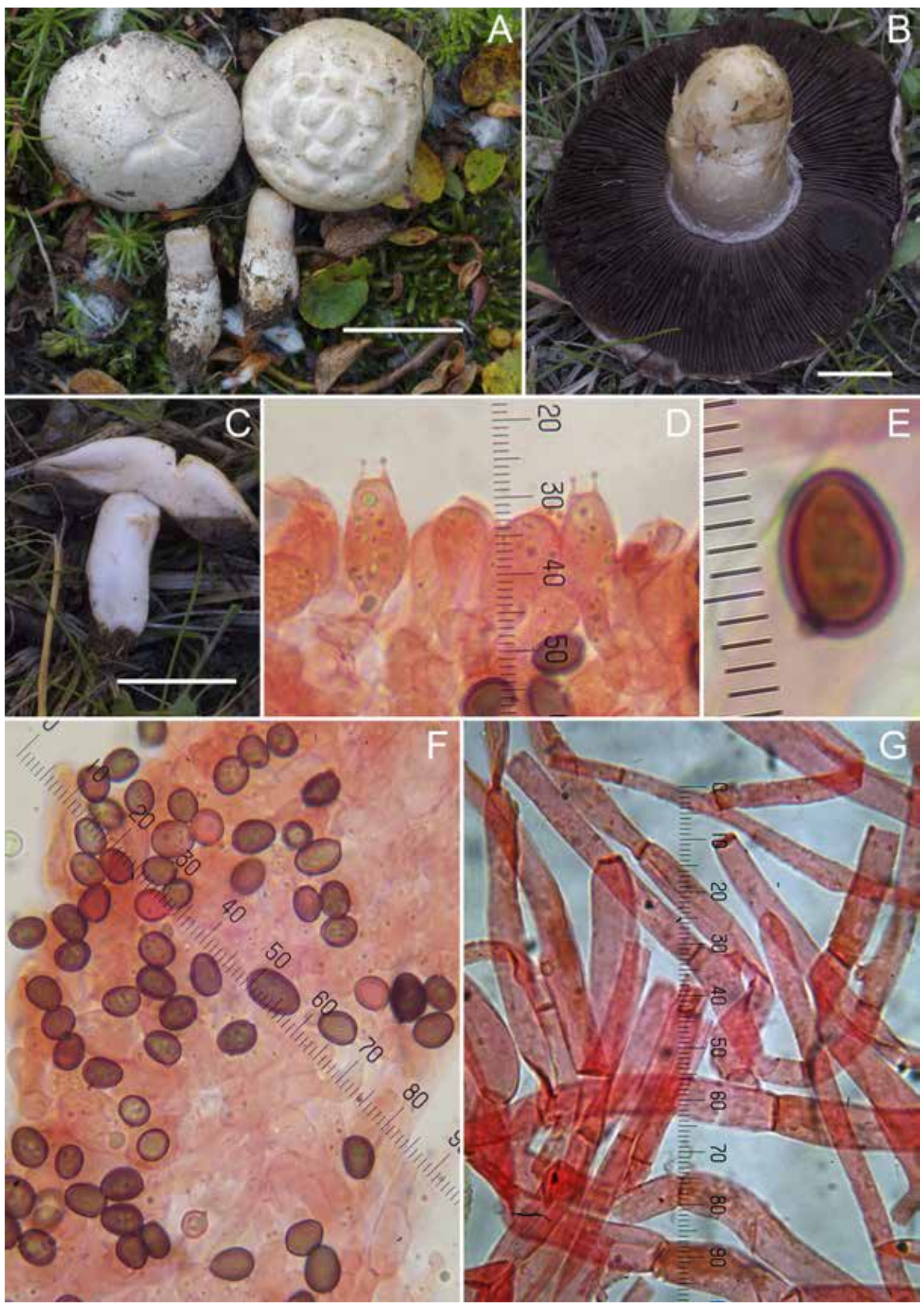

Fig. 19. Agaricus porphyrocephalus subsp. alpinus (LAPAG 1168). A-C: Caracteres macroscópicos. D-E: Caracteres microscópicos. D: Basidios. E: Basidiospora muy aumentada F: Basidiosporas. G: Pileipellis. Medio de montaje: rojo Congo. Barra de escala: 10 mm. Fotografías A: J. Hernanz; B-C: C. Rojo; D-G: L. A. Parra. 
$\mu \mathrm{m}$ de grosor, no o ligeramente estrechadas en los septos, hialinas sin pigmento intracelular o parietal. Elementos terminales no encontrados. Fíbulas ausentes en todas las estructuras estudiadas.

Caracteres moleculares: La secuencia ITS de la colección aquí descrita es homoalélica e idéntica a las italianas del holotipo AH47618 y los paratipos LAPAG 1026, LAPAG 1031 y LAPAG 1032, depositadas en GenBank con los números MK511988, MK511987, MK511990 y MK511990 respectivamente.

Comparado con otras subespecies de $A$. porphyrocephalus (F.H. Møller) F.H. Møller, Agaricus porphyrocephalus subsp. alpinus tiene tres marcadores específicos (Tabla 2): tggatAtgagg@147, acttgAccatg@189y ctctcCtatac@465. Además difiere de $A$. porphyrocephalus (F.H. Møller) F.H. Møller subsp. porphyrocephalus en otras tres posiciones (las posiciones contiguas se cuentan como un único cambio): catttTcatcc@71,ttggaCtgtgg@494ytttgtGTtgttc@614-615 y del holotipo de A.porphyrocephalus subsp. pallidus Kerrigan en dos posiciones adicionales (las posiciones contiguas se cuentan como un único cambio): tttgtTGTagagg@476-478 and tgctcTTtgtgt@609-610 (erróneamente citada como tgctcTTgtgtt en PARRA \& al. 2019).

Material estudiado: ESPAÑA. Huesca: Benasque, Puerto de la Glera, 42.700760 .60342 ( \pm 50 m), 2370 $\mathrm{m}$, gregario en un pequeño grupo de 3 ejemplares, en terreno pedregoso con Salix herbacea, 28-IX-2018, leg. Jorge Hernanz, det. L.A. Parra, LAPAG 1168 (ITS Genbank MN493148).

Tabla 2.

Los caracteres distintivos de la secuencia ITS entre las diferentes subespecies de $A$. porphyrocephalus están marcadas con un asterisco.

\begin{tabular}{|l|c|c|c|c|c|c|c|c|}
\hline SUBSP. / POSICIÓN & $\mathbf{7 1}$ & $\mathbf{1 4 7}$ & $\mathbf{1 8 9}$ & $\mathbf{4 6 5}$ & $\mathbf{4 7 6 - 4 7 8}$ & $\mathbf{4 9 4}$ & $\mathbf{6 0 9 - 6 1 0}$ & $\mathbf{6 1 4 - 6 1 5}$ \\
\hline porphyrocephalus & $-*$ & $\mathrm{G}$ & $\mathrm{G}$ & $\mathrm{T}$ & $\mathrm{TGT}$ & $\mathrm{T} *$ & $\mathrm{TT}$ & $--*$ \\
\hline pallidus & $\mathrm{T}$ & $\mathrm{G}$ & $\mathrm{G}$ & $\mathrm{T}$ & $---*$ & $\mathrm{C}$ & $--*$ & GT \\
\hline alpinus & $\mathrm{T}$ & $\mathrm{A}^{*}$ & $\mathrm{~A}^{*}$ & $\mathrm{C}^{*}$ & $\mathrm{TGT}$ & $\mathrm{C}$ & $\mathrm{TT}$ & GT \\
\hline
\end{tabular}

Comentarios: La colección aquí descrita constituye la primera cita para la Península Iberíca de este taxón, solamente citado con anterioridad en su descripción original en base a cinco colecciones de los Alpes italianos. Agaricus porphyrocephalus subsp. alpinus se caracteriza por su píleo completamente blanco o ligeramente crema en la madurez sin tonos marrones o púrpuras, anillo simple, muy estrecho, frágil y evanescente, contexto blanco inmutable $\mathrm{u}$ ocráceo al roce, esporas de media menores de 7,3× $5 \mu \mathrm{m}$ y ausencia de queilocistidios.

Aportamos aquí una clave para distinguir $A$. porphyrocephalus subsp. alpinus de otros taxones alpinos, de alta cota o muy cercanos filogenéticamente:

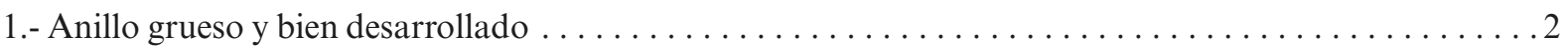

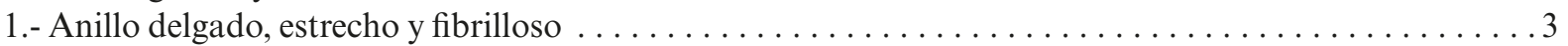

2.- Basidiosporas anchamente elipsoidales o elipsoidales $\left(\mathrm{Q}_{\mathrm{m}}=1,19-1,31\right)$, las mayores de $8 \times 6,12 \mu \mathrm{m}$ de

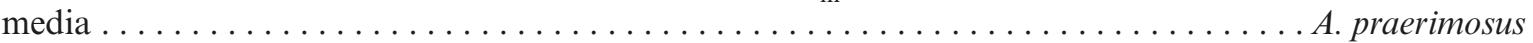

2.- Basidiosporas elipsoidales $\left(\mathrm{Q}_{\mathrm{m}}>1,36\right)$, de $8,73 \times 6,37 \mu \mathrm{m}$ de media. . . . . . . . . . . A. pampeanus

3.- Basidiosporas subglobosas $\left(\mathrm{Q}_{\mathrm{m}}<1,2\right)$ de $8,2 \times 6,9 \mu \mathrm{m}$ de media . . . . . . . . . . . A . aristocratus

3.- Basidiosporas elipsoides $\left(\mathrm{Q}_{\mathrm{m}}>1,3\right)$ más estrechas de $6 \mu \mathrm{m}$ de media $\ldots \ldots \ldots \ldots \ldots \ldots \ldots$

4.- Basidiosporas con $\mathrm{L}_{\mathrm{m}}>7,7 \mu \mathrm{m}$, a menudo provistas de un poro apical rudimentario. . . . . A. campestris

4.- Basidiosporas con $\mathrm{L}_{\mathrm{m}}<7,3 \mu \mathrm{m}$, sin un poro apical rudimentario $\ldots \ldots \ldots \ldots \ldots \ldots \ldots \ldots \ldots \ldots$

5.- Basidiosporas con $\mathrm{W}_{\mathrm{m}}>5 \mu \mathrm{m}$; carpóforos a menudo amarilleando al roce o con la edad. . A. moellerianus

5.- Basidiosporas con $\mathrm{W}_{\mathrm{m}}<5 \mu \mathrm{m}$, carpóforos que no amarillean al roce o con la edad

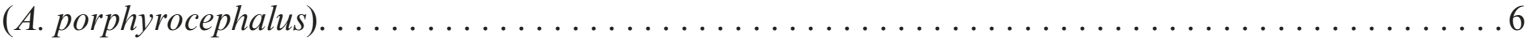

6.- Superficie pileica con tonos marrón o púrpura . . . . . . A. porphyrocephalus subsp. porphyrocephalus

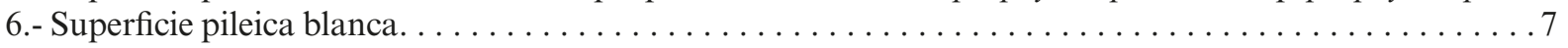

7.- Distribuido en zonas alpinas europeas; esporas con $\mathrm{L}_{\mathrm{m}}>6,4 \mu \mathrm{m}$ y $\mathrm{W}_{\mathrm{m}}>4,6 \mu \mathrm{m} \ldots \ldots \ldots$ $\ldots \ldots \ldots \ldots \ldots \ldots \ldots \ldots \ldots \ldots \ldots \ldots \ldots \ldots \ldots \ldots \ldots \ldots \ldots \ldots$ porphyrocephalus subsp. alpinus

7.- Distribuido en Norteamérica; esporas menores . . . . . . . . . . . porphyrocephalus subsp. pallidus 

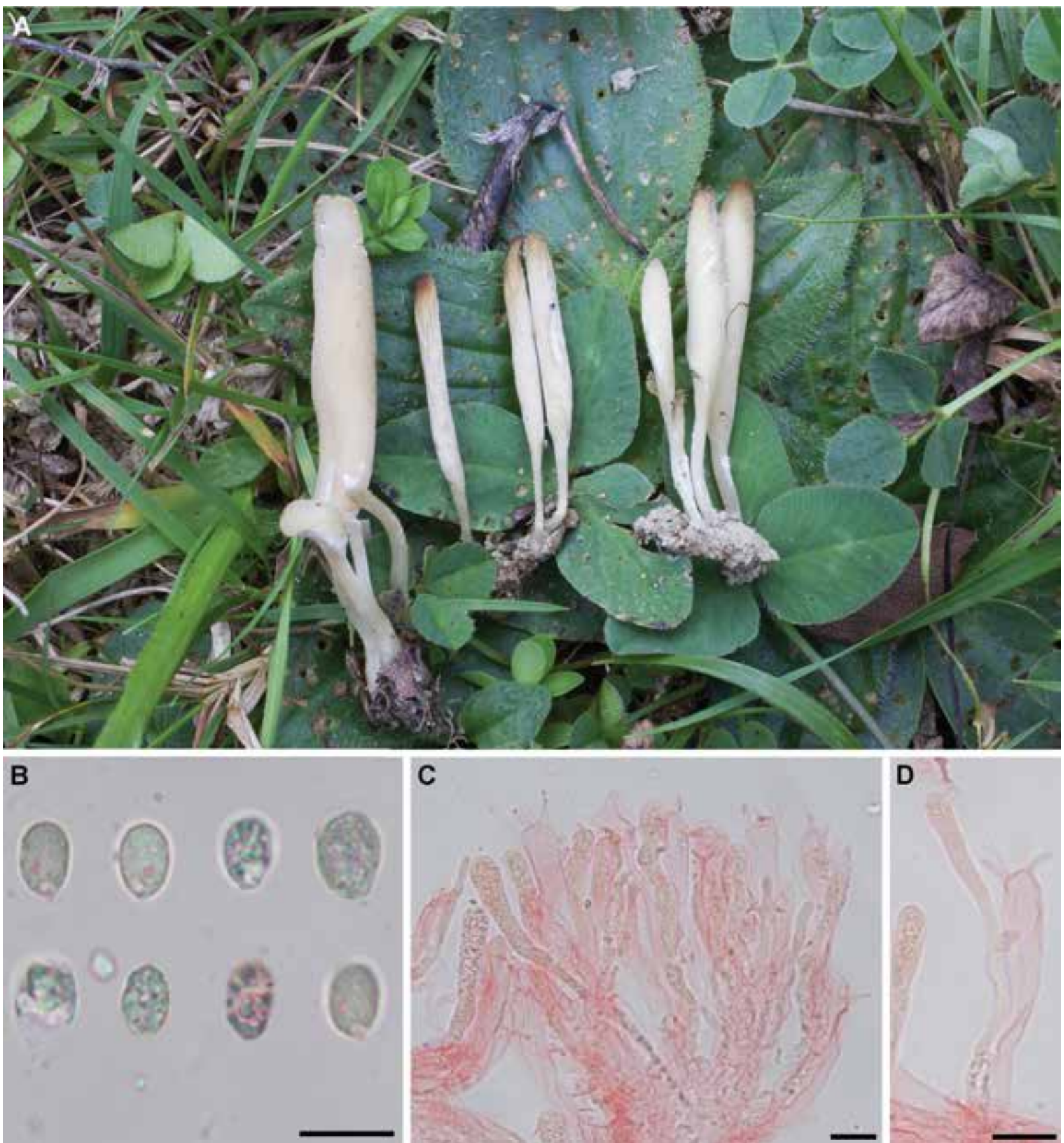

Fig. 20. Clavaria tenuipes (ARAN-Fungi 11295). A: Basidiomas mostrando tonos grises. B: Ascosporas en rojo Congo-SDS. C: Porción de himenio mostrando basidios tetraspóricos. D: Probasidio mostrando fíbula abierta en la base. Barra de escala: $10 \mathrm{~mm}$. Fotografías A: C. Rojo; B-D: I. Olariaga.

Clavaria tenuipes Berk. \& Broome, Ann. Mag. Nat. Hist., Ser. 2, 2(10): 266. 1848.

$\equiv$ Pistillaria tenuipes (Berk. \& Broome) Massee, Brit. Fung.-Fl. 1: 91. 1892.

Holotipo: Reino Unido, bosque de Sherwood, en el suelo, 15-XI-1837, K(M) 80202 (!).

Fig. 20

Basidiomas gregarios o ligeramente fasciculados (2-4 basidiomas), de $15-40 \mathrm{~mm}$ de longitud, simples, con estípite bastante bien delimitado. Clávula de 10-
$24 \times 2-4 \mathrm{~mm}$, inicialmente cilíndrica, posteriormente claviforme, habitualmente comprimida, en ocasiones con un surco longitudinal, inicialmente de color blanco grisáceo, posteriormente gris a gris ocráceo, de color pardo ferruginoso en exsiccatum. Ápice obtuso, inicialmente concolor, posteriormente de color ocre o pardo ocráceo. Estípite de 5-16 × 0,4-1,5 mm, cilíndrico, de color gris pálido, de aspecto translúcido. Micelio basal de color blanco. Sabor dulce y olor insignificante. 


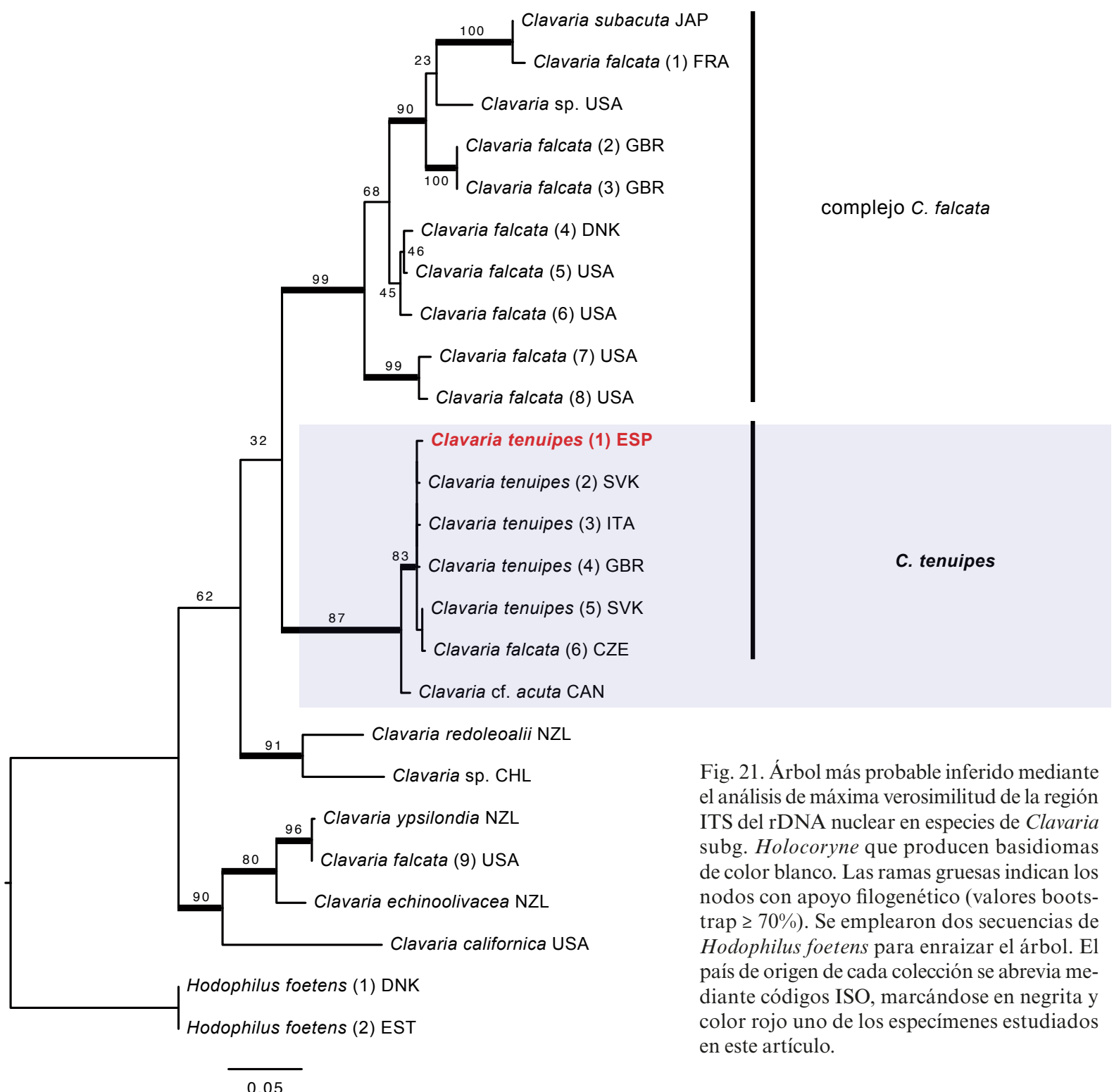

Basidiosporas ovoides en vista lateral, con apículo cúbico a cilíndrico ( $1 \mu \mathrm{m}$ de longitud $)$, de pared delgada, lisas, de contenido refringente, no amiloides, de 7-9 × 4,5-6 $\mu \mathrm{m}\left(\mathrm{L}_{\mathrm{m}}=7,9, \mathrm{~W}_{\mathrm{m}}=5,5, \mathrm{Q}_{\mathrm{m}}=1,4\right.$; $\mathrm{n}=20$ ). Basidios claviformes, de pared delgada, con (2-)4 esterigmas, con fíbula basal abierta, de 57-80 $\times$ 6-8 $\mu \mathrm{m}$. Hifas del contexto paralelas, de cilíndricas a fusiformes, de pared delgada, sin incrustaciones, sin fíbulas, de hasta $20 \mu \mathrm{m}$ de anchura. Cristales ausentes. Micelio basal compuesto de hifas entremezcladas, cilíndricas, de pared delgada o ligeramente engrosada, hialinas, sin fíbulas, $1-2 \mu \mathrm{m}$ de anchura.

Material estudiado: ESPAÑA. Huesca: Seira, Barbaruéns, barranco de Trigars, 42.5244609 0.3803049 ( $\pm 150 \mathrm{~m}), 1400 \mathrm{~m}, 28-\mathrm{IX}-2018$, leg. C. Rojo \& P.P. Daniëls, det. I. Olariaga, ARAN-Fungi 11295 (ITS Genbank MW248489; LSU MW248513).
Comentarios: Clavaria tenuipes pertenece al complejo Clavaria falcata Pers., nom. sanct. (a veces referido como Clavaria acuta Sowerby, nom. sanct.), que incluye especies cuyos basidiomas son de color blanco o pálido y presentan basidios fibulados (OLARIAGA \& al. 2015). Tal y como confirma nuestro análisis filogenético (Fig. 21), las secuencias de la región ITS dentro del complejo $C$. falcata muestran una divergencia considerable que parece deberse a la existencia de varias especies aún no bien delimitadas. Sin embargo, todos los especímenes identificados como C. tenuipes, junto con nuestra recolección, caen en un mismo clado cuyas secuencias muestran homogeneidad, en el que hay varias secuencias identificadas como C. tenuipes. Este clado, el de C. tenuipes, difiere del resto de clados del complejo en que sus basidiomas son de color gris pálido y son marcadamente comprimidos, mostrando en ocasiones 
surcos longitudinales en la parte fértil del basidioma, tal y como han descrito varios autores (CORNER 1950; KAUTMANOVÁ 2012).

El holotipo de C. tenuipes, (estudiado por I. Olariaga), a pesar de encontrarse en muy mal estado, coincide con el material descrito aquí. El holotipo presenta basidiomas cuya parte fértil es claviforme $\mathrm{y}$ de color pardo ferruginoso al igual que en nuestro material, y microscópicamente, posee fíbulas en la base de los basidios, y esporas de aproximadamente $7 \times 5 \mu \mathrm{m}$. La presencia de fíbulas en el holotipo demuestran que la interpretación de $C$. tenuipes realizada por SCHILD (1981), es incorrecta.

Según nuestra búsqueda bibliográfica, basada en OLARIAGA (2009), no existen registros previos de $C$. tenuipes en la Península Ibérica, por lo que nuestra cita representa la primera bien documenta$\mathrm{da}$, aunque es plausible que existan especímenes de herbario de $C$. tenuipes depositados como $C$. falcata o C. acuta.

Clavulina incarnata (Corner) Olariaga, Mycotaxon 121: 38. 2012.

= Clavulina cristata var. incarnata Corner, Ann. Bot. Mem. 1: 692. 1950.

Sintipo: Reino Unido, Inglaterra, Cambridge, Chippenham Fen, 30-VIII-1946, Corner 454 (PC, !).

Fig. 22

Basidiomas de hasta $45 \times 30 \mathrm{~mm}$, muy ramificado, con estípite no bien definido. Ramificación basitónica, politómica, con bifurcaciones en forma de $\mathrm{U}$ o V, divergentes, con rango de ramificación de hasta 4. Ramas cilíndricas, en ocasiones comprimidas o con surcos longitudinales, sólidas, de color rosa grisáceo, posteriormente gris cinéreo con tonos rosados, de color gris violáceo en exsiccatum. Ápices simples, inicialmente agudos, posteriormente obtusos y espatulados. Estípite no bien desarrollado, cilíndrico, de hasta $17 \times 10 \mathrm{~mm}$, cubierto por tomento blanco en la base. Contexto blanco; olor de nulo a dulce y aromático, recordando a las especies de Hebeloma sect. Sacchariolentia.

Basidiosporas ovoides, con apículo pequeño, de pared delgada, lisas, hialinas, con una gútula grande y algunas más pequeñas, no amiloides, de 7,5-9 $\times(5-)$ 6-7 $\mu \mathrm{m}\left(\mathrm{L}_{\mathrm{m}}=8,2, \mathrm{~W}_{\mathrm{m}}=6,2, \mathrm{Q}_{\mathrm{m}}=1,3 ; \mathrm{n}=25\right)$. Basidios claviformes, bispóricos, fibulados, de 35-54 × 5,5-7 $\mu \mathrm{m}$, de pared delgada, en ocasiones con un septo secundario. Cistidios abundantes, sobresaliendo hasta $40 \mu \mathrm{m}$ sobre la superficie del himenio, cilíndricos, con ápice obtuso, en ocasiones con 1-3 septos que presentan fíbulas, en ocasiones con cristales de color pardo rojizo oscuro en su superficie, de 75-100 × 6-7 $\mu \mathrm{m}$. Hifas del contexto paralelas entre sí, de cilíndricas a fusiformes, de pared delgada, hialinas, fibuladas, de 3-15 $\mu \mathrm{m}$ de diámetro. Cristales ausentes. Tomento basal blanco, formado por hifas entrelazadas, cilíndricas, de pared delgada, fibuladas, de 3-6 $\mu \mathrm{m}$ anchura.

Material estudiado: ESPAÑA. Huesca: Benasque, Selva de Cerler, $42.58533420 .5324821( \pm 100$ m), $1400 \mathrm{~m}$, en bosque mixto, bajo Betula pendula, 30-IX-2018, leg. U. Fernandes, J.I. López Amiano, J. Martín \& J. Teres, det. I. Olariaga, ARAN-Fungi 10280 (LSU Genbank MW248514). SUECIA. Uppland: Sollentuna parish, Hansta naturreservat, 59.427872 17.896641, ( $\pm 50 \mathrm{~m})$, bajo Quercus robur, Corylus avellana, Populus tremula y Fraxinus excelsior en suelo rico, 8-IX-2010, leg. K. Hansen, K. Gillen \& I. Olariaga, S-F197088.

Comentarios: Clavulina incarnata es la única especie de Clavulina que posee cistidios en Europa (CORNER 1950; OLARIAGA \& SALCEDO 2012; PILÁT 1958). Macroscópicamente se reconoce por su ramificación basitónica, los ápices de las ramas simples y a menudo espatulados, su color rosa grisáceo en la juventud, y su superficie pruinosa bajo la lupa debido a los cistidios que sobresalen del himenio. Cuando está presente, su olor es también un carácter determinante. Aunque CORNER (1950) no hiciera mención de ningún olor señalado en $C$. incar$n a t a$, sí que la recolección ibérica, así como en varias recolecciones suecas estudiadas por I. Olariaga, un claro olor de caramelo que recuerda a las especies de Hebeloma sect. Sacchariolentia. Sin embargo, este olor no parece estar siempre presente. Los cistidios himeniales son fáciles de observar y abundantes en material fresco, pero difíciles de observar en material desecado. Los cistidios se diferencian de los probasidios por su tamaño habitualmente más largo, presentar en ocasiones septos con fíbulas y cristales de color pardo sobre su superficie. Nuestros análisis de la región LSU (Fig. 23) muestran que las dos muestras estudiadas por nosotros pertenecen a un linaje independiente, y aunque la región LSU no resuelve las relaciones basales entre los taxones de nuestro análisis, sugieren que $C$. incarnata no está cercanamente emparentada al resto de especies de Clavulina europeas.

Clavulina incarnata es una especie poco conocida, pero que probablemente sea muy común en Europa. Se conoce al menos de Noruega, Francia y Suecia, hallándose en bosques maduros, y en ocasiones, como se menciona en el protólogo, en lugares muy húmedos (OLARIAGA \& al., en preparación). Sin embargo, nuestra cita representa la primera cita de la Península Ibérica (OLARIAGA 2009). 

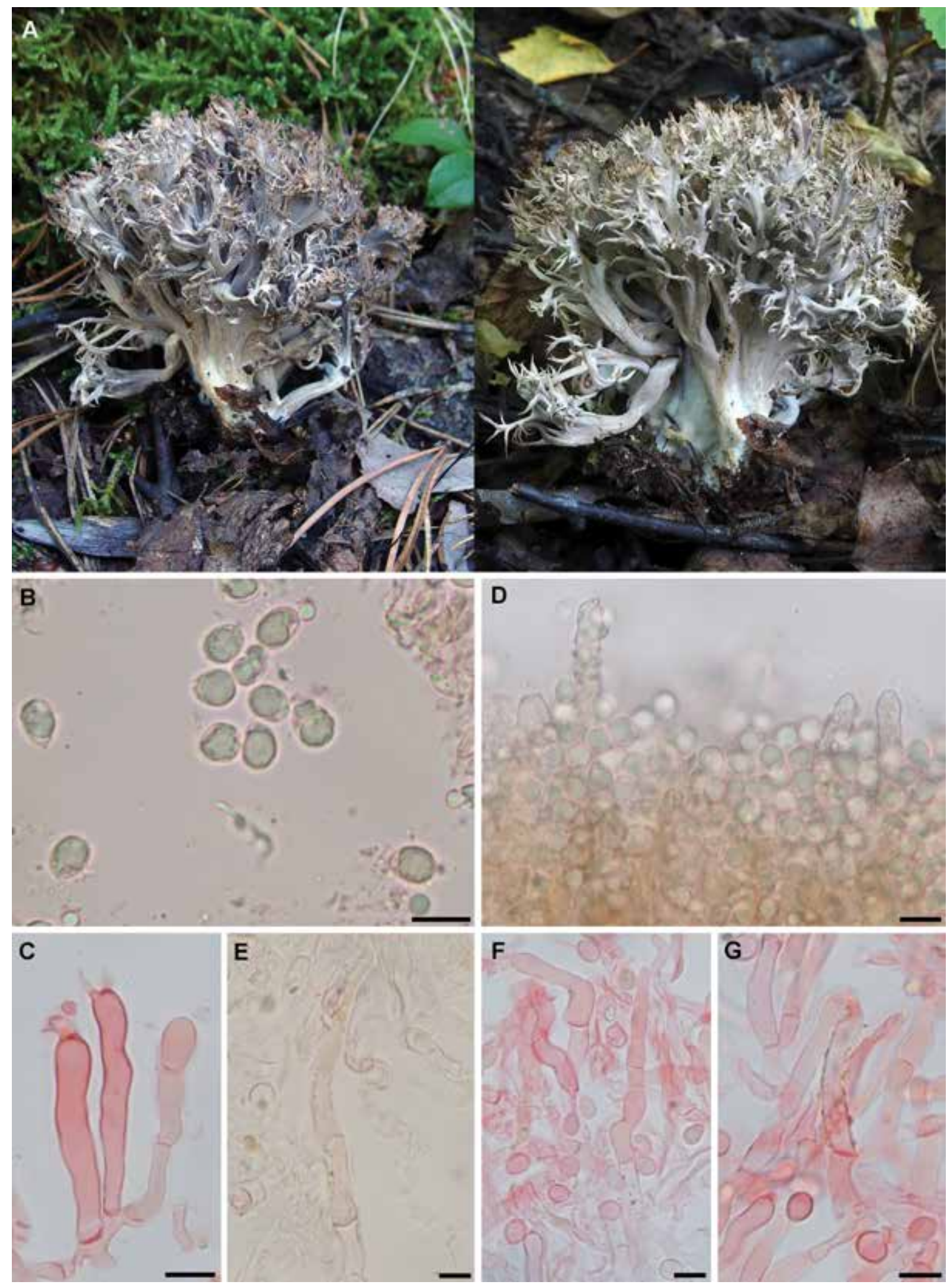

Fig. 22. Clavulina incarnata (ARAN-Fungi 10280). A: Único basidioma recolectado desde diferentes perspectivas. B: Basidiosporas en rojo Congo-SDS. C: Basidios bispóricos. D: Cistidios sobresaliendo del himenio y con cristales incrustados, en agua. E: Cistidio en KOH. F: Cistidios en rojo Congo-SDS. G: Detalle de un cistidio mostrando incrustaciones en la superficie, en rojo Congo-SDS. Barras de escala $10 \mu \mathrm{m}$. Fotografías A: J.I. López Amiano (izquierda), J. Martín (derecha); B-G: I. Olariaga. 


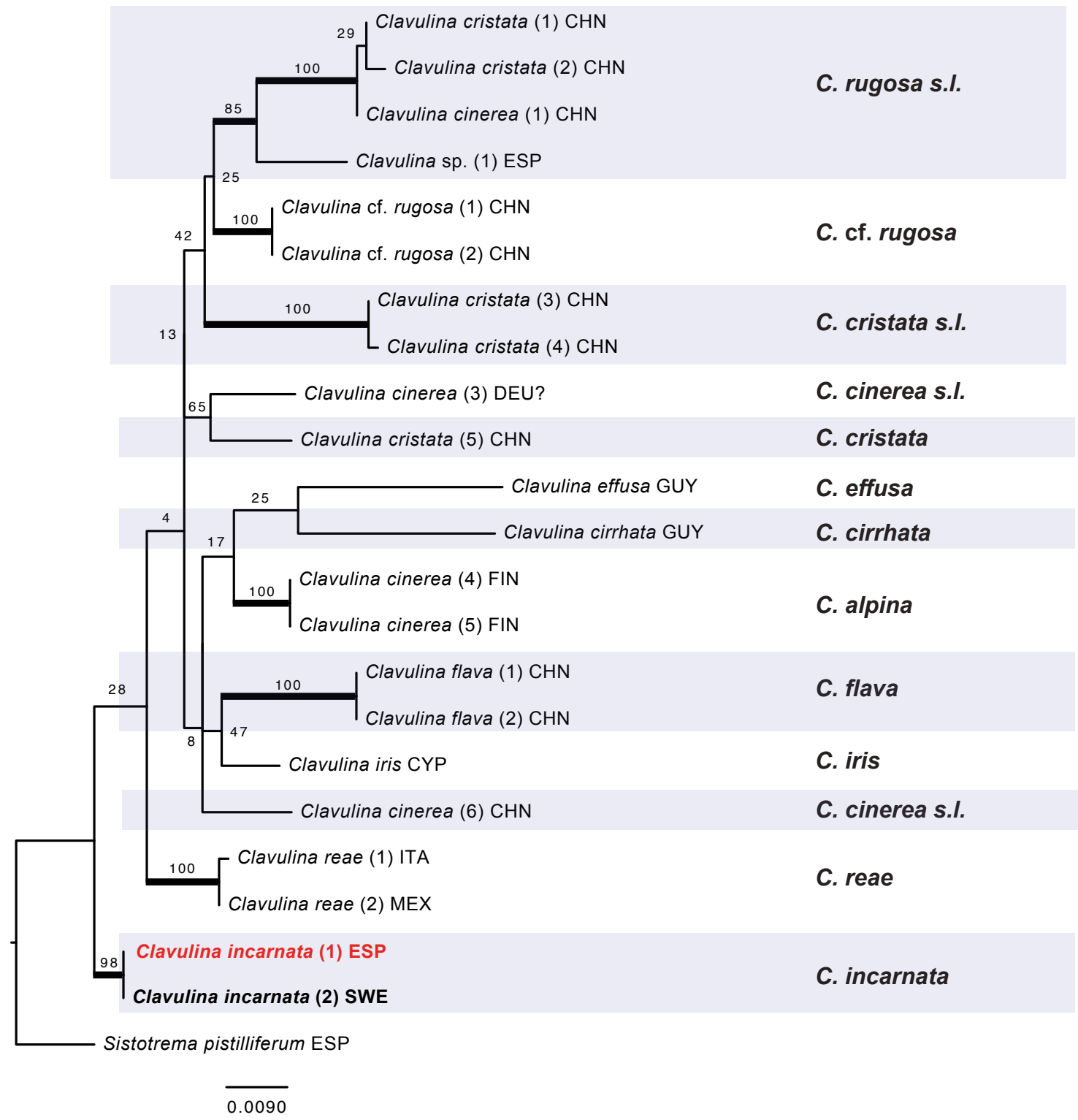

Fig. 23. Árbol más probable inferido mediante el análisis de máxima verosimilitud de la región 28S del rDNA nuclear en especies de Clavulina. Las ramas gruesas indican los nodos con apoyo filogenético (valores bootstrap $\geq 70 \%$ ). Se empleó una secuencia de Sistotrema pistilliferum para enraizar el árbol. El país de origen de cada colección se abrevia mediante códigos ISO, marcándose en negrita los especímenes que se describen en el artículo y además en rojo el espécimen ibérico de $C$. incarnata.

Entoloma byssisedum (Pers.) Donk, Bull. Jard. Bot. Buitenzorg, sér. 3 18: 158. 1949.

$\equiv$ Agaricus byssisedus Pers., Icon. Desc. Fung. Min. Cognit. 2: 56. 1800. [sub "Agaricus byssoideus"], nom. sanct.

=Crepidotus byssisedus (Pers.) P. Kumm., Führ. Pilzk.: 74. 1871.

=Claudopus byssisedus (Pers.) Gillet, Hyménomycètes: 426.1876.

= Rhodophyllus byssisedus (Pers.) Quél., Enchir. fung.: 65.1886.

$=$ ? Entoloma byssisedum var. microsporum Esteve-Rav. \& Noordel. in Noordeloos, Fungi Europaei 5: 1137. 2004.

Fig. 24
Píleo de hasta $25 \mathrm{~mm}$ de diámetro, reniforme, de aplanado a convexo. Superficie pileica ligeramente aterciopelada, ligeramente fibrillosa, de color blanco grisáceo. Margen de ligeramente involuto a incurvado. Láminas adnatas, con numerosas lamélulas, ligeramente ventrudas, irregulares en basidiomas grandes, inicialmente de color grisáceo, posteriormente de color pardo rosáceo. Arista laminar entera y más o menos concolora. Estípite de hasta $5 \times 1,5$ $\mathrm{mm}$, muy reducido, lateral, cilíndrico, de color gris blanquecino, con pequeñas fibrillas grisáceas, peludo y blanquecino en la base. Rizomorfos presentes en la base, blancos. Contexto frágil y delgado. Sin olor y sabor definidos. 

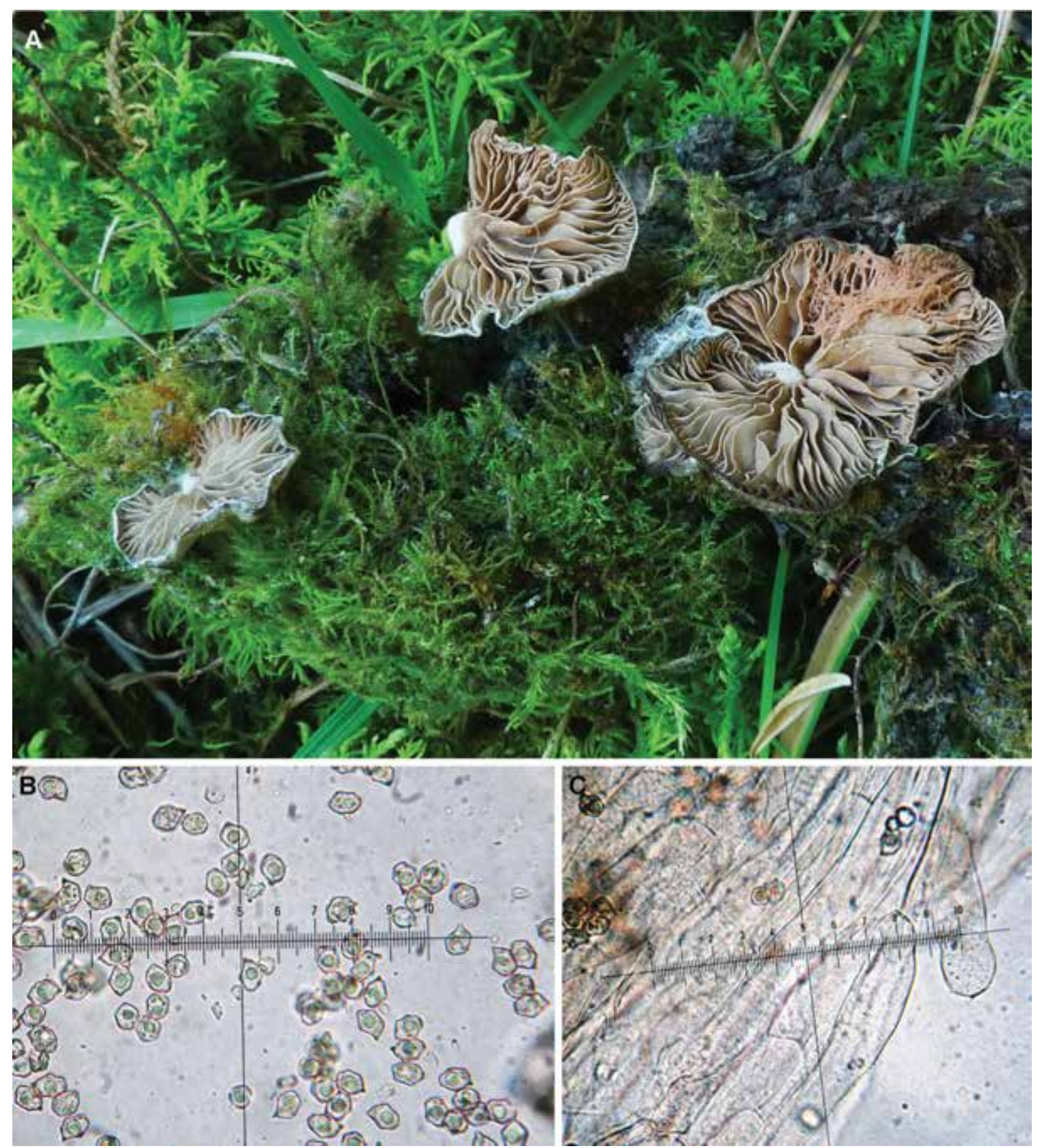

Fig. 24. Entoloma byssisedum (ARAN-Fungi 10321). A: Basidiomas. B: Esporas. C: Hifas de la pileipellis. Medio de montaje: agua. Fotografías A: U. Fernandes; B-C: J. Teres.

Basidiosporas heterométricas, irregularmente nodulosas-angulosas, con 5-6 ángulos vistas de perfil, de color rosa pálido, de $(7,6-) 8,1-10(-10,3) \times(5,8-) 6-$ $7(-7,3) \mu \mathrm{m}\left(\mathrm{L}_{\mathrm{m}}=9,2, \mathrm{~W}_{\mathrm{m}}=6,6\right.$; $\mathrm{Q}=(1,1-) 1,2-1,6(-1,7)$; $\left.\mathrm{Q}_{\mathrm{m}}=1,4\right)$. Basidios claviformes, tetraspóricos. Cistidios ausentes. Pileipellis de tipo cutis, compuesto de hifas cilíndricas a estrechamente fusiformes, irregulares, de pared delgada, con pigmento parietal pardo grisáceo pálido, de hasta $20 \mu \mathrm{m}$ de anchura. Fíbulas presentes en todo el basidioma.
Material estudiado: ESPAÑA. Huesca: Benasque, Cerler, Selva de Conques, 42.5864170 .535648 ( \pm 50 m), 1610 m, en bosque mixto, con Betula pendula, Corylus avellana, Populus tremula, Fagus sylvatica, Pinus sylvestris, Fraxinus excelsior, Abies alba, Buxus sempervirens y otras especies de arbustos, sobres diferentes restos orgánicos y musgo, 30-IX-2018, leg. et det. U. Fernandes, J.I. López Amiano, J. Martín \& J. Teres, ARAN-Fungi 10321 (ITS Genbank MW248490; LSU MW248515). 


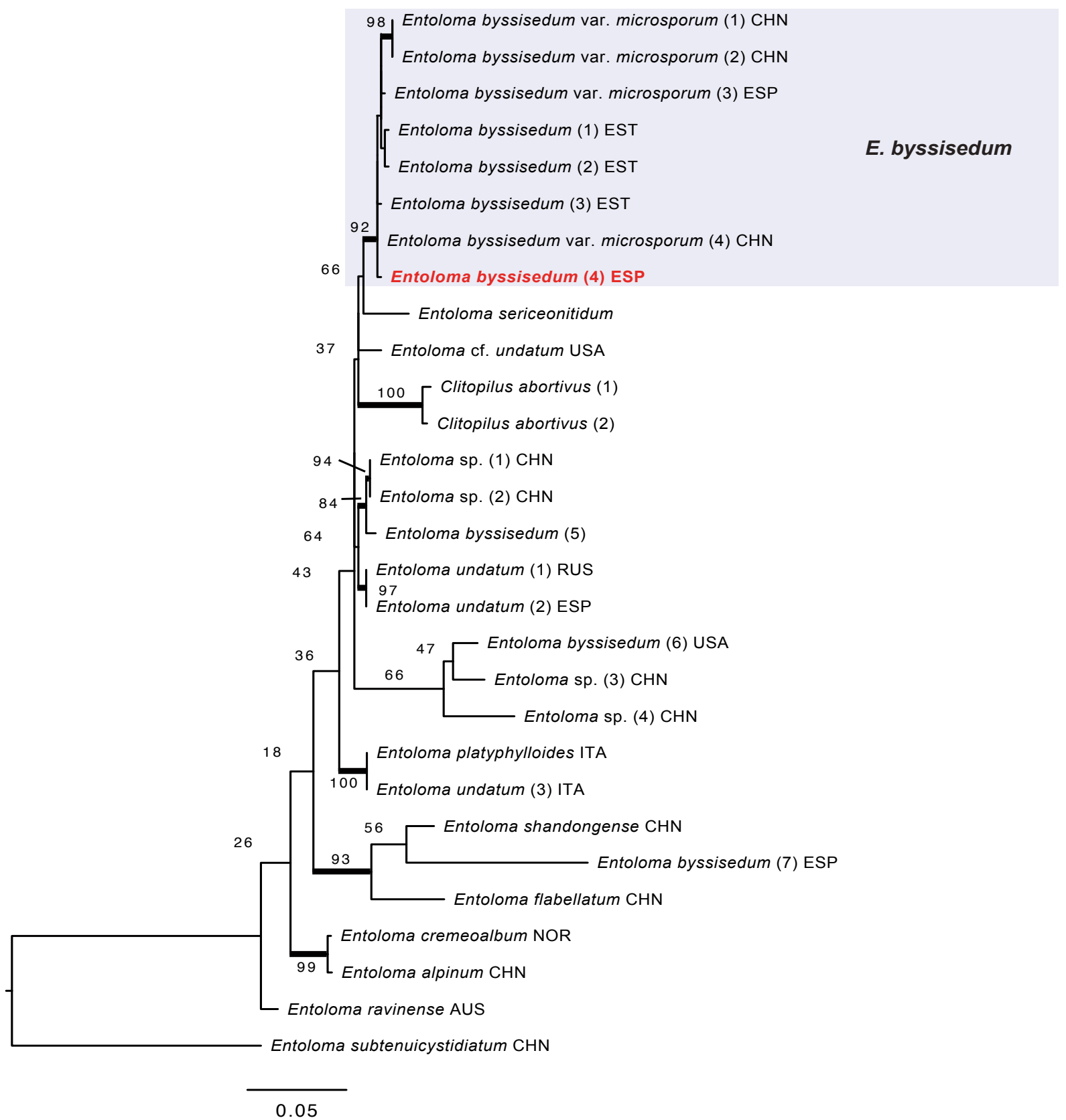

Fig. 25. Árbol más probable inferido mediante el análisis de máxima verosimilitud (ML) de la región región ITS del rDNA nuclear en especies de Entoloma subg. Claudopus. Se muestran los valores bootstrap-ML / probabilidad posterior del análisis bayesiano alrededor de las ramas. Las ramas gruesas indican los nodos con apoyo filogenético en el análisis de ML (valores bootstrap $\geq 70 \%$ ). Los recuadros de colores marcan los principales clados de Entoloma y la muestra descrita en el artículo se destaca en negrita y color rojo. Se empleó una secuencia de Entoloma subtenuicystidiatum para enraizar el árbol. El país de origen de cada colección se abrevia mediante códigos ISO, marcándose en negrita y color rojo el espécimen estudiado en este artículo.

Comentario: Entoloma byssisedum pertenece a Entoloma subg. Claudopus y se caracteriza por sus basidiomas omphalinoides o pleurotoides, a menudo con estípite muy reducido, píleo de color gris pálido y presencia de estípite corto. Siguiendo a NOORDELOOS (2004), nuestra recolección corresponde a $E$. byssisedum var. microsporum Esteve-Rav. \& Noordel. por sus esporas que apenas sobrepasan las $10 \mu \mathrm{m}$ de longitud, lo cual separaría esta variedad de E. byssisedum, cuyas esporas son mayores $(9,5-12 \times 6,5-8 \mu \mathrm{m}$, NOORDELOOS 1992). El material ibérico publicado de E. byssisedum posee esporas que apenas superan las $10 \mu \mathrm{m}$ de longitud (LLORENS VAN-WAVEREN \& LLISTOSELLA 2004; RUBIO DOMÍNGUEZ 2018a), al igual que en nuestro material. 
Sin embargo, nuestro análisis de la región ITS (Fig. 25) muestra que prácticamente todas las secuencias publicadas de E. byssisedum caen en el mismo clado que las muestras identificadas como E. byssisedum var. microsporum. Este clado parece corresponder al taxón que es comúnmente denominado E. byssisedum en Europa y el que con más probabilidad representa su sentido original. Dado a que nuestra colección cae también dentro de este clado, la atribuimos a $E$. byssisedum. Únicamente dos secuencias identificadas como $E$. byssisedum caen fuera de este este clado, siendo posible que representen identificaciones erróneas.

Según nuestro análisis, estudios futuros deberían de integrar secuencias obtenidas a partir de material de esporas grandes como el señalado para $E$. byssisedum s. str. por NOORDELOOS (1992) para: a) esclarecer si existen dos especies diferentes que están siendo atribuidas a $E$. byssisedum y que difieren en el tamaño esporal, o b) evaluar si el tamaño esporal en E. byssisedum es variable.

Según nuestra búsqueda, existen citas dispersas de $E$. byssisedum en el norte peninsular, aunque parece más común en el cuadrante nororiental. Recogemos aquí citas de Álava (FERNÁNDEZ-VICENTE \& al. 2007), Asturias (RUBIO \& al. 2006), Barcelona (e.g. LLORENS VAN-WAVEREN \& LLISTOSELLA 2004), Lérida (e.g. MAIRE 1933, como Claudopus byssisedus), Tarragona (NOORDELOOS
2004: 1137; VILA \& al. 2014) y Valencia (https:// registros.gbif.es/occurrences/45893c01-f0a5-459a9803-2c708a473f29). La secuencia obtenida a partir del material de Girona (VILA \& al. 2014; Fig. 25, como "Entoloma byssisedum (7)") cae fuera del clado con especímenes típicos de $E$. byssisedum por lo que esta cita debería de ser revisada.

Comentario nomenclatural: PERSOON (1800: 56) utilizó el nombre Agaricus byssoideus, pero un año más tarde (PERSOON 1801: 482) claramente indica que se trató de un error tipográfico y que el nombre correcto era Agaricus byssisedus. Por ello, FRIES (1821: 276) sancionó el nombre Agaricus byssisedus.

\section{Entoloma stenocystis Olariaga ad interim}

Figs. 26-27

Píleo de 5-10 mm de diámetro, convexo y deprimido en el centro. Superficie mate, con pequeñas escamas adpresas, a veces lacerada, de color pardo muy oscuro o pardo negruzco, no higrófana. Margen regular, involuto, no estriado por transparencia. Láminas adnatas, de arqueadas a rectas, de hasta 1,5 $\mathrm{mm}$ de espesor, de color rosa, $\mathrm{L}=20-22$. Arista laminar entera, lisa, de color pardo claro. Estípite de 2-3 $\times 2 \mathrm{~mm}$, corto, cilíndrico o comprimido, concoloro con el píleo, liso, mate. Tomento basal no presente. Contexto delgado, sin olor ni sabor definidos.

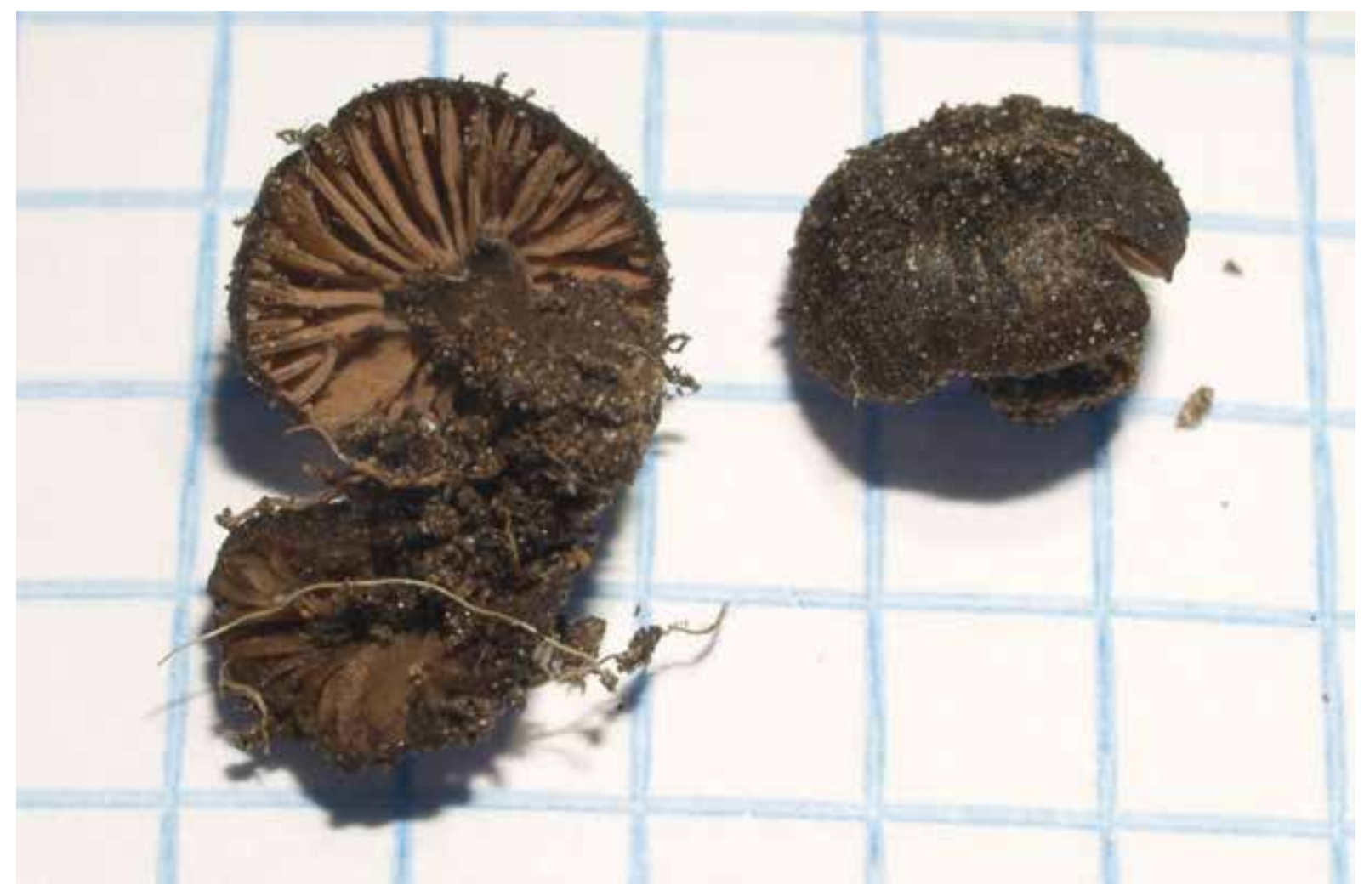

Fig. 26. Entoloma "stenocystis" ad interim (ARAN-Fungi 14202). Basidiomas ex situ. Barra de escala aproximadamente $5 \mathrm{~mm}$. Fotografía I. Olariaga. 

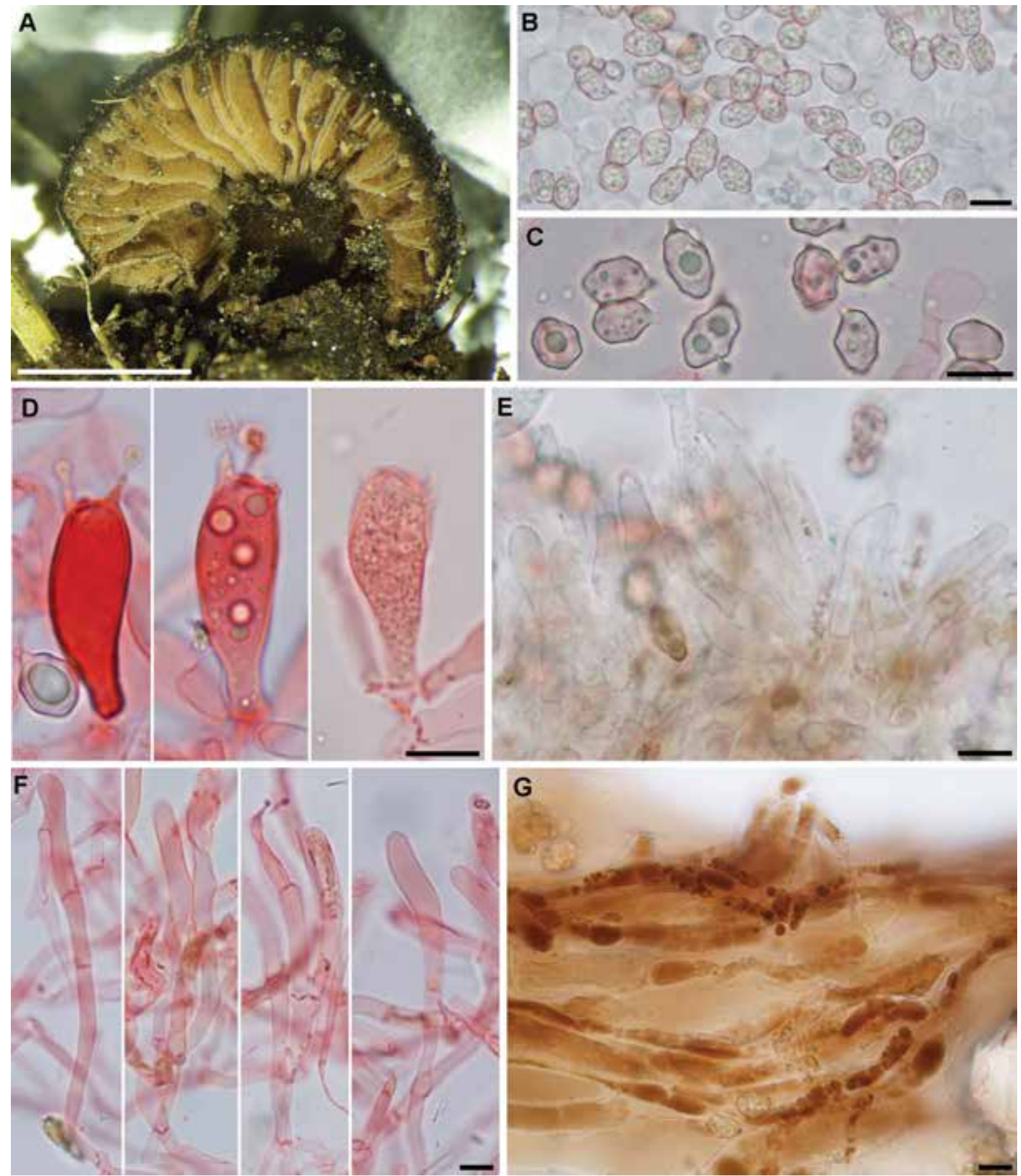

Fig. 27. Entoloma "stenocystis" ad interim (ARAN-Fungi 14202). A: Basidioma mostrando láminas cuya arista es parda, especialmente en el margen. B: Basidiosporas en agua. C: Basidiosporas en rojo Congo-SDS, a mayor aumento. D: Basidios en rojo Congo-SDS. Los dos basidios de la derecha son de pared gruesa. E: Arista laminar mostrando grupo de queilocistidios con contenido vacuolar pardo claro. F: Queilocistidios en rojo Congo-SDS. F: Pileipellis mostrando pigmento vacuolar, en agua. Barras de escala A: $5 \mathrm{~mm}, \mathrm{~B}-\mathrm{G}: 10 \mu \mathrm{m}$. 
Basidiosporas heterométricas, irregularmente nodulosas-angulosas, aproximadamente con 9-14 ángulos vistas de perfil, de color rosa pálido, 9-11($12) \times(5,7-) 6-7,5 \mu \mathrm{m}\left(\mathrm{L}_{\mathrm{m}}=10,4, \mathrm{~W}_{\mathrm{m}}=6,7, \mathrm{Q}=1,4-1,8\right.$, $\left.\mathrm{Q}_{\mathrm{m}}=1,55\right)$. Basidios claviformes, tetraspóricos, en ocasiones de pared gruesa, de 21-35 × 10-11 $\mu \mathrm{m}$. Pleurocistidios ausentes. Arista laminar homómera. Queilocistidios de cilíndricos a estrechamente fusiformes, raramente sublageniformes, a veces con un septo secundario, hialinos o con contenido homogéneo pardo, en exsiccatum con glomérulos de pigmento condensados, de 25-63 × 4,5-7 $\mu \mathrm{m}$. Caulocutis formado por hifas cilíndricas, de pared delgada, hialinas, en ocasiones con pigmento intracelular pardo, de 3-5 $\mu \mathrm{m}$ de diámetro. Caulocistios no presentes. Pileipellis de tipo cutis, con pequeñas escamas formadas con mechones de hifas erectas, con compuesto de hifas cilíndricas a estrechamente fusiformes, de pared delgada, con pigmento vacuolar de pardo a pardo oscuro, de hasta $20 \mu \mathrm{m}$ de anchura. Fíbulas presentes en todo el basidioma.

Material estudiado: ESPAÑA. Huesca: Benasque, Puerto de la Glera, 42.700760 .60342 ( $\pm 50 \mathrm{~m}$ ), 2370 m, 28-IX-2018, en vegetación alpina con Salix herbacea, leg. J. Hernanz, ARAN-Fungi 14202 (ITS-LSU Genbank MW248491).

Comentarios: Esta interesante especie de Entoloma se caracteriza por su porte omphalinoide, láminas adnatas, arista laminar oscura, esporas heterodiamétricas, presencia de queilocistidios de 4,5-7 $\mu \mathrm{m}$ de anchura y pigmento vacuolar en las hifas de la pileipellis, además de su hábitat alpino. Siguiendo la clave artificial de NOORDELOOS (2004), identificamos tentativamente nuestra recolección como E. indutoides, en E. sect. Griseorubida, debido a su porte similar, la presencia de queilocistidios estrechos y fíbulas, y la arista laminar coloreada. Sin embargo, E. indutoides posee un píleo de color más pálido, no parece estar presente en hábitats alpinos, posee esporas más largas y queilocistidios lageniformes (ORTON 1960). Además, la región ITS de nuestra colección y la obtenida del tipo de $E$. indutoides (LN850608), difieren considerablemente de tal manera que no pueden alinearse sin ambigüedades. Entoloma griseorubidum Kühner ex Noordeloos, taxón subordinado a variedad de $E$. indutoides en NOORDELOOS (2004), posee un píleo de color similar a nuestra recolección y posee además hábitat alpino. Sin embargo, el porte de E. griseorubidum es más esbelto, con el estípite más largo, su arista laminar concolor, sus queilocistidios son de hasta $23 \mu \mathrm{m}$ de anchura, siendo las esporas más redondeadas y con menos ángulos (NOORDELOOS 1984).

$\mathrm{El}$ análisis filogenético basado en los marcadores LSU-mtSSU-RPB2 muestran que las secuencias de nuestra muestra entran dentro del clado "Inocephalus-Cyanula" (Fig. 28), que recibe apoyo en el análisis Bayesiano (BPP 0.96), el cual contiene especies asignadas a E. subg. Trichopilus, E. subg. Alboleptonia y E. subg. Leptonia por NOORDELOOS (2004). En base a este resultado, la ausencia de queilocistidios capitados (E. subg. Trichopilus) y el píleo pigmentado (excluyendo Entoloma subg. Alboleptonia), nuestra recolección encaja en Entoloma subg. Leptonia tal y como es concebido por NOORDELOOS (1992, 2004). Así mismo, de acuerdo con su clave infragenérica (NOORDELOOS 1992), E. stenocystis sería un miembro de E. sect. Griseorubida, dentro de E. subg. Leptonia, debido a sus láminas no decurrentes, hifas de la pileipellis mayores a $10 \mu \mathrm{m}$ de anchura y con pigmento intracelular, píleo convexo o plano con el centro deprimido, píleo oscuro, presencia de fíbulas, queilocistidios presentes y esporas con $\mathrm{L}_{\mathrm{m}}>10$ $\mu \mathrm{m}$. Como ha sido mencionado anteriormente, en esta sección no existe ningún taxón que coincida con nuestra recolección.

Las secuencias obtenidas de nuestro material forman un clado con apoyo filogenético con una secuencia sin identificar (MK278052) (Fig. 28). A su vez, una secuencia LSU identificada como Entoloma aff. insolitum Noordel., es hermana a este clado pero sin apoyo filogenético, aunque el mismo clado recibe apoyo cuando la secuencia MK278052 es eliminada para el análisis. El material citado como $E$. aff. insolitum se describe e ilustra en SCHMIDT \& al. (2013). Aunque tal colección presenta un porte similar a nuestro material, presenta queilocistidios hialinos de hasta $20 \mu \mathrm{m}$ de anchura, esporas con menos ángulos y sobre todo, posee pleurocistidios. Mediante una búsqueda BLAST de la secuencia ITS de nuestro material, una secuencia ambiental sin identificar (LS954009) obtenida a partir de material alpino obtiene una similitud de 99,59\%. La muestra identificada con mayor similitud corresponde a una identificada como E. velenoskyi Noordel. (LN850612), taxón alpino cuyo píleo es de color oscuro y con queilocistidios, si bien este taxón se clasifica en $E$. subsect. Cheilocystidiata de E. subg. Nolanea (NOORDELOOS 1979, 2004).

Por tanto, no encontramos ninguna especie descrita que coincida con nuestra colección en las monografías europeas de NOORDELOOS (1992, 2004). Aunque no se haya hecho una búsqueda exhaustiva, parece poco probable que esta especie se haya descrito en base a material de otros continentes. Dado que tan sólo contamos con un único espécimen y la variabilidad de algunos caracteres no se conoce bien aún, proponemos para ella el nombre provisional Entoloma "stenocystis", con el fin de que futuros hallazgos de esta especie puedan asociarse a nuestra recolección pirenaica. 


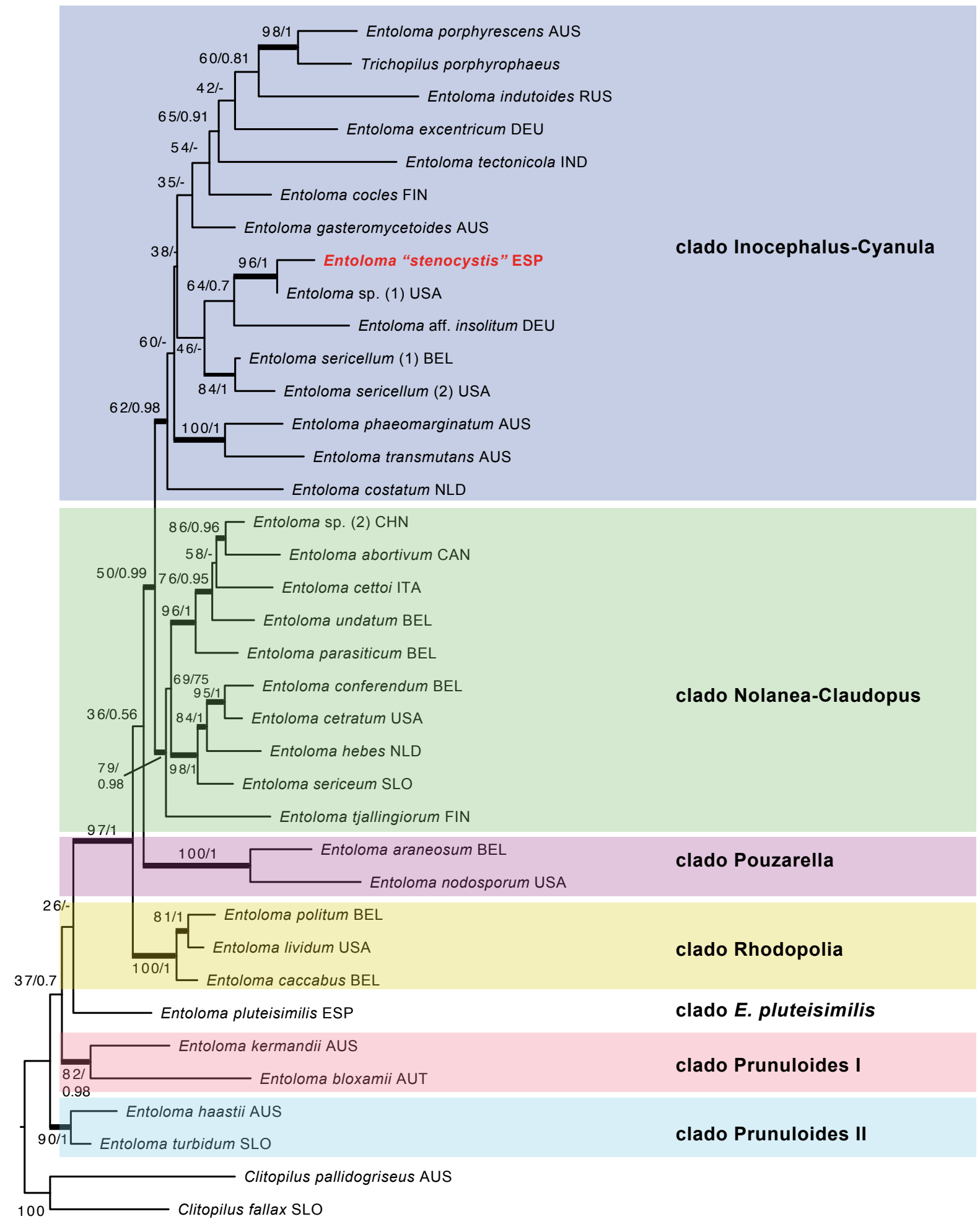

0.03

Fig. 28. Árbol más probable inferido mediante el análisis de máxima verosimilitud (ML) de las regiones 28S rDNA-12S mtDNA-RPB2 (excluyendo el $3^{\circ}$ codon) en especies de Entoloma. Se muestran los valores bootstrap-ML / probabilidad posterior del análisis bayesiano alrededor de las ramas. Las ramas gruesas indican los nodos con apoyo filogenético al menos en un análisis (valores bootstrap $\geq 70 \%$ o probabilidad posterior $\geq 0.95$ ). Los recuadros de colores marcan los principales clados de Entoloma y la muestra descrita en el artículo se destaca en negrita y color rojo. Se emplearon secuencias de Clitopilus pallidogriseus y C. fallax para enraizar el árbol. El país de origen de cada colección se abrevia mediante códigos ISO, marcándose en negrita y color rojo el espécimen estudiado en este artículo. 

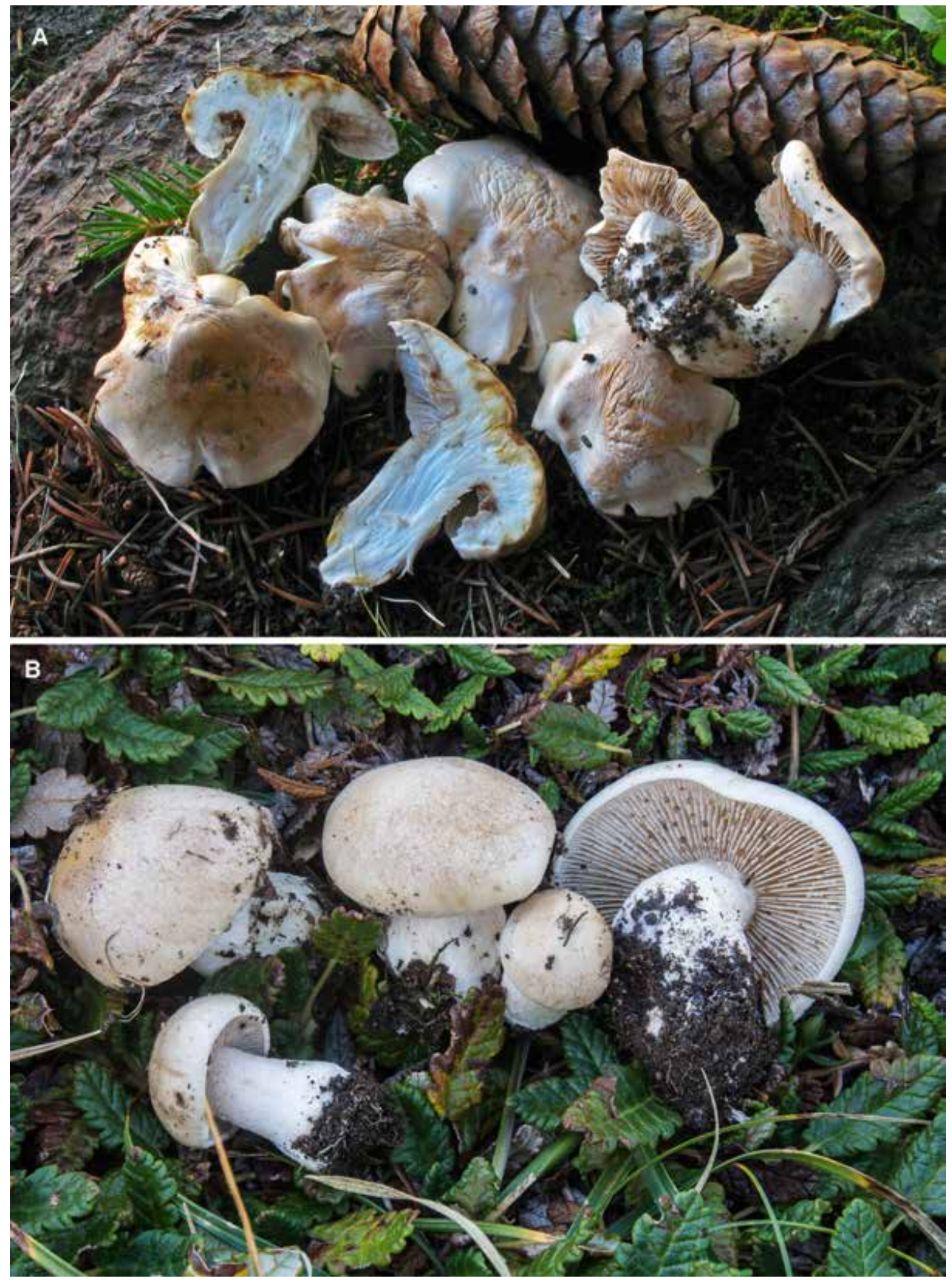

Fig. 29. Hebeloma geminatum, basidiomas in situ. A: LB18092708. B: JACA-MICO 01060, entre Dryas octopetala. Fotografías A: L. Ballester; B: F. Pancorbo.

Hebeloma geminatum Beker, Vesterh. \& U. Eberh., Persoonia 35: 122. 2015.
Píleo sin restos de velo general, algo irregular, de 16-70 $\mathrm{mm}$ de diámetro, 8-18 $\mathrm{mm}$ de altura, inicialmente hemisférico-campanulado, después convexo

Figs. 29-30 


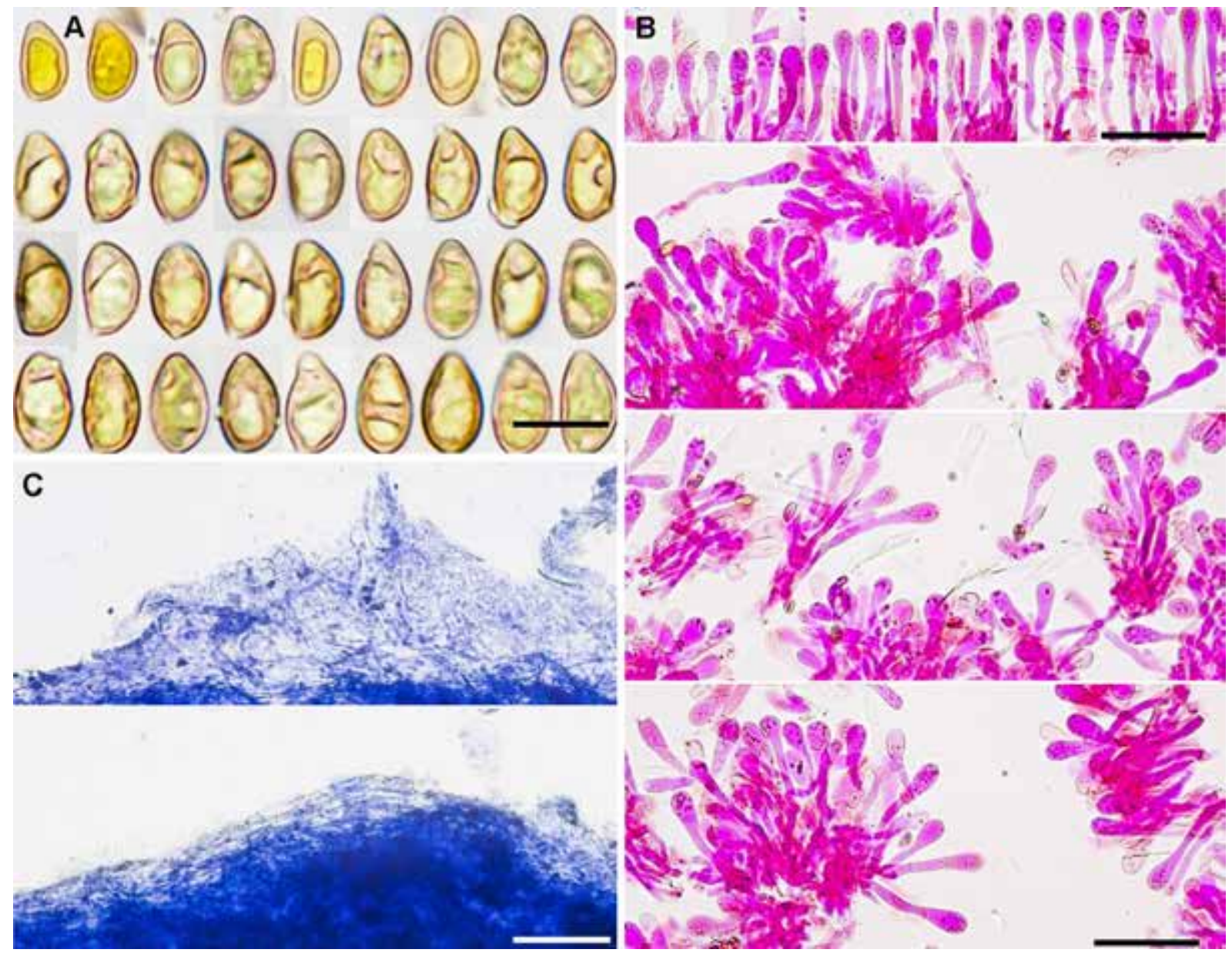

Fig. 30. Hebeloma geminatum (JACA-MICO 01060), caracteres microscópicos. A: Basidiosporas. B: Queilocistidios. C: Pileipellis. Medio de montaje: A: IKI; B: rojo congo+floxina B; C: azul de toluidina. Barras de escala A. $10 \mu \mathrm{m}$; B, C: $50 \mu \mathrm{m}$. Fotografías F. Pancorbo.

o plano-convexo, con el margen inflexo, incluso en basidiomas maduros. Superficie pileica ligeremente viscosa en estado húmedo, con aspecto lanoso, de color crema en el centro y algo más claro hacia el margen. Láminas de adnatas a escotadas, apretadas $(\mathrm{L}=70,1=1-3)$, inicialmente de color crema, después grisáceo y finalmente parduscas; arista fimbriada, de color blanco, sin gotitas o con numerosas gotitas de hialinas a más o menos opacas. Estípite de hasta 25-50 × 10-20 mm, cilíndrico, con la base ensanchándose progresivamente o no, sólido, con la superficie pruinosa hacia el ápice, donde se pueden apreciar gotas similares a las de las láminas en basidiomas jóvenes, de color blanquecino. Contexto de textura firme, blanco. Olor rafanoide no demasiado intenso, sabor dulce.

Basidiosporas amigdaloides en vista lateral, ovales en vista frontal, de color marrón amarillento, gutuladas, de (8,7-)9,0-11,5 $\times(5,0-) 5,4-6,6 \mu \mathrm{m}, \mathrm{Q}=[1,5-$ ] $1,6-1,8[-2]\left(\mathrm{L}_{\mathrm{m}}=10,2-10,5, \mathrm{~W}_{\mathrm{m}}=5,9-6, \mathrm{Q}_{\mathrm{m}}=1,7-1,8\right)$, Ornamentación evidente, solo visible en inmersión, pérdida del perisporio solo visible en algunas esporas en inmersión, reacción dextrinoide nula o débil (D0-
D1). Basidios claviformes, tetraspóricos. Pleurocistidios no observados. Queilocistidios de claviformes a subcapitados, con un largo pedicelo basal, flexuoso, de (45-)51-69(-89) × (7,6-)8,5-10,7(-11,4) $\mu \mathrm{m}$. Caulocistidios presentes en la zona apical del estípite, de forma similar a los queilocistidios. Pileipellis en ixocutis, con un epicutis de 58-144 $\mu \mathrm{m}$ de grosor (medida de material seco) con hifas incrustadas de 2-5,5 $\mu \mathrm{m}$ de anchura. Fíbulas presentes.

Material estudiado: ESPAÑA. Huesca: Benasque, Cerler, 42.5920 .539 ( \pm 150 m), 1558 m, jardín con Picea abies, 27-IX-2018, leg. L. Ballester, det. L. Ballester \& H. Beker, LB18092708 (ITS Genbank MT550873). Bielsa, Portiello de Tella, 2.6114122 $0.183516( \pm 400 \mathrm{~m}), 2070 \mathrm{~m}$, en pradera alpina con Dryas octopetala, 29-VIII-2015, leg. J. Herranz, M.A. Ribes, F. Esteve-Raventós, F. Pancorbo, JACA-MICO 01060, dupla in AH 47651.

Comentarios: Hebeloma geminatum está encuadrado en Hebeloma sect. Denudata, forma parte del complejo H. crustuliniforme (Bull.) Quél. y es muy di- 
fícil de diferenciar morfológicamente de otras especies cercanas, en especial de H. aanenii Beker, Vesterh. \& U. Eberh. BEKER \& al. . (2016) indican que no existe ningún carácter morfológico único que pueda utilizarse para separar $H$. geminatum de $H$. aanenii, especie recientemente citada en Galicia por ALONSO \& RIGUEIRO (2020) y también conocida del contiguo pirineo francés. Sin embargo, las colecciones con esporas con $\mathrm{L}_{\mathrm{m}}<10 \mu \mathrm{m}$ y con los queilocistidios $>9 \mu \mathrm{m}$, pertenecen normalmente a $H$. geminatum (BEKER \& al. 2016). Sin embargo, el $\mathrm{L}_{\mathrm{m}}$ de nuestras colecciones es ligeramente superior a $10 \mu \mathrm{m}$, aunque ambas colecciones han sido confirmadas a nivel molecular utilizando la región ITS (Beker, com. pers.). Otras especies del complejo $H$. crustuliniforme, como $H$. alpinum (J. Favre) Bruchet, H. crustuliniforme, H. eburneum Malençon, se diferencian por presentar esporas con $\mathrm{L}_{\mathrm{m}}>11 \mu \mathrm{m}$ (BEKER \& al. 2016).

Hebeloma geminatum había sido mencionada ya en el listado de hongos recolectados en el Parque Nacional de Ordesa y Monteperdido (PANCORBO \& al. 2017), aunque sin especificar ningún espécimen. Las dos colecciones estudiadas aquí constituyen, por tanto, las dos primeras citas documentadas de $H$. geminatum en la Península Ibérica. Todas las recolectas de las que hay constancia han sido en el norte de
Europa o en los Alpes, por lo que estas 2 recolectas son las más meridionales de las que hay constancia.

Hebeloma ingratum Bruchet, Bull. Mens. Soc. Linn. Lyon 39: 125. 1970.

Fig. 31

Píleo sin restos de velo general, algo irregular, de hasta $75 \mathrm{~mm}$ de diámetro; perfil convexo. Superficie pegajosa cuando está húmeda, de color ocre en el centro y más claro hacia el margen. Margen crenulado. Láminas de color marrón herrumbroso, escotadas, sin gotitas, con el filo fimbriado de color blanco. Estípite de hasta $50 \times 13($ en el medio $) \times 20$ (en la base) $\mathrm{mm}$; con la base claviforme o incluso subbulbosa; con la superficie de pruinosa a débilmente furfurácea hacia el ápice; de color blanco. Contexto de textura firme, blanquecino. Olor rafanoide, sabor algo amargo.

Basidiosporas amigdaloides, de color marrón amarillento, gutuladas, de 9,5-11,7 × 5,0-6,4 $\mu \mathrm{m}$, $\mathrm{Q}=1,6-2,1\left(\mathrm{~L}_{\mathrm{m}}=10,56, \mathrm{~W}_{\mathrm{m}}=5,68, \mathrm{Q}_{\mathrm{m}}=1,86 ; \mathrm{n}=73\right)$. Ornamentación solo visible en inmersión, pérdida del perisporio únicamente visible en algunas esporas en inmersión, reacción dextrinoide poco marcada. Queilocistidios claviformes-lageniformes.

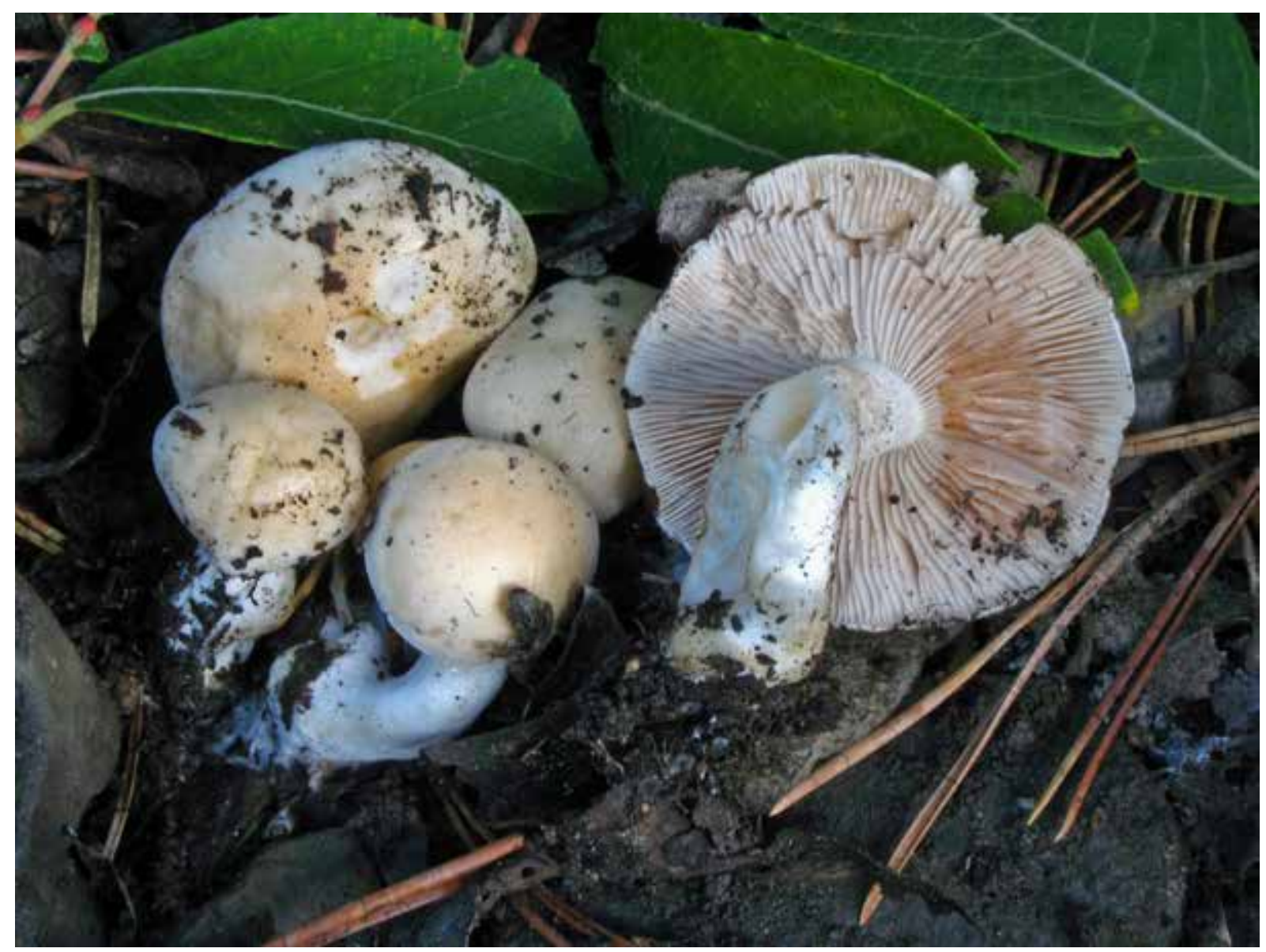

Fig. 31. Hebeloma ingratum (LB16092806). Basidiomas in situ. Fotografía L. Ballester. 
Material estudiado: ESPAÑA. Huesca: Benasque, barranco de Vallibierna, 42.614 0.606 ( $\pm 20 \mathrm{~m}), 1800 \mathrm{~m}$, con Salix caprea, 28-IX-2016, leg. J. Garrido \& L. Ballester, det. L. Ballester \& H. Beker, LB16092806 (ITS Genbank MT550873); Montanuy, Collada de Basibé, $42.5532910 .591872( \pm 10 \mathrm{~m}), 2255 \mathrm{~m}$, prados alpinos sobre suelo calcáreo, entre Salix herbacea, 27-IX-2018, leg. C. Pérez del Amo \& I. Olariaga, det. L. Ballester \& H. Beker, LB18092706 (ITS Genbank MT550874).

Comentarios: Hebeloma ingratum está encuadrado en Hebeloma sect. Denudata, concretamente en Hebeloma subsect. Clepsydroida, y se caracteriza por el píleo de color ocre en el centro, no muy pálido, esporas débilmente dextrinoides, cuyo $\mathrm{L}_{\mathrm{m}}$ es $<11 \mu \mathrm{m}$, y queilocistidios que presentan normalmente la pared engrosada en su parte central (BEKER \& al. 2016). Otras especies cuyos queilocistidios poseen la parte central de paredes engrosadas son $H$. cavipes Huijsman, H. hiemale Bres. H. pseudofragilipes Beker, Vesterh. \& U. Eberh. La primera, H. cavipes, difiere de $H$. ingratum por sus esporas mayores, con $\mathrm{Lm}>11$ $\mu \mathrm{m}$, claramente dextrinoides, mientras que $H$. pseudofragilipes tiene el píleo más pálido y también esporas más fuertemente dextrinoides que $H$. ingratum. Hebeloma hiemale se separa de $H$. ingratum por sus esporas más lisas y queilocistidios con el ápice más claramente dilatado (BEKER \& al. 2016).

Como indican nuestras recolecciones, $\mathrm{H}$. ingratum, crece habitualmente en bosques, pero pueden encontrarse de manera más ocasional en el piso alpino asociada a sauces enanos (BEKER \& al. 2016). Aunque $H$. ingratum tiene una ecología bastante amplia, BEKER \& al. (2016), caracterizan H. ingratum como una especie septentrional en Europa, cuya localidad conocida más meridional se encontraba en Bélgica, por lo que estas dos recolectas que presentamos en este trabajo son las más meridionales conocidas hasta la fecha. Ambas colecciones han sido molecularmente verificadas por $\mathrm{H}$. Beker mediante la secuenciación de la región ITS.

Hygrophorus hedrychii (Velen.) K. Kult, \eská Mykol. 10(4): 232. 1956.

= Limacium hedrychii Velen., \eské Houby 1: 96. 1920.

- Hygrophorus eburneus var. carneipes Kühner in Kühner \& Romagn., Fl. Analyt. Champ. Sup.: 58. 1953 [nom. inval. publ., nom. nudum, Art. 38.1(a)]

Figs. 32-33

Basidiomas estipitados, de porte tricolomatoide y tamaño mediano para el género, naciendo en grupos directamente sobre el suelo. Píleo de 20-60 mm de diámetro, primero convexo, luego extendido, finalmente y en ocasiones algo embudado, con presencia de un umbón central amplio. Superficie pileica vis- cosa, de color marfil o algo crema, el centro con una suave tonalidad amarillenta o rosa rojizo. Margen incurvado durante bastante tiempo, luego extendido, en ocasiones algo asurcado. Láminas subdecurrentes, más bien espaciadas, $\mathrm{L}=35-45$, gruesas, arqueadas, en ocasiones bifurcadas, con lamélulas, primero marfileñas, luego pálidas, rosadas o algo rojizas, al final amarillentas. Esporada blanca. Estípite más largo que el diámetro del sombrero, inicialmente lleno, al final hueco, de 50-120 × 8-15 mm, subcilíndrico, curvado en su zona inferior, base atenuada, longitudinalmente fibrilloso, viscoso en la zona inferior, algo más seco y furfuráceo hacia el ápice; de color blanco marfil que con el tiempo va tomando coloraciones rosadas o rojizas. Contexto más bien delgado, blanquecino. Olor fuerte, algo desagradable y sabor suave, banal. Reacciones macroquimicas no testadas.

Basidiosporas de elipsoidales a obovoides, lisas, hialinas, apiculadas, en general con una gran gútula central, no amiloides, de 7,1-8,7 × 4,5-5,9 $\mu \mathrm{m}$, $\mathrm{Q}=1,3(1,5) 1,7\left(\mathrm{~L}_{\mathrm{m}}=7,9, \mathrm{~W}_{\mathrm{m}}=5,2, \mathrm{Q}_{\mathrm{m}}=1,52 ; \mathrm{n}=50\right)$. Basidios tetraspóricos, claviformes, con fíbula basal, de 35,8-46 × 5,2-8,5 $\mu \mathrm{m}$. Cistidios ausentes. Trama laminar bilateral. Epicutis en ixotricoderma con hifas cilíndricas, y terminaciones erectas con el ápice redondeado o lanceolado, de 3,1-5,5 $\mu \mathrm{m}$ de anchura. Caulocutis en ixocutis en la zona inferior, ixotricodermis en la superior, con hifas erectas que forman haces, de 3,5-5,5 $\mu \mathrm{m}$ de anchura. Fíbulas presentes.

Material estudiado: ESPAÑA. Huesca: Benasque, Selva de Conques, $42.5845830 .528792( \pm 50$ $\mathrm{m}), 1375 \mathrm{~m}$, en bosque mixto, húmedo y suelo básico, con Betula pendula, Corylus avellana, Populus tremula, Fagus sylvatica, Pinus sylvestris, Fraxinus excelsior, Abies alba, Buxus sempervirens y otras especies de arbustos propias de ribera, 28-IX-2018, leg. C. Pérez del Amo, CMP1865 (ITS Genbank MW248492; LSU MW248516); ibidem 30-IX-2018, leg. U. Fernandes, J.I. López Amiano, J. Martín \& J. Teres, ARAN-Fungi 10317.

Comentarios: Hygrophorus hedrychii pertenece a Hygrophorus sect. Hygrophorus, caracterizada por el píleo y estípite glutinosos, y más en concreto al grupo de $H$. cossus, que posee un olor que recuerda a larvas del lepidóptero Cossus cossus (LARSSON $\&$ JACOBSSON 2004). Dentro de este grupo, $H$. hedrychii se caracteriza por el color ocre rosáceo del píleo y las láminas, y además, por crecer asociado a Betula (LARSSON \& JACOBSSON 2004). Hygrophorus cossus (Sowerby) Fr. posee láminas de color blanco o blanco grisáceas, carne que no reacciona con $\mathrm{KOH}$, y se asocia con Quercus, mientras que $H$. eburneus (Bull.) Fr., forma micorrizas con Fagus, posee láminas blanquecinas o con reflejos rosados y reacción naranja al aplicar $\mathrm{KOH}$ en la base del estípite. 

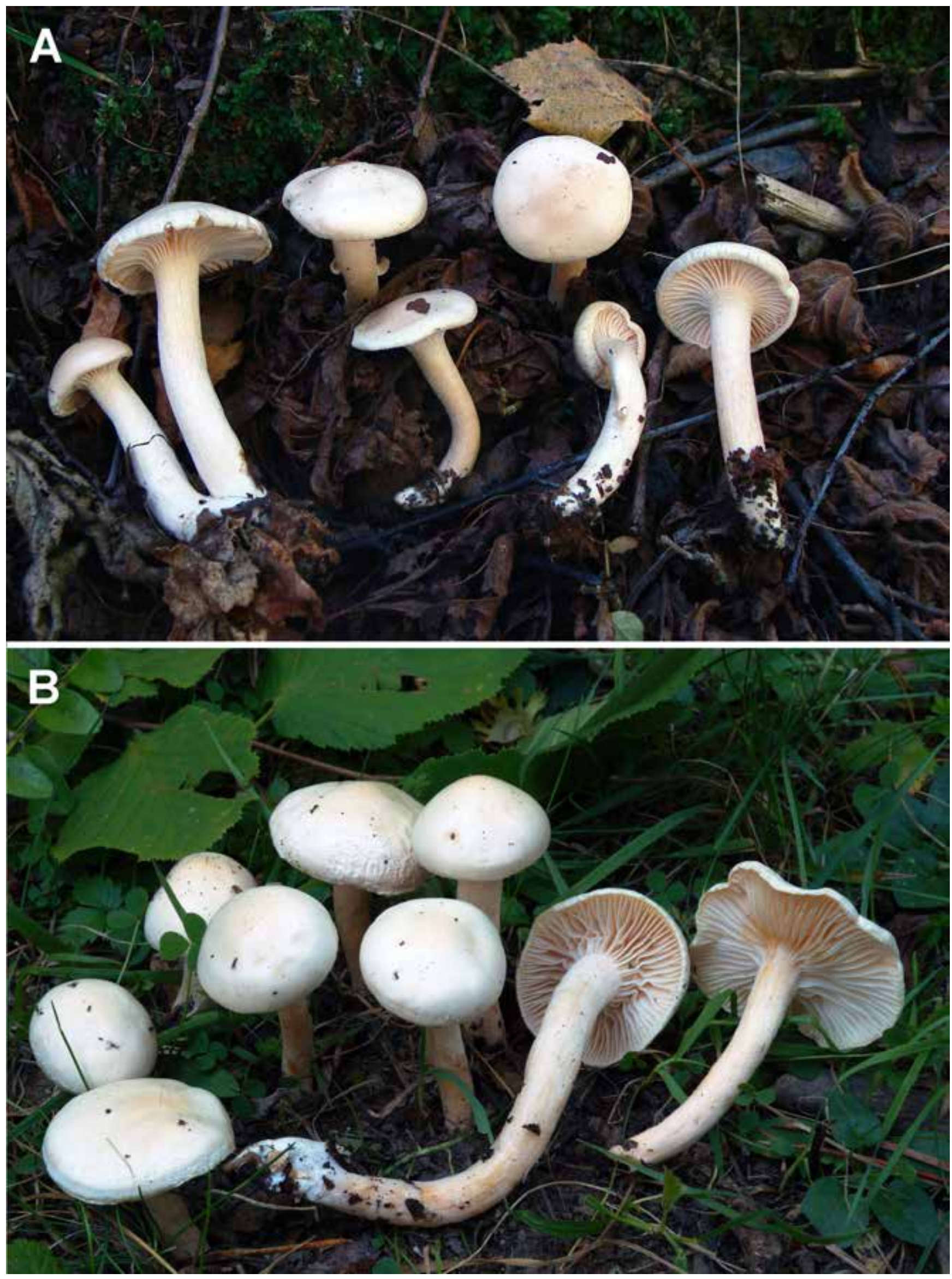

Fig. 32. Hygrophorus hedrychii. Basidiomas in situ. A: ARAN-Fungi 10317. B: CMP1865. Fotografías A: J. Teres; B: C. Pérez del Amo. 

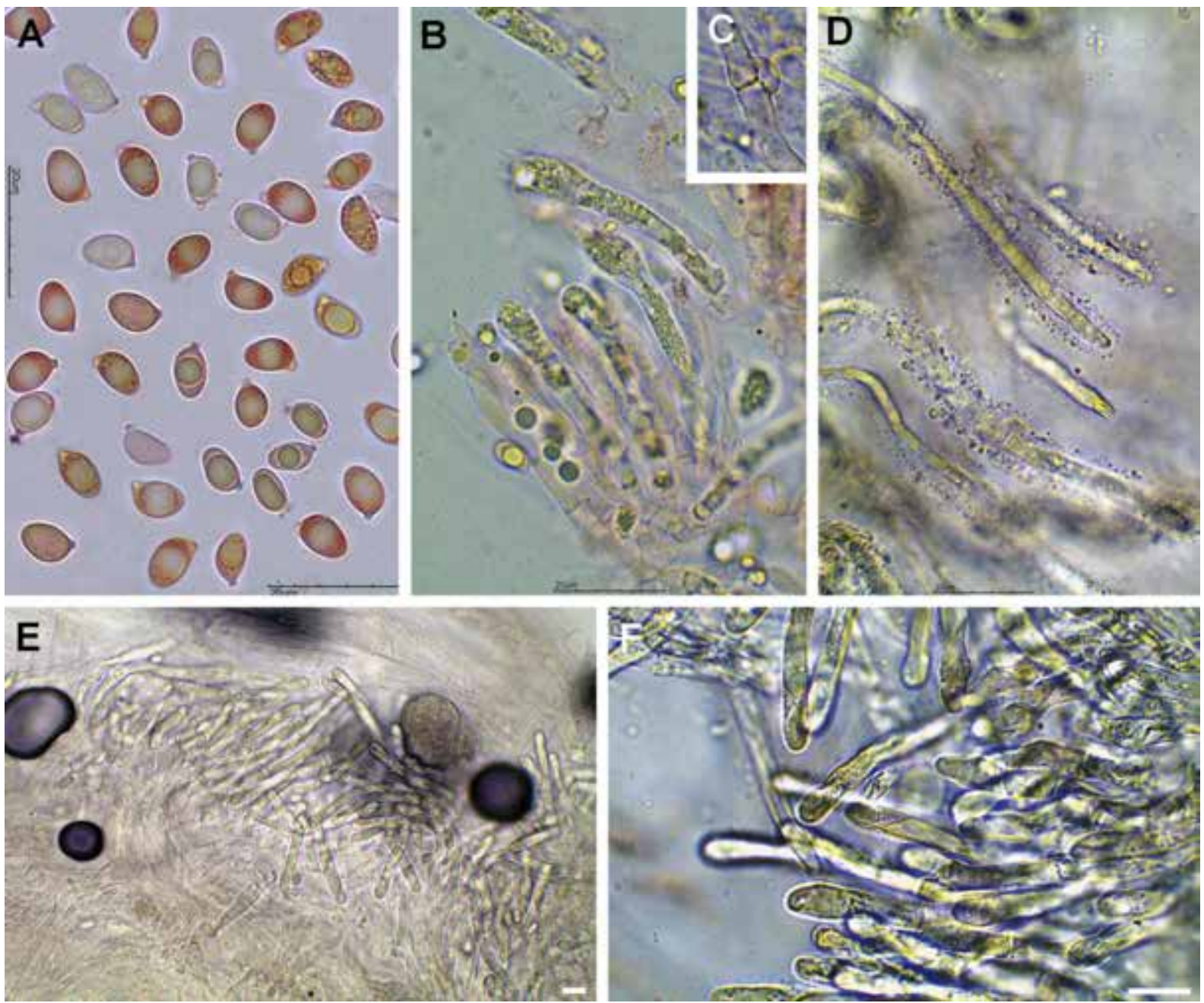

Fig. 33. Hygrophorus hedrychii (CMP1865), caracteres microscópicos. A: Basidiosporas en rojo Congo. B: Basidios en rojo Congo. C: Fíbula. D: Hifas de la pileipellis mostrando hifas gelatinizadas, en agua. E: Hifas de la caulipellis, hifas erectas y fasciculadas. F: Hifas de la caulipellis, hifas erectas y fasciculadas. Barras de escala $10 \mu \mathrm{m}$. Fotografías C. Pérez del Amo.

Nuestro análisis de la región ITS (Fig. 34) confirma la correcta identificación del espécimen pirenaico estudiado aquí, ya que cae en el clado que contiene el resto de secuencias identificadas como $H$. hedrychii de norte de Europa y de Asia.

Según nuestra búsqueda, $H$. hedrychii sólo se ha citado una única vez de la Península Ibérica, en concreto de Andorra (VILA \& al. 1997). Aunque estos autores no presentaron ninguna ilustración, la descripción parece coincidir con nuestro material. Aportamos aquí, por tanto, la primera cita del estado español, además de aportar fotografías y datos moleculares que confirman la presencia de $H$. hedrychii en la Península Ibérica.

Inocybe appendiculata Kühner, Bull. Soc. Naturalistes Oyonnax 9 (suppl.): 4. 1955.

Fig. 35

Píleo de $12-15 \mathrm{~mm}$ de diámetro y $10 \mathrm{~mm}$ de alto, cónico, de color pardo-ocráceo. Superficie pileica seca, mate, no higrófana, de aspecto fibroso-lanoso, con fibrillas de color ligeramente más oscuro, no escamosa. Láminas espaciadas, $\mathrm{L}=28-32,1=1-2$, ligeramente sinuosas, emarginadas, de color crema. Arista laminar fimbriada, más pálida que las caras laminares. Estípite 27-30 × 4-5 mm, cilíndrico, lleno, rígido, quebradizo, blanquecino, manchándose de pardo-ocráceo con la edad o por manipulación, fibrilloso, pruinoso en una estrecha franja apical $(<1 / 10)$ y fibrilloso en el resto de la superficie. Contexto firme, de color blanquecino, con olor subespermático.

Basidiosporas de (8-)8,5-9,6(-10,4) × (4,9-)4,9$5,5(-5,8) \mu \mathrm{m}, \mathrm{Q}=(1,5-) 1,6-1,9\left(\mathrm{~L}_{\mathrm{m}}=9,1, \mathrm{~W}_{\mathrm{m}}=5,2\right.$, $\mathrm{Q}_{\mathrm{m}}=1,7 ; \mathrm{n}=38$ ), elipsoidales en vista frontal, amigdaliformes en vista lateral, con el ápice ligeramente apuntado. Basidios de (19,8-)24,4-29,2(-30,5) $\times$ $(8,7-) 9,2-11,4(-12,6) \mu \mathrm{m}\left(\mathrm{L}_{\mathrm{m}}=26,7, \mathrm{~W}_{\mathrm{m}}=10,2, \mathrm{Q}=\right.$ $[2,1-] 2,3-3[-3,1], \mathrm{Q}_{\mathrm{m}}=2,6$, claviformes, fibulados, tetraspóricos, con esterigmas hasta de $6,5 \mu \mathrm{m}$, que en algún caso presentan un contenido intracelular ocre 


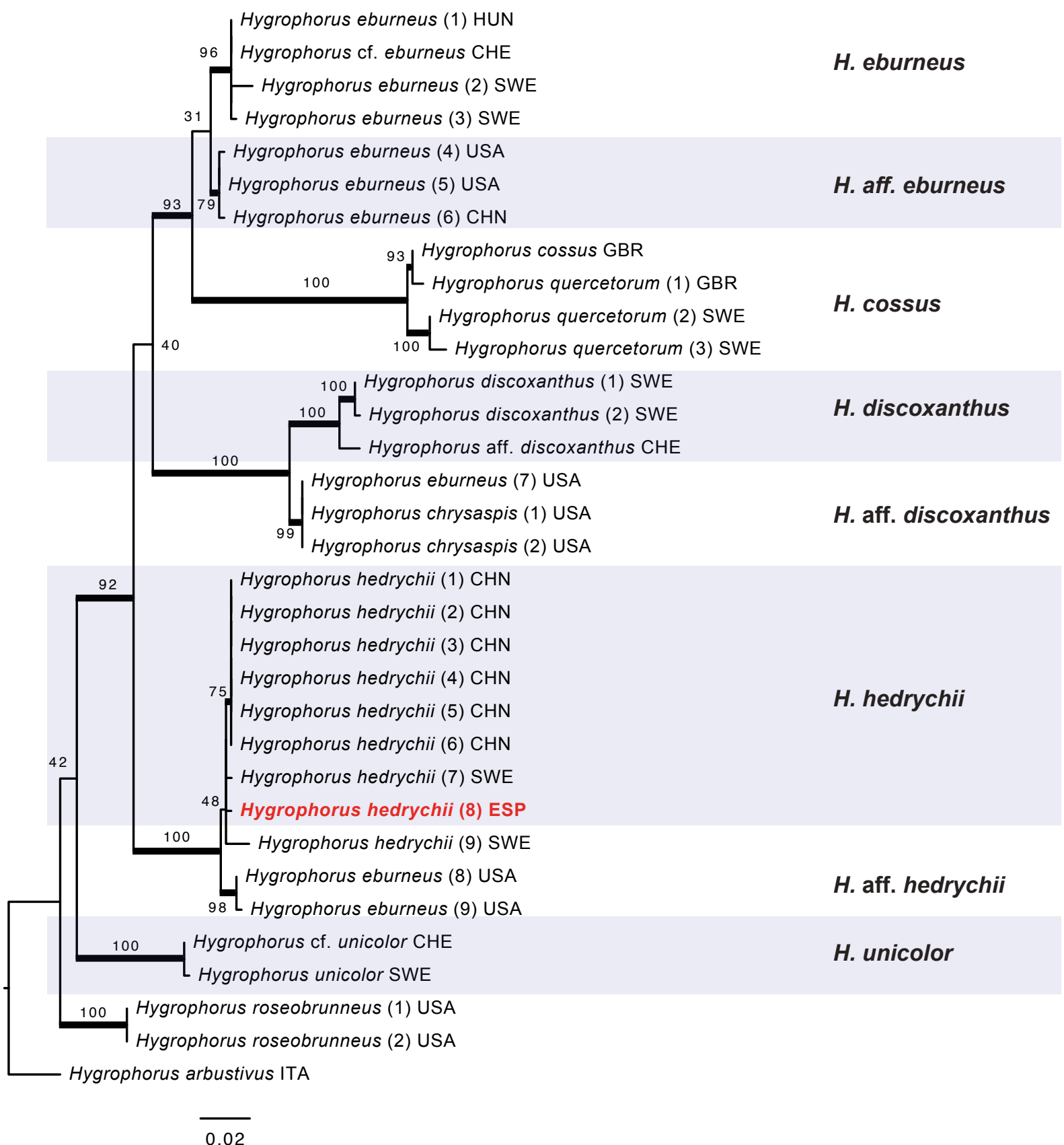

Fig. 34. Árbol más probable inferido mediante el análisis de máxima verosimilitud de la región 28S del rDNA nuclear en especies de Hygrophorus sect. Hygrophorus. Las ramas gruesas indican los nodos con apoyo filogenético (valores bootstrap $\geq 70 \%$ ). Se empleó una secuencia de Hygrophorus arbustivus para enraizar el árbol. El país de origen de cada colección se abrevia mediante códigos ISO, marcándose en negrita los especímenes que se describen en el artículo.

pardusco. Pleurocistidios de (38,2-)40,1-51,7(-63,1) $\times(15,8-) 16,3-19,6(-21,5) \mu \mathrm{m}, \mathrm{Q}=[2-] 2,2-2,9[-3,7]$ $\left(\mathrm{L}_{\mathrm{m}}=46,4, \mathrm{~W}_{\mathrm{m}}=18, \mathrm{Q}_{\mathrm{m}}=2,6 ; \mathrm{n}=39\right)$, anchamente claviformes a piriformes, en algún caso provistos de un amplio pedicelo, de ápice cristalífero y paredes no demasiado gruesas: $(0,8-) 0,81-1,08(-1,1) \mu \mathrm{m}\left(\mathrm{L}_{\mathrm{m}}=0,9\right.$; $\mathrm{n}=11)$. Queilocistidios cubriendo totalmente la arista, similares a los pleurocistidios, mezclados con paracistidios claviformes de paredes finas de $(23,1-$ ) $23,4-27,5(-30) \times(7,8-) 8,4-14(-15,3) \mu \mathrm{m}\left(\mathrm{L}_{\mathrm{m}}=25,3\right.$,
$\left.\mathrm{W}_{\mathrm{m}}=11 ; \mathrm{n}=10\right)$. Caulocistidios ausentes incluso en el extremo apical, solo en el ápice del estípite encontramos unos pelos alargados cilíndricos, no cristalíferos, de 8-13 $\mu \mathrm{m}$ de ancho, ligeramente ensanchados en la base y que presentan un contenido intracelular ocre. Fíbulas presentes.

Material estudiado: ESPAÑA. Huesca: Montanuy, Collada de Basibé, $42.5534180 .592730( \pm 10$ m), 2276 m, entre Dryas octopetala, 27-IX-2018, leg. 

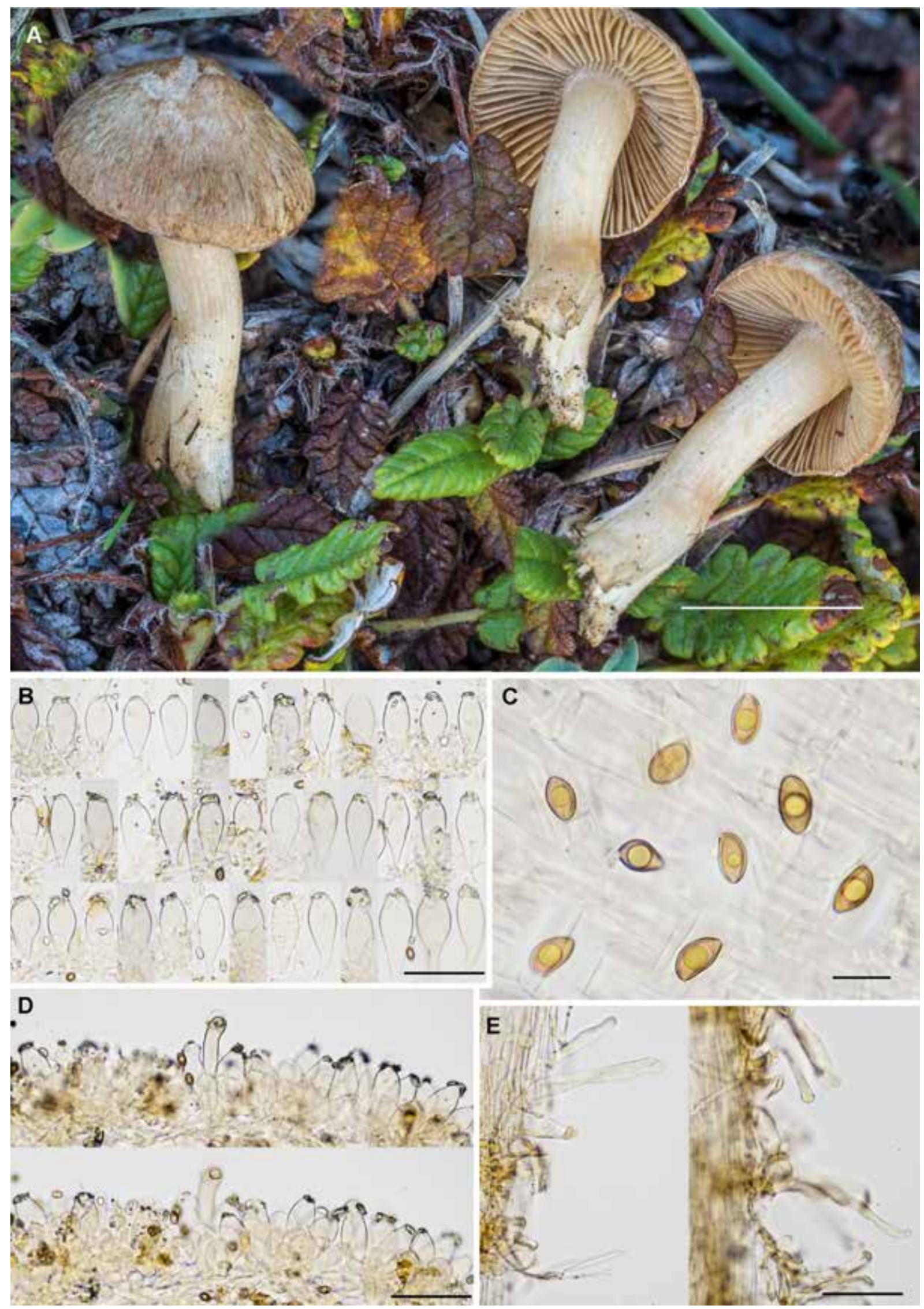

Fig. 35. Inocybe appendiculata (AH5812). A: Basidiomas in situ. B: Pleurocistidios. C: Basidiosporas. D: Arista laminar mostran-

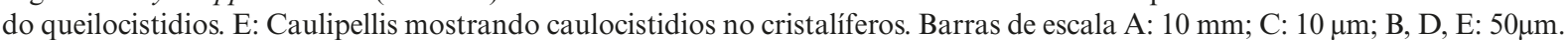
Medio de montaje: $\mathrm{NH}_{4} \mathrm{OH}$. 
F. Pancorbo, det. F. Esteve-Raventós \& F. Pancorbo, AH 51812 (ITS Genbank MW248493).

Comentarios: En la literatura europea consultada tanto de micología alpina (BIZIO 1995, 1997; BON 1997a; CORRIOL 2007; ESTEVE-RAVENTÓS \& al. 1997; ESTEVE-RAVENTÓS \& VILA 1997, 1998; EYSSARTIER \& DELANNOY 2006; FERRARI 2006; JAMONI 2008; LLISTOSELLA \& al. 1994; SCHMID-HECKEL 1985, 1988; VILA \& al. 2001) como del resto (BON 1997b; FERRARI 2010; JACOBSSON 2008; KÜHNER 1955). Inocybe appendiculata es un taxón asociado preferentemente a coníferas de montaña, no citado en zona alpina, que se caracteriza por su velipellis consistente, densa, que forma en el margen del píleo unas mechas apendiculadas-dentiformes, aunque bajo condiciones de fuerte exposición, dicha velipellis puede ser rígida y en el margen sólo ligeramente apendiculada-dentada (KUYPER 1986).

En un principio, nuestra colección al ser de zona alpina nos llevó al grupo de Inocybe immaculipes Kühner, Inocybe piricystis J. Favre e I. heterocystis Kühner que BON (1997b) engloba en Inocybe estirpe Piricystis junto con las especies no alpinas $I$. appendiculata e I. mytiliodora Stangl \& Vauras. Inocybe piricystis se diferencia por presentar un estípite más pardusco en la parte inferior y unas esporas que llegan a las $13 \mu \mathrm{m}$. I. heterocystis presenta unos cistidios variables, de piri-claviformes a \pm fusiformes, raramente lageniformes, sobre todo los queilocistidios, con transiciones hacia los paracistidios más estrechos o estirados.

Inocybe immaculipes fue nuestra primera hipótesis ya que se caracteriza por su píleo de pequeño tamaño $(<20 \mathrm{~mm})$ de color ocráceo que a causa de la velipellis que lo cubre, le da un aspecto blanquecino, un estípite también blanquecino y fibrilloso, la ausencia de cistidios metuloides en el estípite y sobre todo por los cistidios laminares de aspecto piriforme $\mathrm{y} \operatorname{cortos}(<50 \mu \mathrm{m})$.

En nuestro análisis de la región ITS (Fig. 36), nuestra colección anida en un clado compuesto en su mayoría por colecciones típicas (morfológicamente y ecología) de I. appendiculata de Asia, Europa y Norteamérica. Las secuencias que forman este clado poseen poca divergencia y son prácticamente idénticas entre sí. El clado hermano a I. appendiculata, compuesto por dos colecciones de regiones árticas (Svalbard) entre Dryas octopetala, es denominado aquí como Inocybe aff appendiculata. Una de las muestras procede de una muestra de suelo (GEML \& al. 2012) y la otra está identificada como Inocybe cf. flocculosa Sacc. (BJORBÆKMO \& al. 2010).

Inocybe immaculipes parece ser un taxón poco citado: solo hemos encontrado una cita del año 2002 en el Tirol austriaco, (HAUSKNECHT \& al. 2003) aparte de la colección holotipo de KÜHNER (1988). Suscribimos el comentario de HAUSKNECHT \& al. (2003): "La mayoría de estas especies alpinas son muy raras y apenas se puede decir nada sobre su distribución. Si las numerosas especies descritas están realmente justificadas o si es mejor que algunas de ellas desaparezcan en la sinonimia, tal vez las observaciones ulteriores y sobre todo las investigaciones de biología molecular lo demuestren". Por tanto, citamos aquí I. appendiculata por primera vez del piso alpino, a la espera de estudios más detallados en el grupo y que esclarezcan la identidad de I. immaculipes y el resto de especies incluidas en el grupo.

\section{Mycetinis gramineus Olariaga ad interim}

Figs. 37-38

Píleo de 5-10 mm de diámetro, inicialmente convexo, posteriormente plano-convexo, en ocasiones muy ligeramente deprimido en el centro, sin mamelón. Superficie pileica seca, mate, higrófana, de color que oscila entre pardo grisáceo pálido y ocre pálido, en ocasiones ligeramente más oscura en el centro. Margen liso o ligeramente acanalado. Láminas separadas, $\mathrm{L}=16-18$, con numerosas lamélulas que no alcanzan el estípite, rectas, adnadas, de color crema ocráceo muy pálido. Arista laminar más o menos plana, blanca, más pálida que las caras laminares. Estipite de 13-20 × 0.8-2 mm, cilíndrico, fistuloso, concolor con el píleo en el tercio superior, progresivamente pardo rojizo o pardo púrpura en los dos tercios inferiores, de subliso a pubescente en el tercio superior, progresivamente tomentoso hacia la base. Tomento basal que se extiende en el substrato contiguo, sin formar rizomorfos. Contexto blando, de color blanquecino, con olor aliáceo fuerte y penetrante.

Basidiosporas de estrechamente elipsoidales a fusiformes, con el apículo cúbico $(1,3 \mu \mathrm{m})$, de pared delgada, lisas, de (8-)9-12 × 3,5-4,5(-5) $\mu \mathrm{m}\left(\mathrm{L}_{\mathrm{m}}=10,2\right.$, $\mathrm{W}_{\mathrm{m}}=4, \mathrm{Q}_{\mathrm{m}}=2,54 ; \mathrm{n}=20$ ). Basidios claviformes, con 2 a 4 esterigmas, fibulados, de 31-38 $\times 5-8 \mu \mathrm{m}$, de pared delgada. Pleurocistidios ausentes. Queilocistidios formando una arista laminar homómera, anchamente claviformes, con pequeñas protuberancias o claros apéndices digitiformes en su ápice, en ocasiones ramificados o con la pared ligeramente engrosada en el ápice (hasta $1 \mu \mathrm{m}$ ), hialinos, fibulados, de 23-52 $\times 8-12 \mu \mathrm{m}$. Pileipellis himeniforme, compuesta por células poliformas, habitualmente con el ápice ramificado o con protuberancias digitiformes ramificadas hasta 3 veces, ocasionalmente regularmente claviformes o con de pared ligeramente engrosada, predominantemente hialinas, a veces de color pardo claro, de 28-33 × 11-13 $\mu \mathrm{m}$. Stipitipellis de tipo cutis, compuesta de hifas cilíndricas, de pared ligeramente engrosada, hialinas, de 2-3 $\mu \mathrm{m}$ de diámetro. Hifas de la médula del estípite estrechamente fusiformes, de 


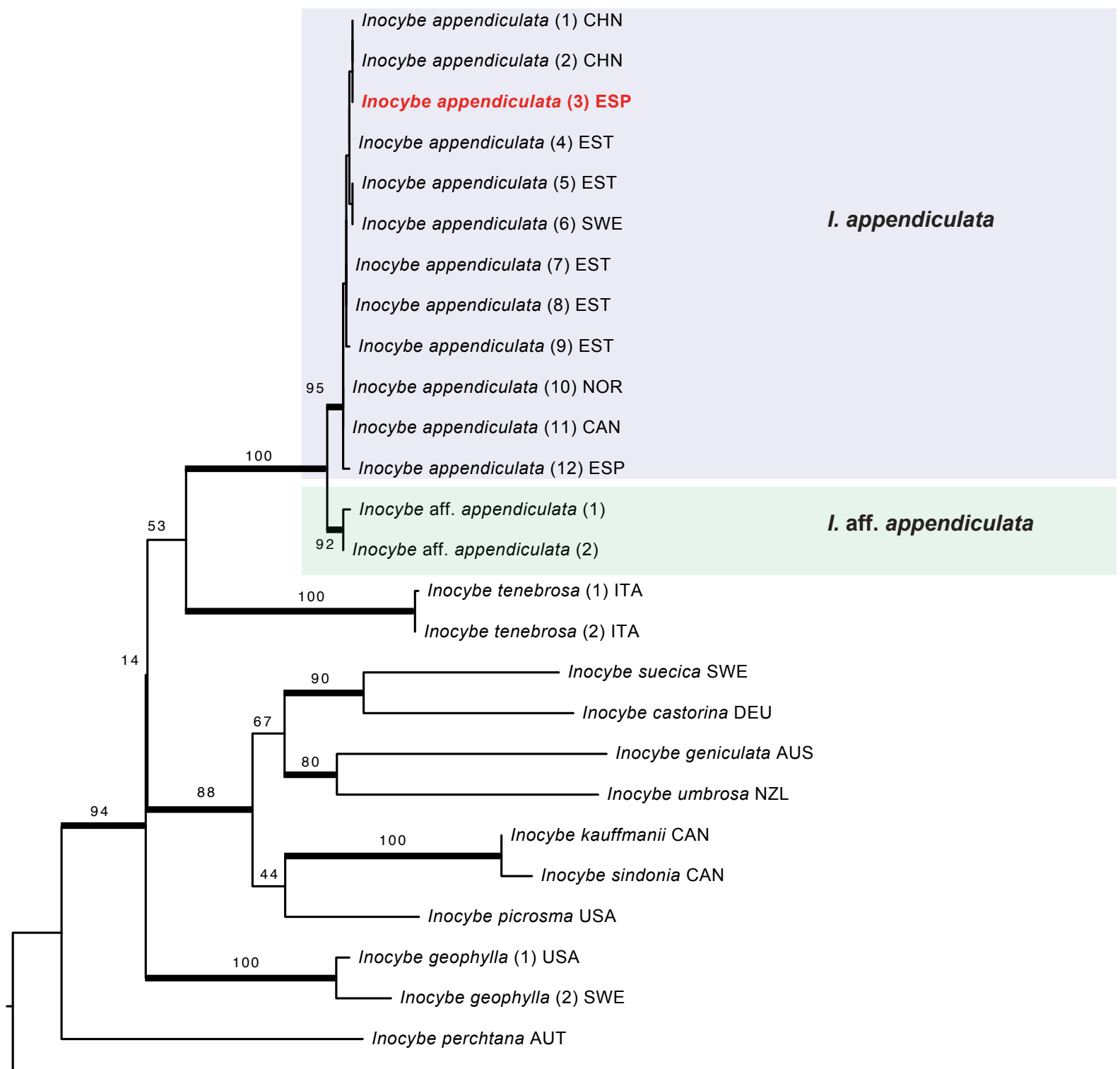

Inocybe splendens FRA

0.04

Fig. 36. Árbol más probable inferido mediante el análisis de máxima verosimilitud de la región ITS del rDNA en especies relacionadas a Inocybe appendiculata. Las ramas gruesas indican los nodos con apoyo filogenético (valores bootstrap $\geq 70 \%$ ). Se empleó una secuencia de I. splendens para enraizar el árbol. El país de origen de cada colección se abrevia mediante códigos ISO, marcándose en rojo y negrita los especímenes que se describen en el artículo.

pared delgada, de hasta $11 \mu \mathrm{m}$ de anchura, hialinas. Caulocistidios abundantes, solitarios o fasciculados, polimorfos, cilíndricos y simples, o ramificados desde la base 1-2 veces, hialinos, de 27-74 × 5-8 $\mu \mathrm{m}$, hialinos. Fíbulas observadas en todos los septos.

Material estudiado: ESPAÑA. Huesca: Benasque, Puerto de la Glera, 42.700760 .60342 ( $\pm 50 \mathrm{~m}$ ), 2370 m, 28-IX-2018, entre hojas muertas de Festuca sp., en vegetación alpina con Salix herbacea, leg. J. Hernanz, ARAN-Fungi 13930 (ITS-LSU Genbank MW248494).
Comentarios: El material descrito anterioremente corresponde al género Mycetinis Earle, debido a la ausencia de células dextrinoides, pileipellis himeniforme formada por elementos no diverticulados, y sobre todo por su fuerte olor aliáceo (WILSON \& DESJARDIN 2005), debido a la presencia de gamma glutamyl marasmina (GMELIN \& al. 1976). Las búsquedas BLAST y los análisis filogenéticos realizados (Fig. 39) confirman su pertenencia al género Mycetinis.

Nuestro material se caracteriza por su porte pequeño, estípite de pubescente a tomentoso, esporas 


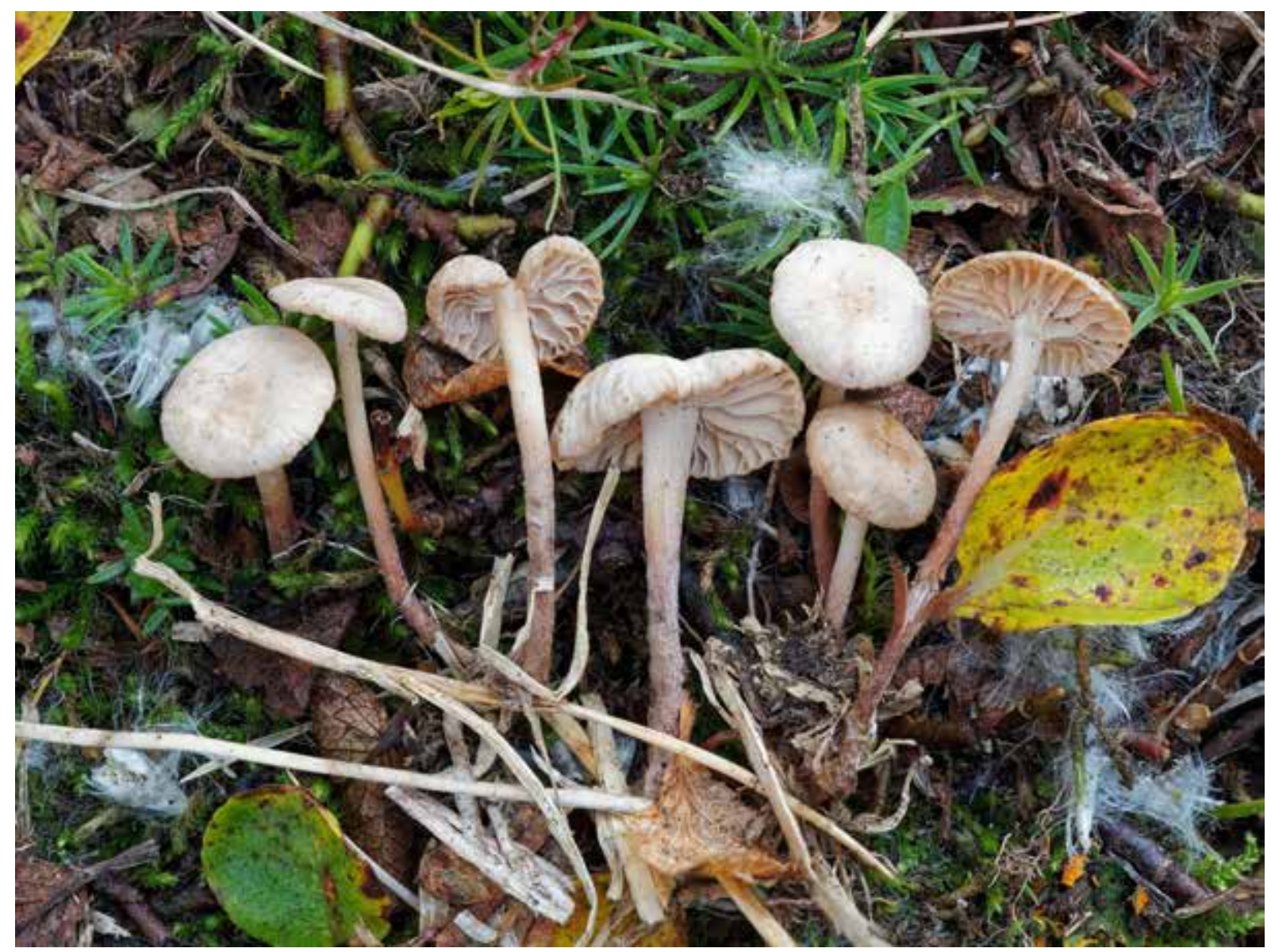

Fig. 37. Mycetinis gramineus ad interim (ARAN-Fungi 13930). Basidiomas ex situ. Fotografía Jorge Hernanz.

de estrechamente elipsoidales a fusiformes, arista estéril formada por queilocistidios que tienden a ramificarse en el ápice, así como elementos de la pileipellis y caulocistidios que son muy a menudo ramificados. Molecularmente, el análisis de la región ITS-LSU sugiere que la especie más próxima es $M$. querceus (Britzelm.) Antonín \& Noordel., formando con esta última un clado con apoyo filogenético (Fig. 39), y apareciendo en una rama basal a las muestras de $M$. querceus. La mayor longitud de la rama se debe a 5 cambios en la región ITS respecto a las secuencias de $M$. querceus. Según nuestro estudio, el material pirenaico difiere de $M$. querceus por su píleo de menor tamaño, menor número de láminas, arista laminar blanca y homómera con queilocistidios bien diferenciados, esporas ligeramente más largas con un $\mathrm{Q}_{\mathrm{m}}$ mayor, elementos de la pilepellis y caulocistidios predominantemente ramificados. Además, la ecología podría ser también un claro carácter diferenciador. Mycetinis querceus es una especie que crece habitualmente sobre hojarasca de Quercus, si bien existen registros sobre hojarasca de otras Fagaceae y Betulaceae. Los basidiomas de nuestra recolección fueron hallados sobre una gramínea cespitosa del gé- nero Festuca (Poaceae), con los estípites insertados en hojas muertas de la planta. También había hojas muertas de Salix herbacea, aunque no pudimos constatar que los basidiomas crecieran directamente sobre hojas de $S$. herbacea. Por otra parte, no conocemos ningún registro de $M$. querceus en el piso alpino. A pesar de que a nivel molecular nuestra muestra es muy próxima a $M$. querceus, las claras diferencias morfológicas y ecológicas observadas sugieren que nuestro material corresponde a otra especie. En la Tabla 3 se sintetizan las diferencias halladas entre nuestro material y las descripciones de $M$. querceus de ANTONÍN \& NOORDELOOS (2010) y PETERSEN \& HUGUES (2017).

Nuestro material tampoco coincide con otras especies alpinas o que nuestros análisis filogenéticos sugieren como cercanas. Mycetinis kallioneus (Huhtinen) Antonín \& Noordel., especie alpina, difiere de nuestro material por su píleo de color pardo oscuro, basidios exclusivamente bispóricos y basidiosporas en proporción mucho más anchas (PETERSEN \& HUGHES 2017). Otra especie alpina, Mycetinis subalpinus (Moreau) R.H. Petersen, posee basidiomas de pequeño tamaño, así como queilocistidios y ele- 

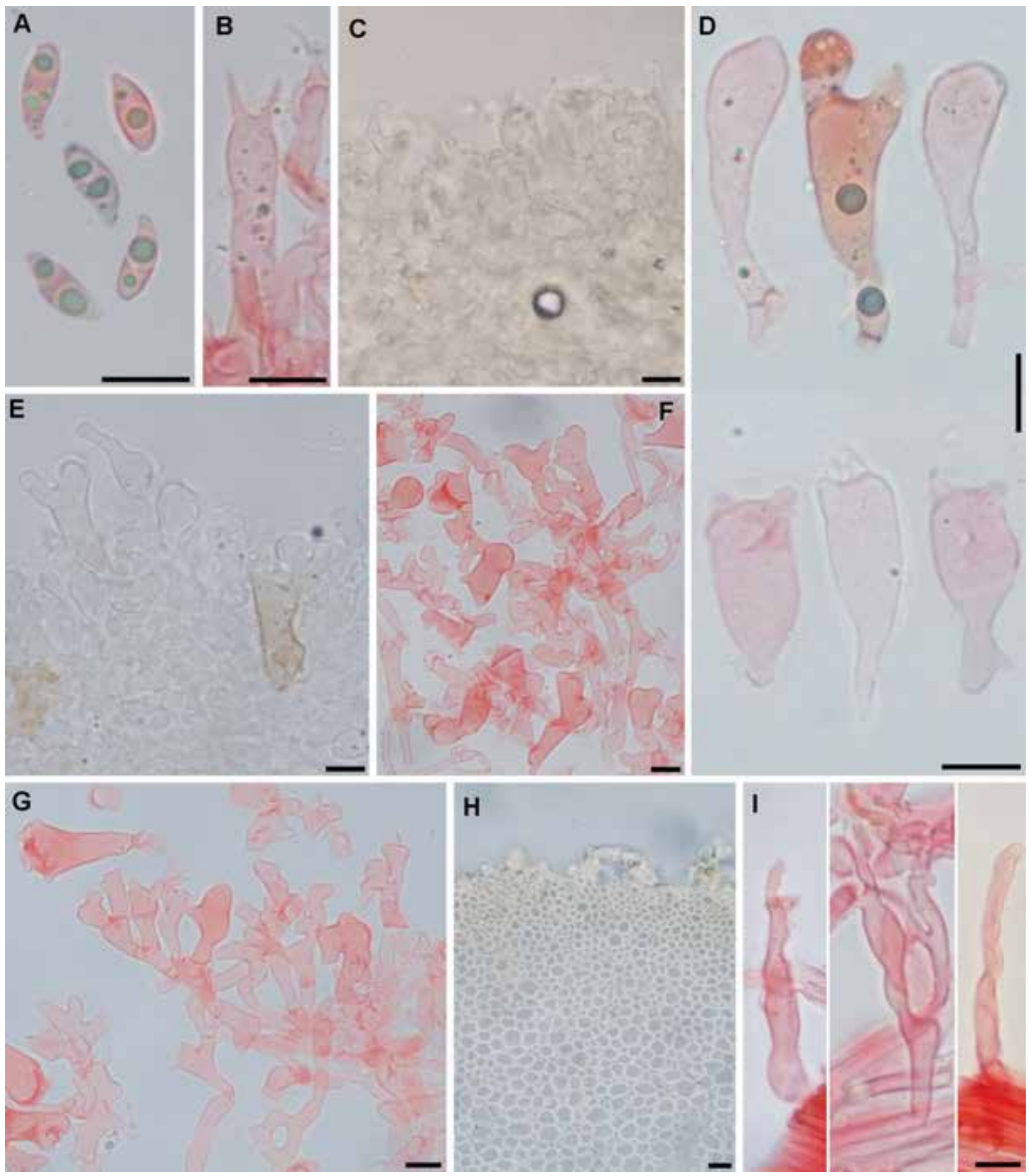

Fig. 38. Mycetinis gramineus ad interim (ARAN-Fungi 13930), caracteres microscópicos. A: Basidiosporas. B: Basidio bispórico. C: Arista laminar mostrando queilocistidios, en agua. D: Queilocistidios. E: Elementos de la pileipellis. F: Elementos de la pileipellis. G: Elementos de la pileipellis. H: Sección del estípite. I: Pelos caulinares. Barras de escala $10 \mu \mathrm{m}$. Medio de montaje A, D, F, G, I: Rojo Congo en SDS; E, H: KOH. Fotografías I. Olariaga.

mentos de la pileipellis similares. Sin embargo, $M$. subalpinus posee un píleo rojo oscuro, sus basidiosporas son más anchas $(5-6,2 \mu \mathrm{m})$ y crece sobre ramas de Rhododendron (MOREAU 2007). Mycetinis applanatipes (Desjardin) A.W. Wilson \& Desjardin es también una especie próxima a nuestro material, pero se caracteriza por sus basidiomas de color más oscuro, por sus basidiosporas más cortas y más anchas, sus queilocistidios psubclavioco diferenciados y fructificar en hojarasca de coníferas (PETERSEN \& HUGHES 2017).

Tras revisar literatura actualizada acerca del género Mycetinis (ANTONÍN \& NOORDELOOS 2010; PETERSEN \& HUGUES 2017), concluimos 


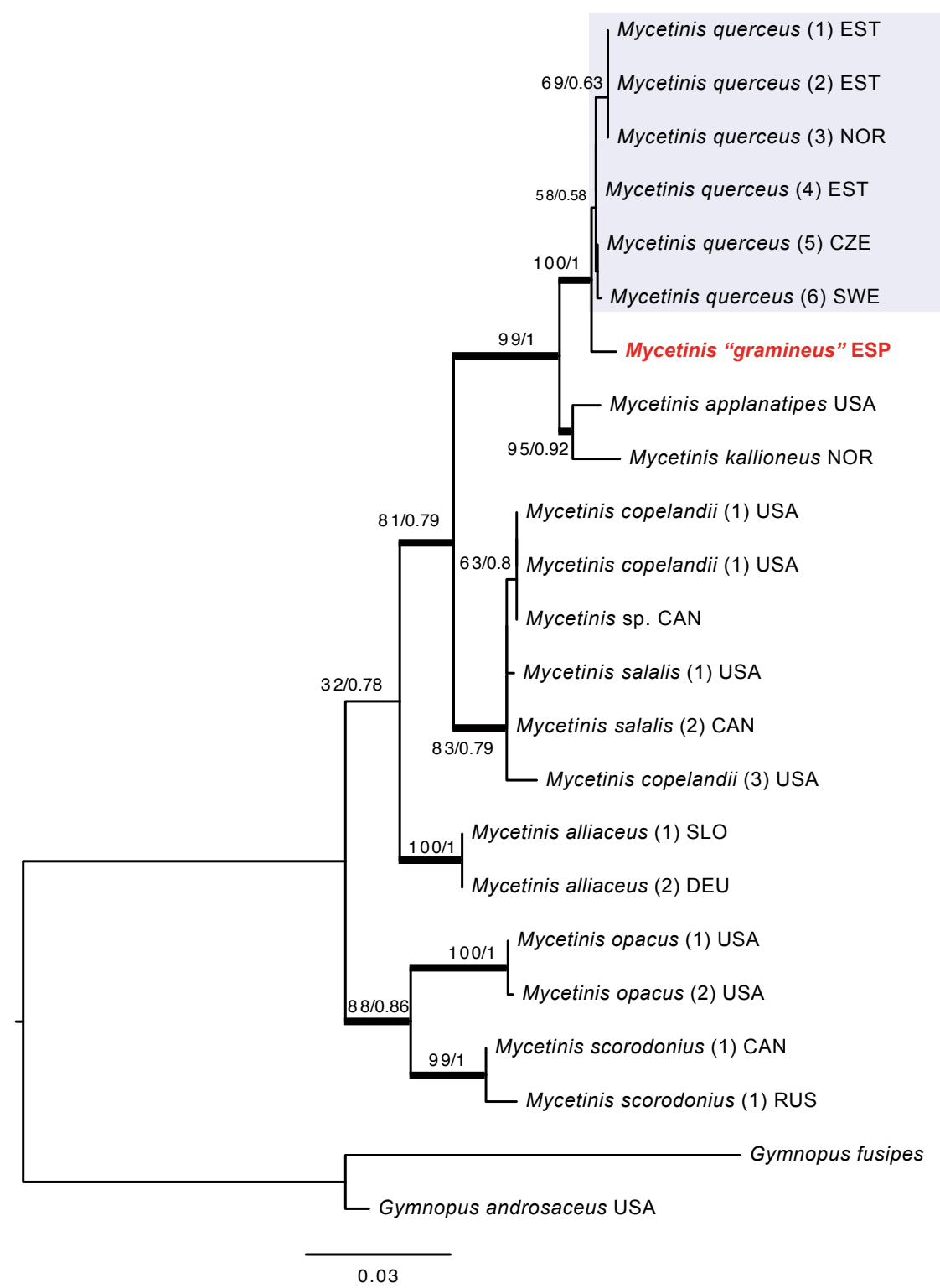

Fig. 39. Árbol más probable inferido mediante el análisis de máxima verosimilitud (ML) de las regiones ITS-28S del rDNA en especies de Mycetinis. Se muestran los valores bootstrap-ML / probabilidad posterior del análisis bayesiano alrededor de las ramas. Las ramas gruesas indican los nodos con apoyo filogenético al menos en un análisis (valores bootstrap $\geq 70 \%$ o probabilidad posterior $\geq 0.95$ ). El recuadro azul muestra el clado con especímenes típicos de $M$. querceus, mientras que la muestra descrita en el artículo se destaca en negrita y color rojo. Se emplearon secuencias de Gymnopus fusipes y G. androsaceus para enraizar el árbol. El país de origen de cada colección se abrevia mediante códigos ISO.

que nuestro material no pertenece a ninguna de las especies descritas en el género hasta la fecha. Sin embargo, dado que conocemos una única recolección y la variabilidad de los caracteres diagnósticos, tanto morfológicos como moleculares no ha podido ser evaluada, preferimos describir Mycetinis gramineus con un nombre provisional sin valor nomenclatural, a la espera de poder encontrar más material y poder proponerla formalmente como especie nueva. 
Tabla 3.

Comparación del material descrito aquí como Mycetinis gramineus y las descripciones de M. querceus de

ANTONÍN \& NOORDELOOS (2010) y PETERSEN \& HUGUES (2017).

\begin{tabular}{|c|c|c|c|}
\hline & Mycetinis gramineus & $\begin{array}{l}\text { Mycetinis querceus } \\
\text { (Antonín \& Noordeloos) }\end{array}$ & $\begin{array}{l}\text { Mycetinis querceus } \\
\text { (Petersen \& Hughes) }\end{array}$ \\
\hline Diámetro píleo & $5-10 \mathrm{~mm}$ & (10)15-28(-40) & $(5) 15-28(40)$ \\
\hline Número de láminas & $16-18$ & $19-28$ & $18-28$ \\
\hline Basidiosporas & $(8-) 9-12 \times 3,5-4,5(-5) \mu \mathrm{m}$ & $(7-) 8-10,5(-12,5) \times 3,5-5,5(6) \mu \mathrm{m}$ & $(7-) 9-10,5(-12,5) \times(3,5-) 4-5,5(-6) \mu \mathrm{m}$ \\
\hline Basidiosporas $\left(\mathbf{Q}_{\mathrm{m}}\right)$ & 2,54 & 2,2 & 1,97 \\
\hline Arista & estéril, homómera & fértil & fértil \\
\hline Queilocistidios & $\begin{array}{l}\text { con apéndices digitiformes, } \\
\text { en ocasiones ramificados }\end{array}$ & ausentes & $\begin{array}{c}\text { no diferenciados, pero } \\
\text { estructuras claviformes a } \\
\text { subampuliformes presentes }\end{array}$ \\
\hline $\begin{array}{l}\text { Elementos } \\
\text { pileipellis }\end{array}$ & $\begin{array}{l}\text { poliformos, con el } \\
\text { ápice ramificado o con } \\
\text { protuberancias digitiformes }\end{array}$ & $\begin{array}{l}\text { claviformes, piriformes, } \\
\text { vesiculosos, ocasionalmente } \\
\text { ligeramente lobulados }\end{array}$ & $\begin{array}{l}\text { de obpiriformes a } \\
\text { vesiculosos, ventrudo- } \\
\text { rostrados a anchamente } \\
\text { claviformes, lobulados }\end{array}$ \\
\hline Caulocistidios & $\begin{array}{l}\text { de cilíndricos y simples a } \\
\text { ramificados desde la base 1-2 } \\
\text { veces }\end{array}$ & $\begin{array}{l}\text { cilíndricos, lageniformes, a } \\
\text { veces subclaviformes }\end{array}$ & $\begin{array}{l}\text { sinuosos, ramificados } \\
\text { ocasionalmente }\end{array}$ \\
\hline Ecología & hojas muertas de Festuca sp. & $\begin{array}{l}\text { especialmente Quercus, } \\
\text { también en Fagus y Carpinus }\end{array}$ & $\begin{array}{l}\text { principalmente Quercus, } \\
\text { ocasionalmente en Fagus, } \\
\text { Betula, Carpinus, etc. }\end{array}$ \\
\hline
\end{tabular}

Paraxerula caussei (Maire) R.H. Petersen, Petersen \& Hughes, Nova Hedwigia, Beih. 137: 303. 2010.

=Xerula caussei Maire, Bull. Trimest. Soc. Mycol. France 53: 265. 1937.

Figs. 40-41

Basidioma colibioide de tamaño medio. Píleo convexo, aplanado y algo mamelonado, de $40 \mathrm{~mm}$ de diámetro. Superficie de color gris a pardo grisáceo, finamente velutina o pruinosa. Margen regular, agudo, concolor, algo excedente. Himenóforo con láminas adnatas o sublibres, ventrudas, espaciadas y algo intervenadas, de color blanco; arista concolor entera. Esporada blanca. Estípite cilíndrico y radicante de $90 \times 50 \mathrm{~mm}$, macizo, con la superficie gris tomentosa como el píleo, pruinosa y blanquecina en la proximidad de las láminas; aproximadamente la mitad de su longitud enterrada o a modo de pseudorizoide. Contexto escaso y fibroso, blanco. Olor nulo.

Basidiosporas de anchamente elipsoides a ovoides de 8-11 × 6-8 $\mu \mathrm{m}\left(\mathrm{Q}_{\mathrm{m}}=1,4\right)$; lisas, hialinas, con pared delgada o moderada. Basidios claviformes de 40-55 × 7-9 $\mu \mathrm{m}$, con (2-)4 esterigmas y con fíbula basal. Pleurocistidios dispersos, fusiformes con cuello largo y extremo distal subcapitado, de 60-100(-150) $\times 10-16 \mu \mathrm{m}$, hialinos de pared moderada. Queilocistidios similares. Hifas de la trama de 3-9 $\mu \mathrm{m}$ de anchura, hialinas, de pared delgada, fibuladas; en contexto sarcodimítico, con elementos hinchados y constreñidos en los septos de hasta $35 \mu \mathrm{m}$ de anchu-

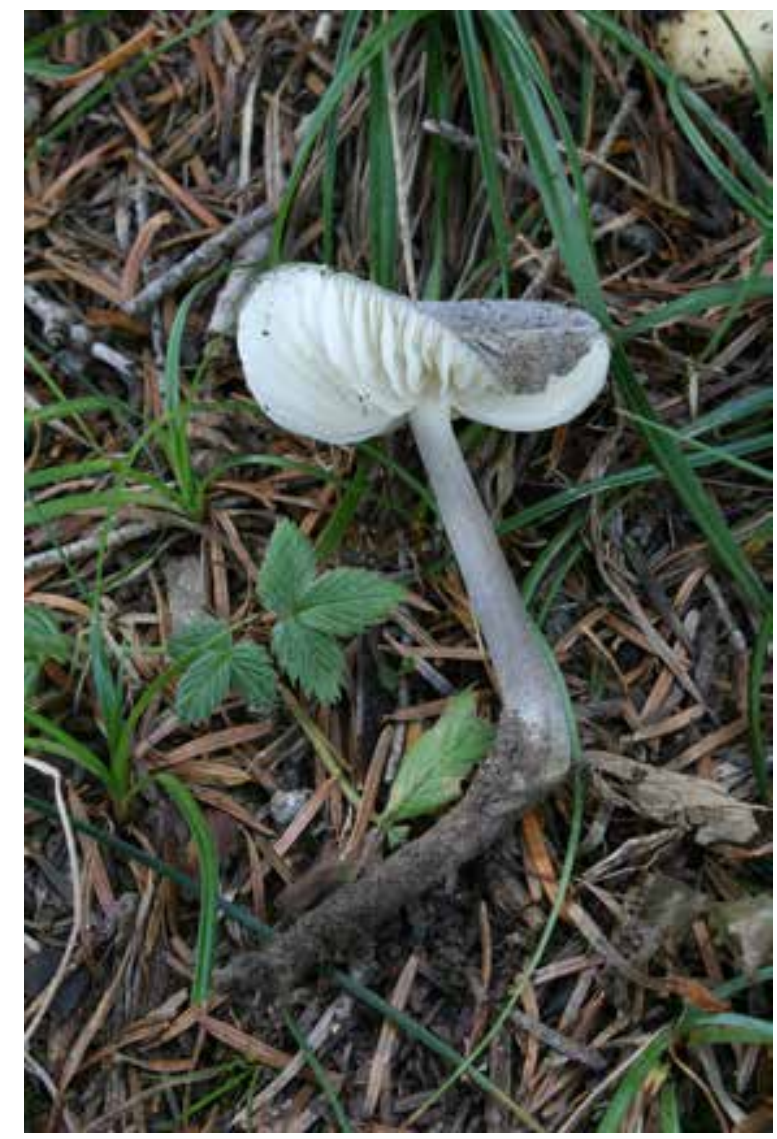

Fig. 40. Paraxerula caussei (AH 48628). Basidioma ex situ. Fotografía P. Pérez Daniëls. 

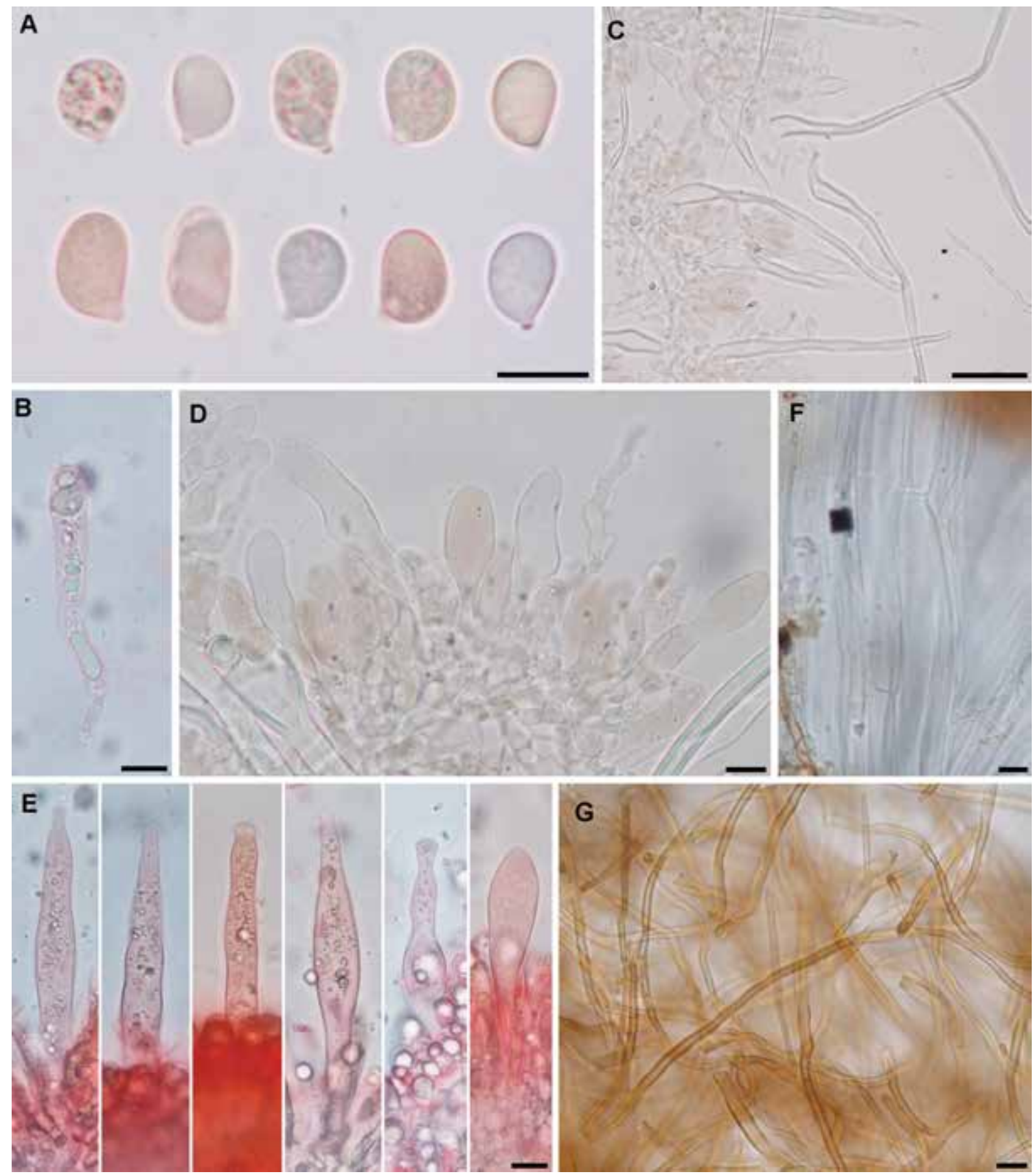

Fig. 41. Paraxerula caussei (AH 48628). Caracteres microscópicos. A: Basidiosporas. B: Basidio. C: Pileipellis mostrando células claviformes y pelos. D: Células claviformes de la pileipellis. E: Pleurocistidios. F: Hifas de un rizomorfo. G: Hifas de la superficie de un rizomorfo. Barras de escala $10 \mu \mathrm{m}$, excepto C $50 \mu \mathrm{m}$. Medio de montaje A, B, E: Rojo Congo en SDS; C, D, F, G: KOH. Fotografías P. Pérez Daniëls \& I. Olariaga.

ra. Pileipellis formada por una himenipellis de elementos claviformes o esferopedunculados de 30-55 $\times 10-12 \mu \mathrm{m}$, con pared delgada a moderada, hialinos o algo coloreados del que se proyectan pelos ventricosos (pileosetas) de 130-410 × 13-18 $\mu \mathrm{m}$ y con 5-6 $\mu \mathrm{m}$ de anchura en la prolongación subulada; hialinos y de pared gruesa y refringente de hasta $4 \mu \mathrm{m}$, con una fíbula amplia, anular, en la base. Stipitipellis con caulosetas similares a las del píleo, dispuestas sobre un cutis de hifas paralelas de 5-18 $\mu \mathrm{m}$ de anchura, hialinas, de pared delgada a moderada.

Material estudiado: ESPAÑA. Huesca: Seira, Barbaruéns, barranco de Trigars, 42.525807 
$0.384003( \pm 10 \mathrm{~m}), 1420 \mathrm{~m}$, bajo Abies alba en bosque de Abies alba con Fagus sylvatica, 28-IX-2018, leg. P.P. Daniëls, det. PP. Daniëls \& I. Olariaga, Daniëls 3520 (AH 48628)(ITS Genbank MW248495; LSU MW248517).

Comentarios: Paraxerula caussei se caracteriza por la superficie del píleo y el estípite cubierto de una pruinosidad de aspecto plateado. Microscópicamente sus esporas son lisas, y presenta setas en el píleo y estípite. El material citado aquí constituye la segunda cita en el territorio, ya que existe una recolección previa de Navarra (ARAN-Fungi A5266513). En Europa se encuentra citado en algunos países como Alemania, Austria, Bélgica, Croacia, Dinamarca, Eslovaquia, Francia, Inglaterra, Italia, Suiza y Ucrania (PETERSEN \& HUGHES 2010). Por su rareza está incluida en algunas listas rojas como en Austria o Suiza y se conocen apenas 117 poblaciones en el mundo (KRISAI-GREILHUBER 2019). Xerula pudens (Pers.) Singer tiene las pileosetas lanceoladas y coloreadas; además el color del píleo y estípite no es gris oscuro sino ocre.

Es una especie saprobia que suele crecer sobre las raíces muertas de bosques climácicos de Fagus sylvatica en suelo básico, algo arcilloso.

Ramaria broomei (Cotton \& Wakef.) R.H. Petersen, Bibliotheca Mycol. 79: 53. 1981.

= Clavaria broomei Cotton \& Wakef., Trans. Brit. Mycol. Soc. 6(2): 170. 1919. [“1918”].

Fig. 42

Basidiomas ramificados, de obcónicos a obovoides, de 60-100 × 30-50 mm aunque al crecer juntos pueden aparentar un tamaño mayor. Base tomentosa, subbulbosa, robusta de hasta $20 \mathrm{~mm}$ de grosor; tomento basal conspicuo, algodonoso y blanco. Estípite a veces definido, corto, turbinado, concolor con las ramas. Ramificación policótoma, rara vez dicótoma o tricótoma al madurar, generalmente en $\mathrm{U}$ al madurar; rango de ramificación de 2-4(-5) con entrenudos que se acortan bruscamente hacia los ápices; ramas cortamente cilíndricas, agrupadas, de 2-7 mm de diámetro; de color amarillo anaranjado a pardo oliváceo; al envejecer o al roce tornan púrpura primero y pardo oscuro o negro después, quedando los basidiomas negros en la vejez. Esporada de color naranja. Ápices obtusos, multicuspidados; al principio de color amarillo, luego del mismo color que las ramas. Contexto fibroso; blanco y marmóreo, al corte se torna purpúreo hacia el borde; sabor amargo y olor fúngico.

Basidiosporas subfusiformes, de 15-22 × 5-6 $\mu \mathrm{m}$ $\left[Q_{m}=3,1\right]$, pared esporal delgada o algo engrosada, amarillo olivácea al M.O., ornamentada con numerosas espinas triangulares de base ancha, de hasta 2 $\times 1 \mu \mathrm{m}$. Basidios largamente claviformes, con fíbula basal, de 50-65 × 7-8 $\mu \mathrm{m}$, con 2 esterigmas. Hifas generativas, con fíbulas, con septos en parte ampuliformes de 8-12 $\mu \mathrm{m}$ de diámetro; hifas de los cordones miceliares de 1,5-3 $\mu \mathrm{m}$ de anchura, con pared delga$\mathrm{da}$, en su zona externa con incrustaciones cristalinas aciculares de hasta $20 \mu \mathrm{m}$ de largo, abundantes; en la trama puede haber también cristales dispersos de hasta $55 \times 4 \mu \mathrm{m}$. Hifas secretoras en la trama y en los cordones miceliares, de 2-5 $\mu \mathrm{m}$ de anchura.

Material estudiado: ESPAÑA. Huesca: Eriste, Casas de Conques, selva de Conques, 42.579570 0.498203 ( $\pm 10 \mathrm{~m}), 1185 \mathrm{~m}$, en bosques de Quercus pubescens con Buxus sempervirens y Corylus avellana, 30-IX-2018, leg. P.P. Daniëls, Daniëls 3503 (AH 48625) (ITS Genbank MW248496).

Comentarios: Ramaria broomei se caracteriza por las ramas que se manchan de púrpura, por sus esporas provistas de espinas, basidios bispóricos y micelio basal cubierto de cristales aciculares. El cambio de color de la carne a púrpura y negro lo tiene en torno a la superficie, y poco o nada en la parte interna por lo que debe variar su intensidad por motivos del entorno. La secuencia ITS obtenida coincide plenamente con la de la muestra de Aragüés del Puerto, la cual presentaba un porte menos ramificado y con ápices menos definidos. Por su rareza está propuesta su inclusión en listas rojas de algunos países nórdicos como Noruega, Finlandia y Suecia (NITARE 2020). Ramaria arcosuensis Schild, Brotzu \& Gennari es muy parecida, pero tiene los basidios tetraspóricos y una distribución más meridional, encontrándose en zonas de menor altitud en Cádiz y Gerona.

En la Península Ibérica, hasta la fecha, $R$. broomei parece limitada al Pirineo oscense: Aragüés del Puerto, Lizara (MA-Fungi 79903) y en Yebra de Basa, Santa Orosia, Collado de las Tres Cruces (MA-Fungi 79905, 79906) en donde fructificaban en praderas con Buxus sempervirens con algunos pies de Fagus sylvatica y Abies alba. La muestra actual es la primera para el Valle de Benasque; posiblemente se encuentre también en el Pirineo navarro y catalán. Se conoce de varios países de Europa como Alemania, Finlandia, Francia, Noruega, Suecia, Rusia (Urales) y Suiza; aunque también se ha citado en Japón (NITARE 2020).

Ramariopsis subarctica Pilát, 凶eská Mykol. 25(1): 10. 1971.

=Clavulinopsis subarctica (Pilát) Jülich, Int. J. Mycol. Lichenol. 2(1): 121. 1985.

Fig. 43

Basidiomas gregarios o fasciculados, de $31 \times 27$ $\mathrm{mm}$, bastante robustos, sin estípite bien definido. Ramificación dicótoma, con bifurcaciones en forma de $\mathrm{U}$, con ramas divergentes, con rango de ramificación 

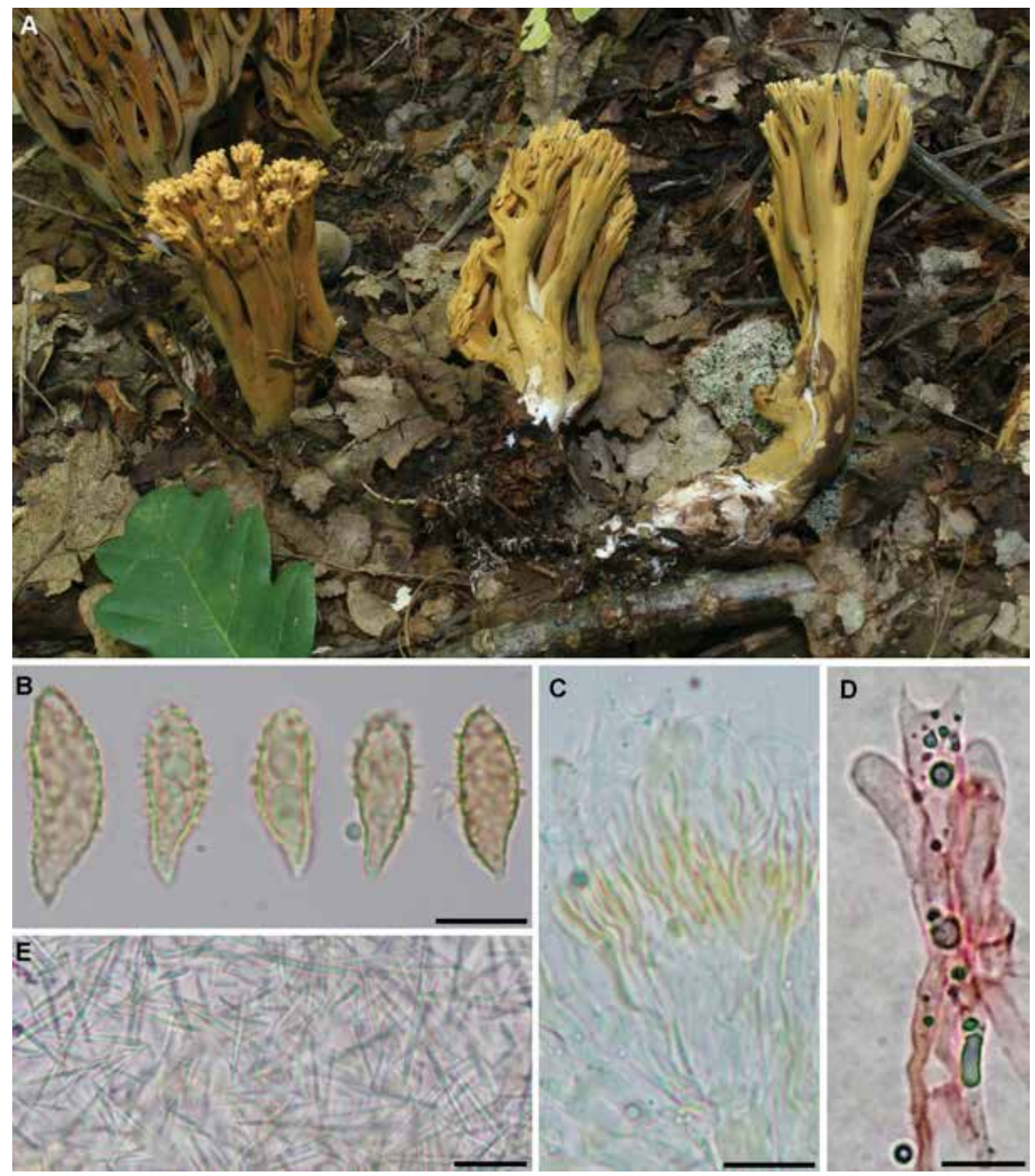

Fig. 42. Ramaria broomei (AH 48625). A: Basidiomas in situ. B: Basidiosporas. C: Porción de himenio mostrando basidios bispóricos, en KOH. D: Basidio bispórico en Rojo Congo amoniacal. E: Cristales aciculares de la superficie de un rizomorfo, en $\mathrm{KOH}$. Barras de escala $10 \mu \mathrm{m}$. Fotografías A, D: P. Pérez Daniëls; B, C, E: P. Pérez Daniëls \& I. Olariaga.

de 1-3. Ramas de cilíndricas a ligeramente comprimidas, lisas o con pequeñas arrugas paralelas al eje de las ramas, de color ocre pálido en fresco y de color ocre en exsiccatum. Ápices obtusos, a veces ligeramente comprimidos, concolores. Estipite 7-16 × 3-8 $\mathrm{mm}$, corto y formado por las bases de las ramas, no claramente diferenciado de la parte fértil, cilíndrico, concolor. Tomento basal presente en la base, blanco. Contexto blanco, sin sabor ni olor definidos. Reacciones macroquímicas no testadas.

Basidiosporas subglobosas, con apículo cúbico $(0,5 \mu \mathrm{m})$, de pared ligeramente gruesa, sublisas o con verrugas bajas, visibles a $1000 \times$, hialinas, no dextrinoides, de 4,5-6 × 3.5-4 $\mu \mathrm{m}\left(\mathrm{L}_{\mathrm{m}}=5,2, \mathrm{~W}_{\mathrm{m}}=3,9\right.$, 

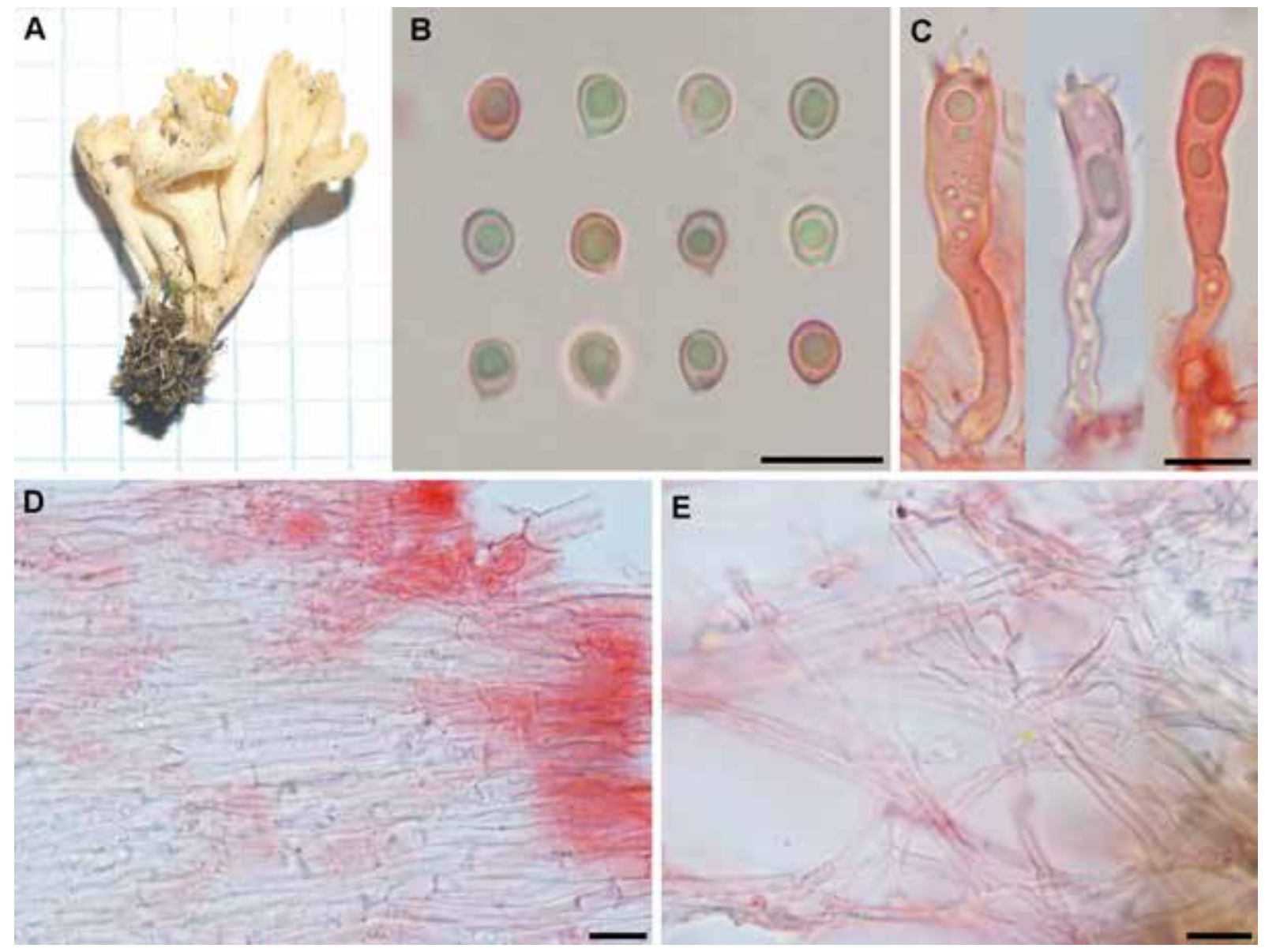

Fig. 43. Ramariopsis subarctica (ARAN-Fungi 13866). A: Basidioma ex situ. B: Basidiosporas. C: Basidios de pared gruesa. D: Hifas del contexto, sin cristales. E: Hifas del sustrato adyacente al tomento basal. Barras de escala: $10 \mu \mathrm{m}$. Medio de montaje: Rojo Congo en SDS. Fotografías I. Olariaga.

$\left.\mathrm{Q}_{\mathrm{m}}=1,36 ; \mathrm{n}=25\right)$. Basidios claviformes, tetraspóricos, fibulados, de 35-46 × 6-8 $\mu \mathrm{m}$, de pared delgada, a veces de pared muy gruesa. Subhimenio formado por hifas entrelazadas, cilíndricas, de pared delgada, fibuladas, de 2-3- $\mu \mathrm{m}$ de diámetro. Hifas del contexto dispuestas paralelamente, de cilíndricas a estrechamente fusiformes, de pared delgada, hialinas, fibuladas, de 2-15 $\mu \mathrm{m}$ de anchura. Cristales ausentes. Tomento basal compuesto de hifas cilíndricas, de pared delgada o ligeramente gruesa, fibuladas, de 2-4 $\mu \mathrm{m}$ de anchura.

Material estudiado: ESPAÑA. Huesca: Benasque, Puerto de la Glera, 42.700760 .60342 ( \pm 50 m), 2370 m, 28-IX-2018, vegetación alpina con $\mathrm{Sa}$ lix herbacea, leg. J. Hernanz, ARAN-Fungi 13866 (LSU Genbank MW248518). SUECIA. Torne Lappmark: Abisko, a $900 \mathrm{~m}$ NW de Abisko tourist station, humedal en cuesta al lado del lago Torne träsk, 68,359090 18,808555 ( \pm 50 m), 6-IX-1985, leg. J. Nitare \& K. Martinsson, UPS F-124183.

Comentarios: Ramariopsis subarctica es una especie caracterizada por sus basidiomas ramificados y compactos, color ocre uniforme, junto con sus basidiosporas grandes y basidios largos (PILÁT 1971) en comparación al resto de especies europeas (OLARIAGA 2009).

El material hallado en los Pirineos coincide con la descripción original de $R$. subarctica, si bien el tamaño de las basidiosporas es ligeramente menor al indicado por PILÁT (1971, 6-8 × 5-6 $\mu \mathrm{m})$, y el observado en el material escandinavo estudiado (I. Olariaga, 5-7 $\times 4.5-6 \mu \mathrm{m}$ ). Así mismo, el tamaño de los basidios de la recolección pirenaica es ligeramente menor al señalado en la descripción original (40-60 $\mu \mathrm{m})$, y el material sueco estudiado aquí (45-60 $\mu \mathrm{m})$. Sin embargo, los basidiomas de color ocre uniforme, los basidios largos, la ausencia de depósitos cristalizados en las hifas del contexto y el hábitat alpino, hacen que 


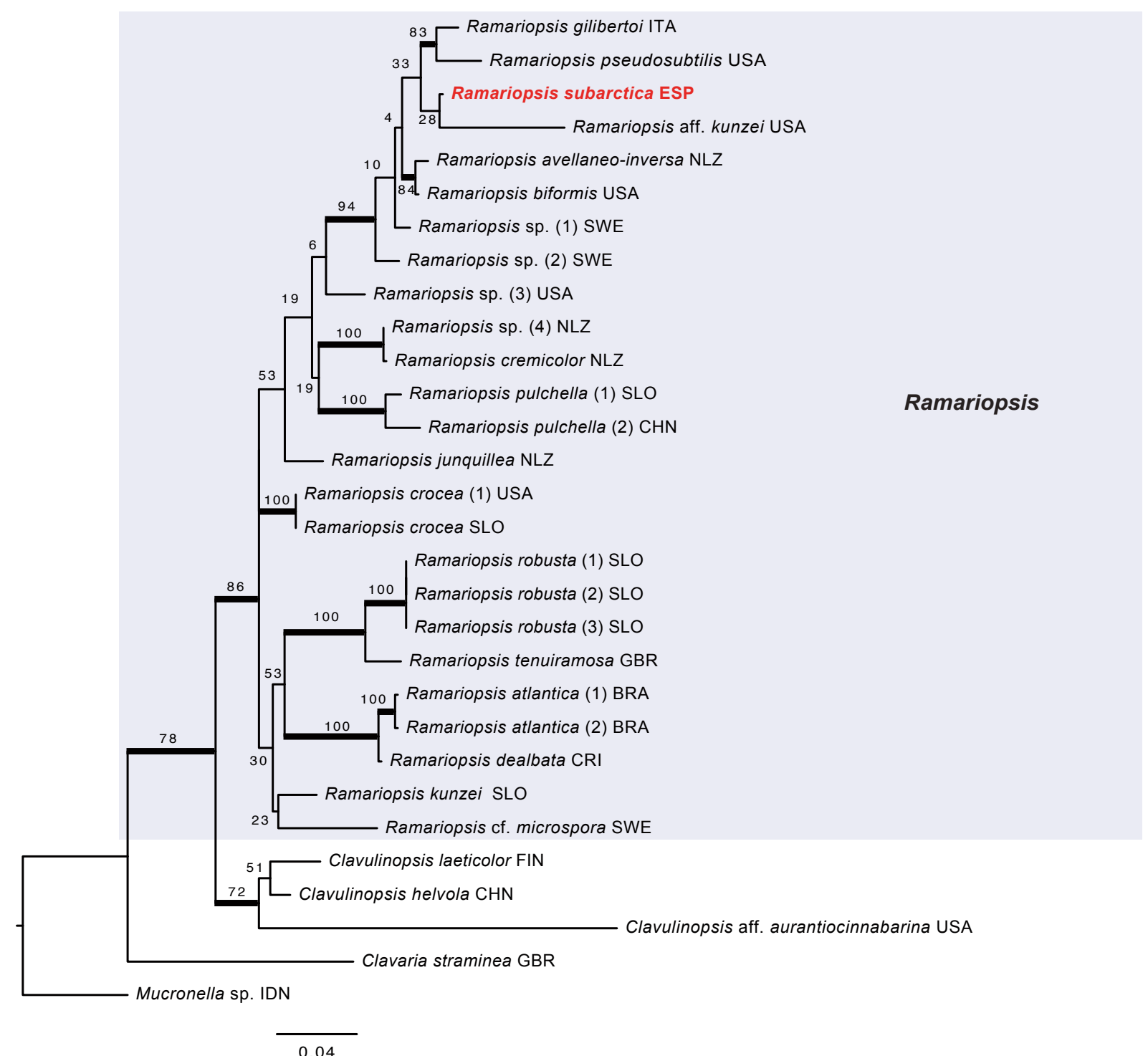

Fig. 44. Árbol más probable inferido mediante el análisis de máxima verosimilitud (ML) de la región 28S del rDNA en especies de Ramariopsis. Se muestran los valores bootstrap-ML. Las ramas gruesas indican los nodos con apoyo filogenético (valores bootstrap $\geq 70 \%$ ). El recuadro azul destaca el clado que contiene las especies de Ramariopsis, mientras que la muestra descrita en el artículo se destaca en negrita y color rojo. Se empleó una secuencia de Mucronella sp. para enraizar el árbol. El país de origen de cada colección se abrevia mediante códigos ISO.

nuestra recolección no pueda atribuirse a ninguna otra especie descrita hasta el momento. Ramariopsis kunzei (Fr.) Corner y $R$. robusta Matouš \& Holec (MATOUS \& al. 2017), se asemejan a $R$. subarctica por el porte bastante robusto y la ausencia de depósitos entre las hifas del contexto, pero difieren por su color blanco y en ocasiones, por presentar manchas rosadas en los basidiomas (OLARIAGA 2009). Los análisis de la región LSU (Fig. 44) respaldan que nuestra recolección pirenaica no pertenece al clado de $R$. kunzei y $R$. robusta, sino a otro formado por especímenes identificados como R. gilibertoi Agnello, $R$. pseudosubtilis R.H. Petersen y R. biformis (G.F. Atk.) R.H. Petersen, entre otros, donde la secuencia $R$. subarctica muestra una divergencia considerable.
Por el momento, no existen secuencias de especímenes escandinavos de $R$. subarctica.

Por tanto, si bien sería conveniente recolectar más material y compararlo molecularmente con material escandinavo, presentamos aquí el primer hallazgo de $R$. subarctica en la Península Ibérica, especie que hasta ahora, se conocía únicamente de Escandinavia según nuestra búsqueda.

Russula azurea Bres., Fung. Trident. 1(2): 20. 1882.

Figs. 45-46

Basidiomas medianos, no muy carnosos. Píleo de 35 a $65 \mathrm{~mm}$ de diámetro en las muestras estudiadas, primero convexo y enseguida aplanado y deprimido 

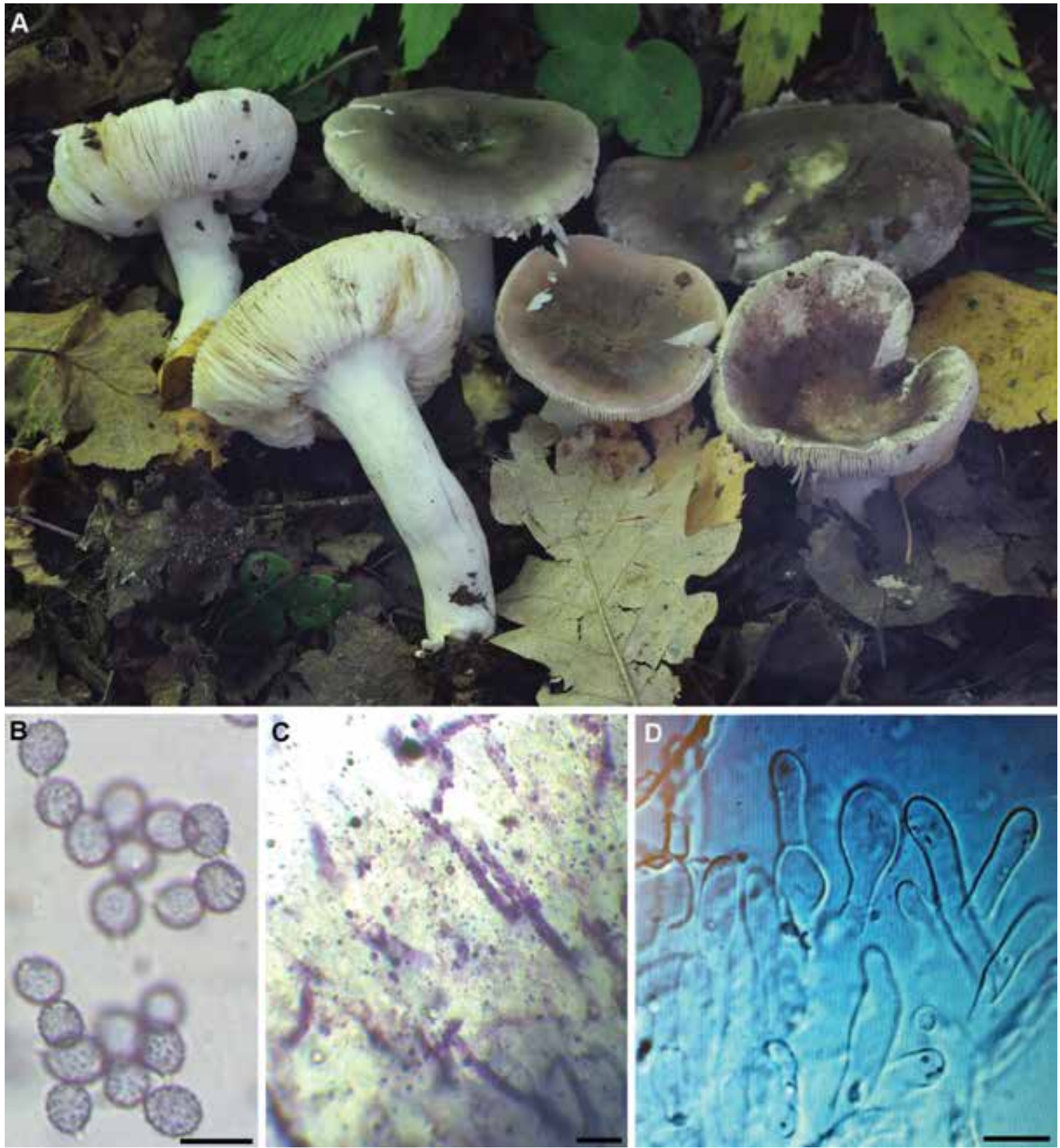

Fig. 45. Caracteres morfológicos de Russula azurea (GSD18.09.27.03). A: Basidiomas. B: Basidiosporas. C: Hifas primordiales incrustadas. D: Pelos de la pileipellis. Barras de escala: $10 \mu \mathrm{m}$. Medio de montaje B: Melzer; C: Fucsina y ácido clorídrico; D: agua. Fotografías G. Sánchez Dueñas.

en el centro, con el margen irregular y algo lobulado. Superficie pileica aterciopelada, pruinosa, seca y ligeramente granulosa en el centro, de color violeta lilacino en algunos ejemplares, verde oliva con zonas rojo oscuro o gris oscuro en otros. Láminas algo espaciadas con la edad, frágiles, blancas, sin lamélulas, con la arista entera. Estípite más o menos cilíndrico, ensanchado en la inserción con las láminas, primero lleno, después esponjoso y poco compacto. Contexto blanco y firme en ejemplares jóvenes, algo frágil al madurar. Sabor dulce, no picante y olor poco apreciable. Reacciones macroquímicas: Reacción positiva a la resina de guayaco. Reacción rosa anaranjado al sulfato de hierro. Con sulfovanillina en el estípite adquiere inicialmente un color rojo fucsia, para al cabo de unos minutos desaparecer, lo que es propio de Russula subsect. Lilacinae. Esporada blanca.

Basidiosporas ovoides con verrugas aisladas en general, algunas unidas con crestas poco gruesas y no muy largas, de $(6,9-) 7,4-8,5(-8,9) \times(6-) 6,3-7,1(-$ 

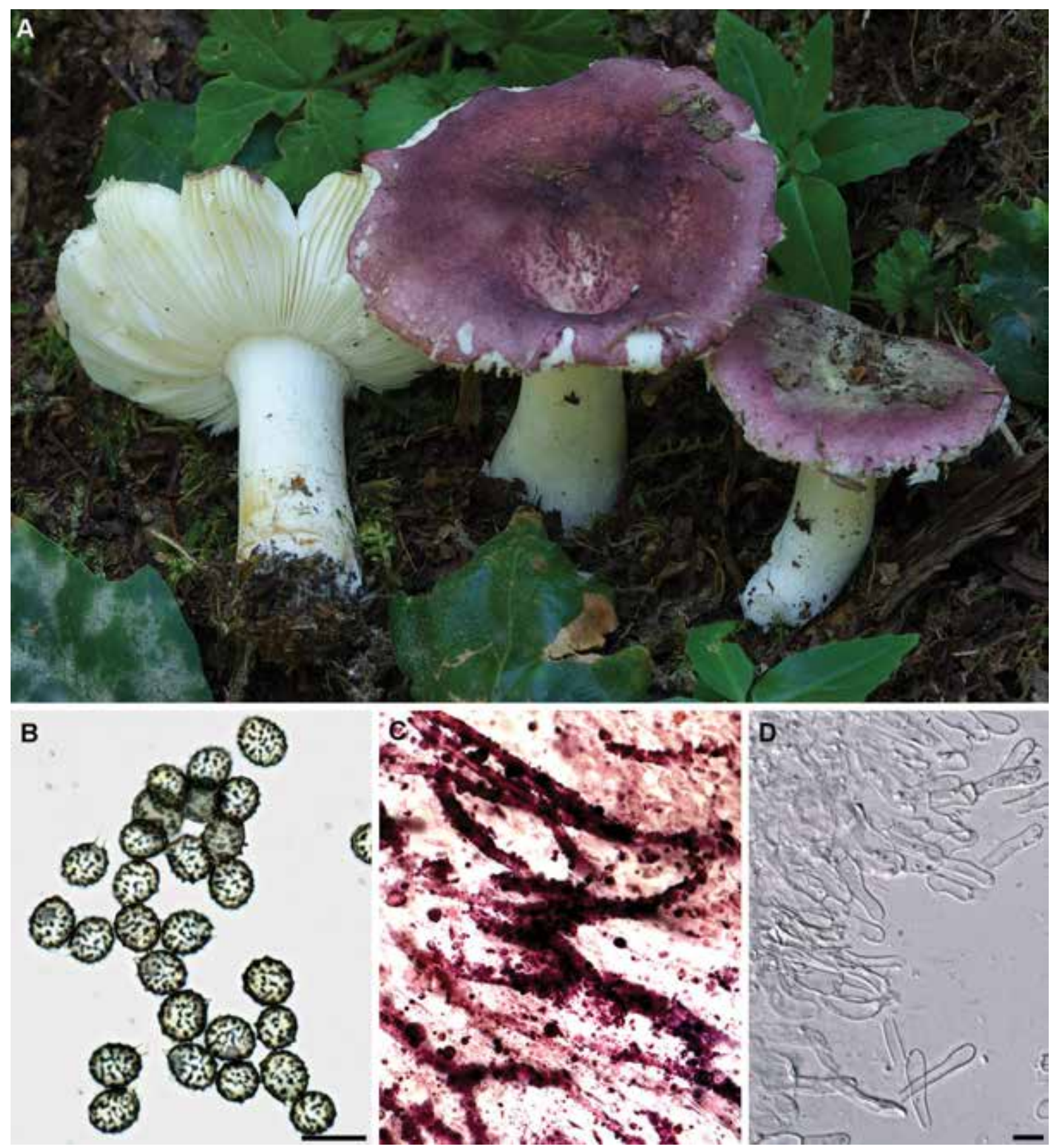

Fig. 46. Caracteres morfológicos de Russula azurea (GSD18.09.27.06). A: Basidiomas. B: Basidiosporas. C: Hifas primordiales incrustadas. D: Pelos de la pileipellis. Barras de escala: $10 \mu \mathrm{m}$. Medio de montaje B: Melzer; C: Fucsina y ácido clorídrico; D: agua. Fotografías A: G. Sánchez Dueñas; B, C, D: J.M. Traba.

7,8) $\mu \mathrm{m}\left(\mathrm{L}_{\mathrm{m}}=8, \mathrm{~W}_{\mathrm{m}}=6,7, \mathrm{Q}_{\mathrm{m}}=1,2\right)$. Pileipellis con hifas incrustadas, como se ponen de manifiesto con la prueba de la fucsina y el lavado en ácido clorídrico, y pelos gruesos de hasta $8 \mu \mathrm{m}$ de ancho.

Material estudiado: ESPAÑA. Huesca: Benasque, Camino del Solano, 42.5739250 .512545 ( \pm $10 \mathrm{~m}), 1750 \mathrm{~m}$, en una zona con Pinus sylvestris y algún Betula sp. cerca, 27-IX-2018, leg. L. Martín Nieto, det. G. Sánchez Dueñas \& J.M. Traba,
GSD18.09.27.03 (dupla in CHT 270918293)(ITS

Genbank MW248497); ibidem, 42.5697520 .509181 ( \pm 10 m), leg. G. Sánchez Dueñas \& J.M. Traba, GSD18.09.27.06 (dupla in CHT 270918294). Salamanca: Guijuelo, Encinar de Casafranca, 40.584535 -5.762264 ( $\pm 300 \mathrm{~m})$, bosque mixto con Quercus Ilex y Quercus rotundifolia 16-VI-2018, leg. C. Monedero \& J.M. Traba, det. J.M. Traba, CHT 180618271 (ITS Genbank MW286832). 


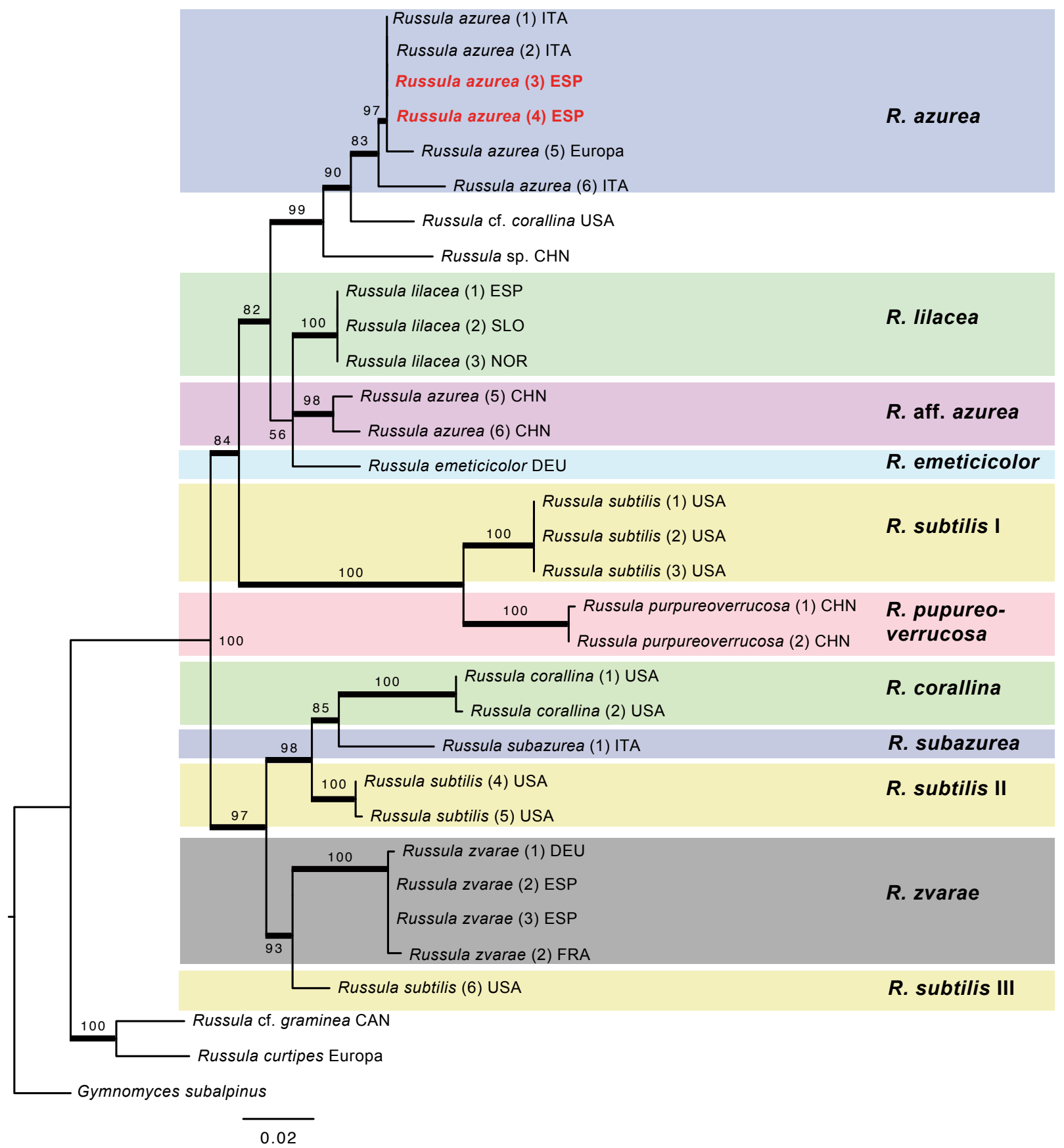

Fig. 47. Árbol más probable inferido mediante el análisis de máxima verosimilitud (ML) de la región ITS del rDNA en Russula azurea y especies afines de la Russula sect. Lilaceinae. Se muestran los valores bootstrap-ML. Las ramas gruesas indican los nodos con apoyo filogenético (valores bootstrap $\geq 70 \%$ ). Los recuadros marcan especies o complejos de especies, mientras que la muestra descrita en el artículo se destaca en negrita y color rojo. Se empleó una secuencia de Gymnomyces subalpinus para enraizar el árbol. El país de origen de cada colección se abrevia mediante códigos ISO.

Comentarios: Las hifas de la pileipellis incrustadas, la ausencia de dermatocistidios, la esporada blanca y la reacción fugaz con sulfovanillina permiten incluir R. azurea en Russula subg. Incrustatula, y dentro de este en $R$. sect. Lilaceinae y $R$. subsect. Lilaceinae (SARNARI 2005). Dentro de esta subsección, hay dos especies que podrían por sus hábitat y características identificarse con nuestras recolectas: R. lilacea Quél. y R. azurea. Por sus pelos de la pileipellis engrosados ( $>5 \mu \mathrm{m}$, de hasta $8 \mu \mathrm{m}$ en el material citado aquí), nuestro material pertenece a $R$. azurea, puesto que $R$. lilacea posee pelos no engrosados. El análisis de la secuencia de la región ITS obtenida de una de las muestras estudiadas confirma 
la identificación (Fig. 47), ya que la secuencia generada de una de nuestras colecciones cae en el clado de especímenes europeos identificados como $R$. azurea.

Russula azurea es una especie poco común de distribución principalmente septentrional, que se encuentra en el piso subalpino asociada a Picea, Abies alba y menos frecuentemente a Pinus sylvestris. Según nuestra búsqueda, existen dos únicas citas previas publicadas de $R$. azurea en la Península Ibérica, en concreto de Girona (LLISTOSELLA 1991) y de Huesca (MONEDERO 2011: 378). Existe, además, una tercera recolección de Salamanca recolectada bajo Quercus ilex y Quercus rotundifolia y verifica- da utilizando la región ITS. Por tanto, confirmamos aquí que $R$. azurea está presente tanto en bosques eurosiberianos como mediterráneos.

\section{Russula flavispora Romagn., Russules Europe} Afrique N.: 235. 1967.

Fig. 48

Píleo de 95 a $115 \mathrm{~mm}$ de diámetro, carnoso y compacto, deprimido, embudado a más o menos crateriforme, al final más aplanado. Superficie pileica poco o nada separable, seca y opaca, ligeramente fieltrada, no estriada ni acanalada, de color blanquecino a crema, crema amarillento, especial-
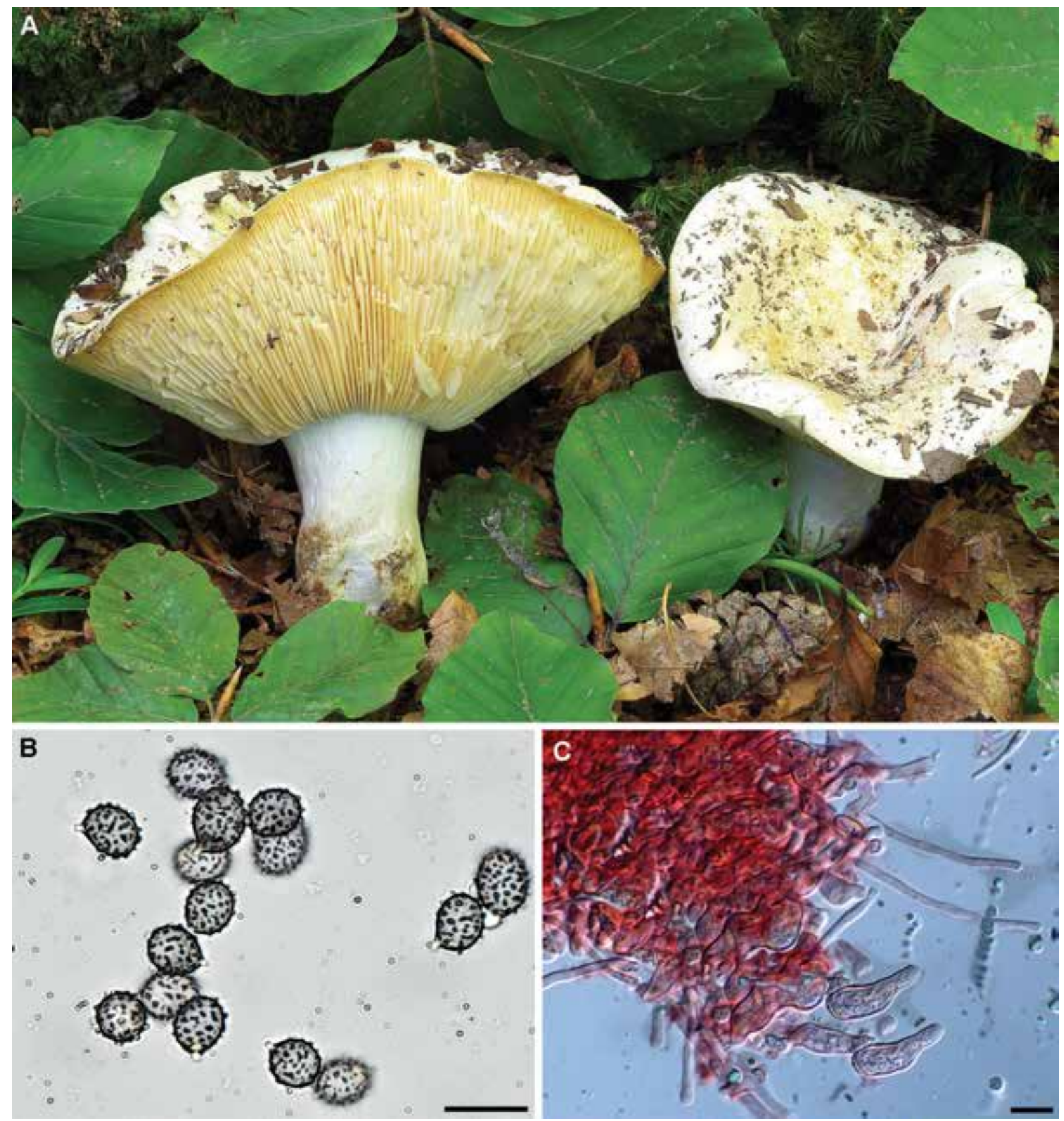

Fig. 48. Caracteres morfológicos de Russula flavispora (CHT 280918298). A: Basidiomas in situ. B: Basidiosporas en Melzer. C: Pileipellis en Rojo Congo. Barras de escala: $10 \mu \mathrm{m}$. Fotografías J.M. Traba. 
mente hacia el centro y con la edad. Láminas poco apretadas, desiguales, estrechas de 4-6 $\mathrm{mm}$, rígidas, frágiles, adnatas-decurrentes, al principio crema, al final ocráceo oscuro bastante intenso que contrasta con el color más pálido del píleo. Esporada amarilla IV-b, según la escala de ROMAGNESI (1953). Estípite duro, robusto, corto de 30-55 × 24-36 mm, cilíndrico, atenuado hacia la base, más o menos liso, ligeramente pruinoso, blanco, al final manchado de pardo amarillento. Contexto grueso y duro, blanco, ocráceo amarillento al aire. Olor complejo, en general no muy agradable, entre afrutado o de pescado en mal estado, sabor acre o muy acre, en todo el carpóforo. Reacción al guayaco rápidamente azul intenso, rosa-salmón al sulfato de hierro. Basidiosporas de obovoides a elipsoidales de $(7,0) 7,5-8,4(8,7) \times$ $(6,1) 6,2-6,9(7) \mu \mathrm{m}\left(\mathrm{L}_{\mathrm{m}}=7,9, \mathrm{~W}_{\mathrm{m}}=6,6 \mu \mathrm{m}, \mathrm{Q}_{\mathrm{m}}=1,2\right)$, equinuladas, de ornamentación formada por verrugas obtuso cónicas, no muy altas, de hasta $0,7 \mu \mathrm{m}$, aisladas, no reticuladas, no crestadas, apenas unidas con algún conectivo disperso, a veces unidas de 2 en 2, placa hilar apenas amiloide. Pileipellis formada en su parte profunda por hifas voluminosas, algunas ampuliformes. Epicutis con pelos muy largos, banales, de 2-3 $\mu$ m y dermatocistidios cilíndricos, bastante largos de hasta 5-6 $\mu \mathrm{m}$ de anchura.

Material estudiado: ESPAÑA. Huesca: Seira, Barbaruéns, barranco de Trigars, 42.525870 .381495 $( \pm 10 \mathrm{~m})$, bajo Fagus sylvatica y Pinus sylvestris, terreno calcáreo, 28-IX-2018, leg. et det. J. M. Traba, CHT 280918298 (ITS Genbank MW248498).

Comentario: Esta especie de tamaño medio-grande, hasta $115 \mathrm{~mm}$ en esta colección, se encuadra "de visu" en $R$. subg. Compactae por su porte robusto, su carne dura, sus colores no vistosos y su cutícula seca; por su forma típicamente embudada-crateriforme, coloraciones pálidas y carne inmutable se incluye en Russula sect. Lactarioides. Sus láminas amarillo pálido más evidentes en la madurez y únicas en este grupo, nos alejan de Russula delica y Russula chloroides de láminas más pálidas, blanquecinas a crema pálido. La especie más parecida es Russula pallidospora cuyas láminas pueden alcanzar tonalidades ocres, incluso con reflejos anaranjados (SARNARI 2005), pero ésta tiene sabor dulce y olor agradable, mientras Russula flavispora es de sabor intensamente picante en todo el carpóforo, de las más picantes de todas las $R$. subg. Compactae. Posee además un olor más complejo y en general desagradable, con matices afrutados y a pescado descompuesto, especialmente en la madurez. Russula pallidospora tiene esporada crema, IIc o IId a lo sumo, mientras $R$. flavispora nos lleva a una esporada amarillo pálido IVa-b. Microscópicamente se diferencia muy bien de $R$. delica, $R$. chloroides y sus variedades, especialmente por la forma y tamaño de sus esporas, ya que $R$. flavispora posee una espora pequeña, no mayor de $9 \mu \mathrm{m}$ para esta recolecta, con verrugas equinuladas y aisladas, mientras las especies vecinas lo son reticuladas y de mayor tamaño, de hasta 11 micras o más. En el caso de $R$. pallidospora posee una espora ligeramente mayor, pluricebrada a subreticulada. La pileipellis de Russula flavispora presenta pelos filiformes de no más de 3 micras de ancho y dermatocistidios cilíndricos, largos o muy largos, no septados, destaca especialmente la presencia en capas más profundas de artículos ensanchados, ampuliformes, de hasta $9 \mu \mathrm{m}$ en esta colección. La búsqueda BLAST de la secuencia ITS obtenida de nuestro material de $R$. flavispora no obtiene ningún resultado con una similitud superior al $90 \%$, hecho que se debe a que no existe ninguna secuencia de $R$. flavispora en bases de datos públicas. El análisis de la región ITS (Fig. 49) confirma que $R$. flavispora pertenece a la Russula sect. Lactarioides, formando un clado con apoyo (ML-bootstrap $90 \%$ junto a las especies del complejo $R$. delica- $R$. chloroides. Curiosamente, $R$. pallidospora ocupa una posición basal al mencionado clado.

Russula flavispora está considerada como una especie rara en Europa y ecológicamente se ha descrito bajo diferentes y numerosas especies arbóreas, especialmente bajo Fagaceae y Betulaceae, en terrenos arcillosos, húmedos y algo calizos. Se ha descrito bajo Fagus sylvatica, Quercus robur, Q. suber, Q. ilex, $Q$. suber, Q. pubescens, Corylus avellana o Carpinus betulus entre otros y especialmente en bosques mixtos, en Italia se ha descrito creciendo bajo Carpinus betulus, Ostrya carpinifolia y Quercus robur (CHIARELLO \& BATTISTIN 2013), bajo Quercus sp. y Fagus sp, (GALLI 1996; SARNARI 1984, 1998); en Francia bajo $Q$. robur y Tilia sp. la describen Romagnesi y Dagron (MAXMULLER 2014). También se han descrito colecciones en Alemania o Eslovenia. Con respecto a la Península Ibérica $R$. flavispora se conocía previamente de tres localidades en la provincia de Barcelona (LLISTOSELLA \& al. 2008).

Russula laccata Huijsman, Fungus 25: 40. 1955.

Fig. 50

Basidiomas pequeños de carne poco compacta. Píleo de 15-25 mm de diámetro, primero convexo, luego aplanado y algo deprimido en el centro, siendo algunos ejemplares claramente mamelonados, con el margen ligeramente acanalado e irregular. Superficie pileica de color rojo púrpura o violeta púrpura que en los ejemplares recogidos se han aclarado por zonas debido a la acción del sol. Láminas algo espaciadas, blancas, con alguna lamélula intercalada, con la arista entera y no aserrada. Esporada blanquecina. Estípite de 17-30 × 7-12 mm, más o menos cilíndrico y ensanchado en la base, algo arrugado y blanco, con alguna mancha amarillenta hacia la base, con 


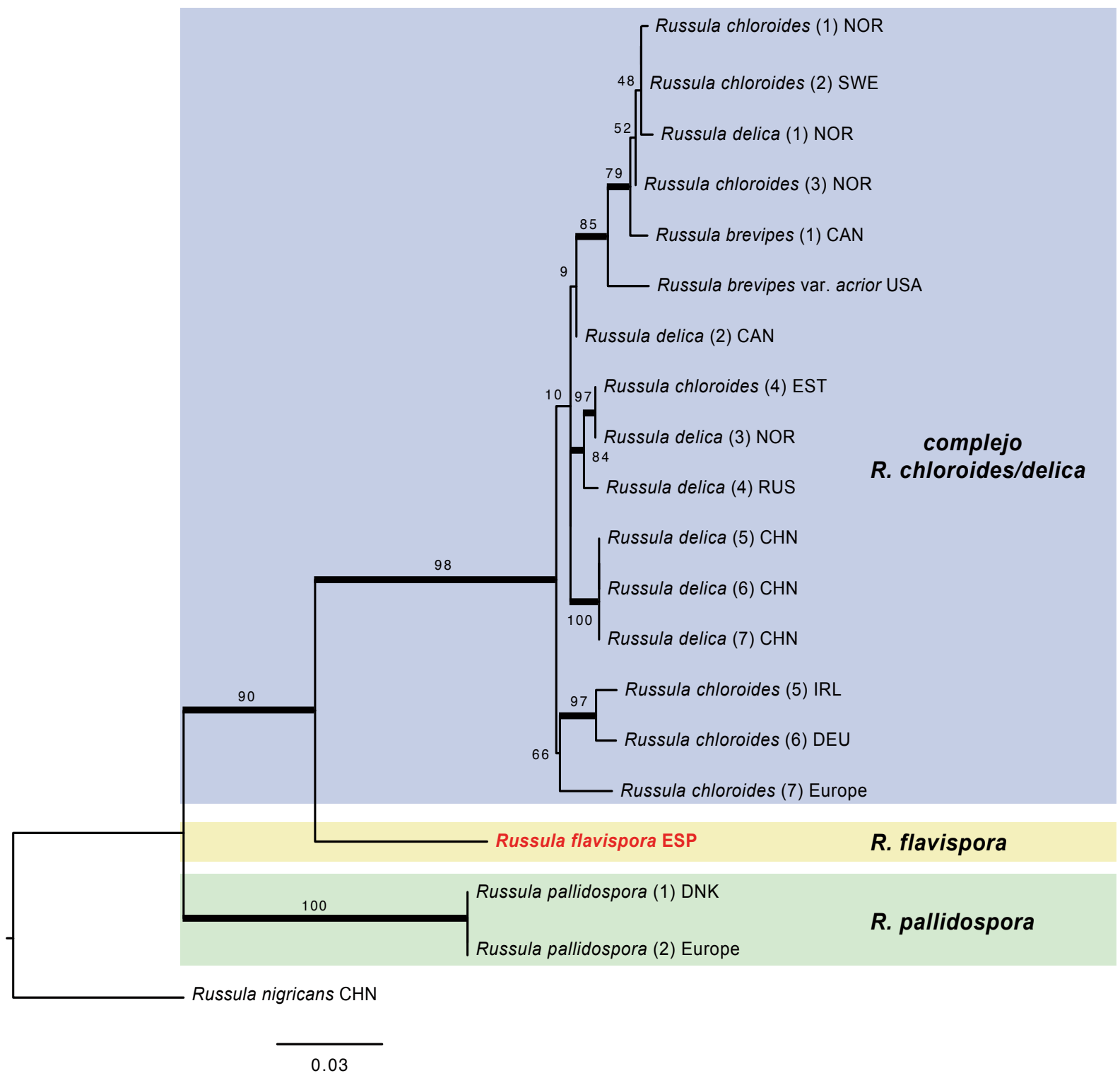

Fig. 49. Árbol más probable inferido mediante el análisis de máxima verosimilitud (ML) de la región ITS del rDNA en Russula flavispora y especies afines de Russula sect. Lactarioides. Se muestran los valores bootstrap-ML. Las ramas gruesas indican los nodos con apoyo filogenético (valores bootstrap $\geq 70 \%$ ). Los recuadros marcan especies o complejos de especies, mientras que la muestra descrita en el artículo se destaca en negrita y color rojo. Se empleó una secuencia de Russula nigricans para enraizar el árbol. El país de origen de cada colección se abrevia mediante códigos ISO.

matices rojizo-rosados en algún ejemplar. Contexto blanco y algo frágil, claramente picante y olor poco apreciable. Reacciones macroquímicas: Resina de guayaco positivo, no rápido; sulfato de hierro banal.

Basidiosporas obovoides con verrugas bajas, reticuladas, placa hilar no amiloide, de (6,5-)6,7$8,1(-8,5) \times(5,2-) 5,3-6,2(-7) \mu \mathrm{m}\left(\mathrm{L}_{\mathrm{m}}=7,5, \mathrm{~W}_{\mathrm{m}}=5,8\right.$, $\mathrm{Q}_{\mathrm{m}}=1,3 ; \mathrm{n}=35$ ). Pileipellis con dermatocistidios presentes, cilíndricos o claviformes.

Material estudiado: ESPAÑA. Huesca: Benasque, Puerto de la Glera, 42.700760 .60342 ( $\pm 20 \mathrm{~m}$ ), 2370 $\mathrm{m}$, vegetación alpina con Salix herbacea y Vaccinum uliginosum, 28-IX-2018, leg. J. Hernanz, det. J.M.
Traba \& G. Sánchez Dueñas, GSD18.09.27.08 (dupla in CHT 270818297)(ITS Genbank MW248499).

Comentarios: Russula laccata es una especie común en países nórdicos, asociada en ellos a la vegetación riparia con Salix sp., aunque también se encuentra en regiones alpinas asociada a sauces enanos. Según la clasificación de SARNARI (2005), R. laccata pertenece a Russula estirpe Atropurpurea, junto con $R$. fragilis y $R$. atrorubens y otras especies con las que podría confundirse. Russula fragilis, además de no estar asociada a sauces en ambiente alpino y poseer un tamaño más grande, difiere de $R$. laccata por sus aristas laminares aserradas y una reacción nula al 

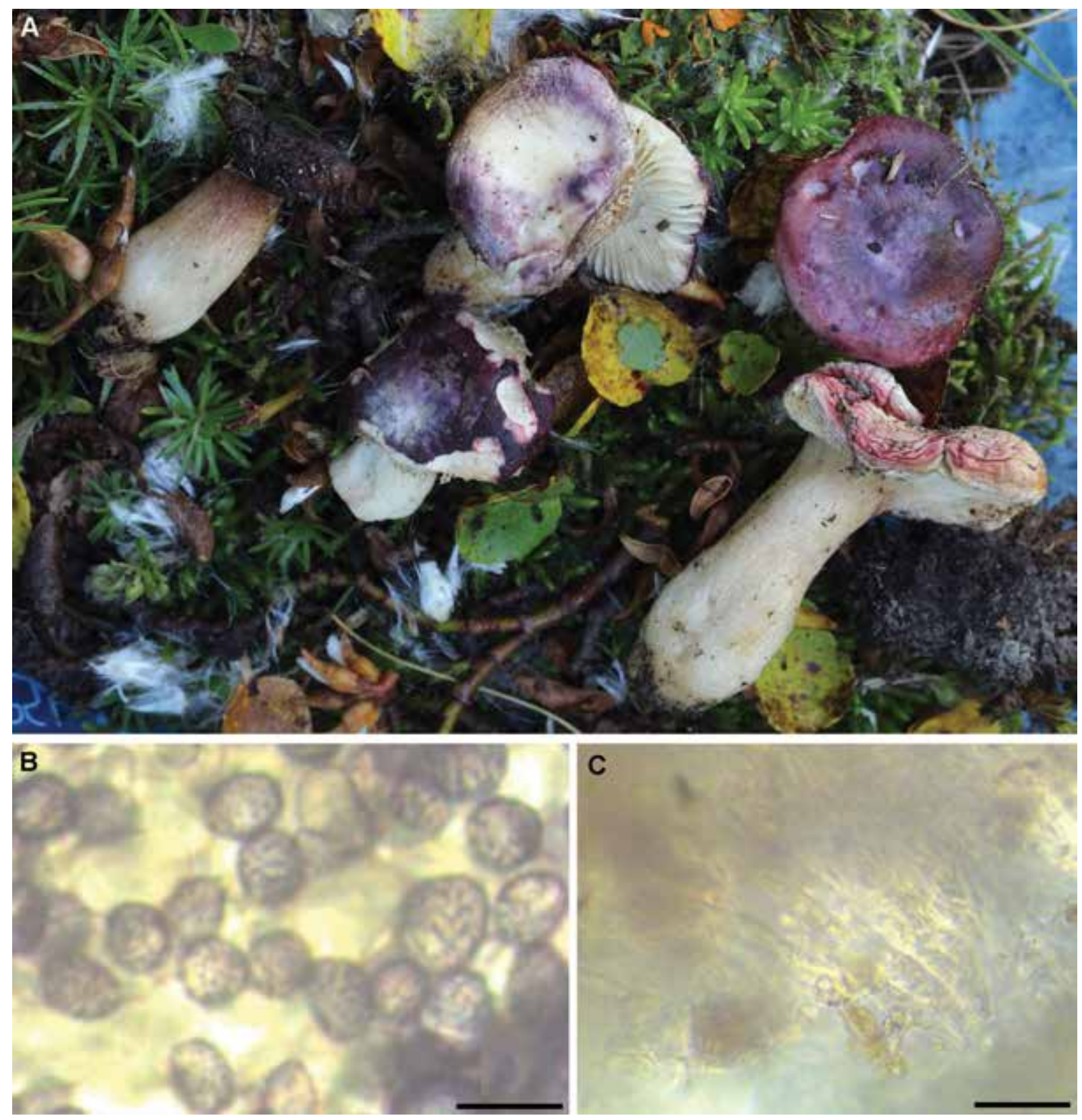

Fig. 50. Caracteres morfológicos de Russula laccata (GSD18.09.27.08). A: Basidiomas. B: Basidiosporas. C: Dermatocistidios. Barras de escala: $10 \mu \mathrm{m}$. Medio de montaje B: Melzer; C: Amoniaco. Fotografías G. Sánchez Dueñas.

guayaco. Russula atrorubens se separa de R. laccata por su claro olor a coco, una estatura mucho mayor y un hábitat bajo coníferas en montaña. Por otra parte, R. laccata también se podría confundir con R. nana, una especie que comparte hábitat, también pequeña y de esporada blanca, pero de color rojo vivo y con una microscopía diferente, con esporas más grandes y una ornamentación muy fina. En el análisis de la región ITS obtenida de nuestro material (Fig. 51), la muestra estudiada cae en un clado con el resto de secuencias de $R$. laccata, observándose también que las secuencias de $R$. laccata muestran una alta divergencia entre sí.

Según nuestra búsqueda, $R$. laccata es una especie rara en la Península Ibérica, donde se conoce únicamente la provincia de Girona (LLISTOSELLA 1991, como R. norvegica) y de Andorra (NIELL \& al. 2008). Este sería, por tanto, el primer registro de R. laccata en Aragón. 


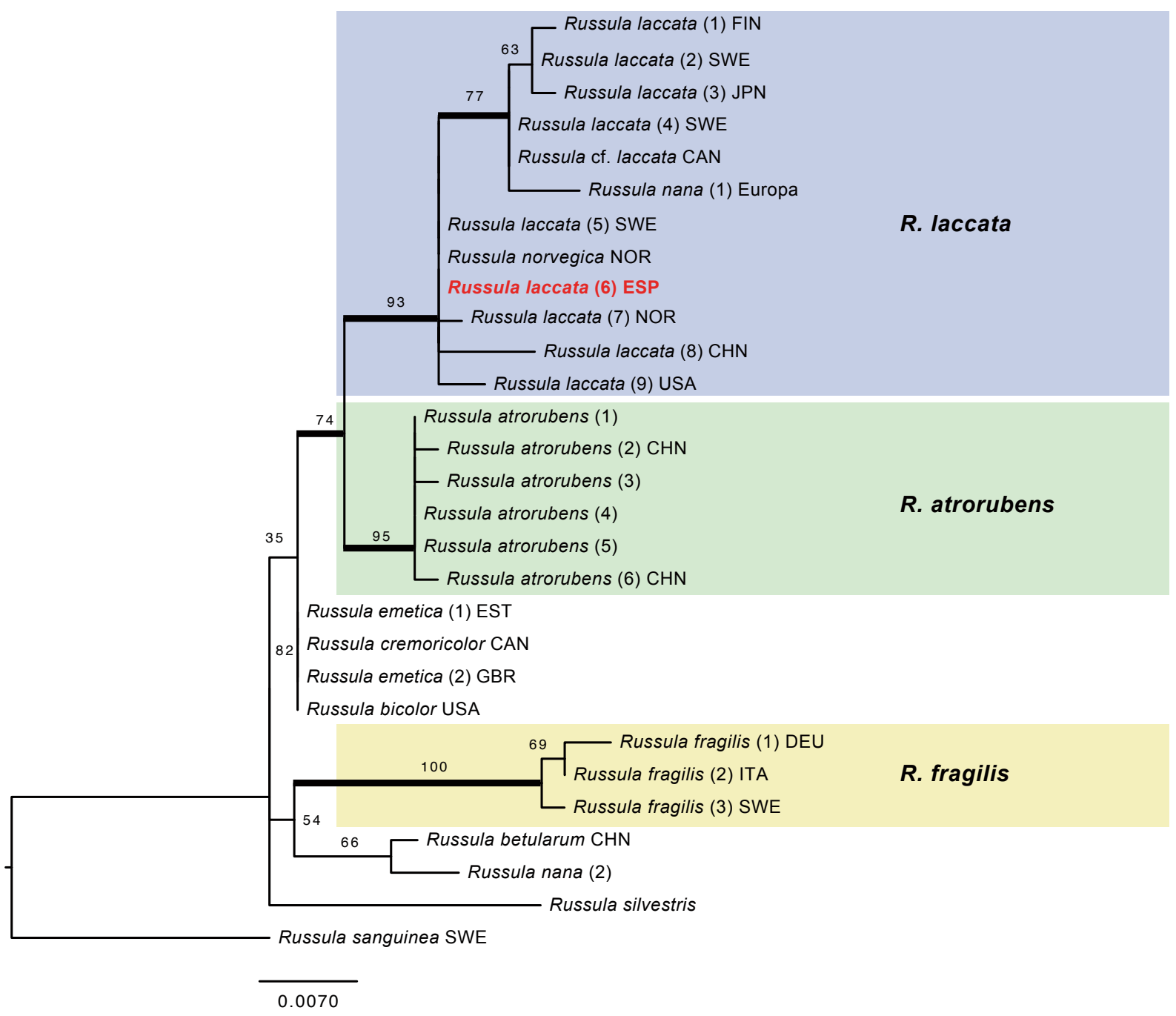

Fig. 51. Árbol más probable inferido mediante el análisis de máxima verosimilitud (ML) de la región ITS del rDNA en Russula laccata y especies afines. Se muestran los valores bootstrap-ML. Las ramas gruesas indican los nodos con apoyo filogenético (valores bootstrap $\geq 70 \%$ ). Los recuadros marcan especies o complejos de especies, mientras que la muestra descrita en el artículo se destaca en negrita y color rojo. Se empleó una secuencia de Russula sanguinea para enraizar el árbol. El país de origen de cada colección se abrevia mediante códigos ISO.

Russula subrubens (J.E. Lange) Bon, Doc. Mycol. 2(5): 33. 1972.

= Russula graveolens var. subrubens J.E. Lange, Fl. Agaric. Danic. 5: VIII. 1940.

Fig. 52

Basidiomas numerosos, algunos algo maduros. Píleo de 30-60 mm de diámetro, en general convexo, alguno algo aplanado y algo deprimido en el centro, con el margen ligeramente acanalado. Superficie pileica de color no uniforme, sobre todo rojo cobrizo, que se aclara en muchas zonas por acción del sol. $L a ́$ minas algo espaciadas, blancas, rectilíneas, algunas bifurcadas, ventricosas al madurar, inicialmente concolores, después oscuras, pardas, sobre todo hacia el borde al madurar. Esporada de color IIIa, según la escala de ROMAGNESI (1953). Estipite claviforme, con la base claramente ensanchada en algunos de los ejemplares, con la superficie arrugada y pruinosa, de color blanco, pero con muchas zonas de color rosa y amarillo-anaranjado. En algunos ejemplares destaca en el ápice del estípite, en su inserción con las láminas, un tinte de color rosa fluorescente, como si fuese un anillo coloreado. Contexto blanco, que se mancha de color marrón por exposición al aire, más bien compacto. Sabor dulce y olor tenue en ejemplares jóvenes y a arenque en ejemplares maduros. $R e$ acciones macroquímicas: Sulfato de hierro verdoso. 

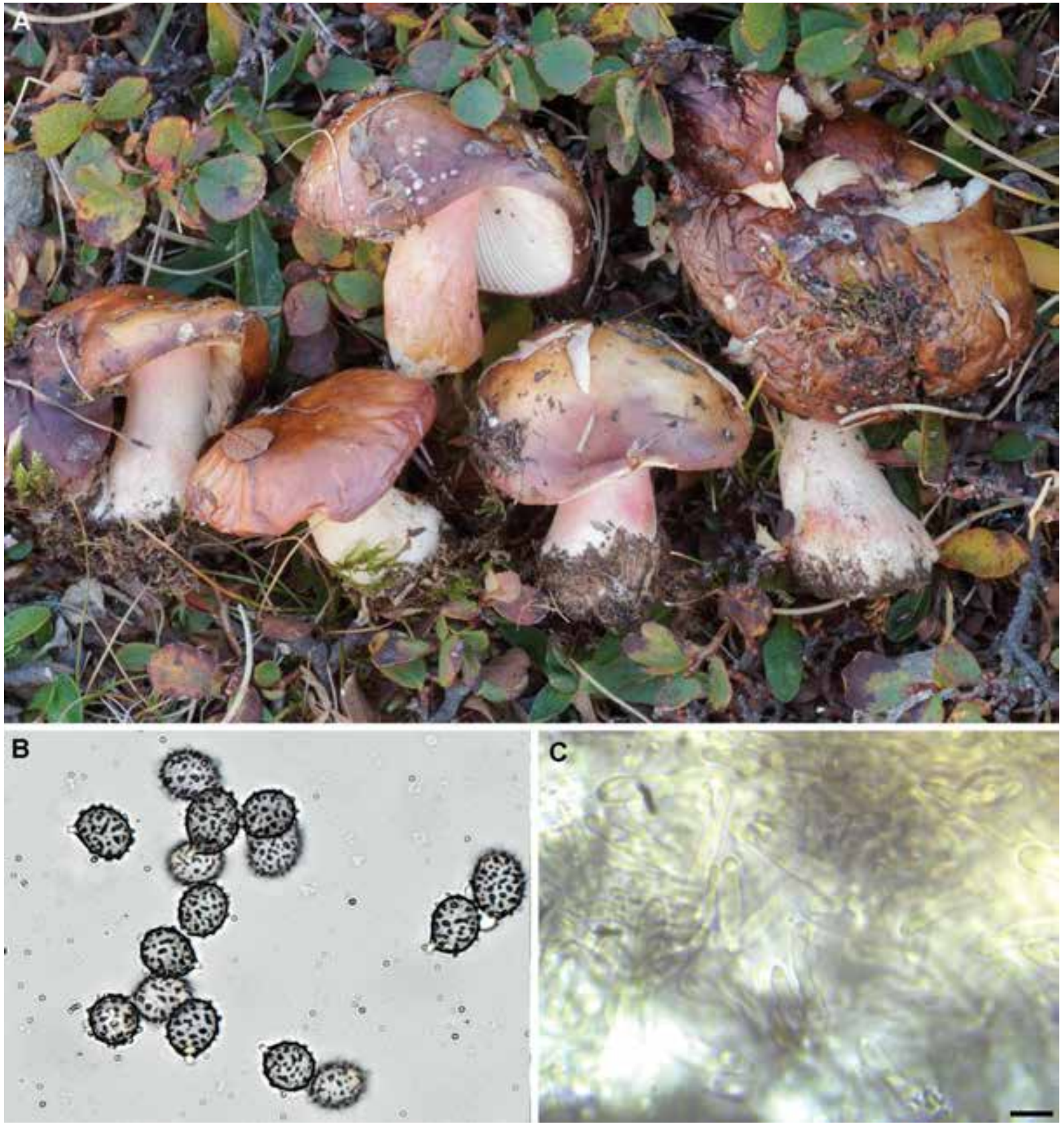

Fig. 52. Caracteres morfológicos de Russula subrubens (GSD18.09.27.07). A: Basidiomas in situ. B: Basidiosporas. C: Pelos de la pileipellis. Barras de escala: $10 \mu \mathrm{m}$. Medio de montaje B: Mezer; C: agua. Fotografías A: Jorge Hernanz; B: I. Olariaga; C: G. Sánchez Dueñas.

Basidiosporas equinuladas, con conexiones poco visibles, de ornamentación cebrada o subreticulada, con placa hilar amiloide, de $(6,2-) 6,7-7,7(-8) \times$ $(5,5-) 6,5(-6,8) \mu \mathrm{m}\left(\mathrm{Q}_{\mathrm{m}}=1,2\right)$. Pileipellis con células terminales en el centro del píleo no infladas y con dermatocistidios cilíndricos.

Material estudiado: ESPAÑA. Huesca: Benasque, Puerto de la Glera, 42.700760 .60342 ( $\pm 20 \mathrm{~m}$ ), 2370 m, 28-IX-2018, vegetación alpina con Salix herbacea, leg. J. Hernanz, det. G. Sánchez Dueñas \& I. Olariaga, GSD18.09.27.07 (ITS Genbank MW248500).
Comentarios: Russula subrubens es una especie común en zonas alpinas con Salix herbacea y otras especies de sauces enanos. Sus características macroscópicas y la reacción verde al sulfato de hierro indican que pertenece a la Russula subsect. Xerampelinae, de acuerdo a la clasificación de SARNARI (2005). Russula subrubens puede ser fácilmente confundida con $R$. pascua. La coloración rojiza del estípite es característica de $R$. subrubens según SARNARI (2005), si bien en $R$. pascua puede estar lavado de rosa pastel. Atendiendo a SARNARI (2005), el 


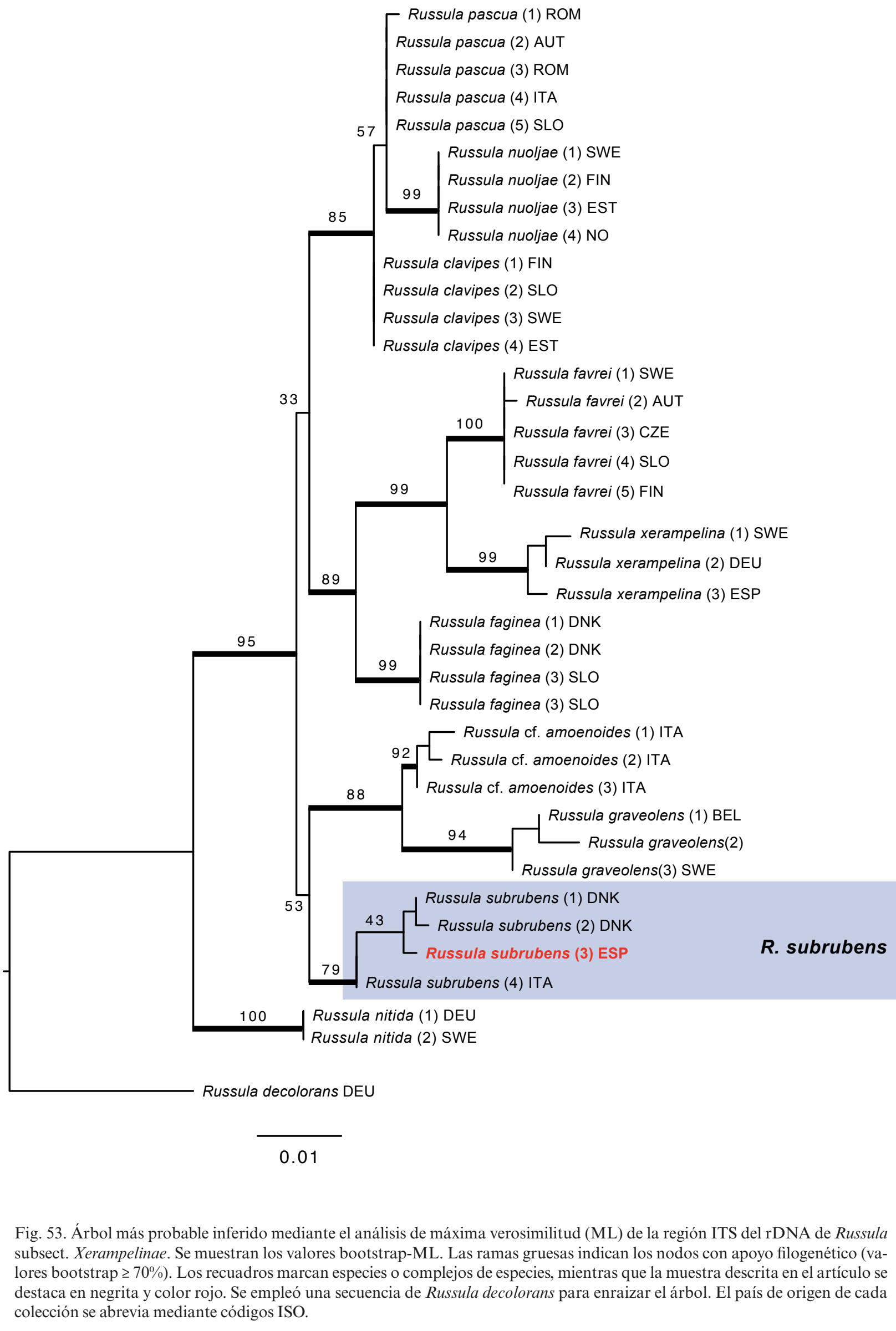


carácter fundamental que separa ambas especies es el ennegrecimiento de los dermatocistidios en estado fresco utilizando SBA (sulfobenzoaldeido). Desgraciadamente, tan sólo pudimos testar la reacción con SV (sulfovanillina), siendo la reacción negativa. En su revisión de la Russula subsect. Xerampelinae, ADAMÍK \& al. (2016), proponen que la morfología de las hifas terminales de la pileipellis en el centro del píleo difiere entre ambas especies, siendo infladas en $R$. pascua. Nuestro material presenta hifas no infladas en el centro de la pileipellis, lo que sugiere que pertenece a $R$. subrubens. El análisis de la región ITS (Fig. 53) obtenida de nuestro material muestra que cae en el clado de $R$. subrubens, confirmando nuestra identificación.

Según nuestra búsqueda, nuestro material supone el primer hallazgo de $R$. subrubens en la Península Ibérica.

Tricholoma frondosae Kalamees \& Shchukin, Folia Cryptog. Estonica 38: 14. 2001.

= Tricholoma equestre var. populinum Mort. Chr. \& Noordel., Persoonia 17(2): 311. 1999.

Fig. 54

Basidiomas estipitados, de tamaño medio para el género, naciendo directamente sobre la tierra en pequeños grupos. Píleo de 50-110 mm de diámetro, inicialmente algo acampanado, más tarde convexo, finalmente aplanado con presencia de umbón obtuso. Borde en ocasiones lobulado, durante bastante tiempo incurvado y al final extendido. Superficie pileica radialmente fibrillosa, viscosilla y brillante en tiempo húmedo, de color amarillo mostaza o amarillo oliva, con irisaciones rojizas y escamas parduscas o pardo oliva dispuestas más o menos concéntricamente e irregulares y más densas hacia el centro. Láminas estrechas, prietas, emarginadas, de color amarillo limón, amarillo azufre o amarillo verdoso. Esporada blanquecina. Estípite en general bastante largo, de 50-110 × 10-20 mm, central, cilíndrico o algo bulboso, normalmente recto pero a veces algo curvado, de coloración similar al píleo o algo más claro, liso o ligeramente fibrilloso y con diminutas escamas pardas. Contexto grueso, más fibroso en el estípite, blanco o blanco amarillento. Olor y sabor harinosos.

Basidiosporas elipsoidales, de 5,1-6,9 × 4-5,4 $\mu \mathrm{m}$, $\mathrm{Q}=1,2-1,4(\mathrm{n}=50)$ en nuestra recolecta, obtenidas mediante esporada libre, lisas, hialinas, no amiloides, con una gruesa gútula central y apículo lateral. $\mathrm{Ba}$ sidios claviformes, tetraspóricos, de 23-37 × 5,8-8,5 $\mu \mathrm{m}$. Cistidios no observados. Trama laminar paralela, con hifas de $6-13 \mu \mathrm{m}$. Pileipellis de tipo cutis a tricoderma, compuesta de hifas cilíndricas enmarañadas de 2,3-5,3 $\mu \mathrm{m}$, algunas emergentes y pigmento pardo amarillo naranja. Fíbulas ausentes.
Material estudiado: ESPAÑA. Huesca: Benasque, Cerler, Selva de Conques, 42.5845830 .528792 ( $\pm 100 \mathrm{~m}$ ), en bosque mixto, húmedo y suelo básico, con Betula pendula, Populus tremula, Corylus avellana, Fagus sylvatica, Pinus sylvestris, Fraxinus excelsior, Abies alba, Buxus sempervirens y otras especies de arbustos propias de ribera, 30-IX-2018, leg. et det. C. Pérez del Amo, CMP1876 (ITS Genbank MW248501; LSU MW248519).

Comentarios. Según CHRISTENSEN \& HEILMANN-CLAUSEN (2013), T. frondosae pertenece a Tricholoma sect. Tricholoma, caracterizada por el píleo blanquecino, grisáceo, verdoso, oliváceo o amarillento, seco o viscoso, pero en general brillante, con fibrillas innatas a escamoso; láminas amarillas, blancas o más raramente grises. Tricholoma frondosae se puede diferenciar, no sin cierta dificultad, de Tricholoma equestre (L.) P. Kumm. por el color de sus basidiomas que son más amarillos verdosos o amarillos oliváceos, las escamas del píleo más conspicuas y numerosas, porte más estilizado y por fructificar en ambientes más frescos y húmedos con presencia de Betula y Populus (KALAMEES 2001). HEILMANN-CLAUSEN \& al. (2017), sobre la base de estudios moleculares de la región ITS, indican que las colecciones identificadas como $T$. frondosae forman tres grupos diferenciados, concluyendo que el espécimen tipo de $T$. frondosae debe pertenecer al clado $T$. frondosae tipo I, por presentar colores más cálidos y esporas más pequeñas que el tipo II. Asimismo, sugieren que el clado T. frondosae (tipo II) pertenece a una especie no descrita. Nuestros análisis de la región ITS (Fig. 55), sugieren que el espécimen estudiado pertenece al clado $T$. frondosae tipo II. Las medidas obtenidas en base a nuestra colección $(5,1$ $6,9 \times 4-5,4 \mu \mathrm{m})$ son más anchas que las mencionadas en el protólogo (4,8-6,4 x 3,2-4,0 $\mu$ m, KALAMEES 2001), por lo que respaldan la idea de que el clado tipo II posee esporas mayores que el tipo I.

Según nuestra búsqueda, existe un único hallazgo previo nombrado como T. frondosae en la Península Ibérica (RUBIO DOMÍNGUEZ 2018b, ERD 7637). A juzgar por el color pardo rojizo del píleo y la anchura esporal $(4,1-5,5 \mu \mathrm{m})$, este material parece pertenecer también al clado T. frondosae tipo II. Asimismo, es posible que exista más material de $T$. frondosae identificado como T. equestre en colecciones científicas. Al menos existe un espécimen (MUÑOZ SÁNCHEZ \& al. 2020, SMB 1999101604, https:// www.gbif.org/occurrence/2565017259) identificado como T. equestre y recolectado bajo Populus que correspondería a $T$. frondosae, y es muy posible que existan más en micotecas que no están disponibles para consultas en línea. 

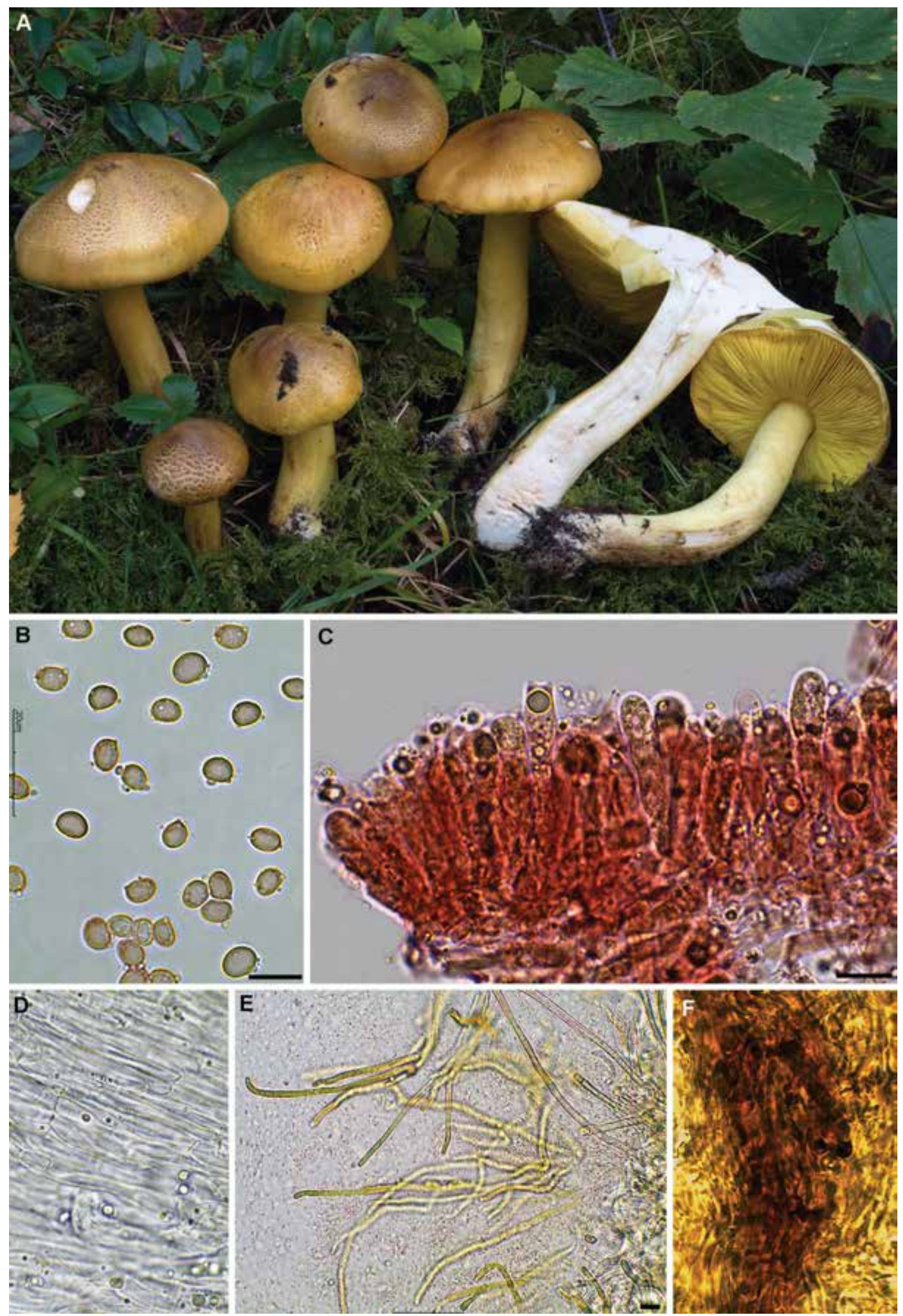

Fig. 54. Tricholoma frondosae (CMP1876). A: Basidiomas in situ. B: Basidiosporas en rojo Congo. C: Basidios en rojo Congo. D: Trama laminar. E: Pileipellis. F: Pigmento de la pileipellis. Barras de escala $10 \mu \mathrm{m}$. Medio de montaje B, C: rojo Congo; C, D, F: agua. Fotografías C. Pérez del Amo. 


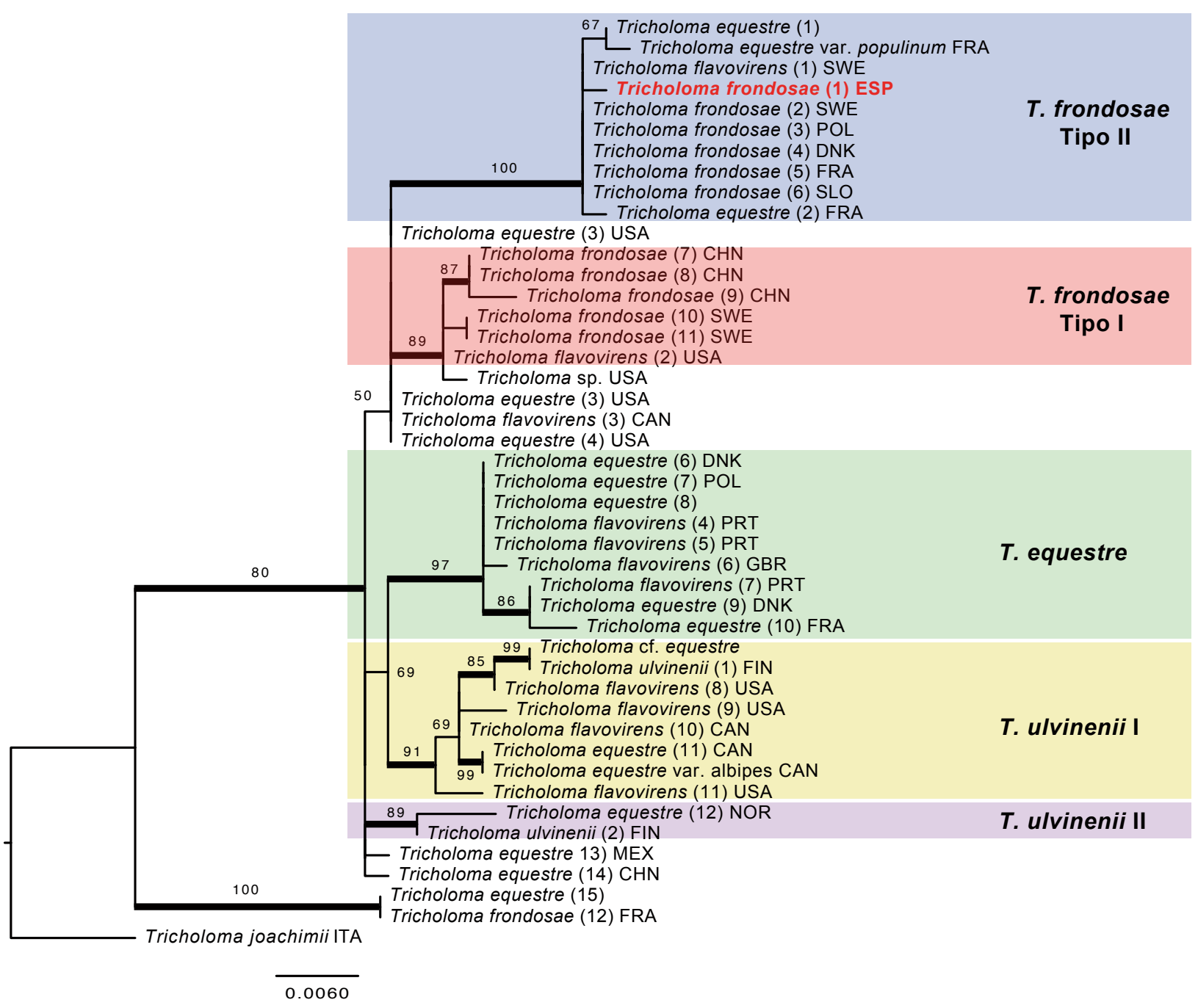

Fig. 55. Árbol más probable inferido mediante el análisis de máxima verosimilitud (ML) de la región ITS del rDNA en Tricholoma frondosae y especies afines de $T$. sección Tricholoma. Se muestran los valores bootstrap-ML. Las ramas gruesas indican los nodos con apoyo filogenético (valores bootstrap $\geq 70 \%$ ). Los recuadros marcan especies o complejos de especies, mientras que la muestra descrita en el artículo se destaca en negrita y color rojo. Se empleó una secuencia de Tricholoma joachimii para enraizar el árbol. El país de origen de cada colección se abrevia mediante códigos ISO.

\section{Phylum Mycetozoa (reino Protozoa)}

Diderma crustaceum Peck, Bull. Buffalo Soc. Nat. Sci. 1: 63.1873.

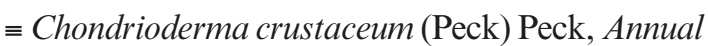
Rep. New York State Mus. 31: 56. 1878.

Fig. 56

Fructificaciones formadas por decenas de esporocarpos, densamente gregarios y deformados por presión mutua. Esporocarpos de 0,3-1 mm de diámetro, sésiles o con estípite corto, subglobosos, de color blanco-crema, lisos cubiertos de cristalizaciones calcáreas. Estípite corto y delgado, al principio oculto bajo la cubierta calcárea. Peridio doble, capa externa gruesa de color blanco e interior mas fina y membranosa incolora o amarilo palido con cristalizaciones. Columela blanca en forma de clavo, a veces inexistente.

Esporas globosas, de color marron púrpura, densamente espinuladas, a veces subreticuladas, de $10-13 \mu \mathrm{m}\left(\mathrm{L}_{\mathrm{m}}=11\right)$. Capilicio ramificado, hialino o de color violeta oscuro, a menudo con pequeños engrosamientos.

Material estudiado: ESPAÑA. Huesca: Benasque, Cerler, La Selva de Cerler, junto a la pista de esquí, 42.5861680 .538394 ( $\pm 50 \mathrm{~m})$, en bosque mixto, sobre planta sin identificar, 30-IX-2018, leg. J.I. López, det. J. Martín, ARAN-Fungi 10298. 

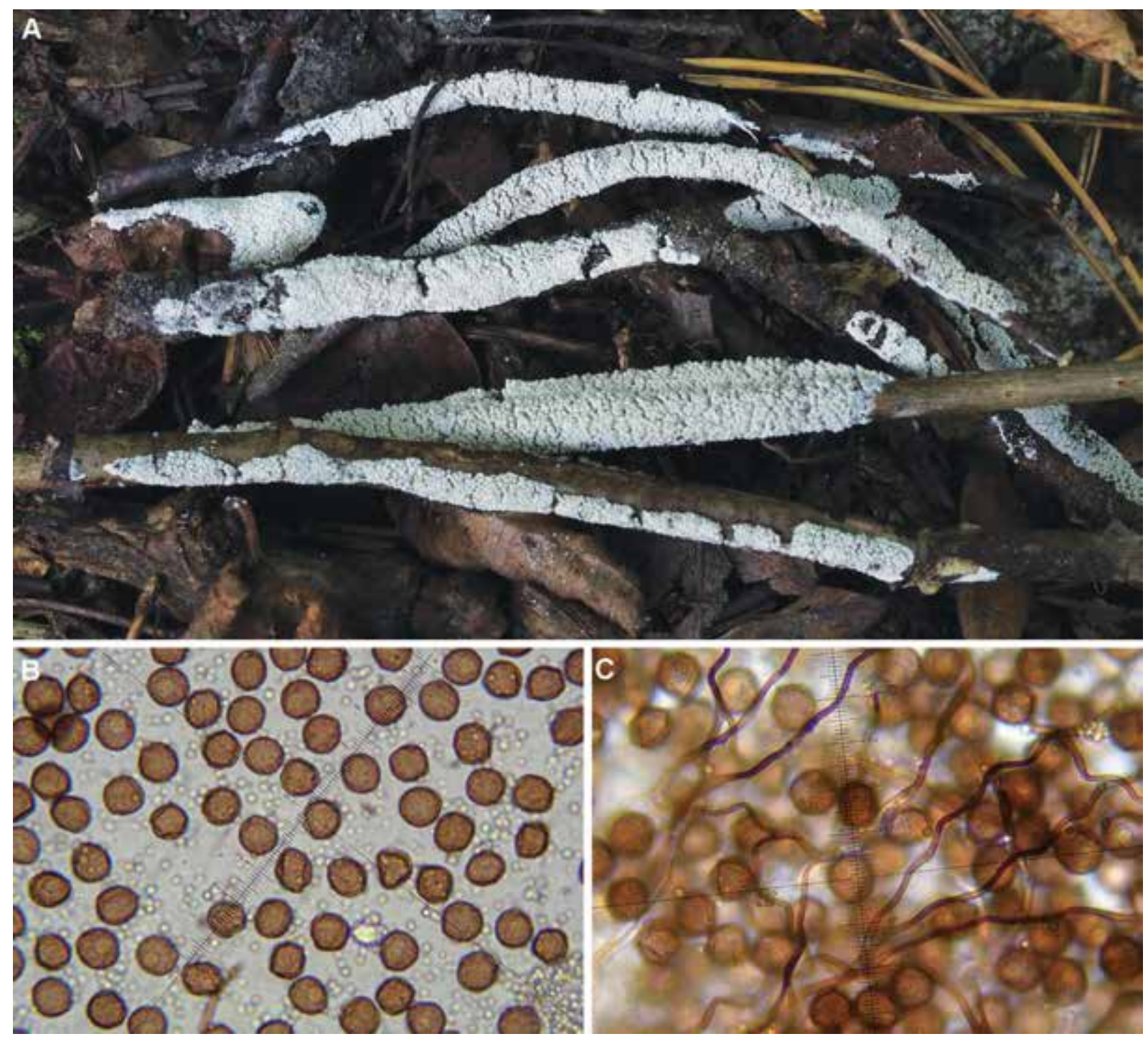

Fig. 56. Diderma crustaceum (ARAN-Fungi 10298). A: Esporocarpos in situ. B: Esporas. C: Capilicio. Medio de montaje B, C: agua. Fotografías J. Martín.

Comentarios. El presente registro representa el primero bien documentado de $D$. crustaceum en la Península Ibérica. Según nuestra búsqueda, existe un registro publicado posteriormente al hallazgo descrito aquí, de la provincia de Lérida (MONTON \& OLARIAGA 2019, https://www.gbif.org/occurrence/2459207231), así como un registro de Álava cuya identificación parece correcta, pero que no parece estar respaldado por material de herbario (TAPIA 2013). Aunque la identificación de este registro es muy probablemente correcta, su identidad no ha podido ser confirmada en el presente trabajo.
Una especie similar a D. crustaceum, D. spumarioides (Fr.) Fr., ha sido ampliamente citada en la Península Ibérica e islas Baleares (LADO 1991). Sin embargo, Diderma crustaceum difiere de D. spumarioides (Fr.) Fr. por sus esporas mayores de $12 \mu \mathrm{m}$ y de color pardo oscuro, además de que su peridio que posee dos capas bien separadas (la exterior calcárea, la interior membranacea), mientras que en $D$. spumarioides estas dos capas aparecen unidas (BUYCK 1982). Dada la similitud macroscópica entre ambas especies, parece posible que algunas de las citas ibéricas de $D$. spumarioides correspondan en realidad a D. crustaceum. 


\section{Agradecimientos}

En primer lugar queremos mostrar nuestro agradecimiento a todos los micólogos que participaron en el encuentro, y que no figurando como coautores de este trabajo, contribuyeron notablemente a ampliar los resultados científicos del encuentro. Agradecemos a Juantxo Garrido su hospitalidad y haber puesto a nuestra disposición el local de la Asociación Micológica Sarllé, además de guiarnos durante el trabajo de campo. Agradecemos a Jorge Hernanz su contribución como recolector de varias especies alpinas presentadas aquí y por haber cedido el material para su estudio. Así mismo, debemos a João Baptista-Ferreira la traducción del resumen a portugués. Santiago Serrano y Aurelia Paz pusieron rápida y amablemente a nuestra disposición varios artículos acerca del género Entoloma. A Fernando Esteve-Raventós por su ayuda y su generosidad al poner su estudio de los tipos de Inocybe immaculipes, I. appendiculata e I. piricystis a nuestra disposición. Expresamos nuestro agradecimiento, en especial Chemi Traba, la ayuda de Antón Vila Sanjurjo (Universidad de A Coruña) por su ayuda en la obtención de algunas secuencias del género Russula. Agradecemos a Bodil Cronholm (Swedish Museum of Natural History) su trabajo para secuenciar varias muestras presentadas aquí, así como a Henry Beker por confirmar a nivel molecular las muestras de Hebeloma presentadas aquí.

\section{Referencias}

ADAM ČÍK S, SLOVAK M, EBERHARDT U, RONIKIER A, JAIRUS T, HAMPE F \& VERBEKEN A (2016) Molecular inference, multivariate morphometrics and ecological assessment are applied in concert to delimit species in the Russula clavipes complex. Mycologia 108(4): 716-730. DOI: https://doi.org/10.3852/15-194

ALONSO J \& RIGUEIRO A (2020) Catálogo da macromicobiota das montañas do Courel (Galicia, NO España). Monografías do Ibader - Serie Cadernos da Estación Científica do Courel. Ibader. Universidade de Santiago de Compostela. Lugo. ALTSCHUL SF, GISH W, MILLER W, MYERS EW \& LIPMAN DJ (1990) "Basic local alignment search tool." J. Mol. Biol.215: 403-410.

ANTONÍN V \& NOORDELOOS ME (2010) $A$ monograph of marasmioid and collybioid fungi in Europe. IHW Verlag, Germany.

APTROOT A (1998) A world revision of Massarina. Nova Hedwigia 66(1-2): 89-162. DOI: https://doi. org/10.1127/nova.hedwigia/66/1998/89

BABINGTON C (1839) Remarks on British lichens and fungi, principally on species or varieties new to our flora. Proc. Linn. Soc. London 1: 32.

BALOCH E, GILENSTAM G \& WEDIN M (2009) Phylogeny and classification of Cryptodiscus, with a synopsis of the Swedish species. Fungal Diversity 38: 51-68.

BARR ME \& BOISE JR (1985) A revision of Exarmidium (Ascomycetes). Mycotaxon 23: 233-240.

BEKER HJ, EBERHARDT U \& VESTERHOLT J (2016) Fungi Europaei 14. Hebeloma (Fr.) P. Kumm. Edizioni Tecnografica, Lomazzo, Italia. BIZIO E (1995) Alcune Inocybe della zona alpina delle Dolomiti. Rivista Micol. 38(2): 3-60.
BIZIO E (1997) Alcune Inocybe piu frequenti della zona alpina delle Dolomiti. $2^{\circ}$ contributo. Rivista Micol. 40(4): 339-362.

BJORBÆKMO \& al. (2010) High diversity of root associated fungi in both alpine and arctic Dryas octopetala. B. M. C. Plant Biology 10: 244. DOI: https://doi.org/10.1186/1471-2229-10-244

BON M (1997a) Clé monographique des inocybes alpins. Bull. Féd. Myc. Dauphiné-Savoie 144: 71109.

BON M (1997b) Clé monographique du genre Inocybe (Fr.) Fr. (2ème partie: Sous genre Inocybe=Inocybium (Earle) Sing.). Doc. Mycol. 27(108): $1-77$.

BRITISH MYCOLOGICAL SOCIETY (2018) Fungal Records Database of Britain and Ireland. Occurrence dataset https://doi.org/10.15468/ietmop [consultado vía GBIF.org el 12-XI-2020]. https:// www.gbif.org/occurrence/2940634986

BUYCK B (1982) The Genus Diderma Persoon (Myxomycetes) in Belgium. Bull. Jard. Bot. Natl. Belg. 52: 165-209.

CAMPOS JC, MATEO JF, MUÑOZ G, OLARIAGA I, PANCORBO F, PARRA LA, PÉREZ DE GREGORIO MÀ, PÉREZ-GORJÓN S, RIBES MÁ, RODRÍGUEZ B, ROJO C, SÁNCHEZ G \& ZAMORA JC (2014) IV Congreso Pirenaico de Micología: Catálogo de taxones y estudio de los más interesantes. Bol. Soc. Micol. Madrid 37: 203-223.

CANNON PF (1996) Systematics and diversity of the Phyllachoraceae associated with Rosaceae, with a monograph of Polystigma. $M y$ col. Res. 100(12): 1409-1427. DOI: https://doi. org/10.1016/S0953-7562(96)80072-4

CHIARELLO O \& BATTISTIN E (2013) A little-known taxon: Russula flavispora. Field Mycol. 14(4): 114-116. 
CHRISTENSEN M. \& HEILMANN-CLAUSEN J (2013) The genus Tricholoma. Fungi of Northern Europe 4. Svampetryk, Denmark.

CORNER EJH (1950) A monograph of Clavaria and allied genera. Ann. Bot. Mem. 1: 1-740.

CORRIOL G (2007) Checklist of Pyrenean alpine-stage macrofungi. Sommerfeltia 31: 29-99. DOI: https://doi.org/10.2478/v10208-011-0004-6

CROUS P \& al. (2019) Fungal Planet description sheets: 951-1041. Persoonia 43: 223-425. DOI: https://doi.org/10.3767/persoonia.2019.43.06

CUBETA MA, ECHANDI E, ABERNETHY T \& VILGALYS R (1991) Characterization of anastomosis groups of binucleate Rhizoctonia species using restriction analysis of an amplified ribosomal RNA gene. Phytopathology 81: 1395400.

DANIËLS P. \& MORENO-ARROYO B (2009) Contribución al estudio de la diversidad fúngica andaluza IV. Ascomycetes. Bol. Soc. Micol. Madrid 33: 31-48.

DENNIS RWG (1981) British Ascomycetes (Revised Edition). J. Cramer. Vaduz.

ERIKSSON OE (2014) Checklist of the non-lichenized ascomycetes of Sweden. Acta Univ. Upsal., Symb. Bot. Upsal. 36(2): 1-501.

ERIKSSON OE \& HAWKSWORTH DL (1993) Outline of the Ascomycetes-1993. Syst. Ascomycetum: 12: 51-257.

ESTEVE-RAVENTÓS F, GONZÁLEZ GARCÍA V \& ARENAL YAGÜE F (1997) Catálogo micológico de los macromicetos de áreas alpinas y subalpinas del Parque Nacional de Ordesa y zonas limítrofes (Huesca, España) recogidos en 1996. Bol. Soc. Micol. Madrid 22: 155-186.

ESTEVE-RAVENTÓS F \& VILA J. (1997) Algunos Inocybe de la zona alpina de los Pirineos de Catalunya, I. Revista Catalana Micol. 20: 177-186.

ESTEVE-RAVENTÓS F \& VILA J (1998) Algunos Inocybe de la zona alpina de los Pirineos de Catalunya. II. Revista Catalana Micol. 21: 185-201.

ETAYO J (2010) Líquenes y hongos liquenícolas de Aragón. Guineana 16: 1-501.

EYSSARTIER G \& DELANNOY A (2006) Notes sur quelques espèces arctiques et alpines. Fungi non Delineati 32: 34-68.

FERNÁNDEZ VICENTE J, IGLESIAS P, UNDAGOITIA JR \& ARAUZO S (2007) La familia Entolomataceae en el Norte de la Península Ibérica. (I). Errotari 4: 88-102.

FERRARI, E. (2006) Inocybe alpine e subalpine. Il genere Inocybe (Fr.) Fr. nel nord Italia e paesi limitrofi. Fungi non delineati 34-36: 1-457.

FERRARI E (2010) Inocybe dai litorali alla zona alpina. Fungi non delineati 54-55: 1-216

FRIES EM (1821) Systema mycologicum. I. Lund. Berlin.
GALÁN R \& RAITVIIR A (1995) Tricharina fibrillosa (Currey) Yang et Korf una specie enigmatica di Pezizales trovata in Spagna. Rivista Micol. 38 (2): 163-167.

GALLI R (1996) Le Russule. Edinatura. Milano.

GEML J, TIMLING I, ROBINSON CH, LENNON N, NUSBAUM HC, BROCHMANN C, NOORDELOOS ME \& TAYLOR DL (2012) An arctic community of symbiotic fungi assembled by long-distance dispersers: phylogenetic diversity of ectomycorrhizal basidiomycetes in Svalbard based on soil and sporocarp DNA. J. Biogeogr. 39: 74-88. DOI: https://doi. org/10.1111/j.1365-2699.2011.02588.X

GMELIN R, LUXA H-H, ROTH K \& HÖFLE G (1976) Dipeptide precursor of garlic odour in Marasmius species. Phytochemistry 15: 1717 1721.

GOBIERNO DE ARAGÓN (2020). Atlas de la Flora de Aragón-Hongos. http://floragon.ipe.csic. es/florahongos/index.php [consultado entre IXXI-2020]

HÄFFNER J (1995) Rezente ascomycetenfunde XV - Marcelleina und Greletia und weitere gattungen der unterfamilie Aleurinoideae Moravec (1987). Rheinl.-Pfälz. Pilzj. 4 (2): 136-154.

HAUSKNECHT A, JAKLITSCH W \& KRISAI-GREILHUBER I (2003) Rezente Pilzfunde aus Osttirol. Österr. Z. Pilzk. 12: 153-192.

HEILMANN-CLAUSSEN J, CHRISTENSEN M, FRØSLEV T, KJØLLER R (2017) Taxonomy of Tricholoma in northern Europe based on ITS sequence data and morphological characters. Persoonia 38: 38-57.

HOLM L (1979) Microfungi on Dryas. Bot. Notiser 132: 77-92.

JACOBSSON S (2008) Inocybe. In: KNUDSEN H. \& VESTERHOLT J. (ed.). Funga Nordica: 868906. Nordsvamp, Copenhagen.

JAMONI PG (2008) Funghi alpini delle zone alpine superiori e inferiori. Associazione Micologica Bresadola, Fondazione Centro Studi Micologici dell'a A.M.B. Trento.

JUNTA DE ANDALUCÍA (2004) IMBA v.1. Inventario micológico básico de Andalucía. Consejería de Medio Ambiente. http://www.juntadeandalucia.es/medioambiente/site/portalweb/menuitem.7e1cf46ddf59bb227a9ebe205510e1ca/?vgnextoid $=\mathrm{c} 0268590 \mathrm{f} 08 \mathrm{ad} 210 \mathrm{VgnVCM} 20000006$ 24e50aRCRD\&vgnextchannel=4b2fa7aaaf4f4310VgnVCM2000000624e50aRCRD

KALAMEES K (2001) Taxonomy and ecology of the species of the Tricholoma equestre group in the Nordic and Baltic countries. Folia Crytog. Estonica 38: 13-23.

KAUTMANOVÁ I (2012) Taxonomy of central European representatives of the genus Clavaria 
(Basidiomycetes, Clavariaceae) [tesis doctoral]. Slovak Academy of Sciences, Bratislava. 162 pp.

KRISAI-GREILHUBER I (2019) Paraxerula caussei. The IUCN Red List of Threatened Species 2019: e.T147537697A148154512 [consultado el 13-IX-2020].

KÜHNER R (1955) Compléments à la «Flore Analytique » 5) Inocybe léiosporés cystidiés. Espèces nouvelles ou critiques. Bull. Soc. Nat. Oyonnax 9 (Suppl.): 1-95.

KÜHNER R (1988) Diagnoses de quelques nouveaux Inocybes récoltés en zone alpine de la Vanoise (Alpes françaises). Doc. Mycol. 19(74): $1-27$.

KUYPER TW (1986) A revision of the Genus Inocybe in Europe. I. Subgenus Inosperma and the smooth-spored species of Subgenus Inocybe. Persoonia (Suppl.) 3: 1-247.

LADO C (1991) Catálogo comentado y síntesis corológica de los Myxomycetes de la Península Ibérica e Islas Baleares (1788-1990). Ruizia 9: 1-142.

LARSSON A (2014) AliView: a fast and lightweight alignment viewer and editor for large data sets. Bioinformatics 30(22): 3272-3276. DOI: https:// doi.org/10.1093/bioinformatics/btu531

LARSSON E \& JACOBSSON S (2004) Controversy over Hygrophorus cossus settled using ITS sequence data from 200 year-old type material. Mycol. Res. 108 (7): 781-786. DOI: https://doi. org/10.1017/S0953756204000310

LLISTOSELLA J (1991) Russulaceae, notes florístiques. Butl. Soc. Catalana. Micol. 14-15: 67-76.

LLISTOSELLA J (2020). Mòdul Fongs. Banc de Dades de Biodiversitat de Catalunya. Generalitat de Catalunya i Universitat de Barcelona. http:// biodiver.bio.ub.es/biocat/homepage.html [consultado entre IV-XI-2020].

LLISTOSELLA J, MARTI O, AGUASCA OM \& MARTÍN MP (1994) Aportaciò a la flora micològica del Parc Nacional d'Ordesa i Monte Perdido (Pirineus centrals). Butl. Soc. Catalana Micol. 16-17: 99-118.

LLISTOSELLA J, PÉREZ-DE-GREGORIO MÀ \& LLORENS-VAN-WAVEREN L (2008) Russula flavispora Romagn., una espècie rara trobada a Catalunya. Revista Catalana Micol. 30: 101-106.

LLORENS VAN-WAVEREN L \& LLISTOSELLA L (2004) Contribució a la flora dels fongs del Parc Natural del Cadí-Moixeró (Catalunya). I. El gènere Entoloma (Fr.) P. Kumm. Revista Catalana Micol. 26: 165-176.

LUSK DE (1987) Pseudoaleuria quinaultiana, a new genus and species of operculate discomycetes from the Olympic Peninsula. Mycotaxon 30: 417-431.
MAIRE R (1933) Fungi catalaunici. Treb. Museu Ciènc. Nat. Barcelona 15: 1-120.

MARCOS-MARTÍNEZ J (2017) Adiciones al catálogo micológico de la provincia de Salamanca. Micobotánica-Jaén 12(3): 1-29.

MARTÍNEZ-GIL R \& CABALLERO A (2016) Ascomicetos raros o interesantes de La Rioja, España (II). Bol. Micol. FAMCAL 10: 73-88.

MATOUS J, HOLEC J \& KOUKOL O (2017) Ramariopsis robusta (Basidiomycota, Clavariaceae), a new European species similar to $\mathrm{R}$. kunzei. Czech Mycol. 69(1): 51-64.

MAXMÜLLER H (2014) Russularum icones I. Anatis. Munchen.

MEDARDI G (2006) Ascomiceti d'Italia. A.M.B. Trento.

MERINO D (2014) Aportaciones micológicas 18. Micobotánica-Jaén 9(1): 46-287.

MILLER MA, PFEIFFER W \& SCHWARTZ T (2010) Creating the CIPRES science gateway for inference of large phylogenetic trees. In: Proceedings of the gateway computing environments workshop (GCE): 1-8. New Orleans, LA.

MONEDERO C (2011) El Género Russula en la Península Ibérica. Centro de Estudios Micológicos de Euskadi.

MONTON J, OLARIAGA IBARGUREN I (2019) SIM-Fungal records compiled by Joan Montón. Sociedad(e) Ibérica de Micología-Iberian Mycological Society. Occurrence dataset https://doi. org/10.15470/dqtuup [consultado vía GBIF.org el 12-XI-2020]. https://www.gbif.org/occurrence/2459207231

MORAVEC J (1969) Některé operkulátní diskomycety nalezené v okresech Mladá Boleslav a Jičín. Česká Mykol. 23(4): 222-235.

MORAVEC J (1987) A taxonomic revision of the genus Marcelleina. Mycotaxon 30: 473-499.

MORAVEC J (2003) Taxonomic revision of the genus Cheilymenia Boud. - 9. The sections Villosae and Obtusipilosae, and a revision of the genus Pseudoaleuria Lusk (Pezizales, Pyronemataceae). Acta Mus. Morav. Sci. Biol. Brno 88: 37-73.

MOREAU P-A (2007) Marasmius subalpinus, un marasme nouveau sur Rhododendron ferrugineum. Bull. Mycol. Bot. Dauphiné-Savoie 186: 49-56.

MUÑOZ-SÁNCHEZ JA, ARANDA-JIMÉNEZ C \& OLARIAGA IBARGUREN I (2020) Herbario de la Sociedad Micológica Barakaldo Mikologia Elkartea. Version 1.2. Sociedad Micológica Barakaldo mikologia elkartea. Occurrence dataset https://doi.org/10.15470/09sbhk [consultado vía GBIF.org el 10-IX-2020]. https://www.gbif. org/occurrence/2565017259 
NIELL M, RADUAN G \& GIRBAL J (2008) Els fongs d'Andorra. Monografies del CENMA. 216 pp.

NITARE J (2020) Ramaria broomei (Cotton \& Wakef.) R.H. Petersen. The Global Fungal Redlist Initiative. http://iucn.ekoo.se/iucn/species view/111880 [consultado el 13-IX-2020).

NOORDELOOS ME (1979) Entoloma subgenus Pouzaromyces emend. in Europe. Persoonia 10(2): 207-243.

NOORDELOOS ME (1984) Studies in Entoloma, 10-13. Persoonia 12: 195-223.

NOORDELOOS ME (1992) Fungi Europaei 5. Entoloma s.l. Libreria Editrice Giovanna Biella. Saronno.

NOORDELOOS ME (2004) Fungi Europaei 5A. Entoloma s.l. Candusso Edizioni s.a.s. Alassio.

OLARIAGA I (2009) The order Cantharellales in the Iberian Peninsula and the Balearic Islands [tesis doctoral]. Univ Basque Country Press, Bilbao. $547 \mathrm{pp}$.

OLARIAGA I \& SALCEDO I (2012) New combinations and notes in clavarioid fungi. Mycotaxon 121: 37-44. DOI: https://doi.org/10.5248/121.37

OLARIAGA I, SALCEDO I, DANIËLS PP, SPOONER B \& KAUTMANOVÁ I (2015) Taxonomy and phylogeny of yellow Clavaria species with clamped basidia - Clavaria flavostellifera sp. nov. and the typification of $\mathrm{C}$. argillacea, $\mathrm{C}$. flavipes and C. sphagnicola. Mycologia 107(1): 104-122.

ORTON PD (1960) New check list of British agarics and boleti. Trans. Brit. Mycol. Soc. 43(2): 159-439.

PANCORBO F, RIBES MÁ, ESTEVE-RAVENTÓS F, HERNANZ J, OLARIAGA I, DANIËLS PP, HEREZA A, SÁNCHEZ G, MATEO JF \& SERRANO F (2017) Contribución al conocimiento de la biodiversidad fúngica del Parque Nacional de Ordesa y Monte Perdido II. Pirineos 172: e032. DOI: http://dx.doi. org/10.3989/pirineos.2017.172007

PARRA LA (2013) Fungi Europaei 1A. Agaricus L., Allopsalliota Nauta \& Bas. Candusso Edizioni s.a.s. Alassio.

PARRA LA, CAPPELLI A, KERRIGAN RW \& BIZIO E (2019) Agaricus porphyrocephalus subsp. alpinus a new subspecies collected in the Italian Alps. Micol. Veg. Medit. 33(2): 67-88.

PERSOON CH (1800) Icones et Descriptiones Fungorum Minus Cognitorum. Pars secunda. Lipsiae. Breitkopf Haerteliani.

PERSOON CH (1801) Synopsis methodica fungorum. Gottingae.

PETERSEN RH \& HUGHES KW (2010) The Xerula/Oudemansiella Complex (Agaricales). Beih. Nova Hedwigia 137: 1-625.
PETERSEN RH \& HUGHES KW (2017) An investigation on Mycetinis (Euagarics, Basidiomycota). Mycokeys 24: 1-138. DOI: https://doi. org/10.3897/mycokeys.24.12.846

PFISTER D (1976) A synopsis of the genus Pulvinula. Occas. Pap. Farlow Herb. Cryptog. Bot. 9: 1-19.

PILÁT A (1958) Přehled hub kyjankovitch-Clavariaceae se zvláštním zřetelem k československým sruhûm. Sborn. Nár. Mus. v Praze, Řada B, Přír. Vědy 14 (3-4): 129-255.

PILÁT A (1971) Species nova turficola generis Ramariopsis (Donk) Corner: Ramariopsis subarctica sp. nov. Česká Mykol. 25: 10.

RAMIREZ J, TULIG M, WATSON K, THIERS B (2020) The New York Botanical Garden Herbarium (NY). Version 1.27. The New York Botanical Garden. Occurrence dataset https://doi. org/10.15468/6e8nje [consultado vía GBIF.org el 12-XI-2020]. https://www.gbif.org/occurrence/1930257315

REHM H (1896) Die Pilze Deutschlands, Oesterreichs und der Schweiz. III. Abtheilung: Ascomyceten: Hysteriaceen und Discomyceten. Leipzig.

RIBES MÁ (2010) Setas del Pirineo Francés 2. Micobotánica-Jaén 3. Accesible en: http://www. micobotanicajaen.com/Revista/Articulos/MARibesR/PirineoFrances002/PirineoFrances002. $\underline{\mathrm{html}}$

RIBES MÁ, HERNANZ J, TELLO S, CAMPOS JC, PAZ A, SÁNCHEZ G, PANCORBO F \& SERRANO F (2016) Contribución al conocimiento de la biodiversidad fúngica del Parque Nacional de Ordesa y Monte Perdido I. Pirineos 171: e021. DOI: http://dx.doi.org/10.3989/Pirineos.2016.171005

ROMAGNESI H (1953) Les Russules d'Europe et d'Afrique du Nord. Bordas. Paris.

RONQUIST F, TESLENKO M, VAN DER MARK P, AYRES D, DARLING A, HOHNA S, LARGE B, LIU L, SUCHARD MA \& HUELSENBECK JP (2012) MrBayes 3.2: efficient Bayesian phylogenetic inference and model choice across a large model space. Syst. Biol. 61: 539-554. DOI: https://doi.org/10.1093/sysbio/sys029

RUBIO DOMÍNGUEZ E (2018a) Entoloma byssisedum. Centro De Estudios Micológicos Asturianos. http://www.centrodeestudiosmicologicosasturianos.org/? $\mathrm{p}=7749$

RUBIO-DOMÍNGUEZ E (2018b) Tricholoma frondosae. Centro De Estudios Micológicos Asturianos. http://www.centrodeestudiosmicologicosasturianos.org/?p=8103

RUBIO E, SUÁREZ A, MIRANDA A \& LINDE J (2006) Catálogo provisional de los macromicetos (setas) de Asturias. Real Instituto de Estudios Asturianos. Oviedo. 
SARNARI M (1984) Il genere Russula. Le Plorantinae a spore colorate. Boll. Gruppo Micol. G. Bresadola 27 (3-4): 117-124.

SARNARI M (2005) Monografía Illustrata del genere Russula in Europa, 2. A.M.B. Fondazione. Centro Studi Micologici. Vicenza.

SCHILD E (1981) Was ist Clavaria tenuipes Berk. \& Broome? Z. Mykol. 47(2): 215-219.

SCHMID-HECKEL H (1985) Zur Kenntnis der Pilze in den Nördlichen Kalkalpen. Nationalpark Berchtesgaden. Forschungsbericht 8: 1-201.

SCHMID-HECKEL H (1988), Pilze in den Berchtesgadener Alpen. Nationalpark Berchtesgaden. Forschungsbericht 15: 1-136.

SCHMIDT M, KARICH A, KELLNER H, KLEINE J \& ULRICH R (2013) Zu Entoloma-Funden mit Pleurozystiden (Entoloma insolitum agg.). Boletus 34(2): 73-84.

SHERWOOD-PIKE MA (1987) The Ostropalean fungi III: the Odontotremataceae. Mycotaxon 28(1): 137-177.

SHERWOOD-PIKE MA \& BOISE J (1986) Studies in lignicolous ascomycetes: Xylopezia and Mycowinteria. Brittonia 38: 35-44.

SKREDE I, BALLESTER L, MATHIESEN C \& SCHUMACHER T (2020) The genera Helve1la and Dissingia (Ascomycota:Pezizomycetes in Europe - Notes on species from Spain. Fung. Syst. Evol. 6: 65-93. DOI: https://doi. org/10.3114/fuse.2020.06.05

SKREDE I, CARLSEN T \& SCHUMACHER T (2017) A synopsis of the saddle fungi (Helve1la: Ascomycota) in Europe - species delimitation, taxonomy and typification. Persoonia 39: 201-253. DOI: https://doi.org/10.3767/persoonia.2017.39.09

SOCIEDAD(E) IBÉRICA DE MICOLOGÍA (2019) SIM-Fungal occurrences compiled by the Iberian Mycological Society. Version 1.2. Sociedad(e) Ibérica de Micología-Iberian Mycological Society. Occurrence dataset https://doi. org/10.15470/pjmaka [consultado vía GBIF.org el 13-X-2020].

SPOONER BMS (1981) New records and species of British Macrofungi. Trans. Brit. Mycol. Soc. 76(2): 265-301.

STAMATAKIS A (2014) RAxML Version 8: A tool for phylogenetic analysis and post-analysis of large phylogenies. Bioinformatics 30(9): 13121313. DOI: https://doi.org/10.1093/bioinformatics/btu033

SUIJA A, HALDEMAN M, ZIMMERMANN E, BRAUN U \& DIEDERICH P (2020) Phylogenetic placement and lectotypification of Pseudotryblidium neesii (Helotiales, Leotiomycetes). Fung. Syst. Evol. 5: 139-149. DOI: https://doi. org/10.3114/fuse.2020.05.09
TAPIA M (2013) Diderma crustaceum Peck 1874. Disponible en https://www.biodiversidadvirtual.org/hongos/Diderma-crustaceum-Peck-1874-img81313.html [Consultado el 26-XI-2020].

THIERS B (2020) Index Herbariorum: A global directory of public herbaria and associated staff. New York Botanical Garden's Virtual Herbarium, http://sweetgum.nybg.org/ih/ [consultado el 15-X-2016].

VAN BRUMMELEN J (1967) A world-monograph of the genera Ascobolus and Saccobolus (Ascomycetes, Pezizales). Persoonia (Suppl.) 1: 1-260.

VILA J, CABALLERO F, CARBO J, ALVARADO P, CATALA S \& HIGELMO MA (2014) Preliminary morphologic and molecular study of the Entoloma rusticoides group (Agaricales - Basidiomycota). Revista Catalana Micol. 35: 65-69.

VILA J, ESTEVE-RAVENTÓS F, LLISTOSELLA J \& LLIMONA X (2001) Contribución al conocimiento de los hongos del piso alpino de los Pirineos de Cataluña. III. Revista Catalana Micol. 23: 51-65.

VILA J, ROCABRUNA A, LLISTOSELLA J, TABARÈS M, LLIMONA X \& HOYO P (1997) Fongs nous o poc citats de Catalunya i Andorra. II. Revista Catalana Micol. 20: 105-123.

VILGALYS R \& HESTER M (1990) Rapid genetic identification and mapping of enzymatically amplified ribosomal DNA from several Cryptococcus species. J. Bacteriol. 172: 4238-4246.

WHITE TJ, BRUNS T, LEE S \& TAYLOR JW (1990) Amplification and direct sequencing of fungal ribosomal RNA genes for phylogenetics. In: INNIS MA, GELFAND DH, SNINSKY JJ, WHITE TJ (ed.). PCR protocols: a guide to methods and applications: 315-322. Academic Press Inc., New York.

WIJATAWARDENE NN, HYDE KD, RAJESHKUMAR KC, HAWKSWORTH DL, MADRID H, KIRK PM, BRAUN U, SINGH RV \& al. (2017) Notes for genera: Ascomycota. Fungal Diversity 86: 1-594. DOI: https://doi. org/10.1007/s13225-017-0386-0

WILSON AW \& DESJARDIN DE (2005) Phylogenetic relationships in the gymnopoid and marasmioid fungi (Basidiomycetes, euagarics clade). Mycologia 97(3): 667-679. DOI: https://doi.org/ $\underline{10.1080 / 15572536.2006 .11832797}$

YANG CS \& KORF RP (1985) A monograph of the genus Tricharina and of a new, segregate genus, Wilcoxina (Pezizales). Mycotaxon 24: 467-531.

ZOLLER S, SCHEIDEGGER C \& SPERISEN C (1999) PCR primers for the amplification of mitochondrial small subunit ribosomal DNA of lichen-forming ascomycetes. Lichenologist 31: 511-516. 


\section{INSTRUCCIONES PARA AUTORES}

\section{OBJETIVOS}

La revista Fungi Iberici que publica la Sociedad Ibérica de Micología (SIM), tiene como objetivo la difusión de los trabajos originales así como trabajos de revisión actualizados que han sido aceptados por el Comité Científico Asesor, y versen sobre temas de micología básica o aplicada.

\section{CONTENIDO DEL BOLETÍN}

Se podrán publicar trabajos científicos, artículos cortos o revisiones sobre las siguientes materias: micología básica (taxonomía, anatomía, fisiología, genética, ecología, corología, terminología, nomenclatura, etc.), micología industrial y económica, micología forestal y agrícola, micología médica humana y animal, micotoxicología, etnomicología e historia de la micología.

\section{INSTRUCCIONES PARA LOS AUTORES}

1. Norma general. Los trabajos serán presentados en español, portugués o inglés, si bien pueden ser aceptados los escritos en otras lenguas, según consideración del Comité Científico Asesor; en este último caso deberá acompañarse de un resumen en español además del resumen en la lengua original y del resumen en inglés. Los trabajos se escribirán en Microsoft Word en fuente Times New Roman de 14 puntos sólo para el título, y de 12 puntos para el resto del documento, interlineado sencillo y con márgenes de $3 \mathrm{~cm}$ a derecha e izquierda. El título, los autores y las direcciones de los autores estarán escritos con justificación izquierda y el resto con justificación total. Todos los comienzos de párrafo tendrán un sangrado normal de $1 \mathrm{~cm}$, excepto en el apartado Referencias del final del artículo en el que cada referencia tendrá una sangría francesa (o inversa) también de $1 \mathrm{~cm}$.

2. Título. El título será lo más informativo y breve posible, indicando los taxones pero no sus autores. Se escribirá en MINÚSCULAS, REDONDA, NEGRITA y justificación izquierda, salvo los nombres de taxones que irán además en cursiva al igual que en todas las partes del texto. No se pondrá punto al final del título. Se dejará un espacio entre el título y los autores. Por ejemplo: El género Cortinarius en León y zonas limítrofes

3. Autores. Los autores del trabajo se escribirán con todas las letras en mayúscula, en negrita y con justificación izquierda, y sólo se incluirá el primer apellido (aunque se pueden incluir los dos apellidos si van unidos por un guión), y la inicial o iniciales del nombre. Si son más de una inicial, éstas irán con punto y sin espacio entre ellas. En el primer autor las iniciales irán detrás del apellido, y en el resto de autores las iniciales irán delante del apellido. Si son varios autores se numerarán con un superíndice detrás de cada nombre, sin paréntesis y sin dejar espacios. No se pondrá punto al final de los autores. Por ejemplo: ESTEVE-RAVENTÓS F. ${ }^{1}$ \& CASTRO M.L. ${ }^{2}$. Si se desea que aparezca el nombre completo por razones de currículum o por cuestiones de identificación precisa del autor (en el caso de que el autor tenga apellidos muy comunes, en común con otro familiar u otras causas), el nombre completo se podrá añadir como primer dato en la dirección postal. Se dejará un espacio entre los autores y sus direcciones.

4. Direcciones de los autores. Se escribirán en letra redonda y normal, con justificación izquierda. Cada dirección de los autores irá precedida por el mismo superíndice que tiene el nombre de cada autor, a continuación irá la dirección con todos los datos separados por comas. Después, tras un punto, irá la dirección de correo electrónico. No se pondrá punto tras la dirección de correo electrónico. Se dejará un espacio entre las direcciones de los autores y el Resumen. Por ejemplo:

${ }^{1} \mathrm{C} /$ Andalucía 3, 4. ${ }^{\circ}$ dcha, 26500 Calahorra, La Rioja, España. E-mail: acamo@ono.com

${ }^{2}$ José de Uña y Villamediana, Avda. Anselmo Clavé 47 dpdo. 3. ${ }^{\circ}$ A (Edificio “Goya"), 50004 Zaragoza, España. E-mail: setadeu@yahoo.es 
5. Resúmenes y palabras clave. Tras la dirección de los autores se incluirá un resumen en español/portugués y otro en inglés (summary, no usar abstract), y unas palabras clave (keywords en inglés). Se escribirá en letra redonda normal (no negrita) con el resumen que los autores quieran hacer del contenido del artículo en un solo párrafo de no más de 200 palabras donde los taxones irán en cursiva y donde se podrá incluir el autor de los mismos de manera opcional. Los nombres de latinos de género y especie irán en cursiva, mientras que los referentes a rangos superiores (familia, orden, clase y superiores) irán en letra redonda normal. Por ejemplo:

A continuación, sin dejar espacio interlineal con el resumen, irán las palabras clave (ver ejemplo anterior). Las palabras clave no repetirán palabras ya incluidas en el título o en el resumen y serán un máximo de 10, separadas por comas, tanto en español, como en inglés. Las leyendas "Palabras clave" y "Keywords" y los dos puntos irán en negrita y el resto sin negrita. Los taxones se indicarán en cursiva, pudiendo aparecer los autores de los mismos. Por ejemplo:

Palabras clave: Fungi, Coprinus, Coprinopsis, vermiculifer, taxonomía, España, Granada, Sierra Nevada.

Keywords: Fungi, Coprinus, Coprinopsis, vermiculifer, taxonomy, Spain, Granada, Sierra Nevada.

6. Texto. Todos los nombres científicos deberán ser citados en el texto en cursiva, independientemente del rango o categoría taxonómica. Ninguna palabra deberá estar subrayada. Las figuras, ya sean fotografías, gráficas, esquemas, mapas, cuadros o tablas, de los trabajos deberán ser citados en el texto y vendrán numeradas en el orden de su citación como Fig. 1, Fig. 5-7 o (Fig. 1) (Fig. 5-7).

La manera de citar a los autores en las referencias a sus trabajos que hay en el texto será con todas las letras en mayúscula. Se usará el primer apellido si es un solo autor y primer apellido de cada autor unidos por la partícula \& si son dos autores; y el apellido del primer autor seguido de \& al. (no et al.), si son más de dos autores, todo ello seguido del año de publicación del trabajo referido entre paréntesis. Por ejemplo: SINGER (1947), MIRANDA \& RUBIO (2000) o KIRK \& al. (2001), si nos referimos a la obra del/de los autor/es, y por ejemplo SINGER \& al. (1947: 223) si deseamos referirnos a una página concreta de un trabajo, o bien (SINGER \& al. 1995) cuando se quiera dar una referencia justificativa de una explicación, en cuyo caso si hay más de un autor se separarán las referencias por punto y coma, por ejemplo: (PILÁT 1950; SINGER 1942: 123; VELLINGA \& al. 2004). Finalmente, si se quiere hacer referencia al texto de un autor que escribe en la obra de otro de forma explícita se pondrá el apellido del autor seguido de la palabra "in" en cursiva, por ejemplo: (VILA \& PEREZ-DE-GREGORIO in BALLARA \& al. 2009: 107). El texto estará estructurado, en la medida de lo posible, aunque no de forma obligatoria, de los apartados siguientes: INTRODUCCIÓN, MATERIAL Y MÉTODOS, RESULTADOS, DISCUSIÓN, AGRADECIMIENTOS y REFERENCIAS. Estos apartados vendrán con todas las letras en mayúsculas, en negrita y sin sangrar. El texto comenzará en la siguiente línea no a continuación del título del apartado. Los posibles subapartados como: Material estudiado, Macroscopía, Microscopía, Hábitat, Comentarios taxonómicos, Riqueza, Diversidad, Productividad, Observaciones, etc., vendrán en negrita, sólo con la primera letra en mayúsculas, sangrados $1 \mathrm{~cm}$. El texto comenzará en la siguiente línea, no a continuación del título del subapartado, excepto en Material estudiado, que continuará en la misma línea. En los tratamientos taxonómicos, las descripciones de los taxones se realizarán cada una por separado. Los autores de taxones se indicarán sólo en el epígrafe donde se describe, discute o cita el taxón en cuestión, como única vez, sin incluirlos en el título del trabajo o resto del texto, aunque los autores podrán aparecer en el Resumen. Los nombres de los autores de taxones vendrán abreviados de acuerdo con la publicación de KIRK \& ANSELL (1992), aunque para los que no puedan consultar esta obra, las abreviaturas de los autores también están disponibles en las siguientes direcciones de Internet:

\section{http://www.indexfungorum.ora/names/AuthorsOfFungalNames.asp}

http://kiki.huh.harvard.edu/databases/botanist_index.html

Las publicaciones periódicas se abreviarán de acuerdo a LAWRENCE \& al. (B-P-H; 1968) y los libros según STAFLEU \& COWAN (TL2; 1976), aunque aquellos que no puedan consultar estas obras, las abreviaturas de revistas y libros también están disponibles en http://kiki.huh.harvard.edu/databases/ publication index.html. Si no se conoce la abreviatura estándar de una revista o libro deberá citarse el nombre completo de dicha obra. Para los acrónimos de los herbarios donde se deposita el material estudiado se seguirá a HOLMGREN \& al. (1990) o bien la siguiente página de Internet de lndex Herbariorum: http://sweetgum.nybg.ora/ih/. Después de un punto y seguido se evitará escribir el nombre 
de un género de forma abreviada. Las indicaciones de los años en fechas de recolección, material de herbario, etc., se harán con 4 cifras y los meses en números romanos. Cuando dentro de un paréntesis haya otro paréntesis, los interiores se cambiarán a corchetes. Esto suele ocurrir cuando se desea escribir sinónimos de especies dentro de un paréntesis y el taxón sinónimo presenta algún autor entre paréntesis. Ejemplo: Betula alba L. (= Betula pubescens subsp. celtiberica [Rothm. \& Vasc.] Rivas Mart.). Para cuestiones ortográficas en aquellos casos en los que una palabra no se encuentre en los diccionarios españoles comúnes (aparte de las palabras técnicas como queilocistidios, perfectamente correctas), como por ejemplo en palabras técnicas como concolor, catenulado, sinonimizar, etc., se considerarán correctas teniendo en cuenta su actual difusión en el campo de la micología. La Península Ibérica será siempre citada con letras iniciales mayúsculas. Para cuestiones de nomenclatura se seguirán las normas de la última edición del ICN (Código Internacional de Nomenclatura para algas, hongos y plantas).

7. Referencias al material de herbario. Se citará, con la tipografía que se especifica: PAÍS (si se hace referencia a material de diversos países, o se desea incluir este dato), PROVINCIA: municipio, paraje, etc. (se pueden incluir otras entidades como región, comarca, valle, parque natural, etc., siempre que se mencionen de mayor a menor superficie), coordenadas, hábitat, fecha (p. e. 18-IV-2003), leg. seguido del nombre del recolector del espécimen (en redonda con la/s inicial/es del nombre de pila y la inicial del/ de los apellido/s en mayúscula y el resto en minúscula), det. seguido del nombre del determinador (sólo si es distinto del recolector, con las mismas especificaciones que para el recolector), ACRÓNIMO DEL HERBARIO O MICOTECA y número de espécimen. Las coordenadas se darán en formato decimal (WGS 84) y estarán acompañadas de una cifra de precisión, dependiendo del método a través del cuál se haya obtenido la coordenada. Ejemplo:

Material estudiado. ESPAÑA. Bizkaia: Bitaño, lzurza, 43.155379 -2.643810 ( \pm 10 m), 360m, plantación de Chamaecyparis lawsoniana con Rhytidiadelphus squarrosus, 7-XII-2005, leg. S. Araujo \& P. Iglesias, det. P. Iglesias, BIO-Fungi 25999.

8. Referencias. Solo deberán estar incluidas en este apartado aquellas referencias explícitamente citadas en el texto. Se citarán siempre todos los autores hasta un máximo de ocho, si se supera esta cifra figurarán los ocho primeros seguido de \& $\mathrm{al}$. Si no se menciona un autor concreto, los editores no son una persona física, y sí figuran colaboradores, asesores, etc., se pondrá VV AA como en el ejemplo de referencias VV AA (1968). Si no se conoce el autor, se tratará como anónimo, como en los ejemplos de referencias ANÓNIMO (1989) y ANÓNIMO (2005). Si no se conoce el año se pondrá s. d. (sine data; sin fecha) dentro del paréntesis del año, como en los ejemplos de referencias de BLACKWELL M, VILGALYS R \& TAYLOR JW (s. d.) o INDEX FUNGORUM (s. d.), y si el año de publicación real se conoce y difiere del año facial (de la cubierta o portada), se indicará la fecha facial entre corchetes después de la fecha real de publicación como en WASSER SP (1977b) [“1976”] de los ejemplos de las referencias. Los boletines oficiales se incluirán en las referencias siguiendo el formato de la referencia del MINISTERIO DE LA PRESIDENCIA (2009) que hemos insertado en los ejemplos. Las referencias se ordenarán alfabéticamente por autores, con los trabajos de igual autoría ordenados de forma cronológica y en el caso de pertenecer a los mismos autores y años se distinguirán añadiendo letras, en minúscula, a continuación del año como en WASSER SP (1977a) y WASSER SP (1977b) de los ejemplos de las referencias; si el primer autor viene acompañado de otros autores, para un mismo año, se ordenarán por el apellido del segundo autor, si este es también el mismo por el apellido del tercer autor, y así sucesivamente. Si se trata de libros independientes que no forman parte de una serie, el título irá en cursiva y se indicará el nombre de la editorial y la ciudad de edición, para casos que se presten a confusión, por ser la editorial un nombre de persona, un objeto (Círculo, Árbol, etc.,) se podrá añadir delante de la editorial la partícula "Ed.", (Ed. Círculo; Ed. Árbol) como en el ejemplo de referencia de MUÑOZ JA (2005). Si se trata de capítulos de libros, se indicará en cursiva el título del libro antecedido del/de los editor/es en mayúscula y la partícula "In:", como en los ejemplos de referencias de ARNOLDS E (1990) o DANIËLS PP (2003). Para los libros se deja como opcional el indicar, al final de la referencia, el número de páginas totales de la publicación, como en los ejemplos de referencias de ARNOLDS E (1990), DANIËLS PP (2003), o KNUDSEN H \& VESTERHOLT J (2008). Si se trata de revistas, el título del artículo irá en redonda, (salvo los nombres científicos) y será el nombre de la misma la que irá en cursiva y abreviado según los estándares antes señalados o bien con el nombre completo si no se conoce su abreviatura estándar. Los diferentes fascículos de un mismo número se consignarán entre paréntesis después del número de revista sin dejar espacios como en el ejemplo de referencia ANÓNIMO (1989). Las páginas web deberán llevar la URL correspondiente en redonda y subrayada, así como la fecha de consulta entre corchetes al final; el título de la página web o el del documento incluido en ella (libro, artículo en pdf, etc.) deberán ir en 
cursiva. Para que todas las referencias se hagan de forma uniforme en el boletín, se escribirán de acuerdo con los ejemplos que se incluyen a continuación en cuanto a citación de autores, años, etc.

9. Índice de figuras. A continuación de las referencias y con el título Índice de figuras, se relacionarán todos los pies de foto o ilustraciones, enumerados y ordenados, indicando la leyenda que deseen los autores del artículo y el autor de las mismas (ver ejemplo al final del párrafo), excepto si el artículo está firmado por un solo autor y todas las figuras son del mismo. Es recomendable añadir el número de colección en dichas leyendas para así conocer el aspecto macroscópico de algunas de las colecciones estudiadas. Cuando una figura tenga varios apartados, las distintas partes se diferenciarán con letras en mayúscula seguidas de dos puntos. Por ejemplo:

Índice de figuras

Fig. 1. Cantharellus romagnesianus. NS-10110620. Foto: J. Cuesta.

Fig. 2. Cantharellus gallaecicus. A: Esporas. B: Hifas de la pileipellis. C: Vista general, basidios y esporas. Escalas $=10 \mu \mathrm{m}$. Fotos: N. Santamaría.

10. Ilustraciones. Todas las ilustraciones tendrán su referencia en el texto. Se enviarán por correo electrónico o por otras vías que permitan su envío a máxima resolución(Wetransfer, Dropbox, etc.). En ningún caso fotografías y dibujos serán insertadas en el texto del artículo, sino en archivos separados en formato TIFF y en archivos nombrados con sus números correspondientes (Fig. 1, Fig. 2, etc.) para poder relacionarlos con las leyendas del índice de figuras. Los árboles filogéneticos serán enviados en formato pdf o vectorial (.eps). Las ilustraciones deben ser sensibles de ser puestas bajo una licencia libre Creative Commons Attribution-ShareAlike 4.0 International (CC BY-SA 4.0)* sin condiciones adicionales.

\section{Instrucciones para planchas en color:}

a.- tamaño de la plancha completa: $18 \mathrm{~cm}$ de ancho y un máximo de $26.2 \mathrm{~cm}$ de alto; resolución de 300 ppp.

b.- las imágenes individuales deberán presentarse en RGB con una resolución de al menos 300 ppp.

c.- barras de escala: 6 pixels.

d.- fuente de las letras: Mayúscula arial regular de 12 pixels.

d.- grosor de las líneas blancas que separan las imágenes: 15 pixels.

\section{DÓNDE ENVIAR LOS TRABAJOS}

Los trabajos serán remitidos en formato digital, directamente por correo electrónico a los siguientes miembros del Comité Científico Asesor: Ibai Olariaga (e.mail: ibai.olariaga@urjc.es), adjuntando el teléfono personal de uno o varios de los autores para poder contactar con los autores en caso de que sea necesario. Los trabajos, una vez en posesión del Comité Científico Asesor, serán revisados, para emitir después un informe sobre su contenido. A la vista de estos informes los trabajos podrán ser rechazados, aprobados sin modificaciones o aprobados después de que se hayan efectuado modificaciones en su forma o contenido. $\mathrm{Si}$ son aprobados con modificaciones serán reenviados a los autores para que efectúen las modificaciones propuestas por los revisores. Si los autores no aceptan las modificaciones sin explicar o justificar los motivos por los cuales no aceptan los cambios, los trabajos serán rechazados. En cambio, si los autores justifican los motivos para no aceptar determinados cambios, el Comité Científico Asesor estudiará los motivos alegados e informará a los autores de la decisión final adoptada. 


\section{EJEMPLOS DE REFERENCIAS \\ PARA FUNGI IBERICI}

ÁLVAREZ-NIETO A, DÍAZ-BALTEIRO L \& ORIA-DE-RUEDA JA (2001) Valoración de la producción conjunta madera-setas. Aplicación al caso de la Carballeda (Zamora). Actas Congreso Forestal Español 5: 775-780.

ANÓNIMO (1989) Agaricus boisseletii Heinemann. Bull. Soc. Mycol. France 105(3): pl. 257.

ANÓNIMO (2005) Relación de variedades comerciales de micelios de champiñón (campaña 2005-2006) El champiñón en Castilla la Mancha 21: 2-4.

ARNOLDS, E. (1990) Mycologist and Nature conservation: 243-264. In: HAWKSWORTH, D.L. (ed.) Frontiers in Mycology. CAB International. Kew. 300 pp.

BASTARDO JA, GARCÍA-BLANCO A \& SANZ-CARAZO M (2001) Hongos -setas- en Castilla y León. Ed. Los Autores. Valladolid.

BLACKWELL M, VILGALYS R \& TAYLOR JW (s. d.). Tree of life. Fungi. http://tolweb.org/tree/Fungi. [Consultada el 14-II-2005].

BON M \& ROUX P (2002) Le genre Gymnopilus P. Karst. en Europe. Fungi non delineati 17: 1-52.

BREITENBACH J \& KRANZLIN F (1984) Champignons de Suisse 1. Les Ascomycetes. Mykologia. Lucerne.

CALONGE FD (1998) Gasteromycetes, I. Lycoperdales, Nidulariales, Phallales, Sclerodermatales, Tulosmatales. Fl. Mycol. Iber. 3: 1-271.

DANIËLS PP (2003) Números 2124-2178: 104-165. In: HERNÁNDEZ JC (ed.). Cuad. Trab. Fl. Micol. Ibér. 19. Bases corológicas de Flora Micológica Ibérica. Números 2070-2178. Consejo Superior de Investigaciones Científicas. Madrid. $171 \mathrm{pp}$.

EWLAD OM (2009) Using Latin in diagnoses: a guide for the perplexed. North American Fungi 4: 1-9. https://doi.org/10.2509/naf2009.004.002

FERNÁNDEZ-TOIRÁN M (1995) Estudio de la producción micológica actual en la Comarca de Pinares de Soria y ensayo de técnicas de mejora de la misma. [Tesis doctoral]. Universidad de Santiago de Compostela.

FERNÁNDEZ-TOIRÁN M, RIGUEIRO A \& CASTRO ML (1996) Effect of forest treatment on mycorrhizal fruit body production in Pinus sylvestris stands in Soria (Spain). Proceedings of the IV European Symposium of Mycorrhizas: 531-534.

FERNÁNDEZ-TOIRÁN M, MARTÍNEZ-PEÑA F (1999) Los hongos en los montes de Soria. Junta de Castilla y León. Valladolid.

GARCÍA-ROLLÁN M (2006) Mycena purpureofusca en la Sierra de Guadarrama. Bol Micol FAMCAL 1: 15-16.

HERNÁNDEZ-CRESPO JC (2006) SIMIL, Sistema de Información Micológica Ibérica en Línea. Real Jardín Botánico, C.S.I.C. Proyecto Flora Micologica lberica I-VI (1990-2008). Ministerio de Educación y Ciencia, España. http://www.rjb.csic.es/fmi/sim.php [consultada el 2-VIII-2011].

HODGE KT, GAMS W, SAMSON RA, KORF RP \& SEIFERT KA (2005) Lectotypification and status of Isaria Pers. : Fr. Taxon 54: 485-489. https://doi.org/10.2307/25065379

INDEX FUNGORUM (s. d.). http://www.indexfungorum.ora/Names/Names.asp [consultada el 12 de julio de 2011].

JACOBSSON S (2008) Inocybe. In: KNUDSEN H. \& VESTERHOLT J. (ed.): Funga Nordica: 868-906. Nordsvamp, Copenhagen.

KIRK PM, CANNON PF, MINTER DW \& STALPERS JA (2008) Ainsworth \& Bisby's. Dictionary of the Fungi $\left(10^{\text {th }}\right.$ ed.). CAB lnternational. Wallingford.

KORNERUP A \& WANSCHER JH (1978) Methuen handbook of colour, $3^{\text {rd }}$ edn. Eyre Methuen, London.

KNUDSEN H \& VESTERHOLT J (eds.) (2008) Funga Nordica. Agaricoid, boletoid and cyphelloid genera. Nordsvamp. Copenhagen. 968 pp.

MINISTERIO DE LA PRESIDENCIA (2009) Real Decreto 30/2009, de 16 de enero, por el que se establecen las condiciones sanitarias para la comercialización de setas para uso alimentario. BOE 20 ( 23 de enero de 2009): 7861-7871. 
MORCILLO-SIERRA M (2002) Nuevas experiencias en el cultivo de hongos silvestres. Comunicación a las XIII Jornadas Micológicas. E.T.S.II.AA. de Palencia (Universidad de Valladolid).

MUÑOZ JA (2005) Fungi Europaei 2. Boletus s. l. (excl. Xerocomus). Ed. Candusso. Alessio.

R.A.E. (2014) Diccionario de la Lengua Española (23a ed.). Espasa. Madrid.

OLARIAGA I (2009) The order Cantharellales in the Iberian Peninsula and the Balearic Islands [tesis doctoral]. Universidad del País Vasco-Euskal Herriko Unibertsitatea, Bilbao. 547 p.

SOCIEDAD(E) IBÉRICA DE MICOLOGÍA (2019) SIM-Fungal occurrences compiled by the Iberian Mycological Society. Version 1.2. Sociedad(e) Ibérica de Micología-Iberian Mycological Society. Occurrence dataset https://doi.org/10.15470/pjmaka. [Consultado vía GBIF.org el 13-X-2020].

TALAVERA S (1997) Taxonomía vegetal: 1-21. In: IZCO, J. \& al. Botánica. Mc Graw Hill-Interamericana. Madrid.

VV AA (1968) Enciclopedia Salvat de las Ciencias 1: Vegetales. Salvat / Instituto Geográfico de Agostini. Pamplona.

WASSER SP (1977a) New and rare species of Agaricaceae Cohn. family. Ukrayins'k Bot Zhurn 34(3): 305308.

WASSER SP (1977b) [“1976”] Familiae Agaricaceae Cohn species pro mycoflora URSS novae vel rarae necnon una pro scientia nova. Novosti Sis.t Nizsh. Rast. 3: 217-228. 